\title{
DESIGN AND VALIDATION OF A WEARABLE, CONTINUOUS, AND NON-INVASIVE HYDRATION MONITOR THAT USES ULTRASONIC PULSES TO DETECT CHANGES IN TISSUE HYDRATION STATUS
}

\author{
A Thesis \\ presented to \\ the Faculty of California Polytechnic State University, \\ San Luis Obispo
}

\author{
In Partial Fulfillment \\ of the Requirements for the Degree \\ Master of Science in Biomedical Engineering
}

by

Zoie Engman

June 2014 
(C) 2014

Zoie Engman

ALL RIGHTS RESERVED 


\section{COMMITTEE MEMBERSHIP}

TITLE:

AUTHOR:

DATE SUBMITTED:

COMMITTEE CHAIR:

COMMITTEE MEMBER:

COMMITTEE MEMBER:
Design and Validation of A Wearable, Continuous, and NonInvasive Hydration Monitor That Uses Ultrasonic Pulses to Detect Changes in Tissue Hydration Status

Zoie Engman

June 2014

Lily Laiho, $\mathrm{PhD}$

Professor of Biomedical Engineering

Kristen O'Halloran Cardinal, $\mathrm{PhD}$

Professor of Biomedical Engineering

Robert Crockett, PhD

Director of General Engineering 


\begin{abstract}
Design and Validation of A Wearable, Continuous, and Non-Invasive Hydration Monitor That Uses Ultrasonic Pulses to Detect Changes in Tissue Hydration Status

Zoie Engman
\end{abstract}

Chronic dehydration is an endemic problem for many population groups. Current methods of monitoring hydration status are invasive, time consuming, cannot be performed while exercising, and require lab resources. A proposed solution is a wearable, continuous, and non-invasive device that uses harm-free ultrasonic pulses to detect changes in tissue hydration status over time. Customer and engineering requirements were defined and used to guide the design process. Literature reviews were performed to identify essential information on dehydration, assess current methods, discover state of the art devices, and describe ultrasonic theory. Market research was performed to identify athletes as the target population group. An adjustable elastic nylon bicep band prototype was manufactured and the integration of more advanced components was proposed. The theoretical signal processing method used to detect hydration status was validated through initial tests with a prototype electrical system composed of a Teensy 3.1 board, two $18 \mathrm{kHz}$ piezoceramic disc elements, and an Arduino/LabVIEW interface. Tests with aluminum, rubber, and sponge materials were performed to compare the signal response to propagation through materials with different acoustic properties and water contents. Finally, tests performed with dehydrated bovine muscle tissue revealed a statistically significant difference between hydrated and dehydrated tissue, a promising indication for future device refinement.

Keywords: Ultrasonic, Hypohydration, Euhydration, Dehydration, Tissue Status, Wearable, Non-invasive, Piezoceramic, PZT, Transducers, Signal Processing, Phase Shift, Harmonics 


\section{ACKNOWLEDGMENTS}

Acknowledgements go to the following people and groups for their significant help, mentoring, and encouragement along the way:

- Dr. Lily Laiho, advisor, for her expertise in design development, guidance in the report process, and significant help in navigating obstacles. This thesis would not have been possible without her help.

- Dr. Kristen O'Halloran Cardinal and Dr. Robert Crockett, committee members, for their guidance, excitement, and encouragement at all stages of the thesis process. Specific acknowledgements go to Dr. Cardinal for her early encouragement to pursue this thesis and to Dr. Crockett for his business-plan related guidance through IME 577.

- $\quad$ The Hannah Forbes Fund for seeing the potential of this thesis and supplying the funding necessary to cover the costs of the prototyping process.

- $\quad$ Ross Gregoriev, for helping with early validation and for providing his expertise in software and electronics to adopt his work for the signal-processing component of this thesis.

- Jake Disraeli, Director of the Cal Poly Hot House, for his input on the commercial potential and future direction of this thesis.

- Ann Livingston-Peters and Gabriel Mountjoy, for use of prototyping space and equipment, supplying materials, bouncing ideas off of, and generally being backup through the process.

- My family, for their unwavering support, encouragement, patience, and coffee money. 


\section{TABLE OF CONTENTS}

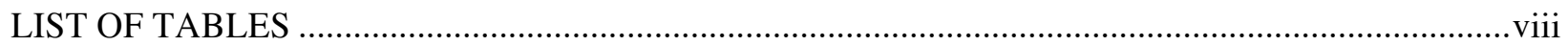

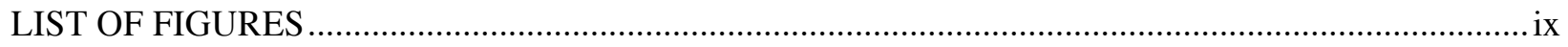

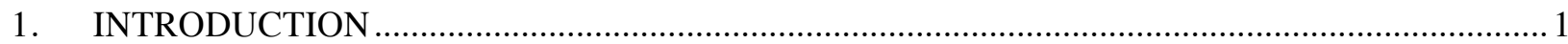

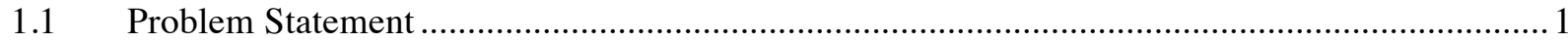

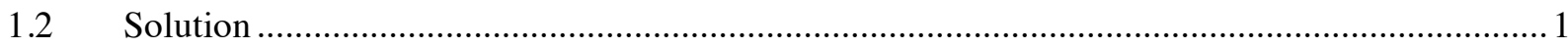

$1.3 \quad$ Purpose

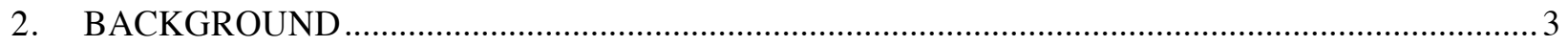

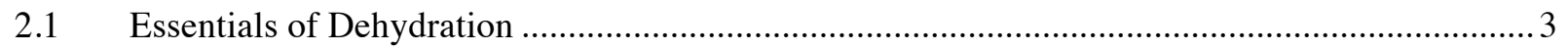

2.2 Healthy Body Water Content and Clinical Presentation of Dehydration ................................ 6

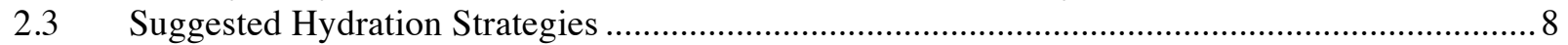

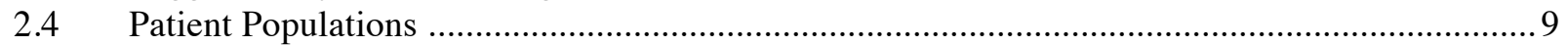

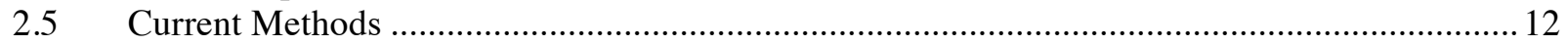

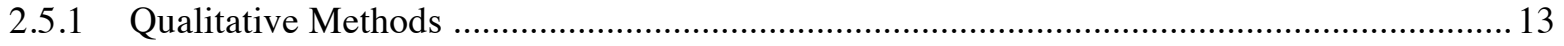

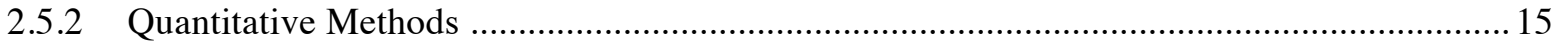

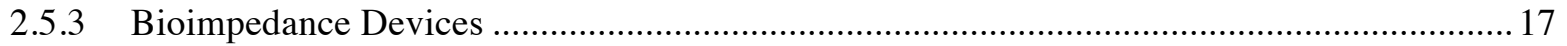

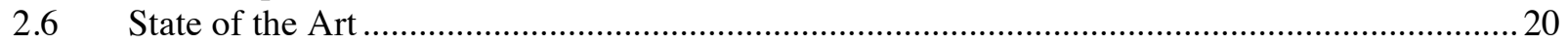

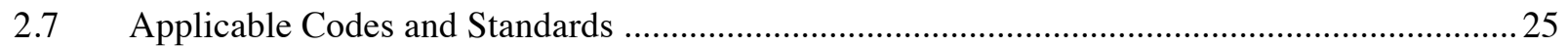

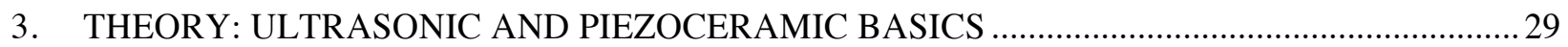

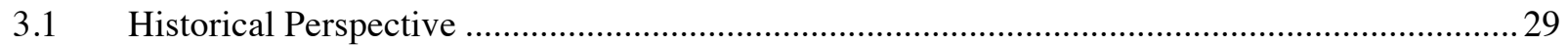

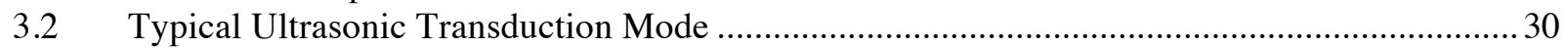

3.3 Tissue Material Factors That Affect Ultrasonic Transduction ................................................... 31

3.4 Wave Factors That Affect Ultrasonic Transduction ............................................................ 33

3.5 Piezoceramic Materials and Their Implementation in Ultrasonic Transducers ..........................35

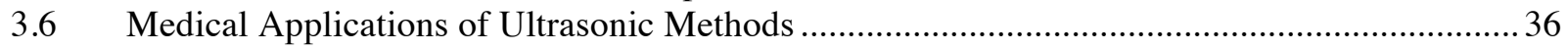

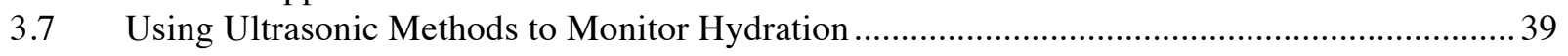

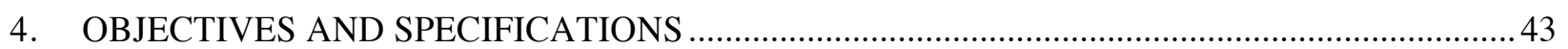

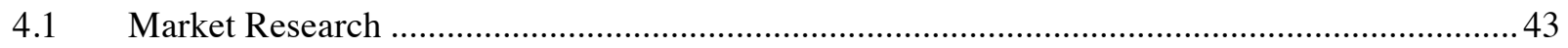

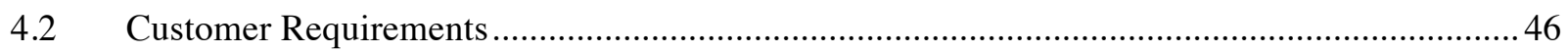

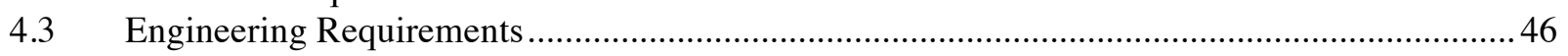

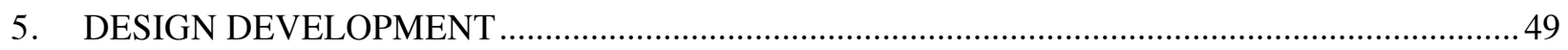

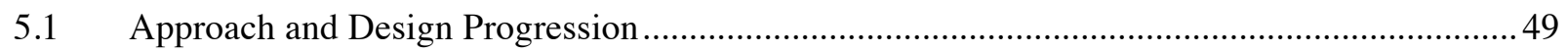

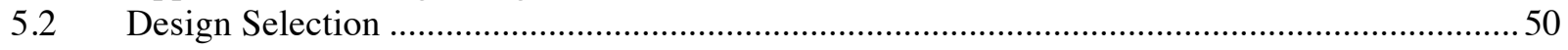

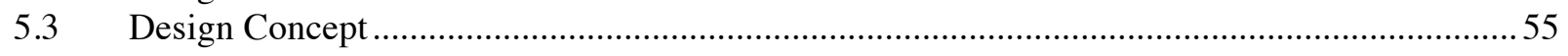

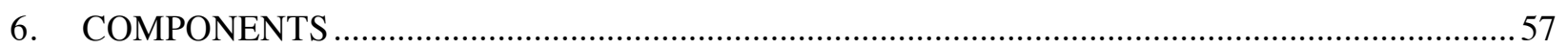

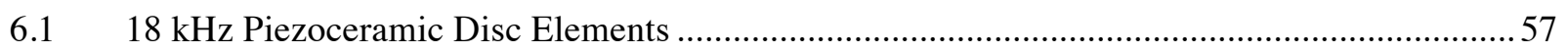

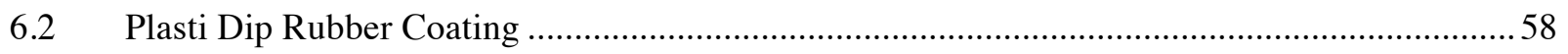

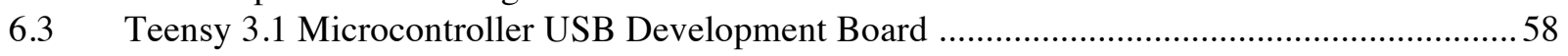

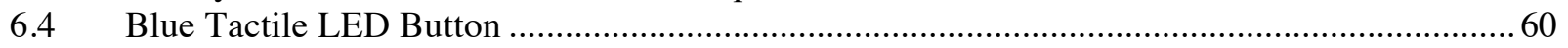

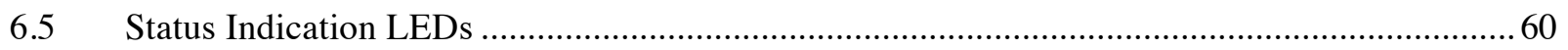

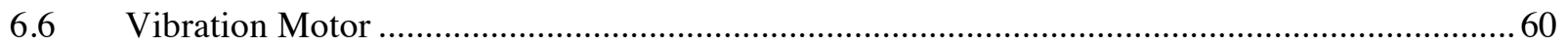

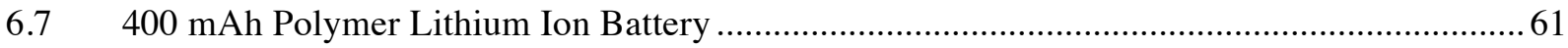

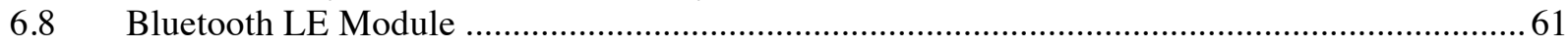

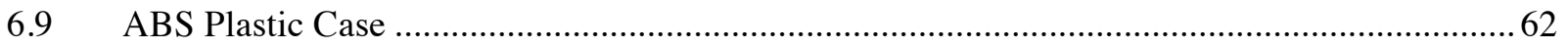

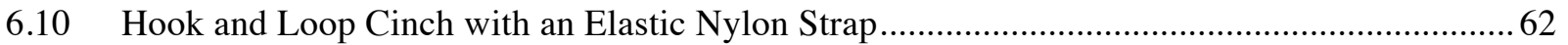

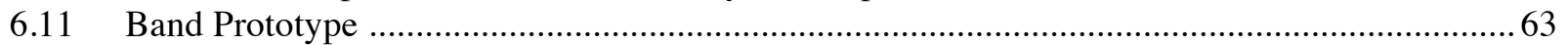

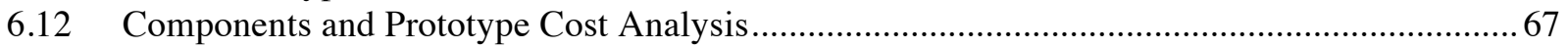




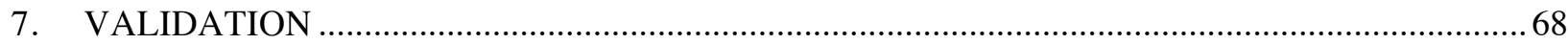

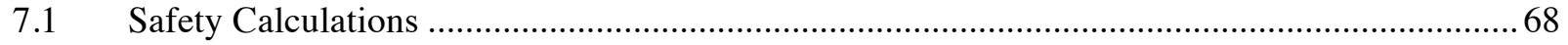

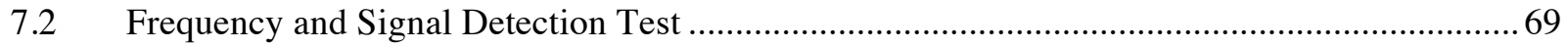

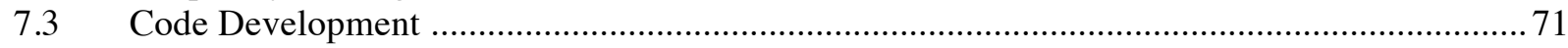

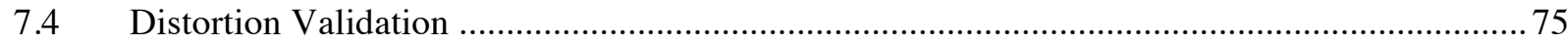

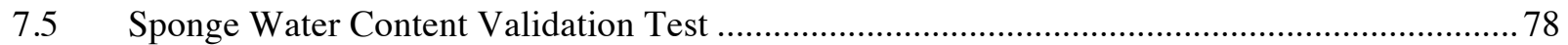

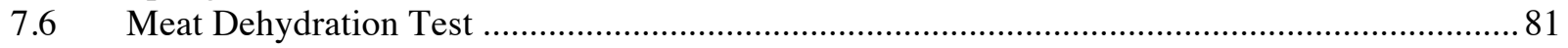

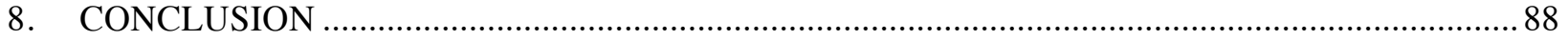

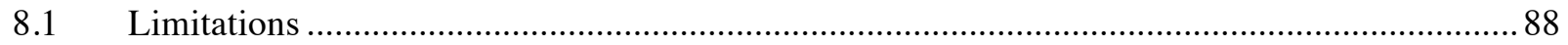

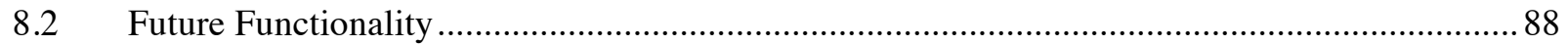

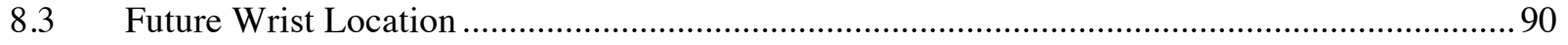

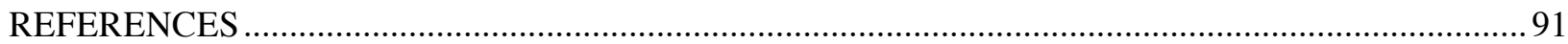

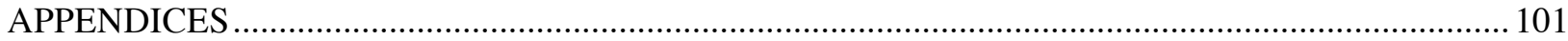

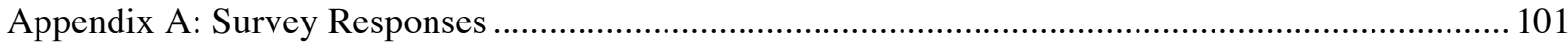

Appendix B: Kickstarter Review Table ………………………………………………………... 102

Appendix C: Manufacturer Supplied Component Datasheets, Diagrams, and Drawings ..................... 103

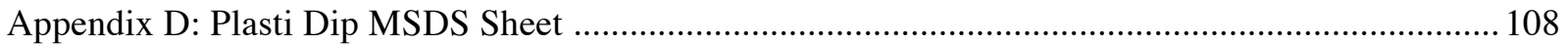

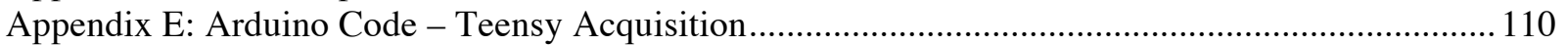

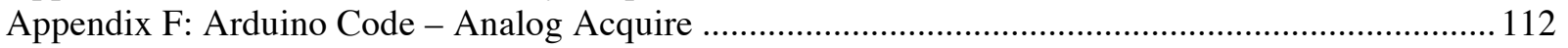

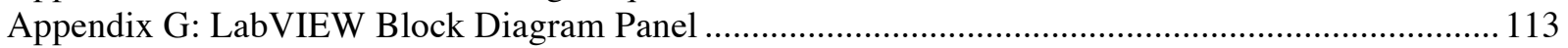

Appendix H: LabVIEW Front Panel ......................................................................................... 114

Appendix I: Accessories to the Distortion Validation Tests ................................................................ 114

Appendix J: Accessories to the Sponge Water Content Validation Test ................................................117

Appendix K: Accessories to the Muscle Dehydration Test .............................................................. 125 


\section{LIST OF TABLES}

Table I: A table of the key properties of water and the role of each property in maintaining homeostasis. 3

Table II: USDA Dietary Reference Intake guidelines for water consumption. AI = allowable income $\ldots . . .9$

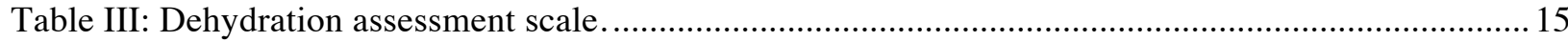

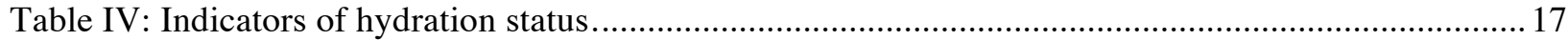

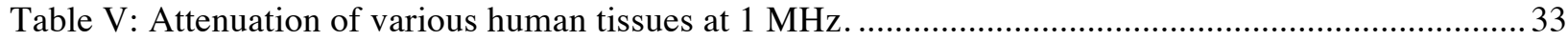

Table VI: A table of common values for diagnostic ultrasound quantities............................................ 34

Table VII: Summary table of customer requirements, engineering requirements, and the corresponding analyses to measure the relative success of the solution....................................47

Table VIII: Explanation of rationale for each engineering requirement specification. ............................ 48

Table IX: Possible anatomic locations, representative sketches at each location, positive and negative features of each location, and identification of top three location options.....................51

Table X: Transverse views of selected sensor location options..........................................................53

Table XI: Summary table of the components for the bicep band prototype design.................................57

Table XII: Technical specifications of the PJRC Teensy 3.1 microcontroller USB development board

Table XIII: Summary table of the suppliers, number, and cost of the components used in the prototype device.

Table XIV: Summary table of the programs used to generate the validation code. ................................71

Table XV: Sample properties for the distortion validation test. ...................................................... 76

Table XVI: Stepwise process, images, and description of actions performed in the meat dehydration test.

Table XVII: Summary table of the weight, \% dehydration, and average harmonics amplitude for each of the samples at four set points. Note that the first set point is the baseline value used to determine percent differences and is not included in trend analysis.

Table XVIII: Summary table of the average harmonic amplitudes at each test time point. The data points in bold were used for statistical analysis of a more hydrated state compared to a dehydrated state.

Table XIX: Summary table of survey responses

Table XX: Goal amounts and total amounts raised for hydration-related products on Kickstarter.......... 102

Table XXI: Raw data for the distortion validation tests

Table XXII: Summary table for the distortion validation test.

Table XXIII: Sample weights for the sponge water content test.

Table XXIV: Raw data for dry, 1T, and $2 \mathrm{~T}$ of the sponge water content test. Dry $=$ sponge prior to water added, Samples given in the form of \#TL where \# = number of tablespoons added and $\mathrm{L}=$ location of the measurement

Table XXV: Raw data for 3T, 4T, 5T, and 6T of the sponge water content test. Dry = sponge prior to water added, Samples given in the form of \#TL where \# = number of tablespoons added and $\mathrm{L}=$ location of the measurement.

Table XXVI: Averaged waveforms used in the generation of the sponge water content test plot.

Table XXVII: Summary table of the temperatures, weights, and averaged locational data from the muscle dehydration test. 


\section{LIST OF FIGURES}

Figure 1: Exchange of gases, nutrients, water, and wastes between the three fluid compartments of the body

Figure 2: Diagram of body water content amounts and the effects of $\%$ BW water loss. ….................... 8

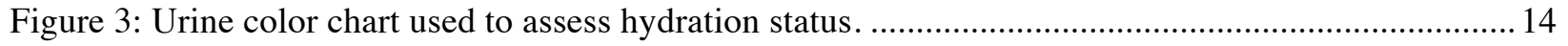

Figure 4: (A) Bodystat 1500 with electrodes. (B) XiTRON Hydra 4200. (C) BCM Body Composition Monitor.

Figure 5: Operation of an embedded piezoresistive microcantilever device for hydration monitoring. .... 20

Figure 6: Image of an inactive flexible electronic patch from mc10 .............................................2 21

Figure 7: Images of: (A) a conceptual hydration monitoring patch by mc10, Inc and (B) a diagram

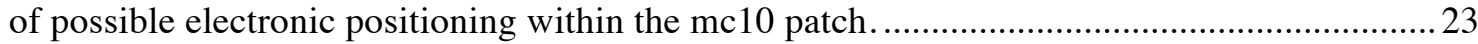

Figure 8: Images of the ultrasonic devices used by (A) Sarvazyan et al., (B) Topchyan et al., and

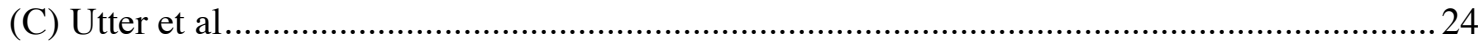

Figure 9: Diagram of the principle behind acoustic reflection at tissue interfaces................................... 30

Figure 10: An example transducer reading from pulse-echo transduction. Green $=$ sent signal, red $=$ received signal.

Figure 11: Diagram of Snell's law for the propagation of an incident wave, reflected wave, and transmitted wave between two mediums of different acoustic impedances. ........................................... 32

Figure 12: Amplitude reflection factor coefficients for various tissues relative to blood...........................32

Figure 13: A comparison chart of the resolution and penetration of ultrasonic waves at different transducer frequencies.

Figure 14: Figures of (A) PZT perovskite crystal structure and (B) under a phase transformation

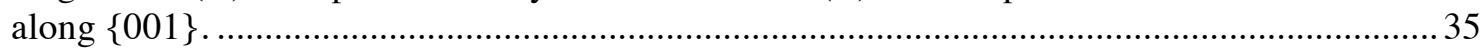

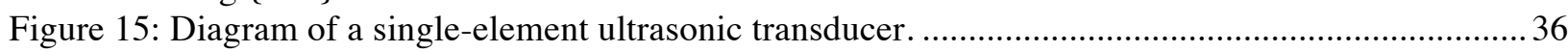

Figure 16: Radiation pattern of a single-element transducer with a focusing lens. .................................. 36

Figure 17: An example of an IVUS image from an atherosclerotic artery. .............................................. 38

Figure 18: Ultrasound velocity as a function of water content in animal muscle tissue for

(A) different animal types and (B) across or along fibers.................................................... 39

Figure 19: Simplified model of a sent ultrasonic signal in the form of a sine wave ................................ 41

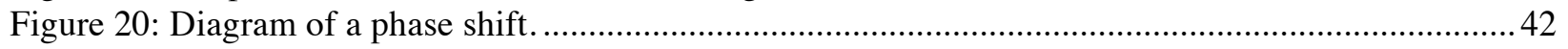

Figure 21: Chart of USA market size for populations of interest. ...................................................... 43

Figure 22: Chart of target price compared to other available fitness devices.........................................45

Figure 23: Anatomic diagrams showing (A) tendons, (B) superficial veins, and (C) deep arteries of the front wrist. Blue boxes and arrows indicate regions of interest. ..........................................5 54

Figure 24: An annotated sketch of the selected design concept. ..........................................................55

Figure 25: An annotated Solidworks model of the prototype band. ......................................................55

Figure 26: An annotated Solidworks model of a future, refined, prototype band.....................................5

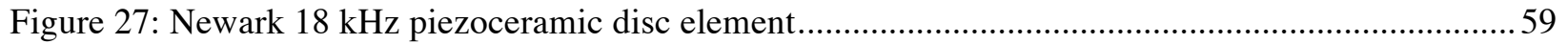

Figure 28: McMaster-Carr Plasti Dip Rubber Coating. ......................................................................5

Figure 29: PJRC Teensy 3.1 Microcontroller USB Development Board. ................................................59

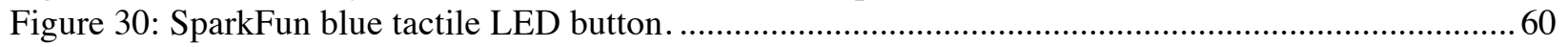

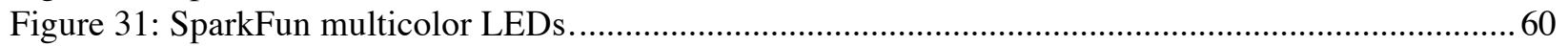

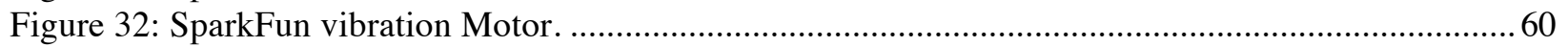

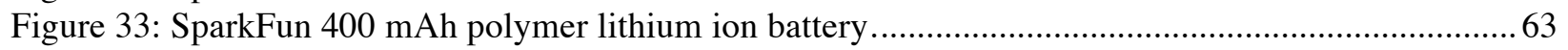

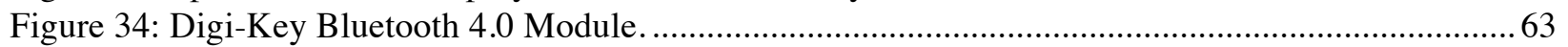

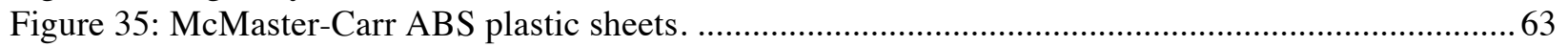

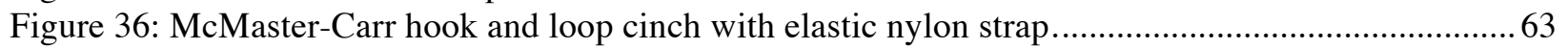

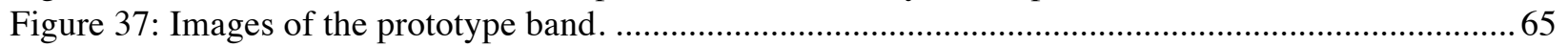


Figure 38: Detail views of the prototype band features.

Figure 39: Intensity of ultrasound vs. irradiation time for safe exposure to medical diagnostic ultrasounds.

Figure 40: Calculations for the worst-case intensity of the selected $18 \mathrm{kHz}$ disc elements.

Figure 41: Image of the oscilloscope and function generator test setup. 70

Figure 42: Example windows of the programs used to generate the validation code; (A) Teensyduino, (B) Arduino IDE, (C) LabVIEW (left) Front Panel and (right) Block Diagram. ...................... 71

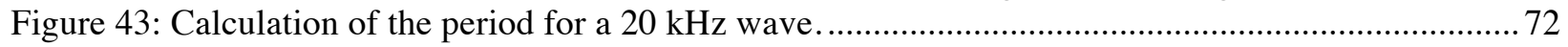

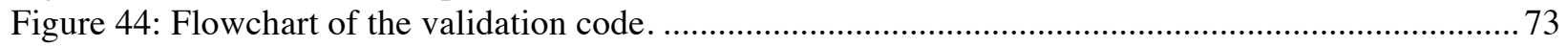

Figure 45: Pinout diagram of the Teensy 3.1 with the validation code. ............................................... 73

Figure 46: Prototype Teensy 3.1 running the validation code via a breadboard and two $18 \mathrm{kHz}$ piezo disc elements.

Figure 47: Identification of the modules within the LabVIEW Front Panel. Note that the $5^{\text {th }}$ harmonics plot is not used for gathering or analyzing data................................................... 74

Figure 48: Comparison diagram of the sent and received signals for the $3.3 \mathrm{~V}, 20 \mathrm{kHz}$ square waves...... 75

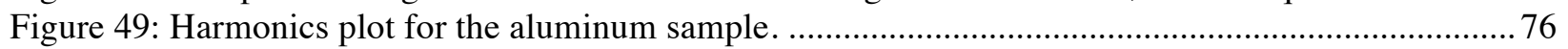

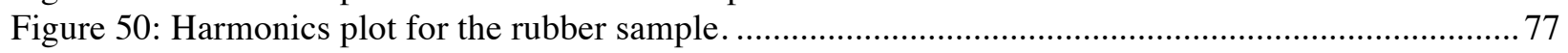

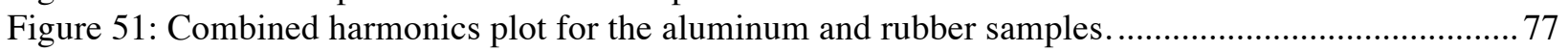

Figure 52: Prototype setup for the sponge water validation test. (A) Protected breadboard connections and connection of the piezo elements to the rubber backing, (B) Placement of sensors and measurement points on the sponge, (C) Side view of the experimental setup with a constant material thickness, and (D) Method of adding water to the sponge........................................ 79

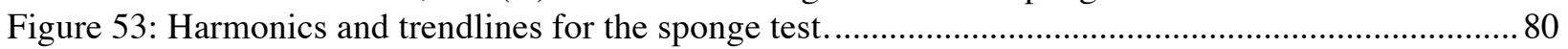

Figure 54: Average harmonic amplitude values for the sponge test. .............................................. 81

Figure 55: Relationship between the average harmonics amplitude and percent dehydration for all

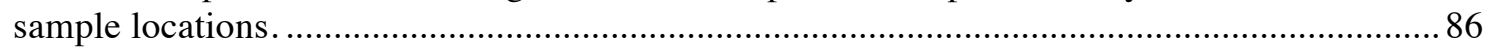

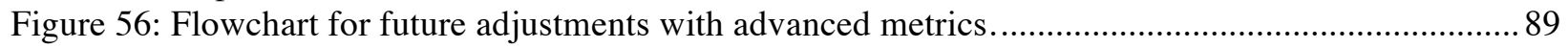

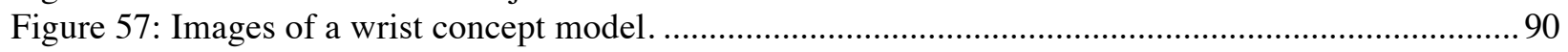

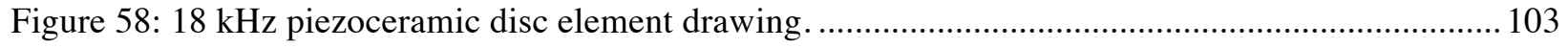

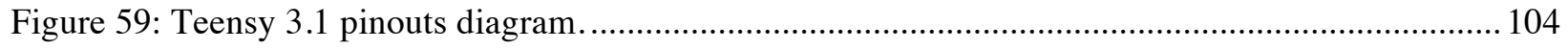

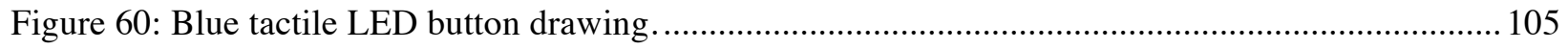

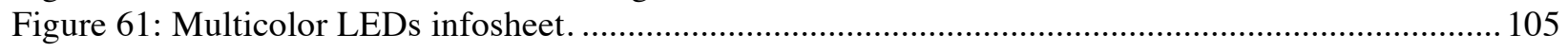

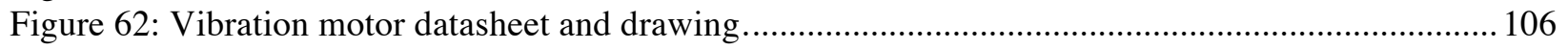

Figure 63: Polymer lithium ion battery internal components diagram. ............................................... 107

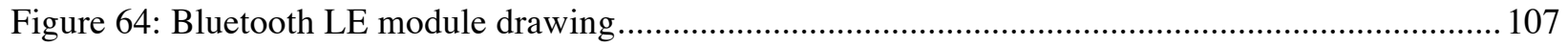

Figure 65: Calculation of the percent difference between the attenuation coefficients and the average

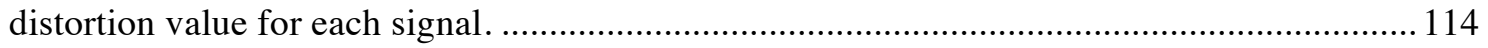

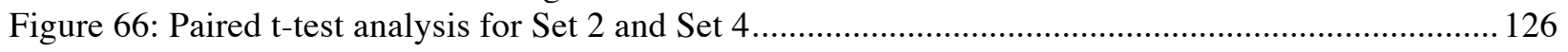




\section{INTRODUCTION}

\subsection{Problem Statement}

Seventy five percent of Americans are chronically dehydrated and care for dehydration results in up to $\$ 5.5$ billion per year in preventable hospital costs in the US alone ${ }^{1}$. In hospital emergency departments, dehydration is the most common diagnosis in general (7\%), early-return (15\%), and return-admit (25\%) populations $^{2}$. In daily life, the average person turns over 4.58 liters of body water per day and inadequate replenishment of body fluids can lead to significant detrimental effects on overall wellness ${ }^{3,4}$. Surprisingly, there is no standardized or satisfactory tool for quantification of hydration status despite common recommendation to provide it for athletes, military, geriatric care, pediatric care, prenatal monitoring, firefighters, dialysis patients, and for EMT and general hospital use $\mathrm{e}^{4-8}$.

There are many studies that have attempted to develop methods to improve the identification of dehydration and subsequent monitoring policies ${ }^{4,6-17}$. Despite frequent investigation, there are no satisfactory continuous and non-invasive hydration monitors for hospital use or on the market. Further, the use of subjective assessment measures by physicians and overall lack of awareness of hydration status contributes to dehydration being under-recognized amongst hospitalized, geriatric, and otherwise healthy populations $^{18}$.

\subsection{Solution}

Studies show that the sole act of wearing a fitness device increases a user's awareness of their fitness levels ${ }^{19,20}$; likewise, wearing a continuous hydration monitor can make users more aware of their hydration and act as a subconscious reminder to stay hydrated. Additionally, the use of a hydration monitor can help prevent dehydration-related illnesses and improve fitness-training methods ${ }^{4,21}$. The proposed solution is a wearable, continuous, and non-invasive device that uses ultrasonic pulses to detect changes in tissue properties over time. This device provides near real-time monitoring of hydration levels and alerts users of their current hydration status. The near real-time monitoring provides a significant 
benefit over other methods that cannot be used while exercising, require constant stops in activity to get feedback, require additional lab equipment, and require significant time resources. This device aims to eliminate invasive, time-consuming, and impractical lab tests to open up a whole new method of patient monitoring and significantly decrease the ineffective subjective treatment of dehydration.

\subsection{Purpose}

The purpose of this thesis is to design, test, and validate a wearable, continuous, and non-invasive hydration monitor that uses harm-free ultrasonic pulses to detect changes in tissue hydration status. Within this purpose, there are four subsidiary goals:

(1) Research current methods of hydration monitoring and identify the benefits of an ultrasonic method.

(2) Identify an optimal target customer and anatomic location for a hydration monitor.

(3) Design a device to meet specified customer and engineering requirements.

(4) Validate the device methods. 


\section{BACKGROUND}

Importantly, there is no standardized test for measuring hydration ${ }^{22}$. The lack of a standardized test is particularly surprising considering the amount of water in the human body, the importance of water in maintaining homeostasis, the significant physiologic impact of relatively small percentages of body weight water loss, and the prevalence of disruptions of water balance in diseases and ailments commonly treated in hospital settings. In this section, the essentials of dehydration, healthy body water content, the effects of dehydration, clinical presentation of dehydration, suggested hydration strategies, patient populations for a hydration monitoring device, current methods of monitoring hydration status, and state of the art hydration monitors will be discussed.

\subsection{Essentials of Dehydration}

Water is the most abundant chemical substance in the body, accounting for $60-80 \%$ of human body weight $^{23}$. The importance of water in the body is derived from five key properties of water: high heat capacity, high heat of vaporization, polar solvent properties, reactivity, and cushioning ${ }^{23}$. See Table I for an explanation of each of these properties and their role in maintaining body homeostasis.

Table I: A table of the key properties of water and the role of each property in maintaining homeostasis $^{23}$.

\begin{tabular}{|c|c|c|}
\hline Property & Description & Role in Homeostasis \\
\hline $\begin{array}{l}\text { High Heat } \\
\text { Capacity }\end{array}$ & $\begin{array}{l}\text { Water absorbs and releases large amounts } \\
\text { of heat before changing in temperature }\end{array}$ & $\begin{array}{ll}\text { - } & \text { Prevents sudden changes in } \\
\text { temperature due to external or internal } \\
\text { factors } \\
-\quad \text { Redistributes heat amongst body tissues }\end{array}$ \\
\hline $\begin{array}{l}\text { High Heat of } \\
\text { Vaporization }\end{array}$ & $\begin{array}{l}\text { Large amounts of heat are required to } \\
\text { vaporize water by transforming from liquid } \\
\text { to gas via the breaking of molecular } \\
\text { hydrogen bonds }\end{array}$ & $\begin{array}{ll}\text { - } & \text { Allows large amounts of heat to be } \\
\text { removed from the body via perspiration } \\
\text { - } & \text { Results in efficient cooling }\end{array}$ \\
\hline $\begin{array}{l}\text { Polar } \\
\text { Solvent } \\
\text { Properties }\end{array}$ & $\begin{array}{l}\text { Polarity of water molecules allows for the } \\
\text { orientation of slightly negative ends of } \\
\text { water towards positive ends of solvents, } \\
\text { thus attracting and surrounding other } \\
\text { molecules }\end{array}$ & 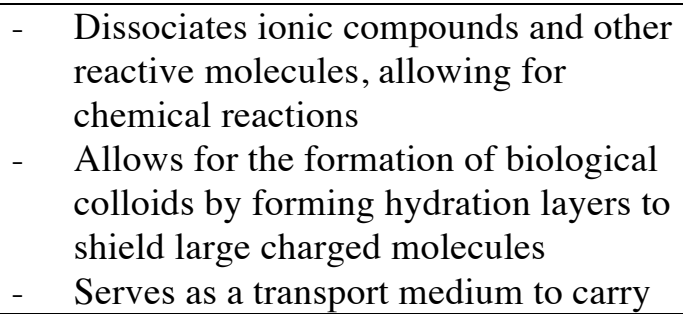 \\
\hline
\end{tabular}




\begin{tabular}{|l|l|l|}
\hline & & $\begin{array}{l}\text { nutrients, respiratory gases, and } \\
\text { metabolic wastes }\end{array}$ \\
\hline Reactivity & $\begin{array}{l}\text { High reactivity allows water to be a } \\
\text { reactant in many chemical reactions }\end{array}$ & $\begin{array}{l}\text { Allows for hydrolysis reactions and } \\
\text { dehydration synthesis, notably in the } \\
\text { cases of food digestion and enzymatic } \\
\text { activity }\end{array}$ \\
\hline Cushioning & $\begin{array}{l}\text { Can be used to form a cushion around body } \\
\text { organs }\end{array}$ & $\begin{array}{l}\text { Protects organs, notably the brain and } \\
\text { spinal cord, from physical trauma }\end{array}$ \\
\hline
\end{tabular}

As seen in Table I, water has a significant role in maintaining proper physiological function. When water homeostasis, known as euhydration, is disrupted, there are substantial side effects ${ }^{24}$. This disruption can be from inadequate water balance or excessive water balance ${ }^{23}$. The following definitions should be considered when investigating hydration status:

- Hyperhydration: a state of water excess, or positive water balance ${ }^{24}$.

- Euhydration: a dynamic state of maintaining a proper water balance ${ }^{24}$.

- Hypohydration: a state of insufficient water, or negative water balance ${ }^{24}$.

- Dehydration: the process of losing water from the body ${ }^{24}$.

- Rehydration: the process of gaining body water ${ }^{24}$.

To understand the consequences of dehydration, it is important to understand the movement of water within the body. See Figure 1 for a diagram of the key water transportation pathways. This diagram shows that total body water resides in two fluid compartments: the intracellular fluid compartment $(\sim 66 \%)$ and the extracellular fluid compartment $(\sim 33 \%)^{23}$. There are two subcompartments within the extracellular fluid compartment: plasma and interstitial fluid ${ }^{23}$. Water moves between compartments along osmotic gradients, which are driven by the concentration of solutes in each compartment ${ }^{23}$. Thus, changes in solute concentration result in net water flow into or out of a compartment ${ }^{23}$. In euhydration, water flow between compartments is regulated to maintain equal osmolalities between all body fluids ${ }^{23}$. To maintain euhydration, increases in the extracellular solute concentration drives water out of cells ${ }^{23}$. Conversely, decreases in the extracellular solute concentration drives water into cells ${ }^{23}$. It is by this mechanism that 
water contributes to the transportation of gases, nutrients, and wastes between the fluid compartments of the body ${ }^{23}$.

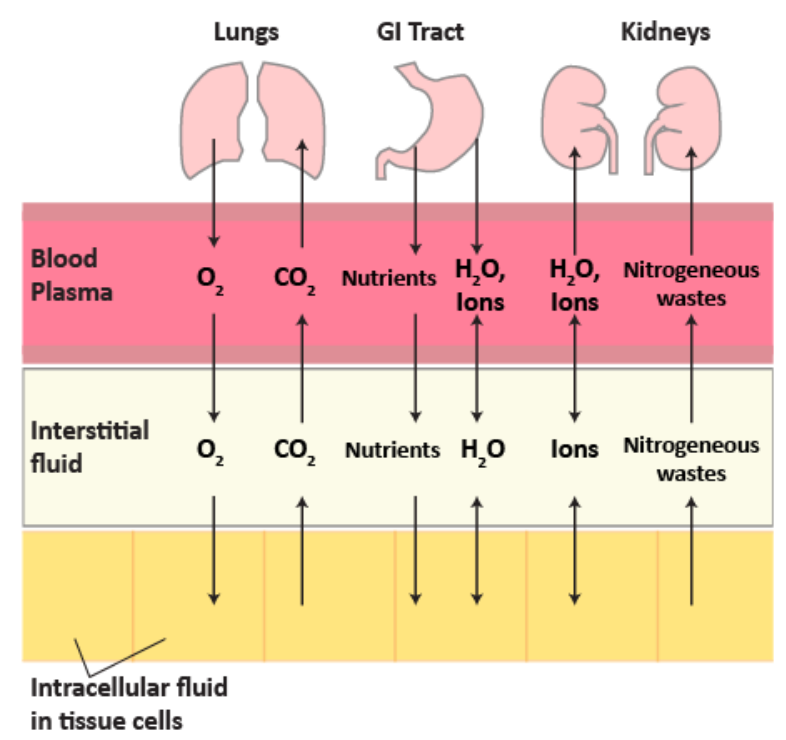

Figure 1: Exchange of gases, nutrients, water, and wastes between the three fluid compartments of the body ${ }^{23}$.

To maintain euhydration, water input must equal water output. Water leaves the body via several routes: vaporized water in expired air, insensible water loss by diffusion through the skin, excretion in feces, and excretion in urine ${ }^{23}$. Water output is countered by ingestion of food or liquids and metabolic water produced by cellular metabolism ${ }^{23}$. The balance between water output and input is regulated through a thirst mechanism in which an increase in plasma osmolality of 2-3\%, presence of angiotensin II, baroreceptor inputs, or other stimuli triggers osmoreceptors in the thalamic thirst center ${ }^{23}$. The thirst response is fulfilled soon after drinking water, as the mucosa of the mouth and throat are moistened and stretch receptors in the GI tract are activated ${ }^{23}$. Importantly, this quenching response is premature; that is, it allows time for the osmotic gradient changes and prevents over-dilution of body fluids ${ }^{23}$.

The premature quench response to hydration does not always provide the body with enough fluids to maintain euhydration ${ }^{23}$. For instance, the thirst response can be quenched during demanding athletic activity before adequate water is consumed, the threshold level for a thirst response is highly variable in 
people ${ }^{22}$, elderly may not recognize thirst signals, and, conversely, renal and cardiac patients may be thirsty despite an overload of fluids ${ }^{23}$.

Dehydration is essentially when water output exceeds water input over a period of time ${ }^{24}$. This can occur through two pathways: intracellular or extracellular dehydration ${ }^{23}$. Intracellular dehydration is caused by pure water loss from the skin via diffusion and from hypotonic solute losses from sweat ${ }^{25}$. Conversely, extracellular dehydration occurs when isotonic solute losses accompany body water, such as during cold or high-altitude exposure and in response to secretory diarrhea ${ }^{25}$. The most significant difference between intracellular dehydration and extracellular dehydration is that intravascular volume contraction is larger in extracellular dehydration, resulting in osmotic and volume differences between the two types of dehydration ${ }^{25}$. It is important to note that the simplistic definition of dehydration does not specify whether the water balance is disturbed through loss of water with solute in the extracellular fluid compartment or from primary water loss in the intracellular fluid compartment, a factor that must be considered when reviewing literature on dehydration. For example, Ely et al. designed a method to assess extracellular water content ${ }^{25}$ while a study by Vivanti et al. did not differentiate between intracellular water loss and total body water loss ${ }^{6}$. Considering that both types of dehydration have detrimental physiological effects, that review of literature reveals inconclusive preferences for the importance of monitoring a specific type of dehydration, and that the design of the device in this thesis measures the combined effect of both types of dehydration, any reference to dehydration in this thesis, unless specifically stated as intracellular or extracellular, can be assumed to be whole body dehydration.

\subsection{Healthy Body Water Content and Clinical Presentation of Dehydration}

Total body water is a function of age, body mass, gender, and relative amount of body fat ${ }^{23}$. Typically, infants are $73 \%$ water, young males are $60 \%$ water, young females are $50 \%$ water, and elderly are $45 \%$ water $^{23}$. The variations in water content among these populations are explained by anatomical differences and tissue-related compositions; for example, infants have low body fat and low bone mass, females have relatively more body fat and less skeletal muscle than males, and greater muscle mass results in higher 
water content ${ }^{23}$. Further, adipose tissue, typically $20 \%$ water, is far less hydrated than skeletal muscle, typically $75 \%$ water $^{23}$. In fact, studies have found that the absolute water content in muscles varies from $65-76 \%$ in people with different total body fat contents ${ }^{26}$.

Thus, healthy body water content is dependent on individual factors. One person's healthy body water content value cannot be extrapolated for large populations of people ${ }^{18}$. To compare extents of fluid loss between people, dehydration is referred in percentage body water weight loss $(\% \mathrm{BW})^{6}$. In general, the clinical presentation of dehydration is dependent on the extent of dehydration. Given the high water content of human bodies and the importance of water for maintaining proper homeostasis, loss of even small $\% \mathrm{BW}$ can have significant consequences ${ }^{4,21,23,24}$. For every $1 \%$ body mass fluid loss, there is an increase in internal body temperature of approximately $0.22^{\circ} \mathrm{C}^{27}$. Water loss of only $2 \% \mathrm{BW}$ results in discomfort, a drop in blood volume, increase in heart rate, and may begin to significantly affect athletic performance and other common bodily functions ${ }^{23}$. Loss of more than $3 \% \mathrm{BW}$ further disturbs physiologic function and increases the risk of heat illness ${ }^{28}$. Loss of $4 \%$ necessitates an increased effort for physical work, $5 \%$ causes difficulty concentration, $6 \%$ causes impairment in exercise temperature regulation, $10 \%$ causes spastic muscles, and $15 \%$ causes death ${ }^{4}$. See Figure 2 for a diagram of average body water contents and the effects of percentages of body water weight loss. 
On average, the human body is up to:

$\begin{array}{llll}\text { Lungs } & = & 90 \% \text { water } \\ \text { Blood } & = & \\ \text { Infants } & = & \\ \text { Brain } & = & 78 \% \text { water } \\ \text { Body } & = & \mathbf{7 0 \%} \text { water }\end{array}$

\% BW weight water loss up to:

$\begin{array}{lll}15 \% & = & \text { Death } \\ 10 \% & = & \text { Spastic Muscles } \\ 7 \% & = & \text { Increase in Pulse \& Respiratory Rate } \\ \mathbf{6 \%} & = & \text { Impairment in Temperature Regulation } \\ \mathbf{5 \%} & = & \text { Difficulty Concentrating } \\ 4 \% & = & \text { Increased Effort for Physical Work } \\ 3 \% & = & \text { Increased Risk of Heat Illness } \\ 2 \% & = & \text { Decrease in Cognitive and Physical Ability } \\ & & \text { Drop in Blood Volume } \\ 1 \% & = & \text { Thirst }\end{array}$

Figure 2: Diagram of body water content amounts and the effects of $\%$ BW water loss ${ }^{4,23,28}$.

\subsection{Suggested Hydration Strategies}

Optimal hydration strategy depends on energy expenditure, environment, and individual needs ${ }^{29}$. See Table II for the United States Department of Agriculture (USDA) Dietary Reference Intake guidelines for water consumption. As seen in the table, the suggested water consumption for males varies from 2.4 to 3.7 L/day and from 2.1 to $2.7 \mathrm{~L} /$ day for females ${ }^{30}$. Note that these guidelines are for median intakes of generally healthy individuals that are adequately hydrated ${ }^{30}$. On top of median intake values, the National Athletic Trainer's Association suggests consuming 200-300 mL of fluid on average for every 10-20 minutes during exercise to prevent more than $2 \% \mathrm{BW}$ water loss per day ${ }^{28}$. More specifically, a guiding committee led by Casa et al. provided USA Track \& Field athletes with a self-testing program for optimum hydration $^{31}$. In this program, it is recommended that a hydration strategy considers the sweat rate, sport dynamics (rest breaks, fluid access), environmental factors, acclimatization state, exercise duration, exercise intensity, and individual preferences ${ }^{31}$. Examination of the suggested hydration strategies revealed a key outcome: the available strategies require complex data logging and must be 
recalculated for each activity, climate, environment, and activity intensity ${ }^{28-30}$. These complexities could be eliminated with the use of a real-time hydration monitor.

\begin{tabular}{|c|c|c|c|}
\hline Nutrient & Function & $\begin{array}{l}\text { Life Stage } \\
\text { Group }\end{array}$ & Al \\
\hline Water & $\begin{array}{l}\text { Maintains } \\
\text { homeostasis in the } \\
\text { body and allows } \\
\text { for transport of } \\
\text { nutrients to cells } \\
\text { and removal and } \\
\text { excretion of waste } \\
\text { products of } \\
\text { metabolism. }\end{array}$ & $\begin{array}{l}\text { Infants } \\
0-6 \text { mo } \\
7-12 \text { mo } \\
\text { Children } \\
1-3 y \\
4-8 y \\
\\
\text { Males } \\
9-13 y \\
14-18 y \\
19-30 y \\
31-50 y \\
50-70 y \\
>70 y \\
\text { Females } \\
9-13 y \\
14-18 y \\
19-30 y \\
31-50 y \\
50-70 y \\
>70 y \\
\\
\text { Pregnancy } \\
14-18 y \\
19-50 y \\
\text { Lactation } \\
14-18 y \\
19-50 y\end{array}$ & $\begin{array}{l}\text { (L/d) } \\
0.7 \\
0.8 \\
\\
1.3 \\
1.7 \\
\\
2.4 \\
3.3 \\
3.7 \\
3.7 \\
3.7 \\
3.7 \\
\\
2.1 \\
2.3 \\
2.7 \\
2.7 \\
2.7 \\
2.7 \\
\\
3.0 \\
3.0 \\
\\
3.8 \\
3.8\end{array}$ \\
\hline
\end{tabular}

\subsection{Patient Populations}

Aside from use by the general population as a tool for maintaining overall fitness, there are many patient populations that could benefit from a wearable, continuous, and non-invasive hydration monitor. In literature, the most frequently listed groups include athletes, soldiers, geriatric care, pediatric care, prenatal monitoring, firefighters, dialysis patients, and for EMT and general hospital use ${ }^{4-8}$.

Given the importance of proper hydration for optimal athletic performance, the effects of dehydration and the importance of hydration monitoring for athletes has been widely studied ${ }^{10,27,29,31-40}$. Regardless of the 
method used to assess hydration status in athletes, a common finding among athletic hydration studies is that athletes frequently report to practices or games in an already-dehydrated state. For example, a study by Prentice et al. found that the hydration status of 30 elite rugby participants was consistently lower than recommended levels ${ }^{32}$, Chia et al. found that 39/40 high school hockey players arrived at a competition already displaying signs of dehydration ${ }^{33}$, and Kutlu et al. reported that elite junior taekwondo athletes display indicators of chronic dehydration ${ }^{34}$. Additionally, athletes commonly train in conditions where heat-related illnesses - like dehydration - are a concern. Football players in preseason summer practices are a particularly at-risk population. Yard et al. reported that since 1995, 31 high school football players have died from heat stroke and that 4.5 per 100,000 athletes suffer from heat-related illnesses, such as dehydration, of which $36.9 \%$ miss more than two days of practice ${ }^{35}$.

Compounding the prevalence of dehydration in athletics are the significant detrimental effects of dehydration on athletic performance. For example, hypohydration has been associated with increased cardiovascular strain and, under severe conditions, cardiac dysrhythmia and arrest may occur ${ }^{41}$. Further, dehydration reduces overall heart rate variability and decreases autonomic cardiac stability following exercise $^{41}$. The detrimental effects of dehydration are seen particularly in marathon runners, where $15 \%$ of runners with exercise-associated collapse (59\% of medical tent visits) require intravenous hydration ${ }^{42}$. In total, the athletic population can significantly benefit from monitoring hydration to decrease the detrimental effects of dehydration and improve overall performance.

In the military, soldiers commonly dehydrate $2-5 \%$ of BW due to high rates of water loss from environmental exposure and performing stressful physical work ${ }^{4}$. In basic training and active duty, recruits may be sent to areas in which they are not acclimatized to the heat, thus increasing the likelihood of exertional heat illness ${ }^{29}$. Additionally, of total dehydration-related exertional heat illness cases during basic training, approximately $50 \%$ of cases occur in recruits without identifiable risk factors ${ }^{27}$. Soldiers in active duty may have to be in the field for long periods of time, for which adequate hydration sources must be available. Maughan et al. suggest that soldiers should consider their hydration status before 
beginning exercise, the need for fluid, electrolyte, and substrate replacement during exercise, and the need for restoration of water and electrolyte balance after exercise ${ }^{29}$. In sum, to reduce the water load carried by soldiers, reduce cases of exertional heat illness, and improve cognitive focus during highly stressful military operations, it would be beneficial to have a real-time hydration monitor.

Hydration monitoring for geriatric care is a frequent area of investigation ${ }^{6-9,13,15,18,43-45}$. Compared with younger populations, the elderly have complications with maintaining euhydration; these complications include a low average body water content, a lack of recognition of thirst signals, and a reduced ability to maintain temperature homeostasis ${ }^{23}$. A diagnosis of dehydration in clinical care has been associated with increased morbidity and mortality, and older people 85-99 years of age were reported to be six times more likely to be admitted to the hospital with dehydration than those 65-69 years old ${ }^{46}$. Additionally, the elderly are the largest growing population group and place large demands on medical providers ${ }^{6}$. The difficulty in balancing geriatric physiology with existing measures of dehydration monitoring is shown in a study by Rösler et al., in which bioelectric impedance had less than $44 \%$ concordance with clinical judgment of dehydration ${ }^{43}$. Thus, a more accurate and non-invasive method of monitoring hydration status may significantly reduce the number of elderly hospital remittances, improve geriatric care, and reduce the burden of an aging population on the health system.

Pediatric care and prenatal monitoring can also benefit from a hydration monitor ${ }^{4,5,10,27,47-49}$. The high water content of infants and children makes proper hydration critical in the prenatal and pediatric stages, specifically for healthy development. For example, failure to increase body water content during pregnancy has been associated with adverse pregnancy outcomes ${ }^{50}$. Additionally, progressive reduction in body water content during gestation has been linked to gestational hypertension and pre-eclampsia, low birth weight, and poor pregnancy outcome ${ }^{50}$. In a pediatric unit, some patients may need hydration status monitoring daily or hourly ${ }^{13}$. While the small size of infants likely requires design modifications, the development of a non-invasive method to monitor hydration is particularly suited for providing ease-ofmind during the prenatal process. 
Firefighters are particularly at risk for dehydration ${ }^{51-53}$. The heat exposure from fires, stressful work environment, heavy personal equipment, time spent in the field, lack of access to drinking water, and heavy protective equipment contribute to profuse sweating and rapid dehydration ${ }^{52}$. Simulations of fire activities found that dehydrated firefighters demonstrated significantly greater cardiovascular strain than euhydrated firefighters, which emphasizes the importance of proper hydration management prior to arriving on the $\mathrm{job}^{52}$. In addition to encouraging firefighters to stay properly hydrated, a hydration monitor could prevent serious instances of dehydration in the field.

A hydration monitor could have significant impact in a hospital environment. For instance, numerous pathologic signs and symptoms, such as significant changes in body fluid retention pre- and post-surgery, digestion problems, high blood pressure, muscle cramps, edemas, or obesity, present in clinical patients with tissue water imbalance ${ }^{4}$. In cardiac applications, fluid overload in patients with acute heart failure has a significant diagnostic and prognostic importance ${ }^{8}$. Thus, a method of easily, quickly, non-invasively, and cost-effectively monitoring hydration can significantly assist diagnostic and therapeutic decisionmaking for cardiac patients. As a final example, patients on bed rest experience a severe restriction of muscular activity and the equilibrium between intake and loss of electrolytes is markedly affected ${ }^{54}$. Proper hydration strategies can significantly decrease the detrimental effects of bed rest on patients, namely the increase in body dehydration status, excessive mineral loss in urine, and abnormal mineral levels in plasma ${ }^{54}$. In sum, including a test for hydration status on a standard patient intake assessment can increase diagnostic capabilities and provide another metric for monitoring critical patients.

\subsection{Current Methods}

In the absence of a standardized method to monitor hydration status, there is debate in literature over the best way to measure dehydration ${ }^{7,8,14,15,21,55}$. In general, there are two classifications of methods to monitor hydration status: qualitative methods and quantitative methods. The use of a particular method depends 
on access to equipment, clinical or home setting, diagnostic importance, time available, access to sampletaking resources, and investigator/user familiarity or preference for a particular method.

\subsubsection{Qualitative Methods}

Qualitative methods for monitoring hydration status include the thirst response, urine color comparison charts, and physician assessment of dehydration-related symptoms. As mentioned in the essentials of dehydration section, the premature quench response to hydration does not always provide the body with enough fluids to maintain homeostasis. For instance, the thirst response can be quenched during demanding athletic activity before adequate water is consumed, the threshold level for a thirst response is highly variable in people ${ }^{22}$, elderly may not recognize thirst signals, and, conversely, renal and cardiac patients may be thirsty despite an overload of fluids ${ }^{23}$. Thus, the thirst response should be avoided as a sole method of monitoring hydration status.

A urine color chart can be used as a visual marker of hydration ${ }^{56}$. See Figure 3 for an example chart in which urine color matching \#1-\#3 is well hydrated, \#4-\#6 is dehydrated, and \#7 or below requires immediate consumption of fluids. Once a person is aware of the general scale, it does not require any equipment to use a urine color chart. However, urine output may be suppressed in cases of moderate to extreme dehydration and the time delay in onset of the effects of dehydration and output of urine is detrimental to maintaining a healthy hydration status. 


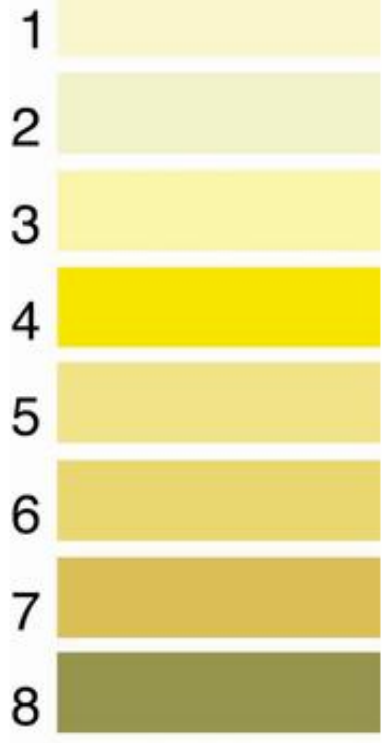

Figure 3: Urine color chart used to assess hydration status ${ }^{56}$.

Physician assessment of dehydration-related symptoms uses the presenting state of a patient to evaluate hydration status. See Table III below for an example of a clinical assessment scale for dehydration. Unfortunately, clinical assessments of dehydration frequently rely on subjective measures performed by physicians that do not regard dehydration as a significant risk factor for hospital monitoring ${ }^{2,57}$. Therefore, assessments of dehydration can vary significantly based on the physician's experience. For this reason, the use of qualitative methods should be supplemented by the development of a standardized quantitative method and, thus, improve the diagnosis and subsequent treatment strategies for patients with dehydration. 
Table III: Dehydration assessment scale ${ }^{57}$.

\begin{tabular}{|l|l|l|l|}
\hline \multicolumn{1}{|c|}{ Sign } & \multicolumn{1}{|c|}{$\begin{array}{c}\text { Mild } \\
(\mathbf{5 \%})\end{array}$} & \multicolumn{1}{|c|}{$\begin{array}{c}\text { Moderate } \\
(\mathbf{6 \% - 1 0 \% )}\end{array}$} & \multicolumn{1}{|c|}{$\begin{array}{c}\text { Severe } \\
(\mathbf{1 0 \%})\end{array}$} \\
\hline Skin turgor & Slightly decreased & Decreased & Very decreased \\
\hline Skin color & Pale & Sallow & Ashen \\
\hline Oral mucosa & Dry & Very dry & Parched \\
\hline Tears & \pm Decreased & Absent & Absent \\
\hline Fontanel & Normal & Depressed & Sunken \\
\hline Pulse & \pm Increased & Increased & Marked tachycardia \\
\hline Blood pressure & Normal & \pm Decreased & Decreased \\
\hline Urine output & Mild oliguria & Oliguria & Anuria \\
\hline Mental status & Irritable & Lethargic & Unresponsive \\
\hline
\end{tabular}

\subsubsection{Quantitative Methods}

Quantitative methods of monitoring hydration level include BW differences, urine output, urine specific gravity, urine osmolality, plasma osmolality, saliva osmolality, dilution methods, and bioimpedance ${ }^{22}$. Of these methods, bioimpedance and BW differences are the only non-invasive options. BW differences have significant limitations for monitoring hydration status, which will be discussed in the next paragraph. Additionally, due to the problem statement emphasis on non-invasive options for monitoring dehydration, bioimpedance is discussed in detail in the following section. The use of multiple quantitative methods in studies is likely due to the lack of a standardized method for monitoring dehydration, the ability to acquire multiple measures from one sample (of blood, urine, or saliva), and overall confusion on the most accurate or applicable measure of dehydration. Due to the ease of weighing subjects and the relative ease of acquiring urine samples as opposed to blood samples, BW differences and urine measures are the most commonly used and defined quantitative methods for measuring hydration status ${ }^{10,33,49}$, and will be discussed.

Change in BW can be used to determine net water output and $\%$ BW water loss ${ }^{18}$. However, this is only accurate in assessing hydration status over a single exercise period and is not an immediate indicator ${ }^{18}$. Over long periods of time, BW changes can be attributed to other factors, such as food intake, bowel movement, substrate metabolism, and body composition ${ }^{34}$. Additionally, relying on pre- and post-exercise changes in BW for hydration status does not allow for changes in hydration strategies during exercise and 
can be thrown off by water weight consumed during, or immediately following, the activity ${ }^{58}$. Further, BW water loss does not allow a measure of starting hydration status and only provides a measure of change in body water weight, which can represent different levels of hydration in different people. Regardless, BW water loss as a percentage of starting weight is a commonly used measure of change in hydration status after exercise ${ }^{10,18,34,51,59}$.

Urine sample measurements for hydration status include specific gravity and osmolality. Urine specific gravity is a measure of the ratio of the density of urine to the density of water ${ }^{33}$ and urine osmolality is a measure of the concentration of solutes within the urine ${ }^{23}$. A study by Takaki et al. found that urine specific gravity and urine osmolality, measured with a handheld refractometer and osmometer, provide results that are significantly equivalent markers to evaluate hydration status ${ }^{60}$. Kutlu et al. found that there were no significant differences in any of the methods used to monitor urine, which included urine osmolality, specific gravity, and arbitrary units for qualitative color comparisons ${ }^{34}$. Of the two measures, urine specific gravity has recently gained traction towards being the preferred method of measuring

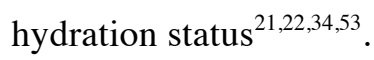

In terms of an absolute scale, urine specific gravity values are usually between 1.010 and 1.030, with: well hydrated, USG < 1.010; minimal dehydration, USG = 1.010-1.020; significant dehydration, $\mathrm{USG}=$ 1.021-1.030; and serious dehydration $>1.030^{37}$. Given that urine specific gravity below 1.020 indicates significant dehydration, the NCAA uses urine specific gravity measurements of $\leq 1.020$ to identify a state of euhydration prior to wrestling weigh-ins ${ }^{10,61}$. See Table IV for a table of the percent change in body mass and the specific gravity of urine indicators of hydration status. 
Table IV: Indicators of hydration status ${ }^{28}$.

\begin{tabular}{|l|r|r|}
\hline \multicolumn{1}{|c|}{ Condition } & $\begin{array}{c}\text { \% Change in } \\
\text { Body Mass }\end{array}$ & \multicolumn{1}{c|}{$\begin{array}{c}\text { Urine Specific } \\
\text { Gravity }\end{array}$} \\
\hline Well hydrated & +1 to -1 & $<1.010$ \\
\hline Minimal dehydration & -1 to -3 & 1.010 to 1.020 \\
\hline Significant dehydration & -3 to -5 & 1.021 to 1.030 \\
\hline Serious dehydration & $>-5$ & $>1.030$ \\
\hline
\end{tabular}

Despite the common use of urine measurements in hydration studies, there remain significant drawbacks to relying on this method to measure hydration status: it is invasive, it requires time out of exercise to provide a sample, sample acquisition may be impossible in cases of extreme dehydration, additional lab equipment is needed, hygienic acquisition procedures must be followed, and, most importantly, it does not provide real-time feedback of hydration status.

\subsubsection{Bioimpedance Devices}

The other available non-invasive quantitative method for measuring hydration is with bioimpedance analysis (BIA) devices or through bioelectrical spectroscopy. For this reason, BIA methods for monitoring hydration have been widely investigated to monitor various patient populations ${ }^{8,14,16,43,62-68}$. Essentially, BIA devices measure tissue conductivity by using electrodes to acquire processed signals that are used to calculate opposition to the flow of electric current through body tissues ${ }^{8}$. At homeostasis, the conductivity of the tissues is directly proportional to the amount of fluid present. Additionally, variations in the impedance - the frequency-dependent opposition of a conductor to the flow of an administered alternating current - of the tissues cause a phase shift in the applied current. At low frequencies, the impedance of the cell membranes and tissue interfaces is too large for conduction of the current and the current is only conducted through the extracellular fluid. At high frequencies, current flow increases as the cell membranes and tissue interfaces lose their capacitive ability and the intracellular water content can be measured ${ }^{68}$. Thus, by using a combination of low and high frequency currents, BIA is used to determine the extracellular, intracellular, or total body water content. 
Hydration studies with BIA devices have several variations in methodology. Different devices, frequency ranges, regression equations, limbs, time frames, target water cavity, and population groups have been investigated ${ }^{8,14,16,43,62-68}$. Devices used by the investigators of BIA studies include the Bodystat 1500 and dual frequency Bodystat Dualscan devices by Bodystat Ltd ${ }^{62,69}$, the Hydra 4200 device by Xitron Technologies ${ }^{16,63,70}$, the BCM Body Composition Monitor by Fresneius Medical Care ${ }^{64,71}$, the ElektroFluid-Graph by AKERN ${ }^{43}$, the SFB3 analyzer by SEAC ${ }^{65}$, the Bodygram by AKERN ${ }^{66}$, and the Impedimed multifrequency analyzer by Impedimed ${ }^{67}$. See Figure 4 for images of three BIA devices, the Bodystat 1500, XiTRON Hydra 4200, and BCM Body Composition Monitor. The Elektro-Fluid-Graph, SFB3, and Bodygram are no longer available for purchase.

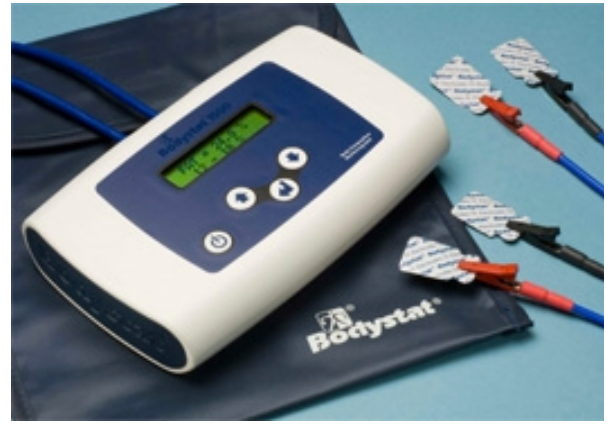

(A)

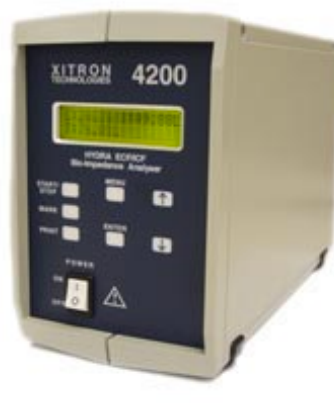

(B)

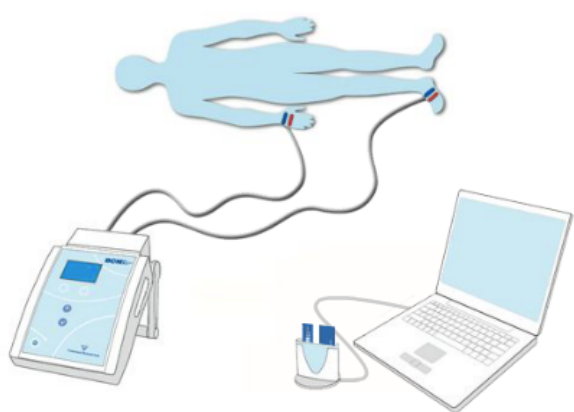

(C)

\section{Figure 4: (A) Bodystat 1500 with electrodes ${ }^{69}$. (B) XiTRON Hydra 4200 ${ }^{70}$. (C) BCM Body Composition Monitor ${ }^{71}$.}

The shortcomings of BIA methods include inconclusive results among geriatric populations ${ }^{43}$, failure to predict changes during short term 2-3\% dehydration and rehydration ${ }^{65}$, the need for precise equations dependent on suitable parameters (age-, gender-, and population-specific) ${ }^{14}$, inability to be consistently used in patients with water-imbalance diseases (such as liver cirrhosis, renal failure, cardiac disease, and obesity $)^{14}$, and variations in reliability and accuracy when monitoring acute changes in hydration status ${ }^{40}$. Importantly, BIA methods can only be used to monitor hydration while the user is inactive, require four electrodes to be adhered to the user, the electrodes/devices have to be calibrated before each measurement, 
proper individual-specific regression equations must be used, the electrodes must be placed either on each limb (whole body) or on a single limb (calf), experienced care must be used to attach and operate the electrodes, large wires run from each electrode to the devices, and the devices are large, cumbersome, and cannot be used in patients with amputations, artificial joints, pregnancies, stents, or pacemakers ${ }^{8,14,16,43,62-68}$. Furthermore, BIA devices are prohibitively expensive; a single unit without the recurring cost of electrodes can run as much as $\$ 1,485^{62}$.

Two other types of BIA devices are handheld body composition analysis devices and scale body fat monitors. These are more accessible, easier to use, and cheaper options than electrode-based BIA devices. However, due to the more established literature on electrode-based systems, there are few studies on the efficacy of these devices. Regardless, four key limitations exist with the handheld and scale methods: the suggested use of these devices is only when optimally hydrated, each device only measures the composition of the body segment nearest to the device (upper body for handheld, lower body for scale), the devices are only intended for use once a day, and they cannot be used while exercising ${ }^{72}$. Additionally, the most popular handheld model contains documentation excluding use for children of growing stage, elderly people, women after menopause, those having swelling, patients of osteoporosis having very low bone density, people with a fever, bodybuilders or professional athletes, patients undergoing dialysis, and pregnant women ${ }^{72}-$ all of whom could benefit from hydration monitoring. Therefore, handheld body composition device and scale body fat monitors are not suitable for continuous monitoring of hydration status and an alternative method would be beneficial for all target populations. 


\subsection{State of the Art}

There have been recent studies that propose novel devices for monitoring hydration by detecting one of the clinical measures of dehydration. Gunter et al. and Stewart et al. used MEMS-based embedded piezoresistive microcantilever sensors to measure osmolality changes in saliva or urine with $1 \%$ accuracy $^{7,13}$. In these devices, organic or synthetic polymeric materials respond to osmolality changes in a user's saliva by expanding or contracting. See Figure 5 for a diagram of this process. This volumetric change is measured by $300 \mu \mathrm{m}$ long piezoresistive microcantilevers and was shown to have a non-linear relationship between resistance (ohms) and relative humidity $(\%)^{7}$. As of 2007 , the researchers were working on larger scale human testing to determine the viability of these sensors as long-term hydration monitoring devices ${ }^{13}$. Regardless of their success in long-term monitoring, there are significant design barriers that must be overcome such as implementation in a device, communication of data, a power source, sensor response to drinking fluids, and clinical studies for different populations, specifically geriatric patients with low salivary response. Furthermore, salivary hydration status sensing is not likely to be continuous.
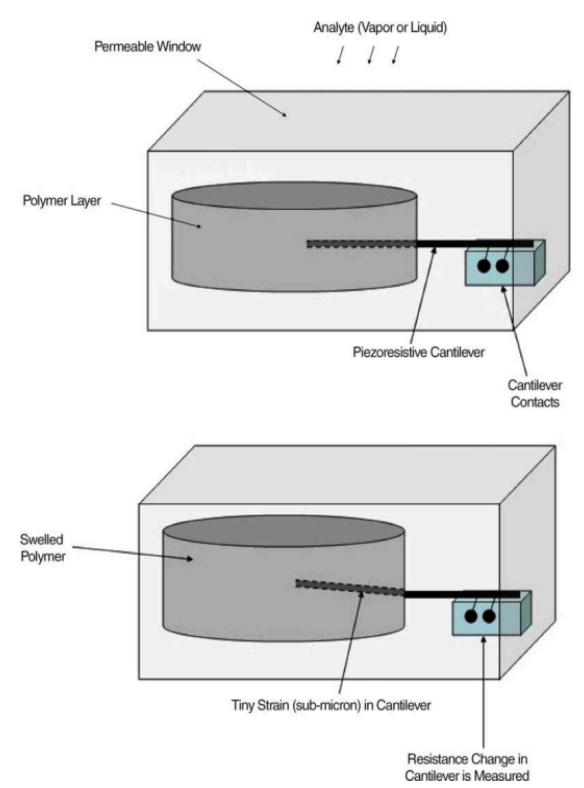

Figure 5: Operation of an embedded piezoresistive microcantilever device for hydration monitoring ${ }^{7}$. 
A MIT-associated company, mc10, Inc., has been investigating small, wearable, and flexible electronic patches to monitor hydration in real-time ${ }^{73-75}$. See Figure 6 for an image of an inactive patch on a model's arm. Mc10 claims that the Biopatch has hydration monitoring capabilities, but the company has not released any information on the method they use. See Figure 7 for a concept image of the patch, obtained via a promotional video on mc10's webpage, and a circuitry image from an infographic depicting possible electronic components within the Biopatch. As seen in Figure 7, a Biopatch could contain an LED, photodetectors, a strain gauge, temperature sensors, EEG/EMG sensors, and ECG sensors. The recent article from the Boston Globe revealed that mc10 is developing a commercially available version of the Biostamp for release next year, but specifically stated that the company will not divulge what the Biostamp will monitor ${ }^{75}$.

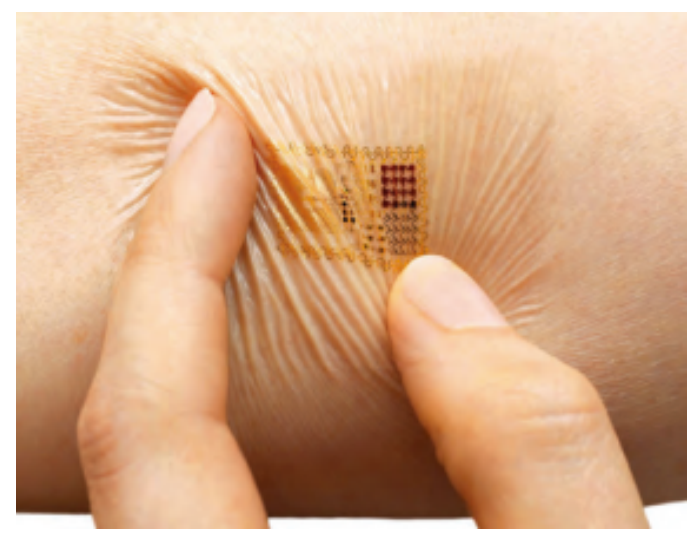

Figure 6: Image of an inactive flexible electronic patch from $\mathrm{mc10}^{74}$.

Further investigation revealed an applied, but not granted, patent \#WO/2013/033724, ELECTRONICS

FOR DETECTION OF A CONDITION OF TISSUE, filed September $4^{\text {th }}, 2012^{76}$. In this patent, mc10 is claiming (in brief summary):

(1) An apparatus for monitoring a condition of a tissue wherein a measure of the electrical property of the tissue using the apparatus provides an indication of the condition of the tissue $^{76}$. 
(2) The condition of the tissue can be the hydration state, volume of sweat lost, mechanical property of the tissue, or a disease state of the tissue ${ }^{76}$.

(3) Specifics regarding the components of the apparatus (brace structures, spacer structures, cross-link structures, encapsulated structures, adhesive structures, and encapsulation materials $)^{76}$.

(4) An apparatus of (1) further containing an ultrasound apparatus, made of an ultrasound generator (piezoelectric crystal) proximate to a first tissue of interest, wherein the ultrasound generator directs ultrasound waves at a portion of the tissue and an ultrasound receiver disposed proximate to a second portion of the tissue of interest provides a measure of ultrasound waves arriving at the second portion of the tissue ${ }^{76}$.

(5) A method wherein comparing the data to a calibration standard provides an indication of the tissue $^{76}$.

(6) Further claims on design possibilities, such as curved components, zigzag circuitry, and nonlinear components ${ }^{76}$.

Given the information contained in the claims, mc10's electronic patches could use bioimpedance, ultrasonic, capacitive, or any combination of the three measurements to obtain information on hydration status. It is important to note that this patent and the claims within have not been granted; grant of a patent does not guarantee that mc10 will pursue development of hydration monitoring, and no clinical studies from the authors of the patent could be found. While the language within this patent application is concerning in terms of the long-term possibilities of this thesis, consultation with a patent attorney revealed that there is no guarantee that mc10 will be granted all of the claims. The patent attorney also advised that development of an ultrasonic method that does not rely on a known distance between sensors remains a viable patent opportunity. Should mc10 be granted the claims within this patent and no viable patent work-around can be found, there still exists an option of licensing the patent from mc10 to develop a marketable device. 
Additionally, a review of mc10's webpage and promotional releases reveals a focus on the Reebok CHECKLIGHT concussion monitor, a different device under development by the 30-person company. The design direction of a patch as opposed to a wearable device is also intriguing; the diminutive size, degradability, lack of hardware components, and ability to wear multiple patches to monitor more metrics is particularly applicable for professional athletes, but may not address a market need for the general population.

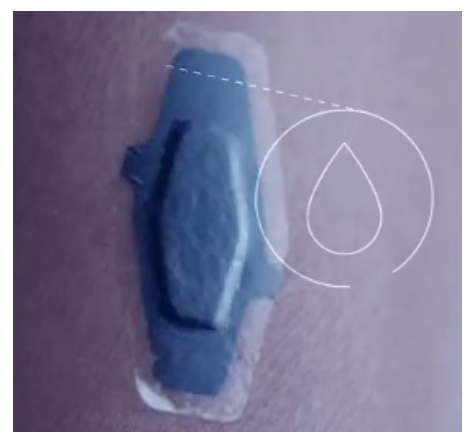

(A)

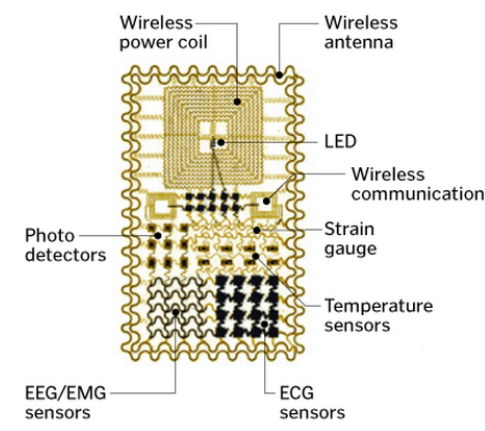

(B)

Figure 7: Images of: (A) a conceptual hydration monitoring patch by $\mathrm{mc10}$, Inc $\mathrm{C}^{73}$ and $(\mathrm{B})$ a diagram of possible electronic positioning within the mc10 patch $^{75}$.

Importantly, a study in 2005 by Sarvazyan et al. proposed a wearable device that uses an ultrasonic method $^{4}$. Sarvazyan, the lead investigator on this study, formed Artann Labs and continued development on this device for two additional studies in 2006 and $2010^{4,9,10}$. See Figure 8 for the design progression of the device. Note that despite the different study primary authors, the same investigative group was involved in all three studies. The device was initially designed with a rigid frame, hinge angle sensor, detached portable electronic unit, and for use with the soleus muscle ${ }^{4}$. The rigid frame and hinge angle sensor allow precise detection of the angle between the probes. Then, the angle can be used to determine the distance between the ultrasonic transducer ${ }^{4}$. The theory behind the ultrasonic method used in this study, and further investigated as a part of this thesis, is described in more detail in the upcoming Theory chapter. 


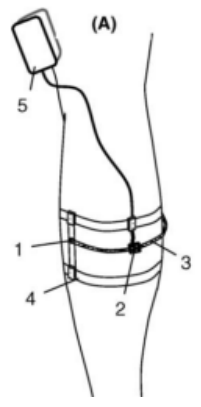

(A)

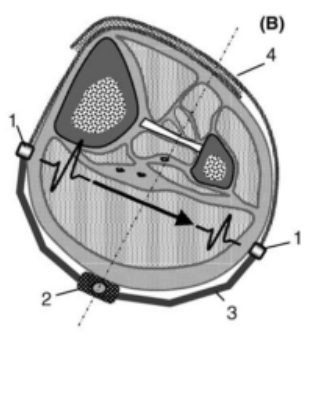

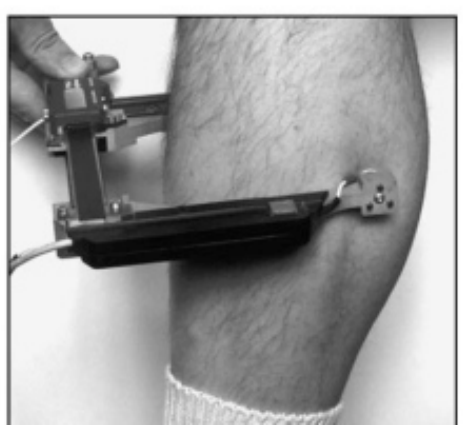

(B)

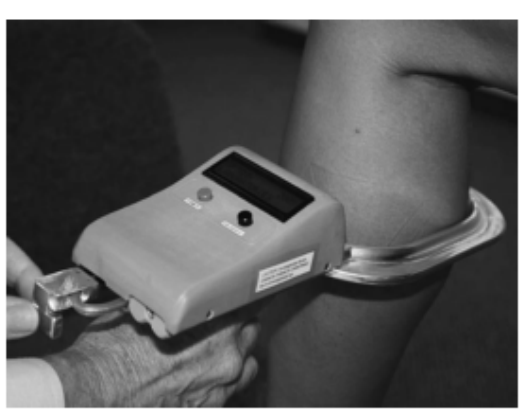

(C)

Figure 8: Images of the ultrasonic devices used by (A) Sarvazyan et al. ${ }^{4}$, (B) Topchyan et al. ${ }^{9}$, and (C) Utter et $\mathbf{a l}^{10}$.

A key requirement for the designs by Artann Labs is a known distance between the two ultrasonic transducers. This requirement was verified after a patent search revealed that Artann Labs was granted two patents (2006 and 2007) on using an ultrasonic method to monitor hydration status:

(1) US7033321 B1: Ultrasonic water content monitor and methods for monitoring tissue hydration $^{77}$.

(2) US7291109 B1: Infant hydration monitor ${ }^{78}$.

The second patent expands on the claims of the first patent, specifically in the design of an infant hydration monitor. In the first patent, Artann Labs is claiming (in brief summary):

(1) An ultrasonic tissue water content monitor comprising of a first ultrasonic means, second ultrasonic means, and support system to hold the ultrasonic means against tissue at a known distance apart. This distance can be determined via a rigid structure or angle sensor.

(2) A method of evaluating tissue water content using partial or whole propagation of ultrasonic waves through tissue, detection of time-of-flight between a first and second ultrasonic means, calculation of the velocity of ultrasonic waves through tissue, or detection of plurality of velocity measurements through layers of tissue.

The language in the summarized claim (2) is concerning for the long-term possibilities of this thesis, but consultation with a patent attorney revealed that development of an ultrasonic method that does not rely on a known distance between sensors remains a viable patent opportunity. Additionally, a proposed future 
direction of this thesis involves a method not discussed in the summarized claim (2). Should no viable patent work-around be found, there still exists an option of licensing the patent from Artann Labs to develop a marketable device.

Refocusing on the current status of Artann Lab's device, the last published results were from the study in 2010 by Utter et $\mathrm{al}^{10}$. In 2011, the device was used in an observational clinical trial funded in collaboration with the Bill and Melinda Gates Foundation (NCT01482208) ${ }^{79}$. This trial was specifically for neonatology and pediatric children and infants and/or children up to age 3 years old with diarrhea ${ }^{79}$. In this trial, the investigators used ultrasound velocity measurements through muscle tissues to follow patient hydration status in acute diarrhea and during rehydration therapy ${ }^{79}$. The clinical trial was completed in October 2012, but no results have been published ${ }^{79}$. Although no study results were published, the results must have been promising - On August 1 ${ }^{\text {st }}, 2013$, Artann Labs was awarded major funding from the National Institute on Aging/National Institutes of Health for development of the hydration monitor specifically for use in the elderly ${ }^{80}$.

The long-term success of Artann Labs in continued development and acquiring funding support for clinical trials is promising for future investigations. Notably, the devices created by Artann Labs do not allow for continuous monitoring, have large form factors, require a separate operator, and can only be used when the subject is sitting down at rest. Despite these design shortcomings, the ultrasonic method proposed, and later investigated, by the three studies and the clinical trial provides a foundation for the device investigated in this thesis. It is also important to note that the state of the art solutions presented by Gunter et al., Stewart et al., mc10, and Artann Labs are not available on the market, nor have the groups disclosed supporting evidence of a timetable to market.

\subsection{Applicable Codes and Standards}

Many codes and standards govern the design of an electrical device for use with the human body. Chief among these codes are the regulations set forth by the Food and Drug Administration (FDA). The Center 
for Devices and Radiologic Health (CDRH) branch of the FDA oversees the approval and sale of medical devices within the USA. The CDRH is in charge of a risk-based classification system for medical devices and can classify devices as low-risk (class I), medium-risk (class II), or high-risk (III) ${ }^{81}$. Depending on classification, a process of approval through the FDA can mean only registering as a manufacturer or it can mean millions of dollars for years of required clinical studies ${ }^{81}$. The development process of a noninvasive hydration monitor depends heavily on what classification, if any, it would receive from the FDA. Therefore, it is important to evaluate if the FDA would classify a wearable and non-invasive hydration monitor and, if so, what classification it would receive.

The relevant FDA definition of a medical device is an apparatus that is intended for use in the diagnosis of disease or other conditions, or in the cure, mitigation, treatment, or prevention of disease ${ }^{81}$. Additionally, a medical device data system is a device that is intended to transfer, store, convert, or display medical device data, and would be a class I medical device ${ }^{82}$. Given these two definitions, any electronic monitoring system for use with the body would be regulated. However, there are three confounding factors in the classification of a hydration monitor:

(1) There are no non-prescription hydration monitors currently regulated by the FDA.

(2) There are different intended use conditions for a hydration monitor.

(3) There is ongoing confusion on the role of the FDA in handling health-associated apps ${ }^{83,84}$. In factors (1) and (2), preliminary research on the FDA's device database revealed no regulated hydration monitors. Expanding the search for fluid status monitors revealed bioelectric impedance devices for use under the direction of a physician. One such device is the ZOE Fluid Status Monitor by Noninvasive Medical Technologies, Inc ${ }^{85}$. This device is a class II device indicated for use in patients with fluid management problems that are taking diuretic medication, living with heart failure, living with end-stage renal disease, recovering from coronary artery disease or suffering from recurrent dehydration ${ }^{85}$. Given that Artann Labs is currently going through a clinical trail process with their non-invasive ultrasonic method - of unknown classification - and that non-invasive bioimpedance monitors like the ZOE Fluid 
Status Monitor are regulated class II devices, it is certain that a hydration monitor for use under physician direction would be regulated by the FDA.

However, as mentioned in factor (2), there are multiple use conditions for a hydration monitor.

Considering the population groups that could benefit from a hydration monitor, a carefully defined intended use condition could avoid or minimize FDA regulation by only intending use as a monitor of hydration status for healthy populations. Additionally, as mentioned in factor (3), the confusion over the role of the FDA in handling health-associated apps could allow a hydration monitor device and accompanying app on the market with little or no regulation. For example, a healthcare data management app by Samsung is a class II regulated device ${ }^{86}$ but common heart rate detection and fitness apps are available for download without FDA regulation ${ }^{84}$. Regardless of the path to market and the intended use conditions, FDA approval would allow a hydration monitor to be used on the elderly, pediatric, and other general hospital patients. In which case, the codes and standards in CFR 21 would apply. These include requirements for:

- $\quad$ Risk-based classification (21 CFR 860) $)^{87}$

- General hospital and personal use devices

$(21 \text { CFR } 880)^{87}$

- $\quad$ Labeling (21 CFR 801) ${ }^{87}$

- $\quad$ Medical Device Reporting (21 CFR 803) ${ }^{87}$

- $\quad$ Registration (21 CFR 807) ${ }^{87}$
- Quality systems (21 CFR 820) ${ }^{87}$

- Performance standards for electronic products (21 CFR 1010) ${ }^{87}$

- $\quad$ Pre-market approval (21 CFR 814) ${ }^{87}$

- $\quad$ Post-market oversight (21 CFR 822) ${ }^{87}$

Beyond the FDA, ASTM International has electronics standards for specifying, evaluating, and testing the performance requirements of materials and accessories used in electronic devices ${ }^{88}$. These standards include contamination control, metallic materials, computerized systems, data analysis, information capture, testing, and documentation ${ }^{88}$. In addition, there are ISO standards on piezoelectric devices, integrated circuits, and electronic component assemblies ${ }^{89}$. The use of ultrasonic technology has specific codes as set by the NCRP in their Exposure Criteria for Medical Diagnostic Ultrasound standards ${ }^{90}$. 
Within this document is information on the safety, criteria, dose models, and standards associated with ultrasound in medical diagnostics ${ }^{90}$. Finally, any device using wireless communication must adhere to the standards and testing of FCC, as contained in CFR $47^{91}$. 


\section{THEORY: ULTRASONIC AND PIEZOCERAMIC BASICS}

Piezoceramic materials are used in ultrasonic transducers to convert an electrical energy stimulus into transmitted mechanical energy in the form of an ultrasonic wave ${ }^{92}$. Conversely, the same piezoceramic transducers can receive a mechanical signal and convert it into a relative electrical signal. The generated ultrasonic wave is affected by the material properties of the tissues through which it propagates; portions of the wave energy are reflected back toward the transmitter, attenuated by the tissue, or propagated through the tissue $\mathrm{e}^{92}$. These characteristics of piezoceramic transducers have been utilized to diagnose, treat, or navigate using ultrasonic methods ${ }^{92}$. There are many benefits of ultrasonic imaging, such as the non-invasive nature, radiation free imaging, relative inexpensiveness, portability, real-time imaging, and tomographic views ${ }^{93}$. These benefits have led to ultrasound imaging being one of the most widely used imaging technologies in modern medicine.

\subsection{Historical Perspective}

The Curie brothers discovered piezoelectric behavior in the 1880's when they noticed electrification of certain crystals under mechanical pressure ${ }^{94}$. A year later, the brothers, using Lippmann's work in thermodynamics, then confirmed the existence of converse piezoelectric effects (deformation/stress under applied electric fields) in $1881^{94}$. The first application of piezoelectric technology was by Langevin, who developed the first SONAR out of a quartz transmitter and receiver system for underwater sound ${ }^{95}$. Piezoelectricity remained a laboratory curiosity until the 1950 s, when the invention of piezoelectric ceramics led to significant implementation in many industrial fields ${ }^{94}$. This rise of piezoceramics led to a corresponding increase in the portability and technologic capabilities of ultrasounds. Similarly, the most widely used piezoceramic, PZT, was discovered in 1952 by Shirane et $\mathrm{al}^{94}$. The complex nature of the high piezoelectric response in PZT remains obscure, and studies suggesting modifications to the material continue to this day ${ }^{93,94}$. 


\subsection{Typical Ultrasonic Transduction Mode}

There are several methods of ultrasonic transduction. See Figure 9 for a diagram of the general principle guiding ultrasonic transduction: acoustic refection at tissue interfaces. The transduction method differs based on the desired application, the designed number of transducers, and the desired outcome (image, wave velocity calculation, phase shift, etc. $)^{96}$. In all methods, a sensor emitter sends a pulse of several cycles of a signal - usually sinusoidal - which travels through the medium, bounces off reflector surfaces, and is captured by the sensor receiver ${ }^{96}$. The received signal depends on the experimental setup; in a single (echo/reflection) transducer setup, the same transducer both emits the signal and receives the reflected wave ${ }^{96}$. In a two-transducer setup (transmission), a receiving transducer, placed on the opposite side of the tested area from the sending transducer, receives the remnants of the original wave after it fully propagates through the $\operatorname{limb} b^{96}$. See Figure 10 for an example transducer reading of pulse-echo transduction.

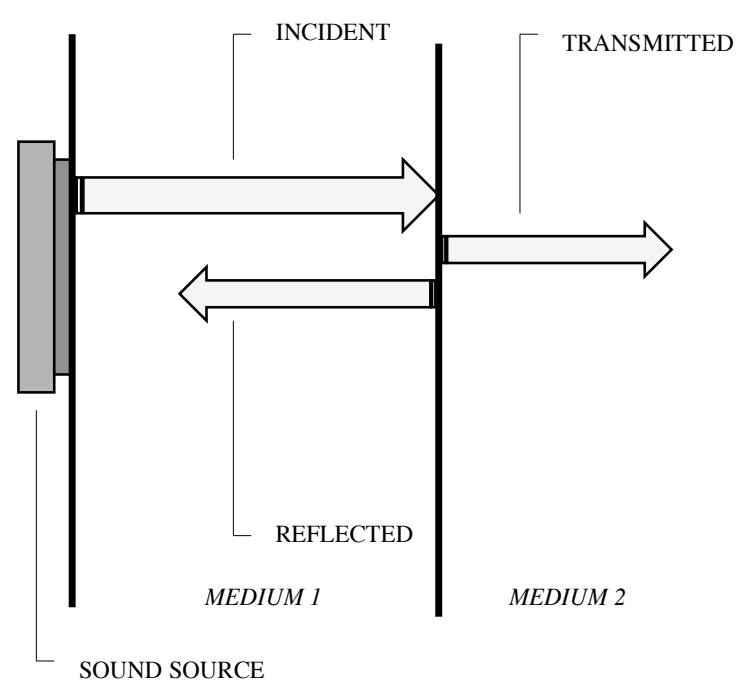

Figure 9: Diagram of the principle behind acoustic reflection at tissue interfaces ${ }^{97}$.

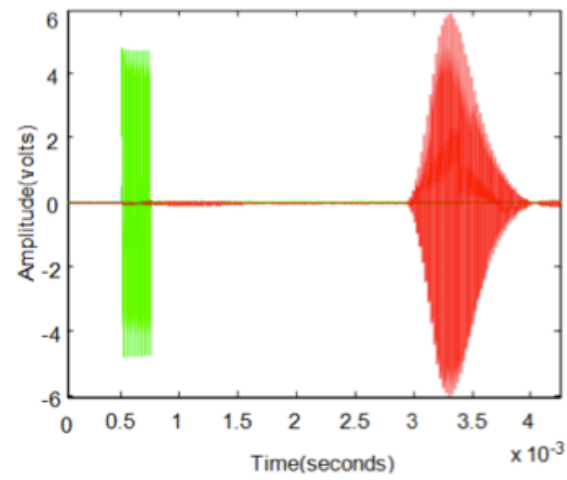

Figure 10: An example transducer reading from pulse-echo transduction. Green $=$ sent signal, red $=$ received signal $^{96}$. 


\subsection{Tissue Material Factors That Affect Ultrasonic Transduction}

The overall outcome of an ultrasonic technique is dependent on the material through which the ultrasound wave is propagating. Specifically, the ultrasound propagation is affected by the elasticity, density, acoustic velocity, acoustic impedance, and attenuation of the targeted tissues ${ }^{97}$. As the wave propagates through the tested area, the material properties of the specific tissue types (skin, bone, muscle, etc.) determine the extent to which the wave is absorbed, reflected, transmitted, or diverted ${ }^{97}$. The elasticity, or the ability of the tissue to return to its original shape after a load, and the density, or mass per volume, of the probed tissue determine the extent to which the molecules of the tissue deform under the wave $\mathrm{e}^{97}$. Similarly, the compressibility, or the fractional decrease in volume as pressure is applied, affects the speed of the wave propagation ${ }^{97}$. The acoustic velocity of a tissue is the combined affect of density and compressibility and is expressed by the relationship in Equation $\mathbf{1}^{97}$. The acoustic impedance, a measurement of a tissue's resistance to the wave speed, is a relationship between the tissue density and acoustic velocity. See Equation $\mathbf{2}^{97}$.

$$
\text { EQ. } 1 \quad c=\frac{1}{\sqrt{K \rho}}
$$

Where:

$$
\begin{aligned}
\mathrm{c} & =\text { acoustic velocity } \\
\mathrm{K} & =\text { compressibility } \\
\rho & =\text { density }
\end{aligned}
$$

$$
\text { EQ. } 2 \quad Z=\rho c
$$

Where:

$$
\begin{aligned}
& Z=\text { acoustic impedance } \\
& \mathrm{c}=\text { acoustic velocity } \\
& \rho=\text { density }
\end{aligned}
$$

Essentially, higher density materials have higher impedances and thus pose larger obstacles for the propagation of the ultrasound. However, the most important material property for the generation of an ultrasound image is not a property of the tissues themselves, rather, it is of the impedance mismatching between two adjacent tissues ${ }^{97}$. Similar to the reflection and refraction of light, an ultrasonic wave propagating through the interface of two tissues with the same acoustic impedance will not be reflected ${ }^{98}$. Conversely, propagation through an interface of two materials with different acoustic impedances results in the reflection of the wave, thus allowing visualization of the tissues via the ultrasonic transducers ${ }^{98}$. See Figure 11 for a basic diagram of this principle, called Snell's law. 


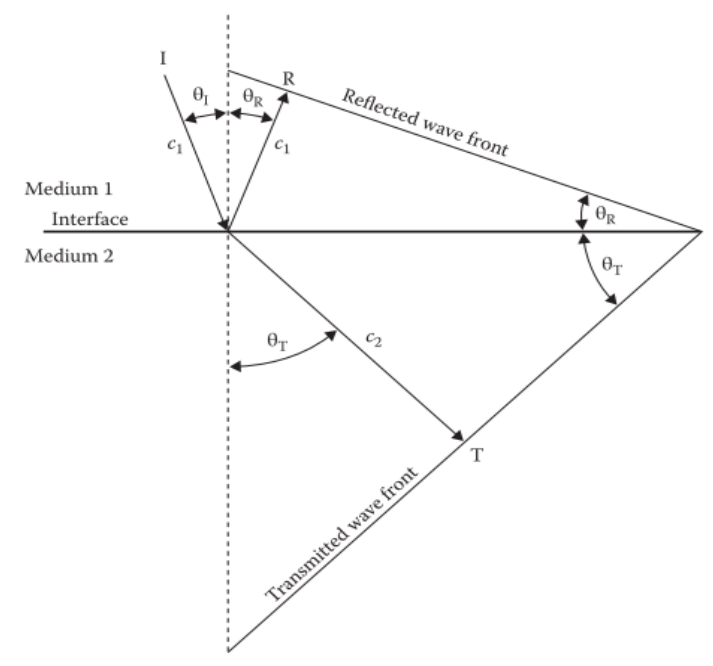

Figure 11: Diagram of Snell's law for the propagation of an incident wave, reflected wave, and transmitted wave between two mediums of different acoustic impedances $^{98}$.
EQ.3 $R F=\frac{\left(Z_{2}-Z_{1}\right)}{\left(Z_{2}+Z_{1}\right)}$

Where:

$$
\begin{aligned}
& \mathrm{RF}=\text { Reflection Factor } \\
& \mathrm{Z}_{1}=\text { impedance of tissue } 1 \\
& \mathrm{Z}_{2}=\text { impedance of tissue } 2
\end{aligned}
$$

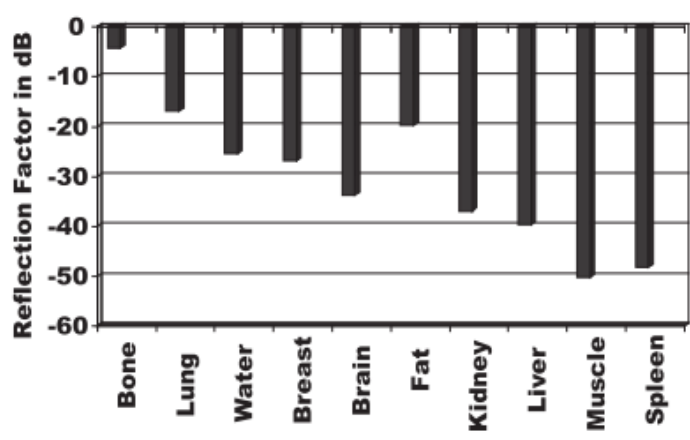

Figure 12: Amplitude reflection factor coefficients for various tissues relative to blood $^{92}$.

In a way, acoustic impedance mismatch behaves like sonar - it takes a difference in impedances to bounce a portion of the ultrasound wave back towards the sensor for visualization. Another method of describing the acoustic impedance mismatch between two tissues is by the amplitude reflection factor coefficients, as shown in Equation $3^{92}$. Visual representation of how ultrasound reflections can be used to identify tissue is seen in Figure 12, where the amplitude reflection factors (presented relative to blood) of different tissues are shown. Conceptually, a larger difference between the bar lengths of two tissues would result in more reflection when an ultrasound wave travels from one tissue to the other ${ }^{92}$.

Finally, the extent to which the specific material absorbs or propagates the ultrasonic wave is a material property known as attenuation ${ }^{97}$. Attenuation is caused by three main factors: absorption, reflection, and scattering ${ }^{97}$. Materials of high attenuation more strongly impede the depth that the ultrasound can propagate $^{97}$. See Table V for a table detailing the attenuation coefficients for selected body tissues at 1 
MHz. As seen the in the table, ultrasonic waves are not significantly attenuated by water, aqueous humor, vitreous humor, or blood, but are highly attenuated by lung (air) and bone.

Specific information on how changes in the tissue water content of muscle can be detected by ultrasonic methods appears in the Using Ultrasonic Methods to Monitor Hydration section.

\section{Table II: Attenuation of various human} tissues at $1 \mathrm{MHz}^{97}$.

\begin{tabular}{ll}
\hline Material & dB/cm \\
\hline Blood & 0.18 \\
Fat & 0.6 \\
Kidney & 1.0 \\
Muscle (across fibers) & 3.3 \\
Muscle (along fibers) & 1.2 \\
Brain & 0.85 \\
Liver & 0.9 \\
Lung & 40.0 \\
Skull & 20.0 \\
Lens & 2.0 \\
Aqueous humor & 0.022 \\
Vitreous humor & 0.13 \\
Water & 0.0022 \\
Castor oil & 0.95 \\
Lucite & 2.0 \\
\hline
\end{tabular}

\subsection{Wave Factors That Affect Ultrasonic Transduction}

Ultrasonic transduction applications can be categorized in two ways: imaging and non-imaging ${ }^{93}$. Imaging applications rely on the real-time display or collection of information to diagnose, navigate, or treat the targeted area ${ }^{93}$. Non-imaging applications rely on the comparison of collected information over time to track tissue status and diagnose ailments ${ }^{93}$. For example, fetal ultrasonography is an imaging application and the use of ultrasonic probes to distinguish between calcified and healthy regions of arteries is a nonimaging application ${ }^{99}$. Due to the difference in the type of outcome between the categories, imaging and non-imaging applications rely more heavily on different design variables ${ }^{93}$. For instance, imaging applications are more focused on the resolution of the generated image while non-imaging applications are more focused on the characteristics of the wave propagation through the target tissues ${ }^{93}$. 
An ultrasonic wave is defined by its frequency $(\mathrm{Hz})$, wavelength $(\mathrm{mm})$, and amplitude $(\mathrm{dB})^{93}$. Ultrasonic wave frequencies range from $20 \mathrm{kHz}$, the upper limit of human hearing, to $20 \mathrm{MHz}$ for intensive medical applications ${ }^{98}$. Given that the wavelength and frequency of ultrasonic waves are inversely related, high frequency waves (with short wavelengths) are used to generate high-resolution images ${ }^{93}$. However, high frequency ultrasonic waves are more attenuated by the target tissue than low frequency waves, thus limiting the penetration of the wave and reducing the effective imaging to more superficial structures ${ }^{93}$. See Figure 13 for a reference chart of how resolution and penetration change with changes in ultrasonic transducer frequency. For example, high frequency transducers (10-15 MHz) are used to image deep stellate ganglion blocks and low frequency transducers $(2-5 \mathrm{MHz})$ are used to image the more superficial lumbar neuraxial structures ${ }^{93}$. Thus, the selection of an ultrasonic transducer is a significant design decision that differs based on the intended application ${ }^{93}$. See Table VI for commonly used frequency, wavelength, attenuation coefficients, and depth values in diagnostic ultrasounds.

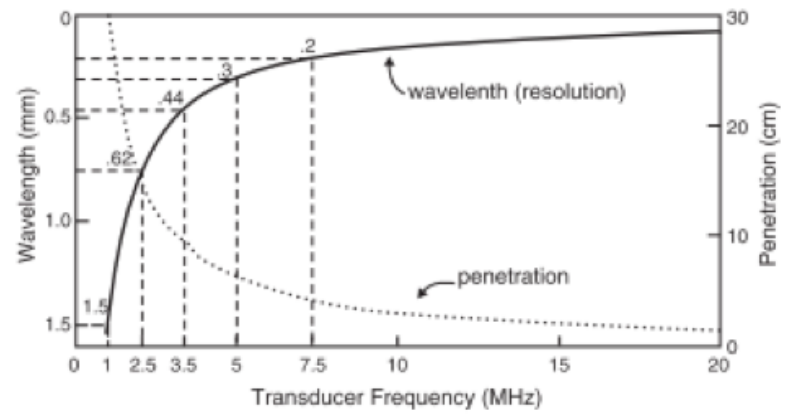

Table III: A table of common values for diagnostic ultrasound quantities ${ }^{96}$.

\begin{tabular}{lccc}
\hline Frequency $(\mathbf{M H z})$ & Wavelength $(\mathbf{m m})$ & $\begin{array}{c}\text { Attenuation } \\
\text { Coefficient }(\mathbf{d B / c m})\end{array}$ & $\begin{array}{c}\text { Imaging } \\
\text { Depth }(\mathbf{c m})\end{array}$ \\
\hline 2.0 & 0.77 & 1.0 & 30 \\
3.5 & 0.44 & 1.8 & 17 \\
5.0 & 0.31 & 2.5 & 12 \\
7.5 & 0.21 & 3.8 & 8 \\
10.0 & 0.15 & 5.0 & 6 \\
\hline
\end{tabular}

Figure 13: A comparison chart of the resolution and penetration of ultrasonic waves at different transducer frequencies ${ }^{93}$.

Alternatively, in non-imaging applications the main investigated outcome is a calculation of changes in the ultrasonic pulse velocity. In these cases, the velocity of the transduced ultrasound wave is dependent on the operating frequency of the transducer and the attenuation of the surrounding tissues ${ }^{96}$. See the upcoming Using Ultrasonic Methods to Monitor Hydration section for more information on the use of non-imaging ultrasonic waves. 


\subsection{Piezoceramic Materials and Their Implementation in Ultrasonic Transducers}

The most common piezoceramic used in ultrasonic transducers is a lead-based solid solution: lead zirconate titanate $\left(\mathrm{Pb}(\mathrm{Zr}, \mathrm{Ti}) \mathrm{O}_{3}\right)$ or $\mathrm{PZT}^{94}$. $\mathrm{PZT}$ has a perovskite crystal structure, as seen in Figure $14^{94}$. It can be tailored for specific design constraints via doping to alter the piezoelectric response of the material $^{94}$. The specific piezoelectric response is induced in the material by heating it within a large $(>2000 \mathrm{~V} / \mathrm{mm})$ electric field to distort the structure and induce permanent polarization ${ }^{94}$. Applied fields or stresses will induce shape changes or voltage rises, respectively ${ }^{94}$.

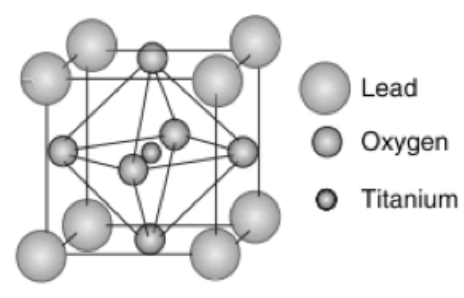

(a)

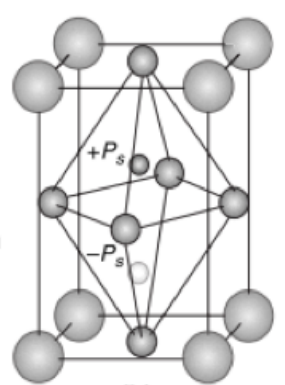

(b)

Figure 14: Figures of (A) PZT perovskite crystal structure and $(B)$ under a phase transformation along $\{\mathbf{0 0 1}\}^{94}$.

The coupling coefficient, $\mathrm{k}$, is the extent to which the PZT material is piezoelectric ${ }^{94}$. In other words, the coupling coefficient is an indication of how efficiently PZT can convert electrical energy to mechanical energy and vice versa. See Equation 4 for the coupling coefficient of a PZT poled ceramic ${ }^{94}$.

$$
\text { EQ. } 4 \quad k^{2}=\frac{E m^{2}}{\epsilon_{0} \epsilon_{r}}
$$

Where:

$$
\begin{aligned}
& \mathrm{k}=\text { coupling coefficient } \\
& \mathrm{E}=\text { Young's modulus } \\
& \mathrm{m}=\text { piezoelectric motor coefficient } \\
& \epsilon_{0}=\text { permittivity of free space } \\
& \epsilon_{\mathrm{r}}=\text { relative permittivity of the material }
\end{aligned}
$$


The efficiency of PZT (0.7 compared to 0.1 of a quartz crystal) directly explains why PZT is so widely used in ultrasonic applications where power consumption, inexpensiveness, and portability are key design features ${ }^{94}$.

The most common implementation of PZT in ultrasonic methods is via a single-element transducer ${ }^{94}$.

There are four main components of a single-element transducer: a matching layer/lens, electrodes, piezoelectric element, and backing ${ }^{94}$. See Figure 15 for a diagram of a single-element transducer. Since the piezoelectric element has a high acoustic impendence compared to biological tissues, the additional polymer-based layers are added to the active layer to increase the axial resolution of the transducer ${ }^{94}$. The backing material is used to dampen the transducer resonance and increase resolution ${ }^{94}$. This material is selected based on the application; the closer the acoustic impedance is to that of the piezoelectric element, the more dampening the backing applies to the transducer ${ }^{94}$. Lastly, the matching layer is used to increase the sensitivity of the transducer and the lens is used to focus the ultrasonic beam at a desired focusing distance $^{94}$. This distance can be manipulated by changing the radius of curvature of the lens ${ }^{94}$. See Figure 16 for a diagram of the radiation pattern of single-element transducers with a focusing lens.

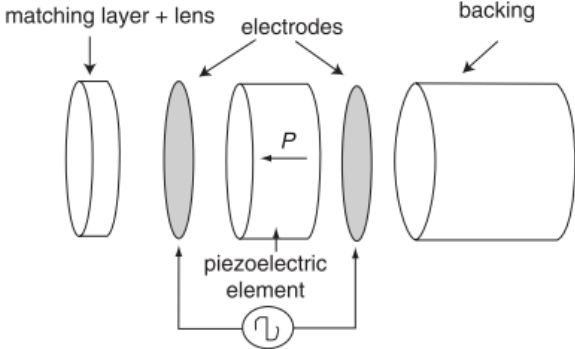

Figure 15: Diagram of a singleelement ultrasonic transducer ${ }^{94}$.

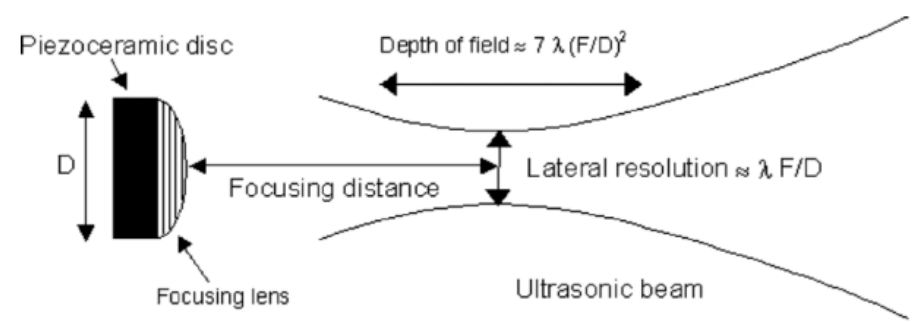

Figure 16: Radiation pattern of a single-element transducer with a focusing lens ${ }^{94}$.

\subsection{Medical Applications of Ultrasonic Methods}

The most common application of piezoceramic ultrasonic transducers is for ultrasonography ${ }^{94}$.

Ultrasonography is the use of an array of ultrasonic transducers in a delay line setup to image the body in 
real-time ${ }^{94}$. In addition, there are other lesser-known medical applications of ultrasonic methods like healing bone analysis, speeding fresh fracture repair, and analysis of material structures.

In healing bone analysis, the clinical assessment of fracture healing process is a subjective assessment that greatly depends on the physician experience, deficient radiographic images, and limited manual manipulation of the fracture site. These limitations can lead to incorrect medical treatment and delayed responses to improper fracture healing. Ultrasonic methods are used as a non-invasive and quantitative method in the testing of healing bone by detecting the changes in attenuation over time at the site of the fracture as four stages of bone fracture healing $\operatorname{occur}^{23,99}$. Since the materials at the fracture interface are constantly changing, the attenuation at the site of the fracture differs a significant amount based on the stage of fracture healing. Thus, ultrasonic probing of the area over time can give an indication of how the repair is progressing. Specifically, both echo/reflection and transmission testing methods can be used to determine the thickness of a bone callus layer and estimate the bone healing level by analyzing variations in the sent vs. received ultrasonic waves ${ }^{99}$.

In ultrasonic methods of speeding fresh fracture repair, pulsed low-power ultrasound waves can be used daily to speed the repair of fresh fractures. For example, one study found that daily ultrasound therapy reduced the healing time of broken arm and shin bones by $35-45 \%{ }^{23}$. The more rapid healing rate is caused by several mechanisms, mainly by the ultrasonic waves stimulating chondrocytes to more rapidly form a fibrocartilage callus ${ }^{100}$.

As an example of the use of ultrasonic techniques to diagnose ailments, IntraVascular Ultrasound Imaging (IVUS Imaging) is an imaging method that uses an ultrasonic probe mounted on the distal end of a catheter to image the endothelium of blood vessels. It is commonly used to assess the amount of atherosclerotic plaque in the arteries of the heart. An IVUS image is composed by rotating the ultrasonic emitter inside the vessel while the piezoelectric transducer emits ultrasonic waves and receives echoed signals. Due to the proximity of the probe to imaged area, high frequency ultrasonic waves can be used to 
generate high-resolution images. The result is a $360^{\circ}$ tomographic view of the vessel endothelium ${ }^{99}$. See Figure 17 for an example IVUS image.

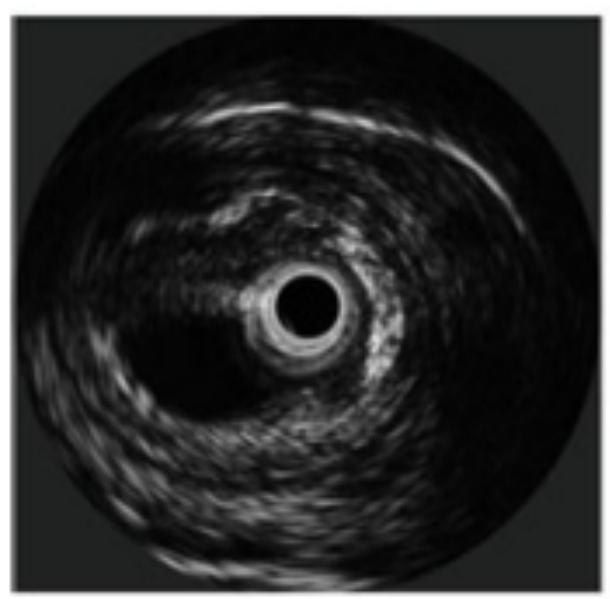

Figure 17: An example of an IVUS image from an atherosclerotic $\operatorname{artery}^{99}$.

As outlined in discussion of the tissue material factors and wave factors introduction sections, there are many factors to consider when selecting and using piezoceramic ultrasonic transducers. Unfortunately, not all challenges with using ultrasonic methods can be mitigated by proper design selections. The two largest challenges, speckle and propagation limitations, are discussed below.

Ultrasound images, like many other visualization techniques, are corrupted by the presence of unintended noise. This noise, appearing as a granular pattern called speckle, is caused by reflectors within the tissue $^{101}$. Like static on a television screen, speckle reduces the overall resolution of the received image and can be problematic for proper diagnoses that depend on ultrasound clarity. However, some studies propose that speckle has information about tissue acoustic properties that can be used for diagnostic purposes $^{94}$. The hypotheses around this method of speckle interpretation rely on speckle being indicative of pathological differences, such as an increase in stiffness or surface roughness, in portions of the same tissue type. For example, the density and pattern of speckle could be used to characterize the echomorphology of atherosclerotic plaque within blood vessels ${ }^{99}$. 
The therapeutic and imaging capabilities of ultrasonic methods depend largely on the ability of the ultrasound to propagate through the target tissue. However, materials with high attenuation coefficients hinder ultrasonic waves and limit the applications in which ultrasonic techniques can be used. For example, ultrasonography is of little value for looking at air-filled structures, like the lungs, or those
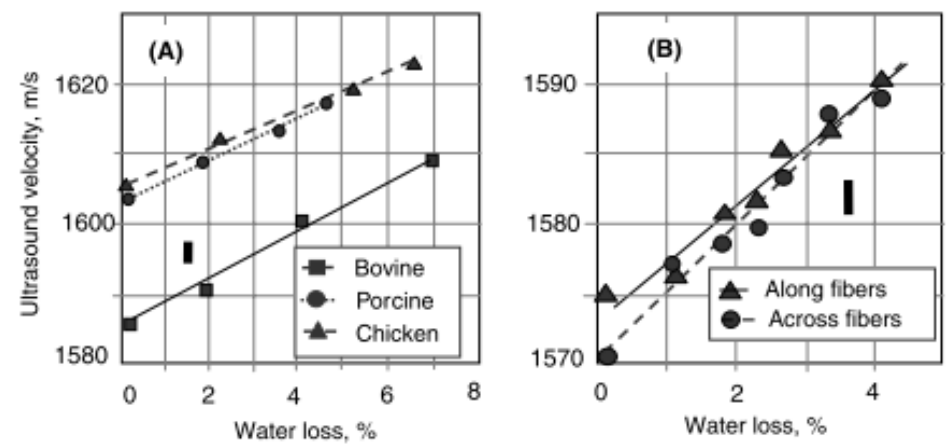

Figure 18: Ultrasound velocity as a function of water content in animal muscle tissue for (A) different animal types and (B) across or along fibers ${ }^{4}$.

surrounded by bone, such as the brain and spinal $\operatorname{cord}^{23}$.

\subsection{Using Ultrasonic Methods to Monitor Hydration}

Studies have shown that muscle tissue properties at hypohydrated, euhydrated, and hyperhydrated levels vary a detectable amount ${ }^{4,9,10}$. Given that most soft tissues contain about $70-80 \%$ water, with the remaining 20-30\% consisting of major molecular components, a shift of the molecular concentration causes a change in the velocity due to the contributions of each molecular component on the velocity ${ }^{4}$. Additionally, as described earlier, tissues with lower water levels have higher attenuation coefficients. Assuming other tissue variables remain constant, the change in wave velocity is a direct indication of a change in tissue hydration status ${ }^{4,9,10}$. This method has been used by the Artann Labs group to measure muscle dehydration with $99 \%$ accuracy ${ }^{4}$. Sarvazyan et al.'s 2005 study found an approximately linear relationship between ultrasound velocity and tissue water content: $3.0 \pm 0.2 \mathrm{~m} / \mathrm{s}$ per $1 \%$, which held 
constant for up to $10 \%$ water $\operatorname{loss}^{4}$. See Figure 18 for graphs showing the experimental results for ultrasound velocity of bovine, porcine, and chicken tissues with changing water content.

Additionally, the study found that the molecular composition determines the velocity of ultrasound, while structural and intracellular interactions have less influence ${ }^{4}$. The effect of structural components was described to be only $1.5 \%$ of the change in the ultrasound velocity with the decrease in tissue water content ${ }^{4}$. However, while the results of the study were promising, there are confounding factors in adapting this laboratory method for field use. These factors include individual differences in overall muscle structure, short-term changes during physiological activity of muscle, individual variations in the anatomy of the tested subjects, temperature changes in the tested muscle, variable blood flow, and variation in concentration of molecular components of muscle other than water ${ }^{4}$. Specifically, the investigators reported that ultrasound velocity increases up to $3 \mathrm{~m} / \mathrm{s}$ with contraction due to the increase in blood flow to the tissue and that temperature can have a significant effect on the accuracy of the method ${ }^{4}$. Regardless, the group's 2010 study found that changes in ultrasonic velocity reflect the changes of urine specific gravity, urine osmolality, and body mass during acute dehydration and rehydration ${ }^{10}$.

The research of Artann Labs focuses on the change in velocity of an ultrasonic wave through muscle tissue over time. To monitor this change, the investigators require a distance value for each measurement. However, this places undesirable constraints on a device since the transducers must either be kept at a known distance or there must be an accessory structure that reports the distance between the transducers. Additionally, the confounding factors listed by the investigators pose challenges for integration in a continuous real-time device. Thus, it is desirable to find an alternative process for using ultrasonic transduction in the detection of changes in tissue status.

One alternative process is using the phase shift from a sent signal to a received signal. Considering that ultrasonic vibrations travel in the form of a wave, a simplified model of a sent signal can be seen in 
Figure 19. This signal is an analog sine wave defined by the wavelength $(\lambda)$, frequency (f), and period (T) of a complete cycle ${ }^{102}$. See Equation 5 for the relationship between frequency and period; Equation 6 for the relationship between wavelength, frequency, and acoustic velocity; Equation $\mathbf{7}$ for the relationship between wavelength, period, and acoustic velocity; and Equation 8 for the relationship between material thickness, acoustic velocity, and time of flight ${ }^{102}$.

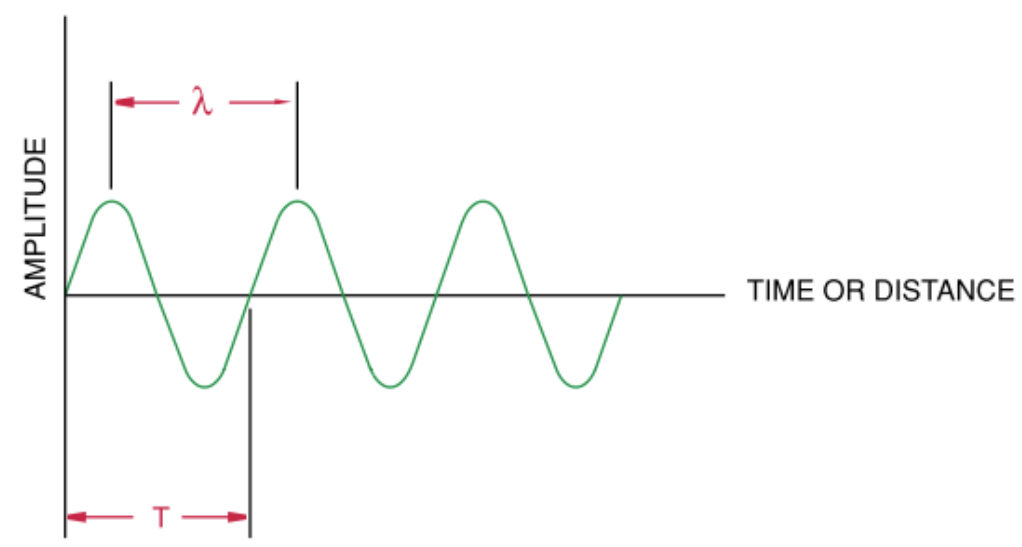

Figure 19: Simplified model of a sent ultrasonic signal in the form of a sine wave $\mathrm{w}^{102}$.
EQ.5
$f=\frac{1}{T}$
EQ.6 $\lambda=\frac{c}{f}$

Where:

$$
\begin{aligned}
& \mathrm{f}=\text { frequency }(\mathrm{Hz}) \\
& \mathrm{T}=\text { period }
\end{aligned}
$$

Where:

$$
\begin{aligned}
& \lambda=\text { wavelength } \\
& \mathrm{c}=\text { acoustic velocity } \\
& \mathrm{f}=\text { frequency }(\mathrm{Hz})
\end{aligned}
$$

EQ. $7 \quad \lambda=c T$

Where:

$$
\begin{aligned}
& \lambda=\text { wavelength } \\
& \mathrm{c}=\text { acoustic velocity } \\
& \mathrm{T}=\text { period }
\end{aligned}
$$

$$
\text { EQ.8 } \delta=\frac{c t}{2}
$$

Where:

$$
\begin{aligned}
& \delta=\text { material thickness } \\
& \mathrm{c}=\text { acoustic velocity } \\
& \mathrm{t}=\text { time of flight }
\end{aligned}
$$

Shown in Equations 5-7 is a direct relationship between the acoustic velocity of a medium and the definition of the wave. Equation 8 shows the method used by Artann Labs, where a known material thickness and sensed time of flight are used to calculate changes in the acoustic velocity. Recalling that 
changes in tissue hydration affect the acoustic velocity of the medium, a change in hydration will result in a detectable phase shift between a sent signal and a received signal, as seen in Figure $20^{103}$.

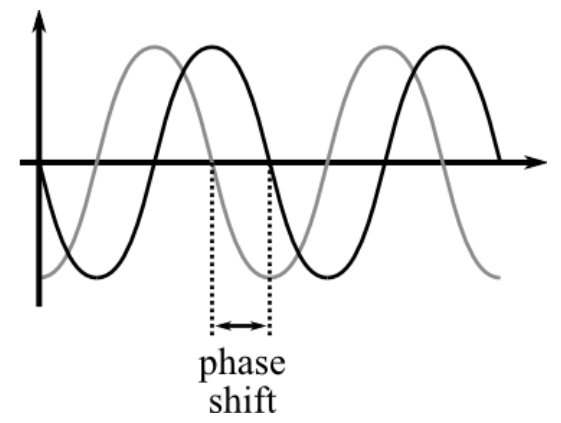

Figure 20: Diagram of a phase shift ${ }^{103}$.

In theory, individualized measurements are possible by performing a calibration step that establishes a baseline phase shift at a euhydrated state. Over time, deviations from this baseline shift indicate hypohydration, maintenance of euhydration, or hyperhydration. Accurate implementation of this method will require future investigation of the effect of other physiological variables on the phase shift of the received signal. The sensitivity of the sensors, frequency of measurements, and predictable effect on the phase shift will allow for a device to overcome these effects or even deduct other metrics from the phase shift of the received signal. However, such investigations are beyond the scope of this thesis and are discussed in the Future Functionality section of the Conclusion chapter. 


\section{OBJECTIVES AND SPECIFICATIONS}

The design of a wearable, continuous, and non-invasive device to monitor hydration status can be directed towards two main use conditions: use by a medical professional in a hospital setting or use by an end-user in daily-life situations. These two conditions have widely different design requirements associated with them, such as the level of expertise of the user, restrictions on the size of the device, restrictions on the weight of the device, the likelihood of misuse, the necessity for ergonomic design, the necessity of ease of use, and the overall conditions in which the device would be used. Therefore, it was necessary to address the design of the device toward one specific use condition.

\subsection{Market Research}

Market research was performed to determine which use condition to address. First, the market size of the populations of interest was characterized ${ }^{104-110}$. See Figure 21 for a chart of top five populations. As seen in Figure 21, elderly and pediatric populations have the largest market size in the US. However, the market size for athletes is likely underrepresented since only high school and college athletes were included in official census records.

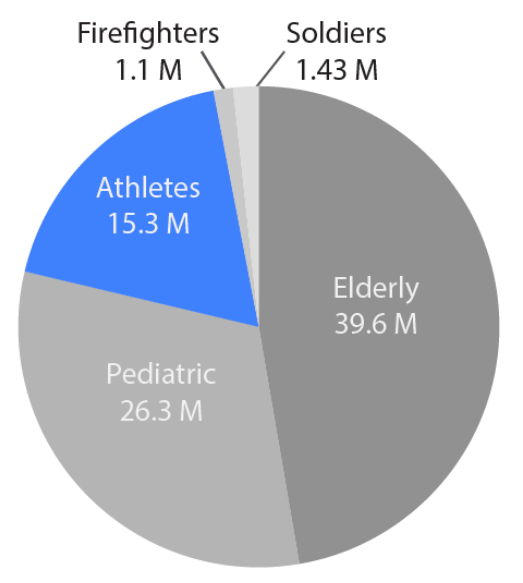

Figure 21: Chart of USA market size for populations of interest. 
Considering the large market size of athletes and the information presented in the Codes and Standards section, an athletic market was chosen for several reasons:

- It likely would not need or have minimal FDA approval, resulting in a significantly shorter and less expensive path to market.

- Coding and reimbursement processes would not need to be pursued.

- The athletic market is enthusiastic about purchasing fitness/wearable devices ${ }^{111}$.

- Future integration with other fitness/wearable devices is an exciting possibility.

The commercial potential of the smart wearables market for athletes is large and rapidly expanding. A 2013 IHS report on wearable technologies stated that the world market for wearable technology reached $\$ 8.5$ billion in revenues in 2012, shipping 96 million devices in that year ${ }^{111}$. By 2018 , unit shipments are expected to reach 210 million, resulting in $\$ 30$ billion in revenue ${ }^{111}$. Separately, the top 20 sports and wellness apps had 230 million installs ${ }^{111}$. Overall, there is a significantly growing market for fitness devices, and a hydration sensing technology can meet an available market need.

Additionally, it was necessary to consider a target price for the device before entering the design process. Given that dedicated ultrasonic transducers can cost over $\$ 100$, setting a target price significantly guided design decisions by helping to optimize the trade-off between features and cost effectiveness. Commonly available fitness devices range in price from $\$ 50$ to over $\$ 450$, as seen in Figure 22. Feedback received from surveys of athletes and coaches (cross-fit, ultimate, triathloners, marathoners, college, and a former professional football player), consideration of the components necessary for the device, and reviews of hydration-associated products on Kickstarter led to a target price of under $\$ 100$. See Appendix A: Survey Responses and Appendix B: Kickstarter Review Table for more information on the surveys and Kickstarter products. 


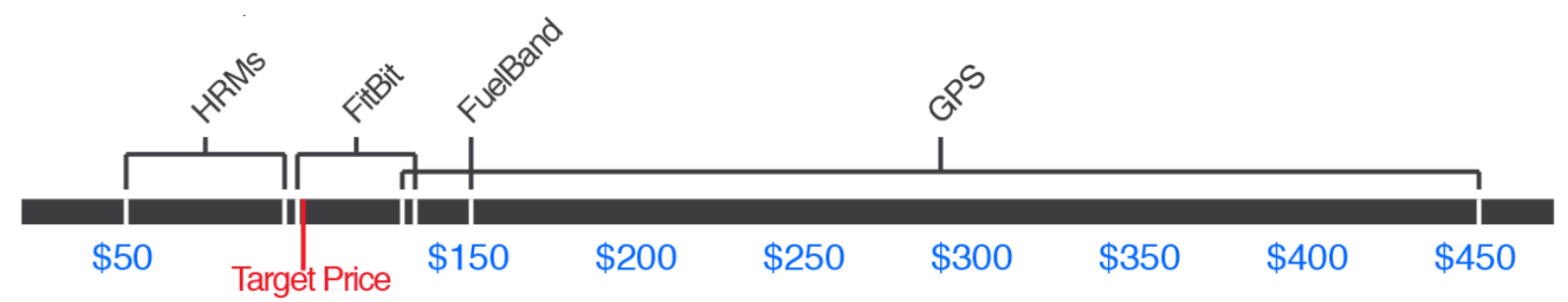

Figure 22: Chart of target price compared to other available fitness devices. 


\subsection{Customer Requirements}

The following customer requirements were compiled with the intention of addressing the average athlete.

- Alerts to a change in hydration status

- Allows users to track hydration over time

- Easy to use

- Fashionable/sleek appearance

- Lightweight

- Long battery life

- Non-obtrusive design

- Provides accurate feedback on hydration status

- Provides continuous feedback on hydration status

- Provides quick indication of hydration status

- Wearable in the rain/with sweat

\subsection{Engineering Requirements}

Each customer requirement is addressed by the following engineering requirements.

- Contains sensory feedback that is activated by changes in hydration status

- Can store information of at least three days of activity, with transfer of information to a computer or smartphone

- Can perform desired functions within three seconds

- $\quad 80 \%$ of surveyed users like the overall aesthetics of the design

- Maximum weight of $0.5 \mathrm{lb}$

- Minimum battery life for three days of average use

- Maximum thickness of 0.5"

- Detects hydration changes of $1 \% \mathrm{BW}$ 
- Acquires data once per minute

- Contains sensory feedback without manual interaction with the device

- Does not malfunction in the presence of sweat and is splash proof

See Table VII for a summary of the customer requirements, engineering requirements, and a brief introduction to how the success of the proposed solution will be assessed for each requirement. Note that the Final Prototype Testing Results section provides an in-depth description of each analysis.

Table VII: Summary table of customer requirements, engineering requirements, and the corresponding analyses to measure the relative success of the solution.

\begin{tabular}{|c|c|c|}
\hline Customer Requirement & Engineering Requirement & Applicable Analysis \\
\hline $\begin{array}{l}\text { Alerts to a change in } \\
\text { hydration status }\end{array}$ & $\begin{array}{l}\text { Contains sensory feedback that is } \\
\text { activated by changes in hydration } \\
\text { status }\end{array}$ & $\begin{array}{l}\text { Device contains visual, auditory, } \\
\text { and/or vibration feedback when } \\
\text { hydration status changes }\end{array}$ \\
\hline $\begin{array}{l}\text { Allows users to track } \\
\text { hydration over time }\end{array}$ & $\begin{array}{l}\text { Can store information of at least } \\
\text { three days of activity, with transfer } \\
\text { of information to a computer or } \\
\text { smartphone }\end{array}$ & $\begin{array}{l}\text { Device on-board memory is } \\
\text { sufficient for at least three day's } \\
\text { worth of data } \\
\text { Device contains data transfer } \\
\text { process }\end{array}$ \\
\hline Easy to use & $\begin{array}{l}\text { Can perform desired functions } \\
\text { within three seconds }\end{array}$ & $\begin{array}{l}\text { User functions on device can be } \\
\text { performed within three seconds }\end{array}$ \\
\hline $\begin{array}{l}\text { Fashionable/sleek } \\
\text { appearance }\end{array}$ & $\begin{array}{l}80 \% \text { of surveyed users like the } \\
\text { overall aesthetics of the design }\end{array}$ & $\begin{array}{l}\text { Survey intended end-users for } \\
\text { satisfaction with device aesthetics }\end{array}$ \\
\hline Lightweight & Maximum weight of $0.5 \mathrm{lb}$ & Weigh final device \\
\hline Long battery life & $\begin{array}{l}\text { Minimum three days of battery life } \\
\text { in average use conditions }\end{array}$ & $\begin{array}{l}\text { Device has enough battery life for } \\
\text { three days of calculated power draw }\end{array}$ \\
\hline Non-obtrusive design & Maximum thickness of $0.5 "$ & Measure device thickness \\
\hline $\begin{array}{l}\text { Provides accurate feedback } \\
\text { on hydration status }\end{array}$ & $\begin{array}{l}\text { Detects hydration changes of } 1 \% \\
\text { BW }\end{array}$ & Validate accuracy of device \\
\hline $\begin{array}{l}\text { Provides continuous } \\
\text { feedback on hydration } \\
\text { status }\end{array}$ & Acquires data once per minute & $\begin{array}{l}\text { Verify that device is acquiring new } \\
\text { values each minute }\end{array}$ \\
\hline $\begin{array}{l}\text { Provides quick indication } \\
\text { of hydration status }\end{array}$ & $\begin{array}{l}\text { Contains sensory feedback without } \\
\text { manual interaction with the device }\end{array}$ & $\begin{array}{l}\text { Device includes visual indication of } \\
\text { hydration status }\end{array}$ \\
\hline $\begin{array}{l}\text { Wearable in the rain/with } \\
\text { sweat }\end{array}$ & $\begin{array}{l}\text { Does not malfunction in the } \\
\text { presence of sweat and is splash } \\
\text { proof }\end{array}$ & $\begin{array}{l}\text { Device is designed to respond to the } \\
\text { presence of sweat } \\
\text { Electronics are housed in sealed } \\
\text { containers }\end{array}$ \\
\hline
\end{tabular}

Rationale for each engineering requirement is found in Table VIII. 
Table VIII: Explanation of rationale for each engineering requirement specification.

Engineering Requirement

Contains sensory feedback that is

activated by changes in

hydration status

Can store data from at least three days of activity, with transfer of information to a computer or smartphone

Can perform desired actions

within three seconds

$80 \%$ of surveyed users like the overall aesthetics of the design Maximum weight of $0.5 \mathrm{lb}$

Minimum three days of battery life in average use conditions

Maximum thickness of 0.5 "

Detects hydration changes of $1 \%$ BW

Acquires hydration status data once per minute

Contains sensory feedback without manual interaction with the device

Does not malfunction in the presence of sweat and is splash proof

\section{Rationale}

Including sensory feedback will increase user interaction with the device and more easily allow users to adjust hydration strategies.

Given that marathon runners and triathletes are key targets for hydration monitoring within the athletic market and that some events take place over multiple days at remote locales, including on-board tracking of at least three days allows for weekend excursions. Transfer of information to a computer or smartphone will allow for long-term collection of data, visualization of trends, and more processing-heavy calculations.

Minimizing the amount of time required to perform desired actions will increase user satisfaction with the device. Three seconds was selected so athletes can perform actions without having to stop activity.

Designing a device that appeals to the most users possible will increase the likelihood of market success and user satisfaction. Athletes commonly run or train with smartphones in bicep bands, a habit verified by over 15,000 phone armbands available on Amazon ${ }^{112}$. Given that the average smartphone is $0.3 \mathrm{lb}^{113}$, a maximum of $0.5 \mathrm{lb}$ was specified to stay within an established user comfort zone.

On-board battery life of at least three days will allow for continuous tracking during weekend excursions. At the same time, maximization of battery life will limit the number of interruptions when users have to stop monitoring to charge the device.

A maximum thickness of 0.5 " will decrease the device bulkiness while allowing room for the internal electrical and processing components of the device.

Given that changes of $2 \% \mathrm{BW}$ result in discomfort, a drop in blood volume, increase in heart rate, and may begin to significantly affect athletic performance and other common bodily functions ${ }^{23}$, detection within $1 \%$ BW will increase the efficacy of the device.

Although ingested water requires five minutes to be present in plasma and red blood cells ${ }^{3}$, acquiring hydration status data once per minute will provide more data for future investigation into the detection of trends in hydration status and integration with other sensors (such as accelerometers, heart rate monitors, sweat rate monitors, etc.). Access to hydration status at a glance will reduce complexity in using the device and allow users to get instant feedback on hydration status.

Given that long distance runners can sweat a significant amount more than sedentary people ${ }^{114}$, the device must be able to provide accurate data in the presence of sweat. Additionally, a splash proof design will decrease the likelihood of malfunction in sweaty or rainy conditions and provide a key selling feature. 


\section{DESIGN DEVELOPMENT}

\subsection{Approach and Design Progression}

The step-by-step approach for the development of the hydration monitor was as follows:

1. Identification of the problem:

i. Researched existing methods of monitoring hydration.

ii. Researched existing devices on the market.

iii. Performed market research to validate a market need.

2. Identification of a solution:

i. Identified problems with the existing monitoring methods.

ii. Reviewed literature to identify a possible solution.

iii. Investigated validity of the proposed solution method.

3. Design Process:

i. Brainstormed and selected the top three possible body locations.

ii. Brainstormed and created conceptual sketches of designs.

iii. Identified the top design choice.

iv. Identified components required for the top design.

v. Obtained components and materials for preliminary tests.

4. Sensor Selection:

i. Researched possible sensor options.

ii. Optimized sensor selection for design needs.

iii. Tested and modified sensors to identify the best option.

5. Method Validation:

i. Created testing code and method.

ii. Evaluated sensor selection. 
iii. Tested for validation.

6. Design Review:

i. Identified areas of future improvement.

ii. Created CAD models of the final prototype and future design direction.

iii. $\quad$ Prepared all documentation, testing processes, and prototypes for review.

iv. Created the final thesis report.

\subsection{Design Selection}

After identifying the athletic market as the target customer for the device, the next step was identifying device location options. Based on athletic form factors and common locations of fitness trackers, nine anatomic locations were brainstormed. See Table IX for a list of the locations, sketches of a device at each location, the positive and negative features of each location, and identification of the top three location options. The top three options were selected through qualitative weighting of the positive and negative features of each location, comparison with the customer and engineering requirements, and with consideration to the skill, cost, and time constraints of the project. 
Table IX: Possible anatomic locations, representative sketches at each location, positive and negative features of each location, and identification of top three location options.

\begin{tabular}{|c|c|c|c|}
\hline Location & Positive Features & Negative Features & $\begin{array}{l}\text { Top } \\
\text { III }\end{array}$ \\
\hline Ankle B & $\begin{array}{ll}+ & \text { Unique location } \\
+ & \text { Possible future integration } \\
& \text { with shoes, socks }\end{array}$ & $\begin{array}{ll}\text { - } & \text { Different shoe lengths may } \\
\text { interfere with device } \\
\text { - } & \text { Sock interference } \\
\text { - } & \text { High bone impedance } \\
\text { - } & \text { Inaccessible at a glance } \\
\text { - } & \text { Pain with ankle bone impact } \\
\text { - } & \text { May be confused with a } \\
& \text { convict ankle monitor }\end{array}$ & $x$ \\
\hline Bice & $\begin{array}{ll}+ & \text { Familiar location } \\
+ & \text { Ample size for a device } \\
+ & \text { Large muscle mass with } \\
& \text { small bone impedance } \\
+ & \text { Possible future integration } \\
& \text { with clothes, football jersey } \\
& \text { sleeves } \\
+ & \text { Easy glance at status }\end{array}$ & $\begin{array}{ll}- & \text { Tight feeling when flexed } \\
- & \text { May interfere with sleeves }\end{array}$ & $\checkmark$ \\
\hline $\mathrm{C}$ & $\begin{array}{ll}+ & \text { Ample size for a device } \\
+ & \text { Large muscle mass with } \\
& \text { small bone impedance } \\
+ & \text { Possible future integration } \\
& \text { with shin guards, high socks }\end{array}$ & $\begin{array}{ll}\text { - } & \text { Inaccessible at a glance } \\
\text { - } & \text { Unfamiliar location } \\
\text { - } & \text { May interfere with capri style } \\
\text { pants }\end{array}$ & $\checkmark$ \\
\hline & $\begin{aligned}+ & \text { Familiar location } \\
+ & \text { Possible future integration } \\
& \text { with heart rate monitors, } \\
& \text { clothing }\end{aligned}$ & $\begin{array}{ll} & \text { Inaccessible at a glance } \\
\text { - } & \text { May interfere with chest- } \\
\text { based heart rate monitors } \\
\text { - } & \text { High lung impedance } \\
\text { - } & \text { Large band size required } \\
\text { - } & \text { Uncomfortable long-term } \\
& \text { wear }\end{array}$ & $x$ \\
\hline & $\begin{array}{ll}+ & \text { Unique location } \\
+ & \text { Easy glance at status }\end{array}$ & $\begin{array}{ll}- & \text { Smallest size constraints } \\
- & \text { Not allowed in athletic } \\
\text { - } & \text { Interferes with grip- } \\
& \text { associated activities } \\
- & \text { More likely to get snagged } \\
- & \text { High bone impedance } \\
- & \text { Finger sizing issues } \\
\end{array}$ & $x$ \\
\hline Band & $\begin{array}{l}+\quad \text { Easy glance at status } \\
+\quad \text { Ample size for a device }\end{array}$ & $\begin{array}{ll}- & \text { Unfamiliar location } \\
\text { - } & \text { Tendency to slide down arm } \\
\text { - } & \text { Interferes with sleeves } \\
\text { - } & \text { High bone impedance }\end{array}$ & $x$ \\
\hline Phone Attachment & 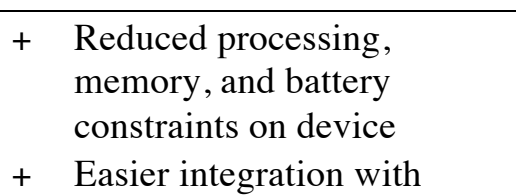 & $\begin{array}{ll} & \text { Wired connection } \\
- & \text { Complicated development } \\
& \text { process } \\
- & \text { Cannot function without }\end{array}$ & $x$ \\
\hline
\end{tabular}




\begin{tabular}{|c|c|c|c|}
\hline & $\begin{array}{l}\text { social networks, other } \\
\text { fitness tracking apps }\end{array}$ & $\begin{array}{l}\text { phone } \\
\text { - Requires a different } \\
\text { accessory band for each } \\
\text { phone }\end{array}$ & \\
\hline Upper Leg & $+\quad$ Ample size for a device & $\begin{array}{ll}\text { - } & \text { Unfamiliar location } \\
\text { - } & \text { Large muscle mass and femur } \\
\text { bone likely exceed } \\
\text { measurement capability } \\
\text { - } & \text { Inaccessible at a glance } \\
\text { - } & \text { Likely to be uncomfortable } \\
& \text { when running }\end{array}$ & $x$ \\
\hline Wristband & $\begin{array}{ll}+ & \text { Familiar location } \\
+ & \text { Easy glance at status } \\
+ & \text { Possible future integration } \\
& \text { with existing Smartwatch } \\
& \text { and fitness tracking devices }\end{array}$ & $\begin{array}{ll}- & \text { Smaller size constraint } \\
\text { - } & \text { Crowded marketplace } \\
- & \text { May not have enough muscle } \\
& \text { for accurate measurement } \\
- & \text { May interfere with smart } \\
& \text { watch devices } \\
\end{array}$ & $\checkmark$ \\
\hline
\end{tabular}

After preliminary qualitative comparisons with the customer requirements, the ankle, chest, finger, phone attachment, and upper leg locations were immediately eliminated due to their negative aspects significantly outweighing the positive aspects. The remaining locations were further assessed through visual analysis of possible signal transduction routes through the limb. Recalling that muscle tissue is the intended measurand of the ultrasonic signal, visual analysis focused on a linear path of least impedance through muscle tissue. See Table $\mathrm{X}$ for the resulting sensor location options. 
Table X: Transverse views of selected sensor location options ${ }^{115}$.

Upper Arm (Bicep):

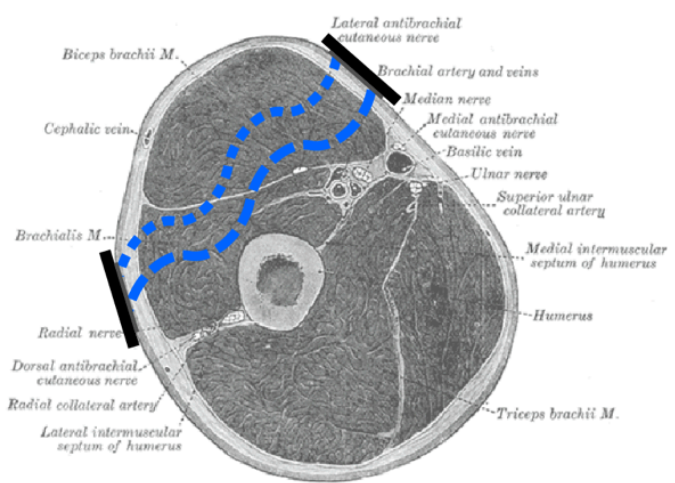

Middle of the Leg (Calf):

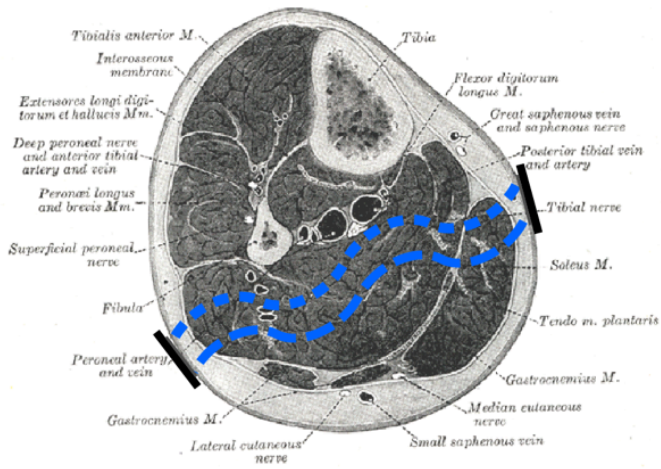

Middle of the Forearm:

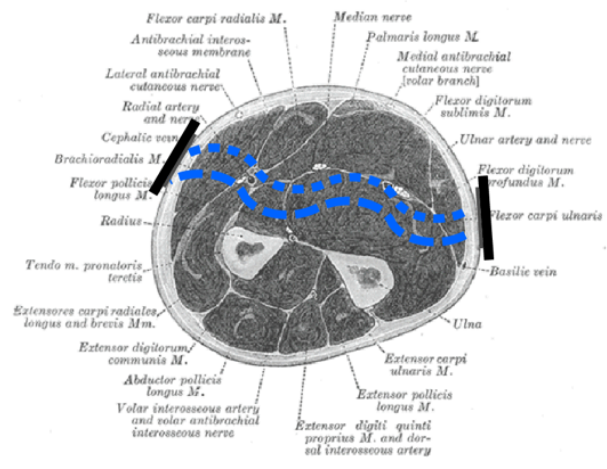

\section{Wrist:}

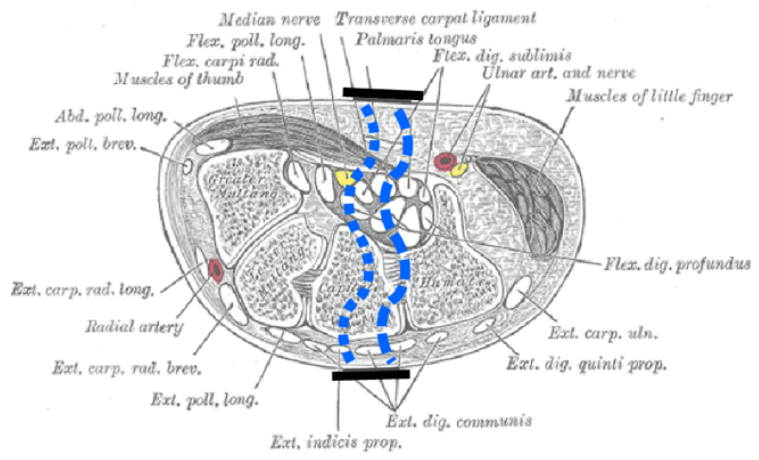

As seen in Table IX and with respect to the transverse views shown in Table $X$, the top three location options were determined to be the bicep, the calf, and the wrist. One key difference stands out between the calf and the bicep or wrist options: the calf location is not easily accessible. Given that three of the eleven customer requirements (easy to use, non-obtrusive design, and quick indication of hydration status) govern ease of access and use, the calf location was eliminated as a design option. Thus, the remaining location options were the bicep and the wrist. As seen in Table $\mathrm{X}$, the wrist signal path does not cross a large muscle. However, the possibility of future integration with existing smartwatches and fitness devices was chosen to take precedence over the efficacy unknowns associated with a lack of muscle tissue. Future investigation into the ability to detect signal changes in other tissues could reveal a novel method of detecting hydration status through characteristic changes in blood plasma or tendon tissue. To this end, the superficial front wrist contains a high-density region of tendons as well as superficial veins and deep arteries ${ }^{115}$, as seen in Figure 23. 


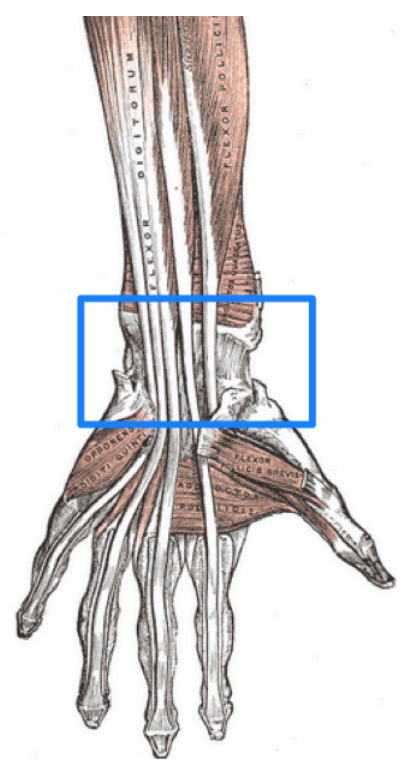

(A)

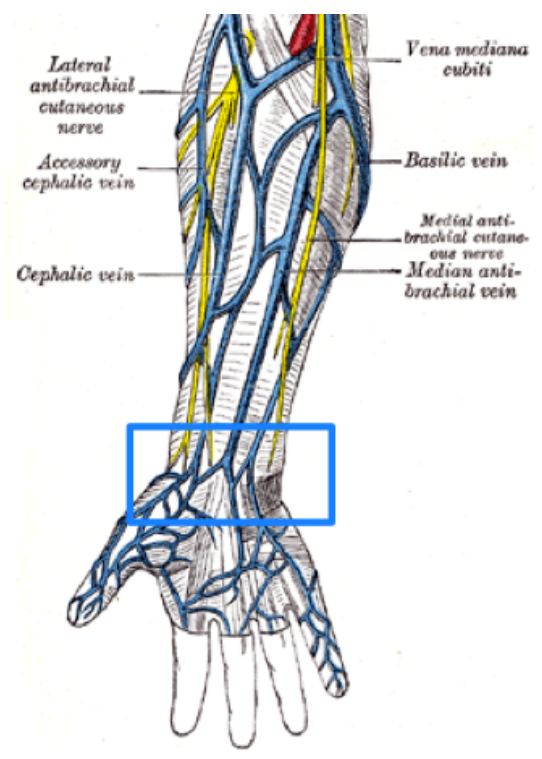

(B)

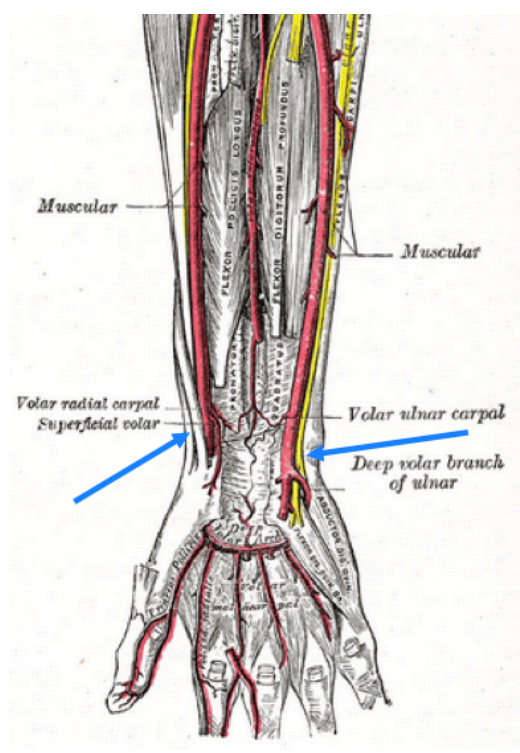

(C)

Figure 23: Anatomic diagrams showing (A) tendons, (B) superficial veins, and (C) deep arteries of the front wrist $^{115}$. Blue boxes and arrows indicate regions of interest.

Considering that existing literature on ultrasonic methods for hydration monitoring relies on differences

in muscle tissue $e^{4,9,10}$, it was determined that validation of the device method will focus on implementation at a muscular location. Therefore, the bicep location was chosen for the device design. Future design and testing could be performed to probe the validity of the wrist location. See the Future Wrist Location section for more information on adopting a bicep band for a wrist location. 


\subsection{Design Concept}

The selected design was created with an athletic form factor. See Figure 24 for an annotated sketch of the design concept, Figure 25 for a Solidworks model of the prototype band, and Figure 26 for a Solidworks model of a future, more refined, flexible rubber band with embedded electronics.

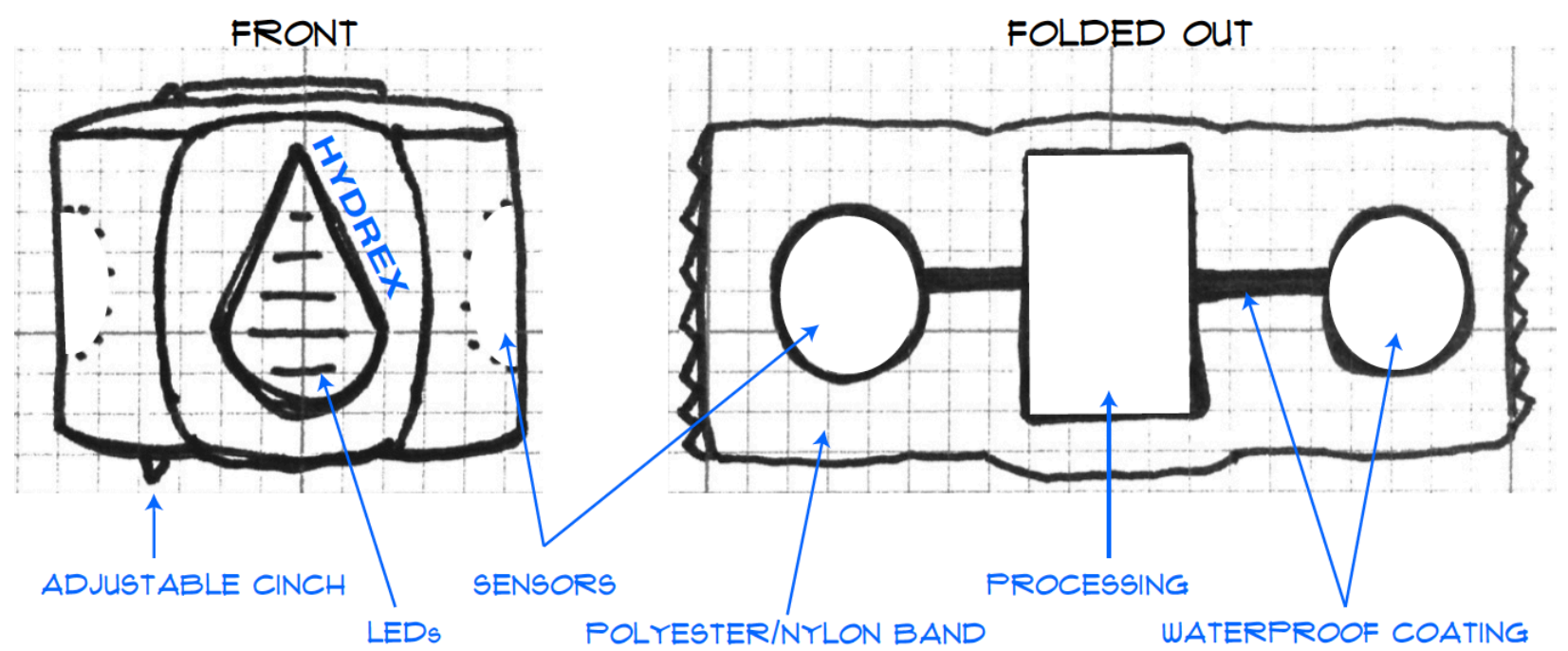

Figure 23: An annotated sketch of the selected design concept.
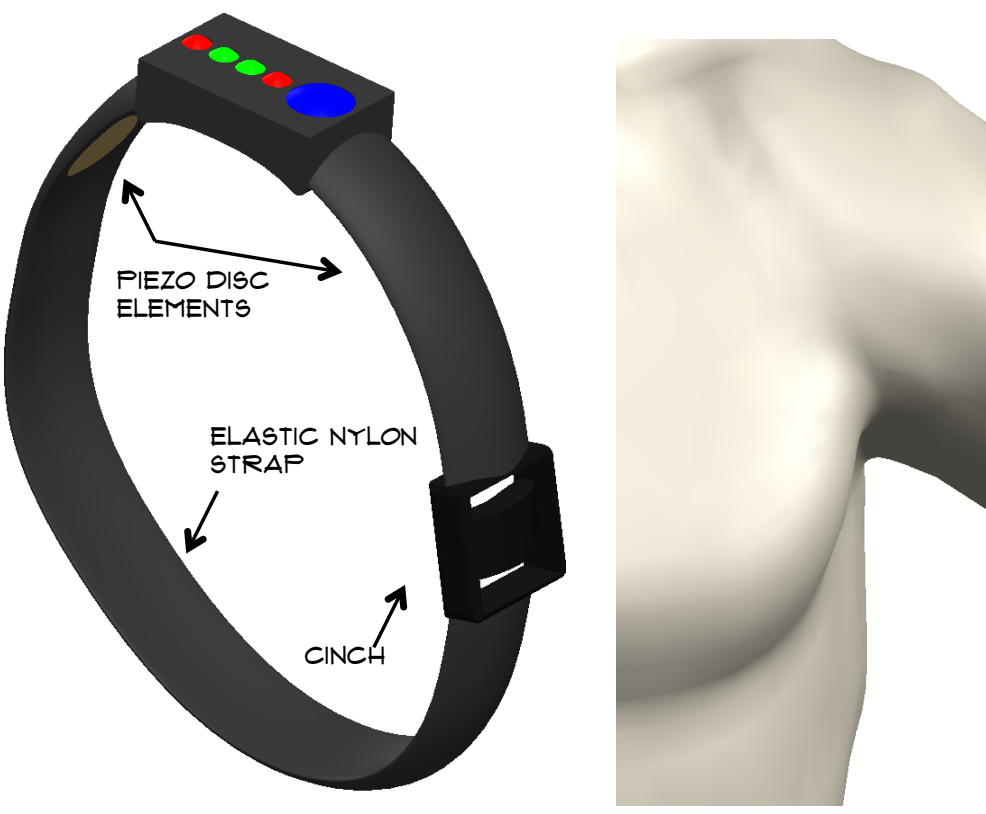

Figure 25: An annotated Solidworks model of the prototype band. 


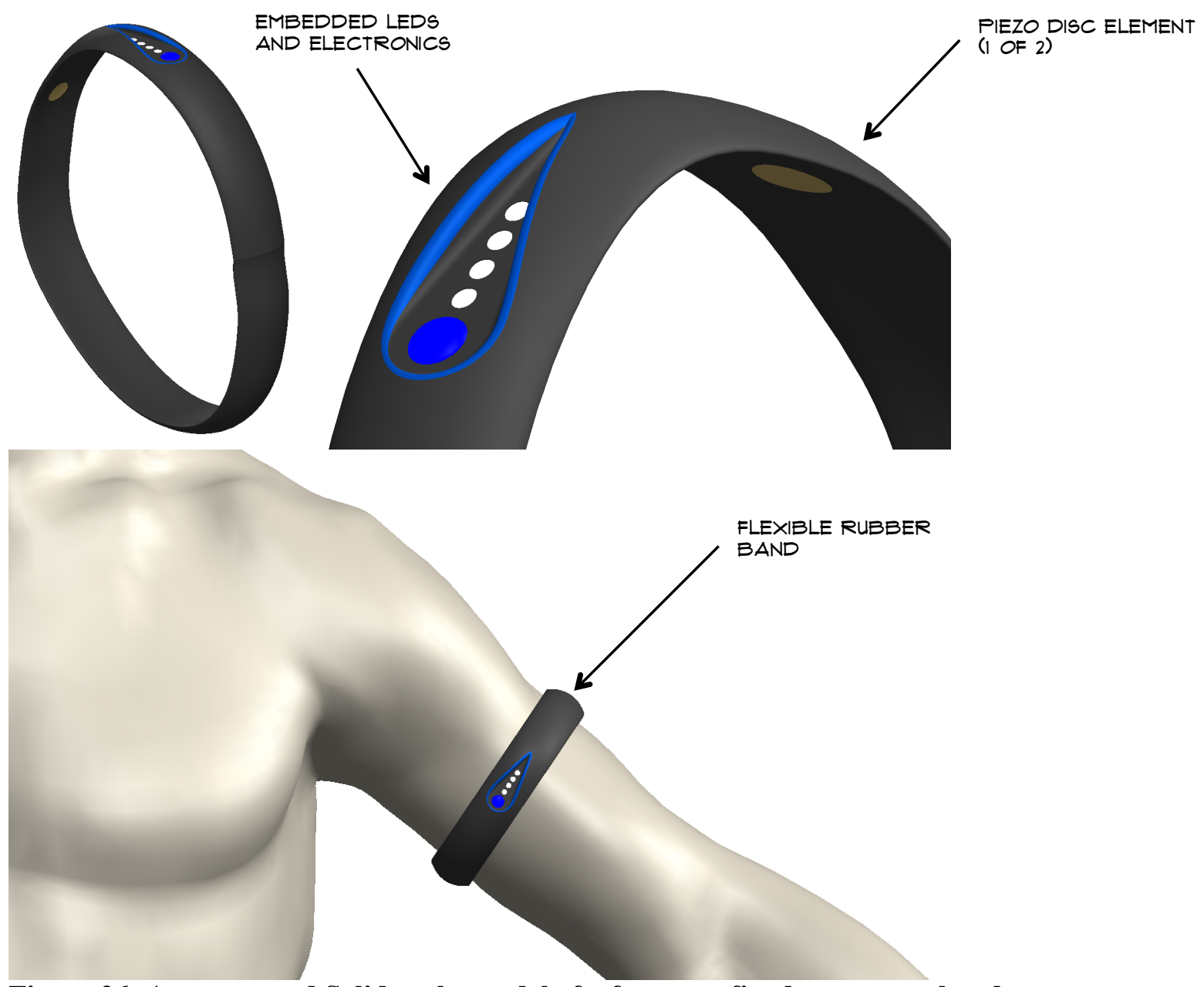

Figure 26: An annotated Solidworks model of a future, refined, prototype band. 


\section{COMPONENTS}

Summary Table XI has a list of the components used in the bicep band prototype design. Images, descriptions, and supporting decisions for each component can be found in the subsections that follow Table XI.

Table XI: Summary table of the components for the bicep band prototype design.

\begin{tabular}{|l|l|}
\hline \multicolumn{1}{|c|}{ Item } & \multicolumn{1}{c|}{ Purpose } \\
\hline Piezoceramic Disc Elements & Ultrasonic transducers \\
\hline Plasti Dip Rubber Coating & Waterproofing and increased durability for the transducers \\
\hline Teensy 3.1 Microcontroller & Processor and microcontroller for the device \\
\hline Blue Tactile LED Button & On/Off button \\
\hline Multi-color LEDs & Status indication lights \\
\hline Vibration Motor & Vibration feedback \\
\hline Polymer Lithium Ion Battery & Battery power \\
\hline Bluetooth LE Module & Wireless communication \\
\hline ABS Plastic Case & Housing for electronics \\
\hline Elastic Nylon Hoop and Loop Cinch & Adjustable strap to hold device on the bicep \\
\hline
\end{tabular}

\section{1 $18 \mathrm{kHz}$ Piezoceramic Disc Elements}

As opposed to dedicated single-element transducers, a piezoceramic disc with a natural frequency near the ultrasonic range can effectively be used as an ultrasonic transducer. Using a disc element instead of a transducer significantly reduces the cost, design complexity, and size of the transducer; however, there is a corresponding drop in signal quality and signal manipulability due to the lack of the polymer backing layers, matching layer, and lens. Three main factors contributed to the decision to use a disc element:

- Purchasing an ultrasonic transducer is cost-prohibitive and requires a custom order from a manufacturer.

- The desired transducer materials, dimensions, and signal properties are unknown at this early prototyping stage.

- The small size and power requirements of a disc element make it appealing for use in a wearable device. 
There are varieties of natural frequency piezos with different surface areas. However, the most important technical feature of a piezo disc element is that it has optimal performance at or near its natural frequency. Therefore, a disc with an $18 \mathrm{kHz}$ natural frequency was chosen because it was the highest natural frequency piezo element available for purchase without a custom order ${ }^{116}$. See the Validation chapter for the outcome of the piezo element tests and Figure C1 of Appendix C: Manufacturer Supplied Component Datasheets, Diagrams, and Drawings for a drawing of the $18 \mathrm{kHz}$ disc element.

\subsection{Plasti Dip Rubber Coating}

Plasti Dip rubber coating was used to coat the transducers for improved water resistance, shock resistance, and durability. It was chosen for the ease of application, availability, relatively quick setting time, different application methods, and flexibility ${ }^{117}$. Tests were performed to determine the effect of a coating on the strength of the signal and select the optimal number of coatings. See the Validation chapter for the tests and Appendix D: Plasti Dip MSDS Sheet for the material safety and data sheet.

\subsection{Teensy 3.1 Microcontroller USB Development Board}

The Teensy 3.1 is an Arduino compatible microcontroller board that is programmable via USB cable ${ }^{118}$. The Teensy 3.1 was chosen primarily for its compatibility with Arduino, small size, fast CPU, breadboard compatibility, availability, concurrent measuring of two analog signals, and 3.3V analog pins. Given the infeasibility of custom manufacturing a board at an early prototype stage, using the Teensy 3.1 with the Teensyduino add-on for the open-source Arduino IDE provided access to online Arduino libraries while staying within the cost, time, and technical knowledge limits of this thesis. See Table XII for the technical specifications of the Teensy 3.1 and Figure C2 of Appendix C: Manufacturer Supplied Component Datasheets, Diagrams, and Drawings for a pinout diagram. 
Table XII: Technical specifications of the PJRC Teensy 3.1 microcontroller USB development board $^{118}$.

\begin{tabular}{|c|c|c|}
\hline \multicolumn{2}{|c|}{ Technical Specification } & Value \\
\hline & Price & $\$ 19.80$ \\
\hline & Dimensions & $1.4 \times 0.7 ”$ \\
\hline \multirow{3}{*}{ Processor: MK20DX256VLH7 } & Core & Cortex-M4 \\
\hline & Rated Speed & $72 \mathrm{MHz}$ \\
\hline & Overclockable & $96 \mathrm{MHz}$ \\
\hline \multirow{2}{*}{$\begin{array}{r}\text { Flash Memory: } \\
256 \text { kbytes }\end{array}$} & Bandwidth & 192 Mbytes/sec \\
\hline & Cache & 256 bytes \\
\hline & RAM & 64 kbytes \\
\hline \multirow{2}{*}{\multicolumn{2}{|c|}{$\begin{array}{r}\text { EEPROM } \\
\text { Direct Memory Access }\end{array}$}} & 2 kbytes \\
\hline & & 16 Channels \\
\hline \multirow{2}{*}{ Digital I/O: 34 Pins } & Voltage Output & 3.3 Volts \\
\hline & Voltage Input & $5 \mathrm{~V}$ Tolerant \\
\hline \multirow{3}{*}{ Analog Input: 21 Pins } & Converters & 2 \\
\hline & Touch Sensing & 12 Pins \\
\hline & Comparators & 3 \\
\hline \multicolumn{2}{|r|}{ Analog Output } & 1 Pin \\
\hline \multicolumn{2}{|r|}{ Timers } & 12 Total \\
\hline \multicolumn{2}{|r|}{ Communication } & USB, Serial, SPI, I2C, CAN Bus, I2S Audio \\
\hline
\end{tabular}

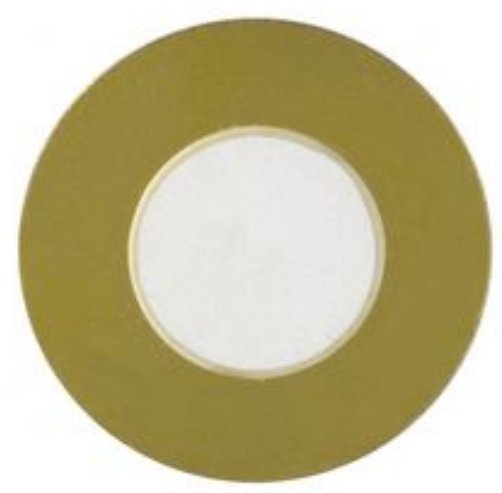

Figure 27: Newark $18 \mathrm{kHz}$ piezoceramic disc element ${ }^{116}$.

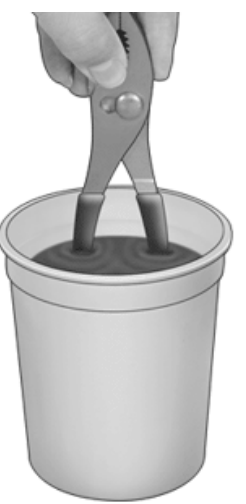

Figure 28: McMaster-Carr Plasti Dip Rubber Coating $^{117}$.

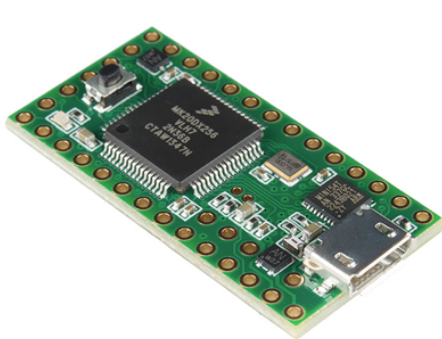

Figure 29: PJRC Teensy 3.1 Microcontroller USB Development Board ${ }^{118}$. 


\subsection{Blue Tactile LED Button}

A tactile LED button was chosen as an On/Off button to provide users with both tactile and visual feedback about the status of the device. A blue tactile LED was chosen for its size, color compatibility, and availability ${ }^{119}$. See Figure C3 of Appendix C: Manufacturer Supplied Component Datasheets, Diagrams, and Drawings for a drawing of the button.

\subsection{Status Indication LEDs}

Multicolor LEDs were chosen as indications of hydration status due to their inexpensiveness, ease of implementing in code, small power draw, and the availability of different colors to indicate different ranges of hydration ${ }^{120}$. See Figure C4 of Appendix C: Manufacturer Supplied Component Datasheets, Diagrams, and Drawings for an info sheet of the LEDs.

\subsection{Vibration Motor}

A vibration motor was chosen to provide users with noticeable tactile feedback on changes in hydration status, alert users that interaction is necessary, or affirm the selection of an interaction. The use of vibration was chosen over audible alerts because of its discrete nature and because athletes often listen to music or are in loud environments while training. This vibration motor was selected for its small power draw, relatively high vibration output, compatibility with the Teensy 3.1 board, and small size ${ }^{121}$. See Figure C5 of Appendix C: Manufacturer Supplied Component Datasheets, Diagrams, and Drawings for a datasheet of the vibration motor.

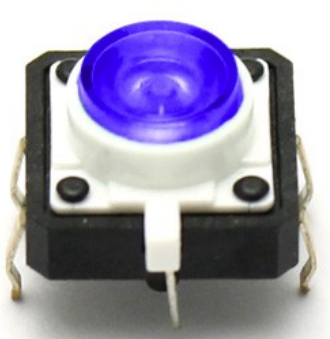

Figure 30: SparkFun blue tactile LED button $^{119}$.

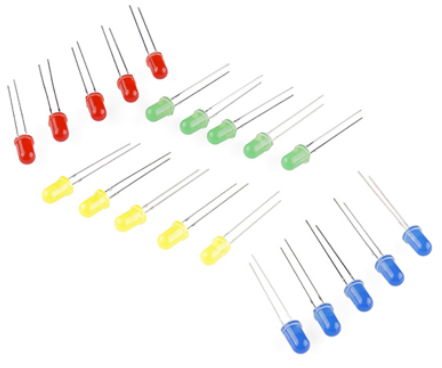

Figure 31: SparkFun multicolor LEDs ${ }^{120}$.

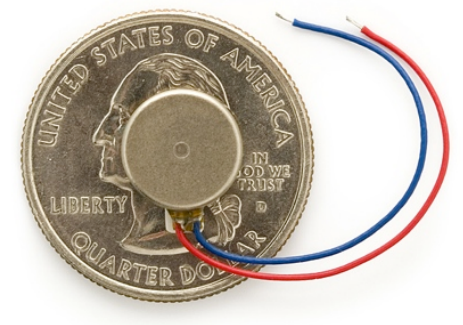

Figure 32: SparkFun vibration Motor $^{121}$. 


\section{7 $\quad 400 \mathrm{mAh}$ Polymer Lithium Ion Battery}

A polymer lithium ion battery was selected as a power source due to its availability, small size, reduction in user recurring costs (vs. repeatedly buying coin cell, AA, or AAA batteries), compatibility with USB recharging methods, relatively long battery life, and compatibility with the Teensy 3.1 board $^{122}$. A 400 mAh battery was selected primarily for its availability without a custom order. A review of other fitness tracking devices with battery lives of 3-7 days revealed batteries ranging from 50-300 mAh, indicating that $400 \mathrm{mAh}$ with a well designed power saving system is more than sufficient to meet the engineering requirement of three days of intermittent (once per minute) use. Regardless, future calculation of the power requirements for a prototype with additional functionality (as discussed in the Future chapter) will lead to a more informed battery selection. See Figure C6 of Appendix C: Manufacturer Supplied Component Datasheets, Diagrams, and Drawings for an image of the internal components of the $400 \mathrm{mAh}$ battery.

\subsection{Bluetooth LE Module}

A Bluetooth LE (BLE) module was selected to provide wireless communication for the device. BLE is the lowest power Bluetooth protocol available and allows for interaction with any 4.0 Bluetooth enabled device $^{123}$. Additionally, the use of BLE has become an industry standard in wearable devices ${ }^{123}$. See Figure C7 of Appendix C: Manufacturer Supplied Component Datasheets, Diagrams, and Drawings for a drawing of the module. 


\subsection{ABS Plastic Case}

ABS plastic was selected as the electronics housing material due to its availability, inexpensiveness, common use in electronics, color options, low density, and ease of machining ${ }^{124}$. The plastic case holds the electronic components and allows for increased water resistance if the appropriate seals are used on any holes. Future iterations of the device could use custom-molded ABS shapes to minimize the overall size and increase the durability of the device.

\subsection{Hook and Loop Cinch with an Elastic Nylon Strap}

A hook and loop cinch with an elastic nylon strap was chosen for the bicep band material due to its flexibility, availability, inexpensiveness, and ability to maintain a pressured contact surface between the

bicep and the transducers ${ }^{125}$. The cinch system allows for custom sizing with small increments for fitting a large variety of bicep sizes. With proper sizing, this band is sturdy enough to hold the electronic components without sliding down the arm of a user. Additionally, elastic and nylon are commonly used in available athletic bicep bands and have desirable sweat wicking properties. 


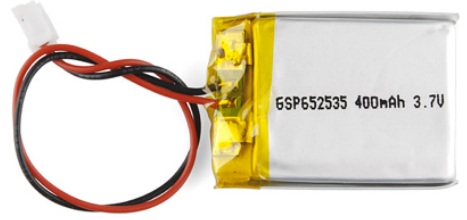

Figure 33: SparkFun 400 mAh polymer lithium ion battery ${ }^{122}$.

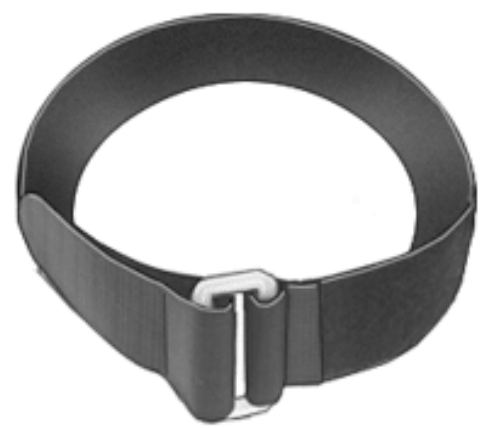

Figure 36: McMaster-Carr hook and loop cinch with elastic nylon strap ${ }^{125}$.

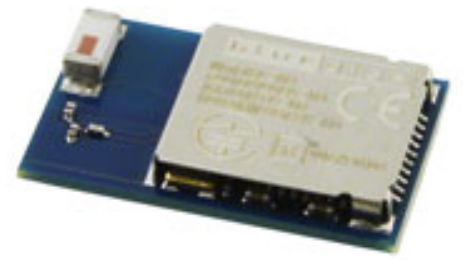

Figure 34: Digi-Key Bluetooth 4.0 Module M $^{123}$.

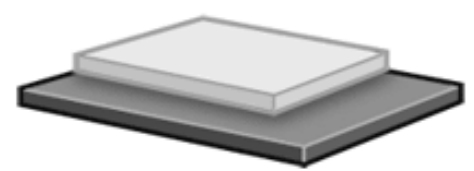

Figure 35: McMaster-Carr ABS plastic sheets ${ }^{124}$.

\subsection{Band Prototype}

See Figure 37 and Figure 38 for images of the prototype band. Unfortunately, unforeseen complications in the development process put significant time constraints on the development and testing opportunities of a fully functional wireless prototype. Due to the time constraints, it was not possible to adopt the wired breadboard prototype into a mounted wireless version. As is, there are two main components to the device:

(1) An elastic nylon bicep band with an adjustable cinch, Velcro attachments, and nylon tubes that hold the coated piezo disc elements in place. The tubes run the wires from the piezo disc elements, through an opening in the band, and into an interior pocket that would hold the 
electronic components. There is a reflective patch covering the location of the interior pocket to indicate where LEDs would appear in a final prototype.

(2) An electronics breadboard prototype with the Teensy 3.1, uncoated piezo disc elements, and micro-USB connection to a computer for power and data acquisition.

Since it was not possible to assemble and test a wireless version of the device, the main focus of this thesis is on using the electronics breadboard prototype to validate the method of detecting dehydration. All of the testing performed in the Validation chapter was performed using the breadboard prototype. Regardless, the prototyped band shows how the sensors and electronics can be integrated in a flexible, lightweight, and wearable device. See the Validation chapter for more information on the electronics breadboard prototype and the Future Functionality section of the Conclusions chapter for a discussion on possible future directions for an integrated prototype. 

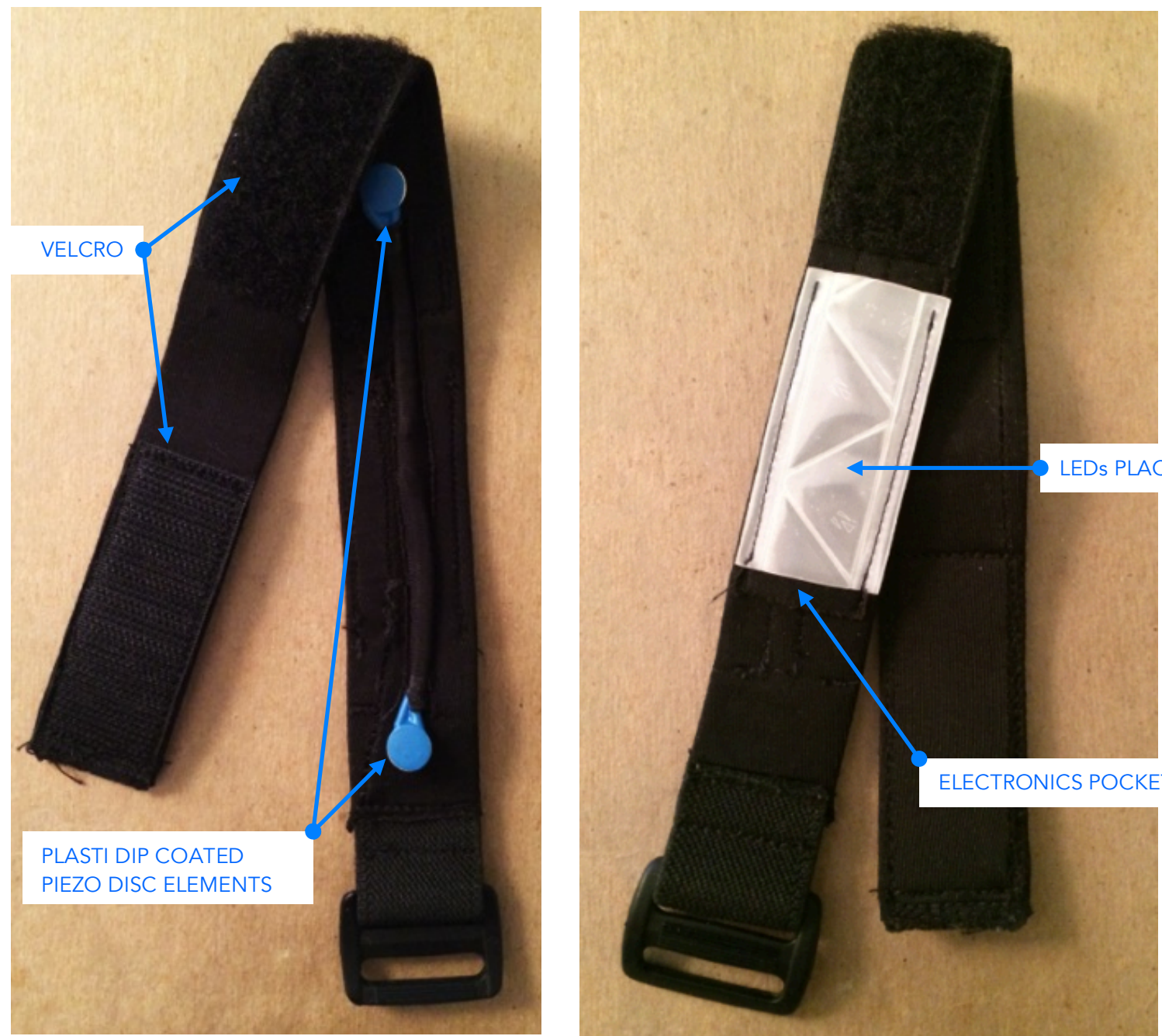

LEDs PLACEHOLDER
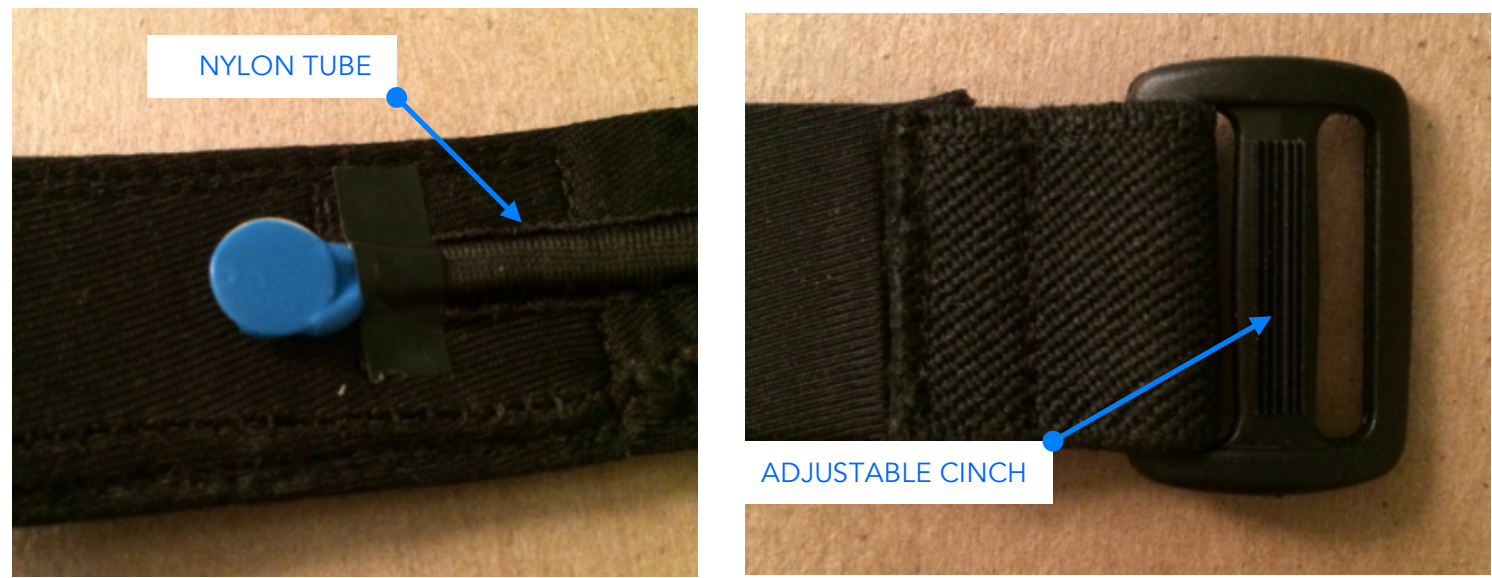

Figure 37: Images of the prototype band. 

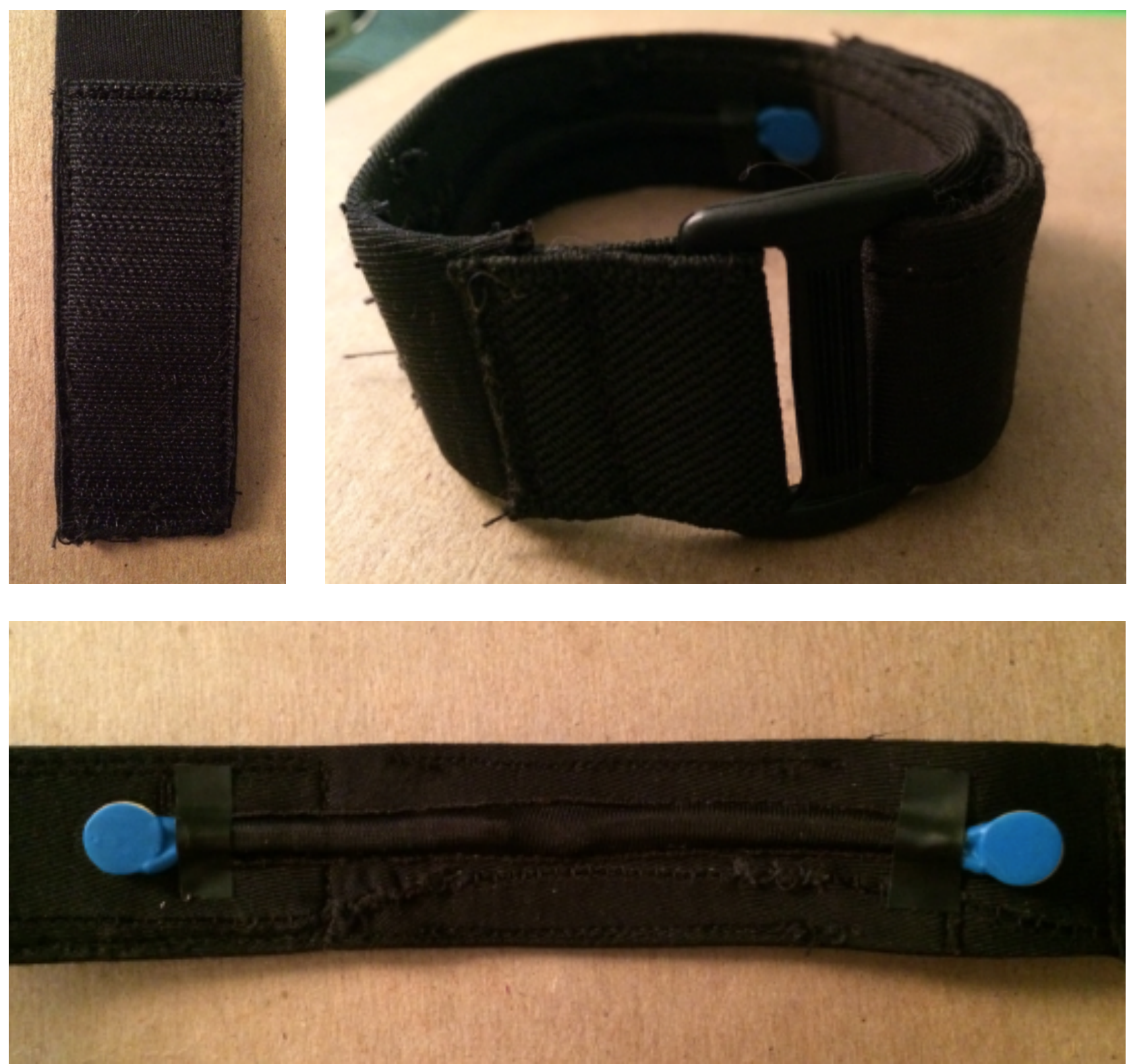

Figure 38: Detail views of the prototype band features. 


\subsection{Components and Prototype Cost Analysis}

See Table XIII for a summary table of the components used in the prototype band. Note that this is not a compilation of all expenses in this thesis, nor does it include the cost of taxes and shipping. Items without vendors were found or provided locally at no expense, but an estimated cost is provided for calculation of the total cost of the prototype. As seen in Table XIII, the total cost for the prototype band is $\$ 22.52$.

Future additions of battery power and Bluetooth LE communication would add an additional $\$ 27.43$ for a total cost of $\$ 49.95$ per band.

Table XIII: Summary table of the suppliers, number, and cost of the components used in the prototype device.

\begin{tabular}{|c|c|c|c|c|}
\hline Component & Vendor & Vendor Item \# & Quantity & Cost $(\$)$ \\
\hline Teensy 3.1 USB Board & PJRC & TEENSY31 & 1 & 19.80 \\
\hline Multicolor LEDs & SparkFun & COM-12062 & 4 & 0.59 \\
\hline $\begin{array}{l}18 \mathrm{kHz} \text { Piezo Disc } \\
\text { Element }\end{array}$ & Newark & 25R0595 & 2 & 0.54 \\
\hline Blue Plasti Dip Coating & McMaster-Carr & $9560 \mathrm{T7}$ & $\sim 0.45 \mathrm{oz}$ & 0.31 \\
\hline Electrical Wire & - & - & $\sim 12 "$ & 0.20 \\
\hline Solder Wire & - & - & $\sim 0.125 "$ & 0.05 \\
\hline 1" Elastic Fabric & McMaster-Carr & $88225 \mathrm{~K} 67$ & $\sim 12 ”$ & 0.23 \\
\hline $0.75 "$ Velcro & - & - & $\sim 3 "$ & 0.10 \\
\hline Spandex Material & - & - & $\sim 24$ x 1" & 0.20 \\
\hline 1" Plastic Cinch & - & - & 1 & 0.50 \\
\hline & & & Total & $\$ 22.52$ \\
\hline $\begin{array}{l}\text { 400mAh Polymer } \\
\text { Lithium Ion Battery }\end{array}$ & SparkFun & PRT-10718 & 1 & 6.95 \\
\hline Bluetooth 4.0 Module & Digi-Key & 1446-1028-1-ND & 1 & 20.48 \\
\hline \multicolumn{4}{|c|}{ Wireless \& Battery Powered Total } & $\$ 49.95$ \\
\hline
\end{tabular}




\section{VALIDATION}

\subsection{Safety Calculations}

The safe implementation of the ultrasonic method was investigated through theoretical calculations. The relationship between the intensity (in Watts/cm) and irradiation time of an ultrasonic process determines the safe exposure. See Figure 39 for a plot of this relationship, as given by the NCRP standards for exposure to ultrasonic mechanisms. In addition to an increasingly non-linear response within the tissue, at high intensities ultrasonic waves can produce enough heat to rapidly melt solids or cause cavitation - a phenomenon that occurs when the stresses generated in the ultrasonic waves produce free chemical radicals and promote certain chemical reactions, leading to the formation of cavities - in liquids ${ }^{98}$. While cavitation caused by high intensity ultrasound is beneficial in many applications like ultrasonic cleaning, sonochemistry, transdermal drug delivery, hyperthermia for cancer treatment, and ultrasonic ablation, it is extremely important to avoid unintentional cavitation ${ }^{98}$. For this reason, the theoretical intensity of the selected disc element was calculated. See Figure 40 for the equations and results of this calculation process. Note that this calculation is for a worst case scenario: the highest intensity region of the 6-mm diameter piezo element on wet skin with a reduced resistance of $1000 \Omega^{126}$. 


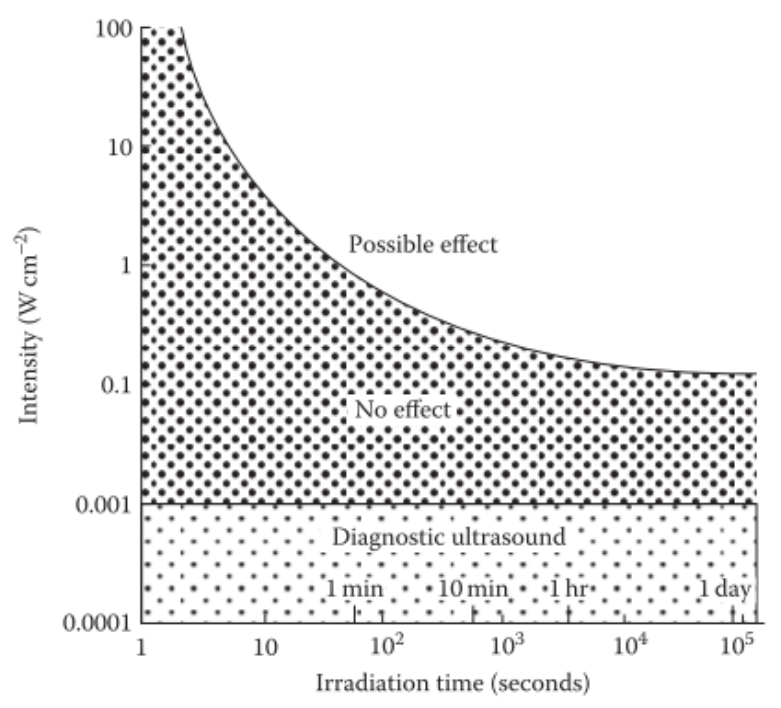

Figure 39: Intensity of ultrasound vs. irradiation time for safe exposure to medical diagnostic ultrasounds ${ }^{90}$.

$$
\begin{gathered}
\text { Power }=\frac{V_{p}^{2}}{R} \\
\text { For } \mathrm{V}_{\mathrm{p}}=3.3 \mathrm{~V} \text { and } \mathrm{R}=1000 \Omega: \\
\text { Power }=\frac{(3.3 \mathrm{~V})^{2}}{1000 \Omega} \\
\text { Power }=0.01089 \text { Watts } \\
\text { Intensity }=\frac{\text { Power }}{\text { Area }} \\
\text { For } A=\pi r^{2}, \mathrm{r}=0.3 \mathrm{~cm}: \\
\text { Intensity }=\frac{0.01089 \mathrm{Watts}^{2}}{\pi(0.3 \mathrm{~cm})^{2}} \\
\text { Intensity }=0.0385 \frac{\mathrm{Watts}^{2}}{\mathrm{~cm}^{2}}
\end{gathered}
$$

Figure 40: Calculations for the worst-case intensity of the selected $18 \mathrm{kHz}$ disc elements.

In comparison with the safe exposure chart, the calculated worst-case intensity of $0.0385 \mathrm{Watts} / \mathrm{cm}^{2}$ does not have an effect at any irradiation time. Theoretically, the selected piezo element could be in contact with wet skin while transmitting ultrasonic waves non-stop at the highest intensity the Teensy 3.1 board can output with no adverse effects on a user.

\subsection{Frequency and Signal Detection Test}

Tests and calculations were performed to determine the desired frequency and shape of the ultrasonic signal. The following factors were considered in the selection of the frequency:

- The lower limit of the ultrasonic range is $20 \mathrm{kHz}$.

- Piezo disc elements have optimal performance at or near their natural frequency.

- Power draw increases with increasing frequency.

- The signal processing capabilities are limited by the Teensy 3.1 specifications.

In sum, minimizing the frequency minimizes the processing and power requirements while maximizing the performance of the $18 \mathrm{kHz}$ piezo disc element. Thus, a signal frequency of $20 \mathrm{kHz}$ was chosen. 
The sent wave can be a sinusoidal wave or a square wave. While the Theory chapter discussed the use of sinusoidal signals, square signals demonstrate the same shifts but can be easier to process because there are more distinct changes within the signal. Thus, preliminary testing was performed to visually identify which wave shape has a more noticeable change between the sent signal and the received signal. In this testing, an oscilloscope and a function generator were connected to a piezo disc element and used to generate $10 \mathrm{~V}_{\mathrm{p}-\mathrm{p}}$ sinusoidal and square waves. Another piezo disc element was connected to the second input of the oscilloscope and used to receive the signal. The piezo elements were placed on either side of various limbs to visually identify if the $20 \mathrm{kHz}$ signals could be detected and, if detected, which wave shape showed the most identifiable differences between the sent and received waves. See Figure 41 for a diagram of this setup with a $10 \mathrm{~V}_{\mathrm{p}-\mathrm{p}}$ square wave through a male forearm.

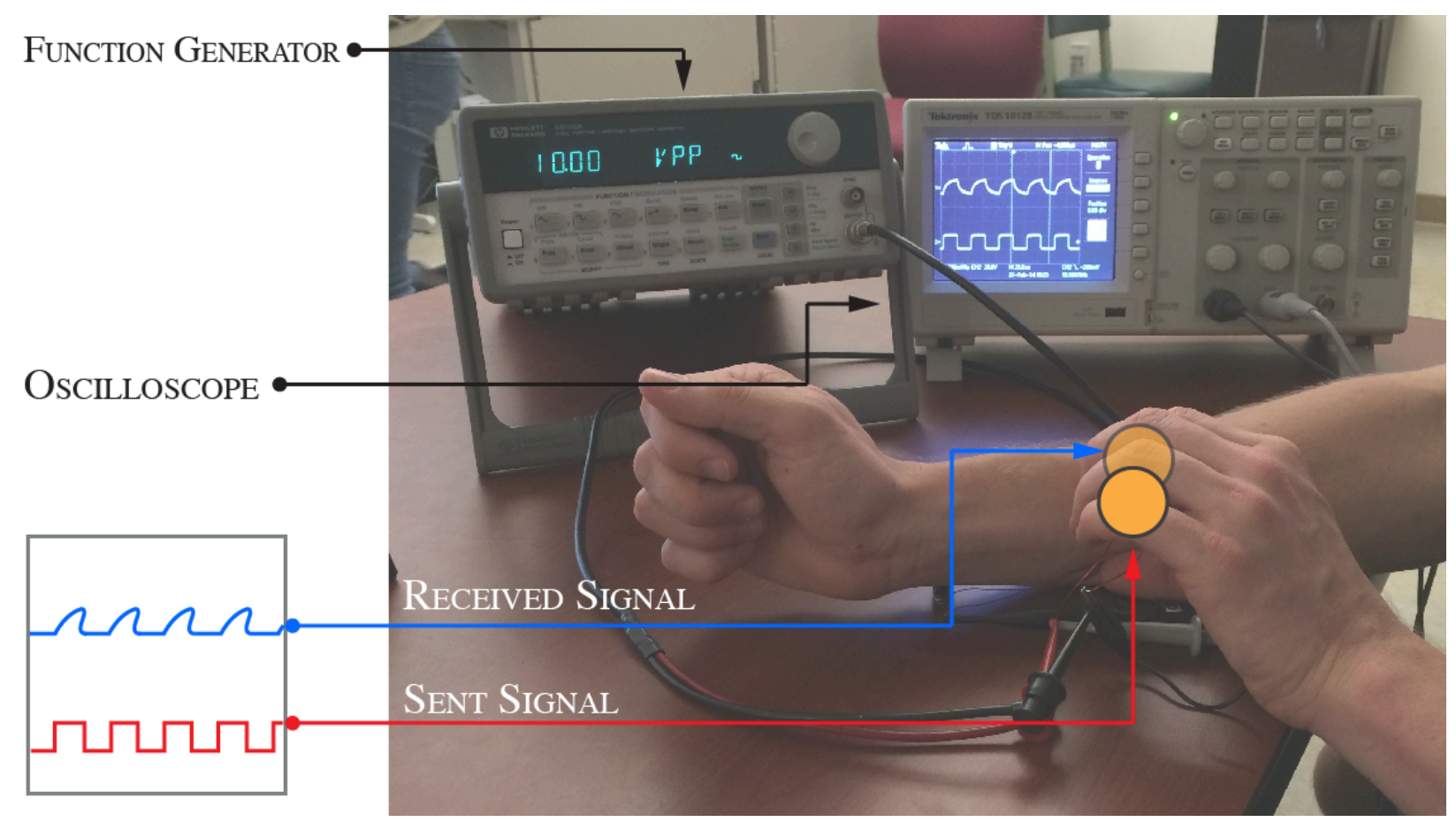

Figure 41: Image of the oscilloscope and function generator test setup.

As seen in Figure 31, the received signal from the $10 \mathrm{~V}_{\mathrm{p}-\mathrm{p}}$ square wave is easily detected, well defined, and noticeably shifted from the sent signal. Given this behavior, the ability to detect signals from piezo disc elements was validated and a square wave shape was chosen for use in the prototype. 


\subsection{Code Development}

Through a collaborative process, Ross Gregoriev (MS MATE ‘ 14, Cal Poly SLO) generously helped create the validation code by adopting his previous work in analog signals for the purposes of this thesis.

Three programs were used to compile the code for the validation process. See Table XIV for a list of the programs and their role in the validation code.

Table XIV: Summary table of the programs used to generate the validation code.

\begin{tabular}{|l|l|}
\hline \multicolumn{1}{|c|}{ Program } & \multicolumn{1}{c|}{ Role } \\
\hline Teensyduino & $\begin{array}{l}\text { Plug-in interface between PJRC's Teensy 3.1 board and the Arduino IDE. Upon } \\
\text { installation, Teensyduino added the Teensy 3.1 board to the Arduino IDE board } \\
\text { options list. After any changes to the code within the Arduino IDE, Teensyduino } \\
\text { served as an intermediary for loading code onto the Teensy 3.1. }\end{array}$ \\
\hline Arduino IDE & $\begin{array}{l}\text { Development environment used to program the Teensy 3.1 for the analog output and an } \\
\text { analog input signal. The finished Arduino code was loaded onto the Teensy 3.1 once. } \\
\text { Subsequent control of the Teensy 3.1 was performed via an Arduino IDE interface in } \\
\text { LabVIEW. }\end{array}$ \\
\hline LabVIEW & $\begin{array}{l}\text { Interface used to run the Teensy 3.1, troubleshoot the code, process the signals, and } \\
\text { acquire data on the processed signals. LabVIEW is advantageous over the Arduino IDE } \\
\text { because it allows for graphic coding using block diagrams and shows live views of the } \\
\text { acquired signals via graphs on the front panel. }\end{array}$ \\
\hline
\end{tabular}

See Figure 42 for example windows of the Teensyduino, Arduino IDE, and LabVIEW programs.

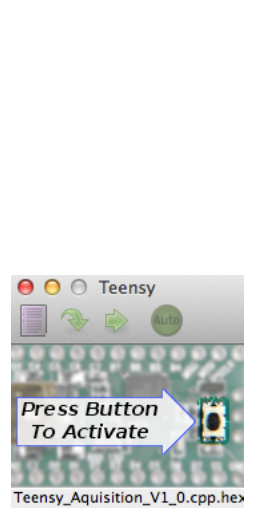

(A)

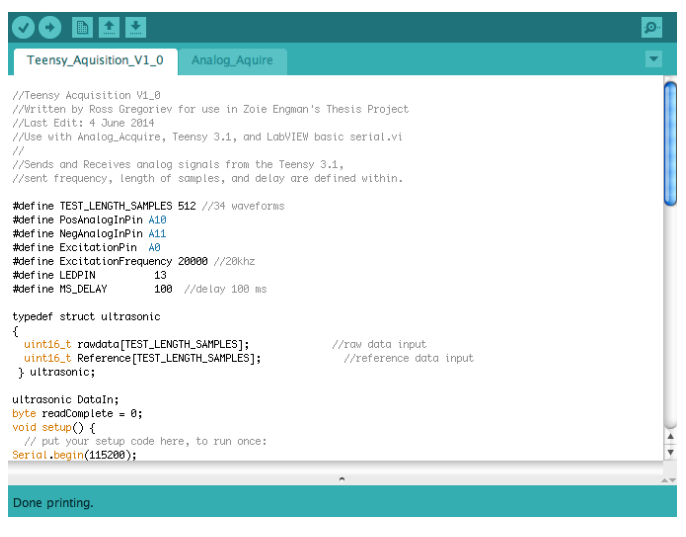

(B)

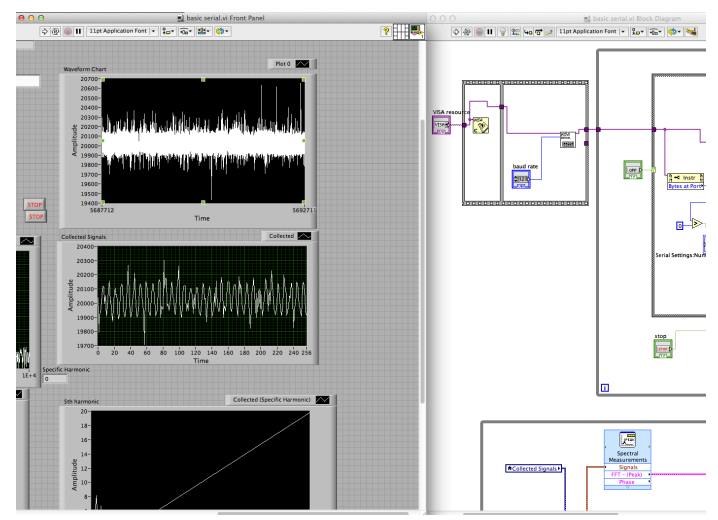

(C)

Figure 42: Example windows of the programs used to generate the validation code; (A) Teensyduino, (B) Arduino IDE, (C) LabVIEW (left) Front Panel and (right) Block Diagram. 
The general process of the code development and subsequent data acquisition was as follows:

- Optimal signal acquisition timing calculated.

- Timing variables defined in the Arduino Teensy_Acquisition and Analog_Acquire code.

- Arduino code loaded onto the Teensy 3.1 via the Arduino IDE and Teensyduino.

- LabVIEW interface with Arduino created in the Block Diagram panel.

- Signal processing loops created in the LabVIEW Block Diagram panel.

- Desired output graphs generated in the LabVIEW Front panel.

- Run test.

- Export data from the desired output graphs in the LabVIEW Front panel to Excel.

- Generate charts from the data in Excel.

The analog signal generated by the Arduino/Teensy 3.1 code is

characterized by the number of samples in each period, the voltage of

$$
f=\frac{1}{T}
$$

the waveform, and the length of the period. The Teensy 3.1 processor

$$
T=\frac{1}{f}
$$

datasheet and the provided Freescale ADC calculator were used to

calculate the optimal number of samples per period at 15 samples. The

$$
\begin{aligned}
T & =\frac{1}{20,000 \mathrm{~Hz}} \\
T & =50 \mu \mathrm{s}
\end{aligned}
$$

voltage of the waveform is $3.3 \mathrm{~V}$, as dictated by the Teensy 3.1 analog pin outputs. Finally, using Equation 5 (as shown in Figure 43), the desired frequency of $20 \mathrm{kHz}$ was used to calculate the period of the Figure 43: Calculation of the period for a $20 \mathrm{kHz}$ wave. wave at $50 \mu \mathrm{s}$.

See Figure 44 for a flowchart of the validation code, Figure 45 for a pinout diagram of the Teensy 3.1, Figure 46 for an image of the prototype circuitry, and Figure 47 for identification of the modules on the Front Panel. The full Arduino codes can be found in Appendix E: Arduino Code - Teensy Acquisition and Appendix F: Arduino Code - Analog Acquire. The full LabVIEW Block Diagram and Front Panel can be found in Appendix G: LabVIEW Block Diagram Panel and Appendix H: LabVIEW Front Panel. 


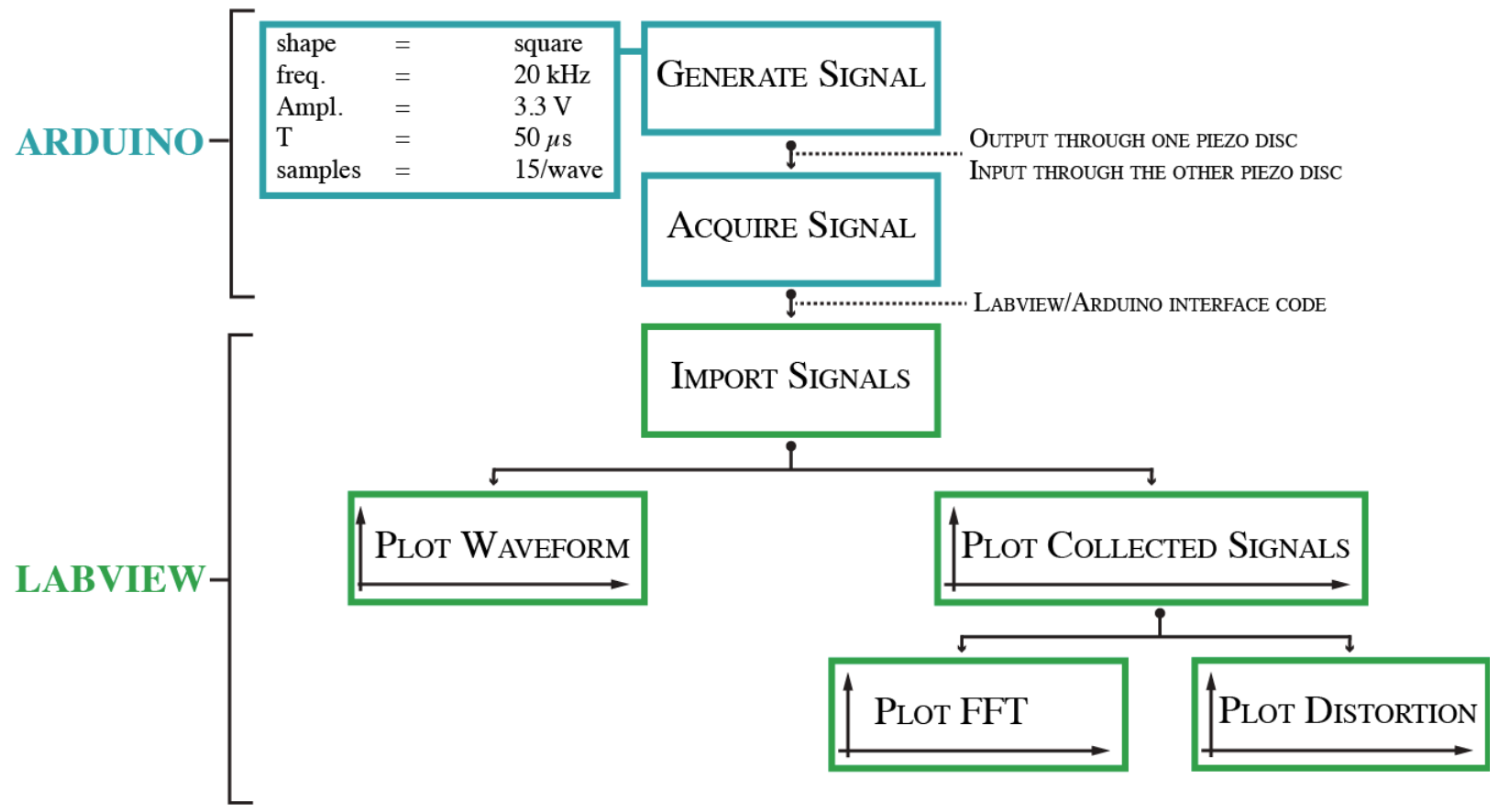

Figure 44: Flowchart of the validation code.

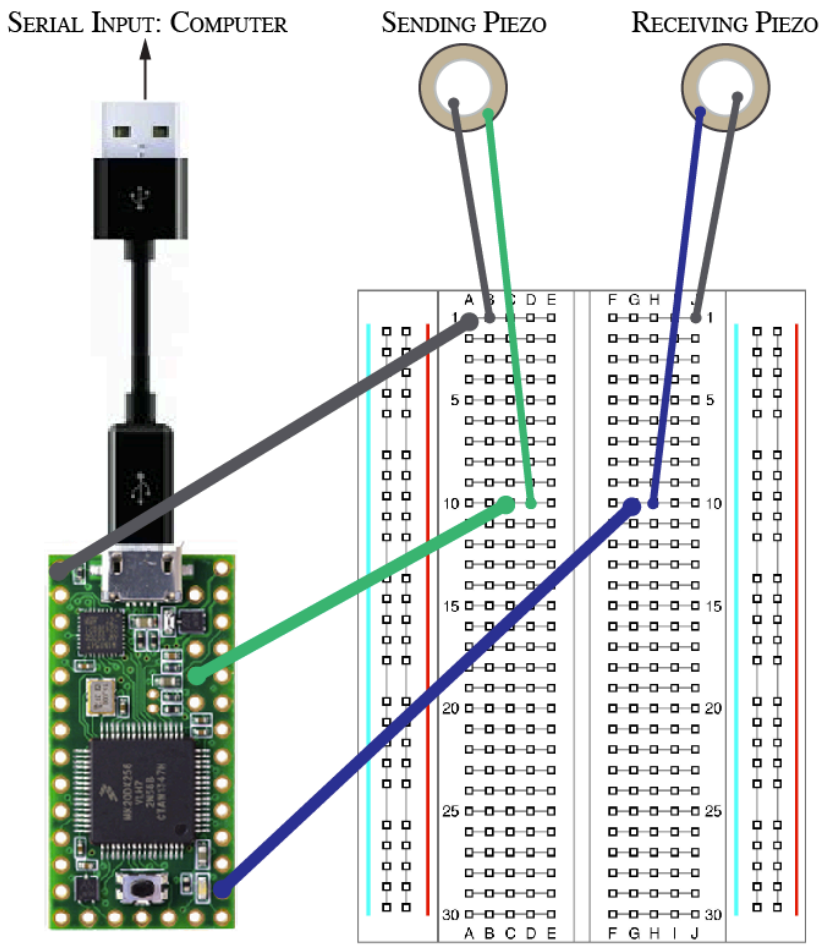

Figure 45: Pinout diagram of the Teensy 3.1 with the validation code.

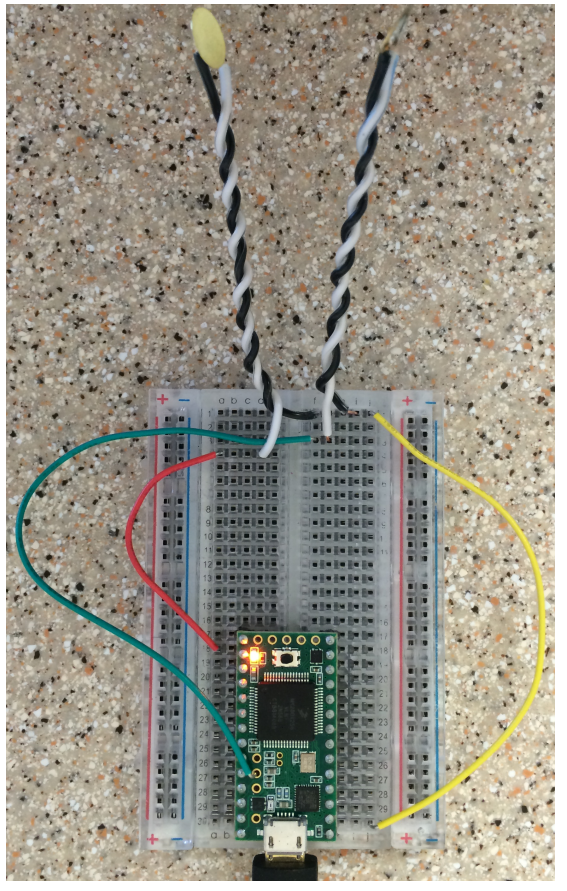

Figure 46: Prototype Teensy 3.1 running the validation code via a breadboard and two $18 \mathrm{kHz}$ piezo disc elements. 


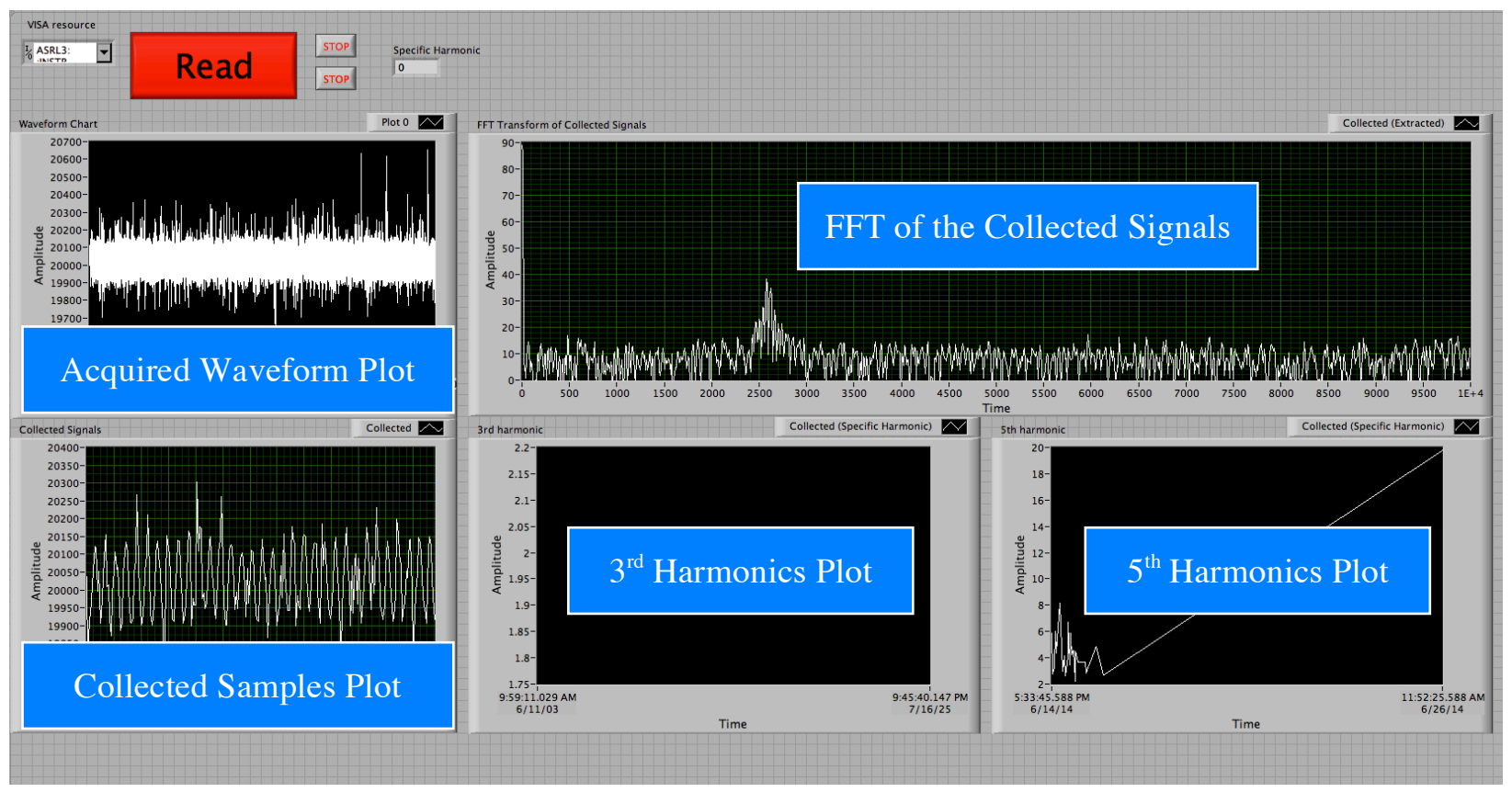

Figure 47: Identification of the modules within the LabVIEW Front Panel. Note that the $5^{\text {th }}$ harmonics plot is not used for gathering or analyzing data.

Essentially, this code is generating a specific analog signal to send through one piezo element, receiving an analog signal at the other piezo element, converting the received signal to digital data, processing the data, and printing graphs of the processed received signal. An example diagram of the sent, received, and an overlay of the sent/received signals is shown in Figure 48. As seen in Figure 48, the received signal carries a certain amount of distortion compared to the sent signal. Recall the goal of determining hydration status from the magnitude of a phase shift between a calibrated baseline signal and an acquired signal; likewise, the amount of distortion can be used to compare the two signals. The distortion in the received signal is due to the attenuation, or capacitive effect, of the material through which the signal is propagating. Theoretically, a decrease in tissue water content leads to more attenuation, which causes more distortion, thus indicating dehydration. In the case of this validation code, distortion is shown as a plot of the harmonics of the sent signal. While the ultimate goal for the code in the hydration monitor is to have a comparator numeric value from the calculation of the phase shift between two signals, the time constraints of this thesis restrict the validation to visual analysis of two signals. 

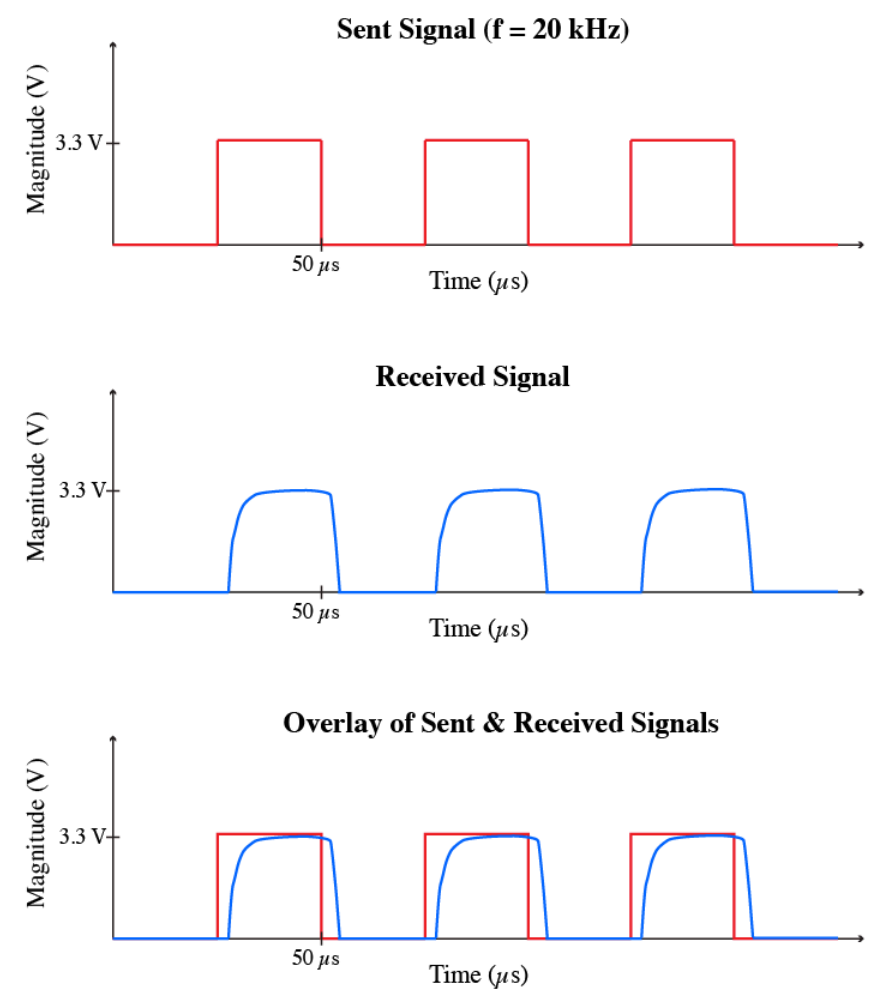

Figure 48: Comparison diagram of the sent and received signals for the $3.3 \mathrm{~V}, 20 \mathrm{kHz}$ square waves.

\subsection{Distortion Validation}

To validate attenuation as the theoretical cause of distortion, the signals received through two materials of similar thickness and different attenuation properties were measured. See Table XV for the materials, images of the samples, thickness of the samples, and the calculated average distortion amplitude. Note that attenuation coefficient values could not be found for the materials at $20 \mathrm{kHz}$, but the attenuation of solid materials varies with frequency by an approximately linear relationship, so the ratio between the two attenuation coefficients is similar at $20 \mathrm{kHz}^{127}$. Raw data from these tests can be found in Appendix I: Accessories to the Distortion Validation Tests. As seen in the aluminum sample images, there are two holes extending through the sample. Care was taken to keep the transducers on the middle solid portion of the aluminum sample. 
Table XV: Sample properties for the distortion validation test.

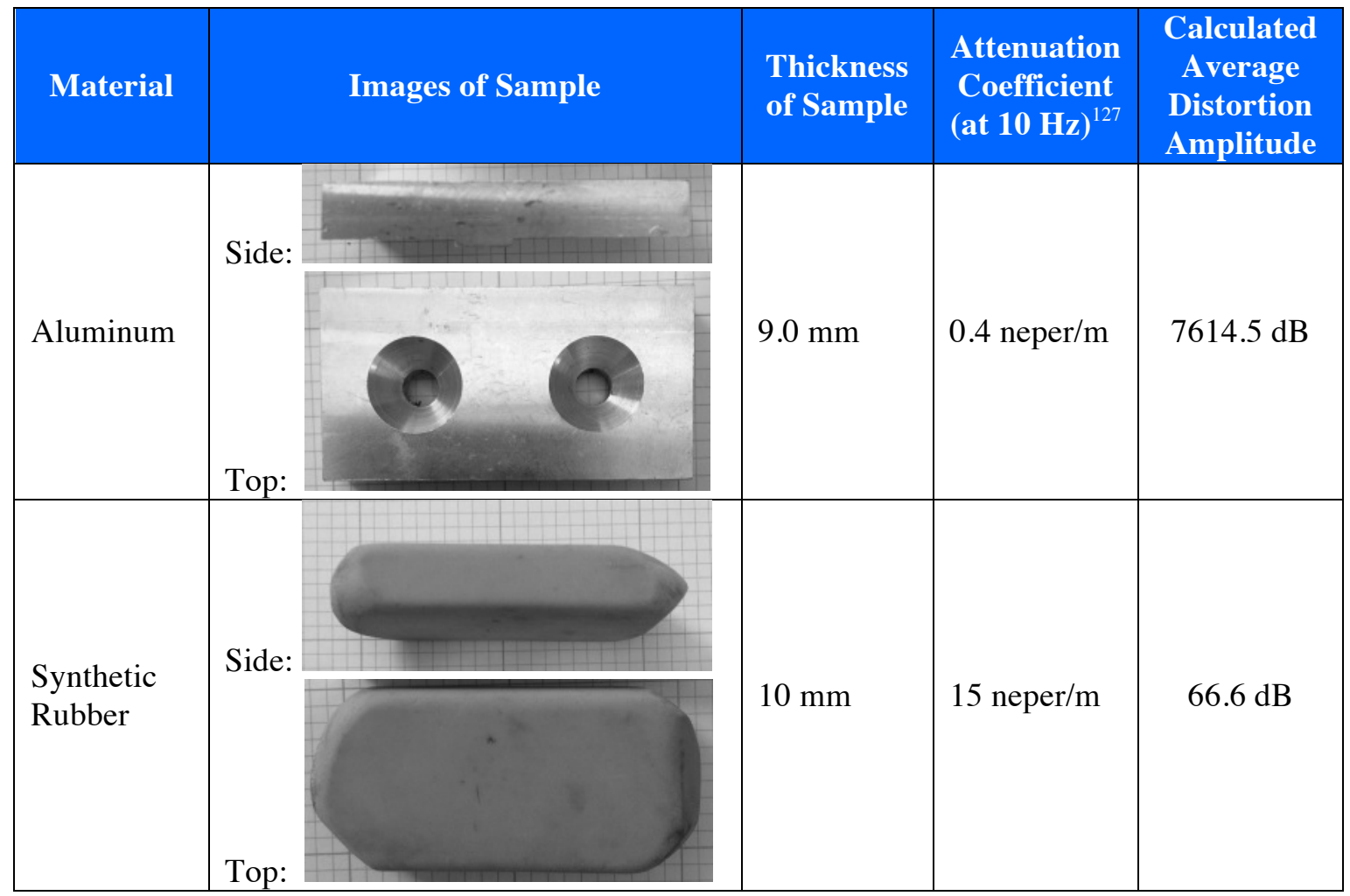

See Figure 49 and Figure 50 for the harmonic plots of the two material samples.

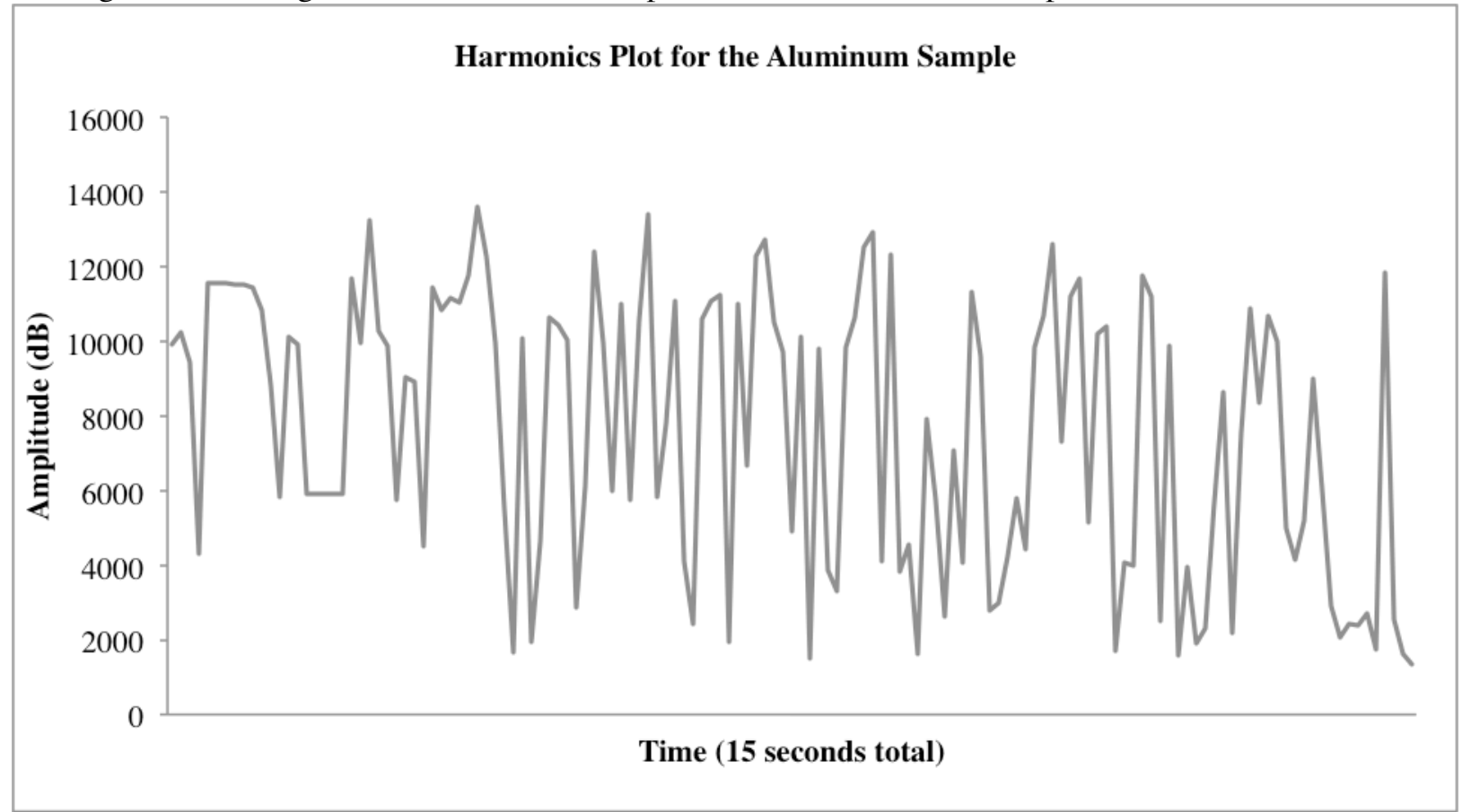

Figure 49: Harmonics plot for the aluminum sample. 


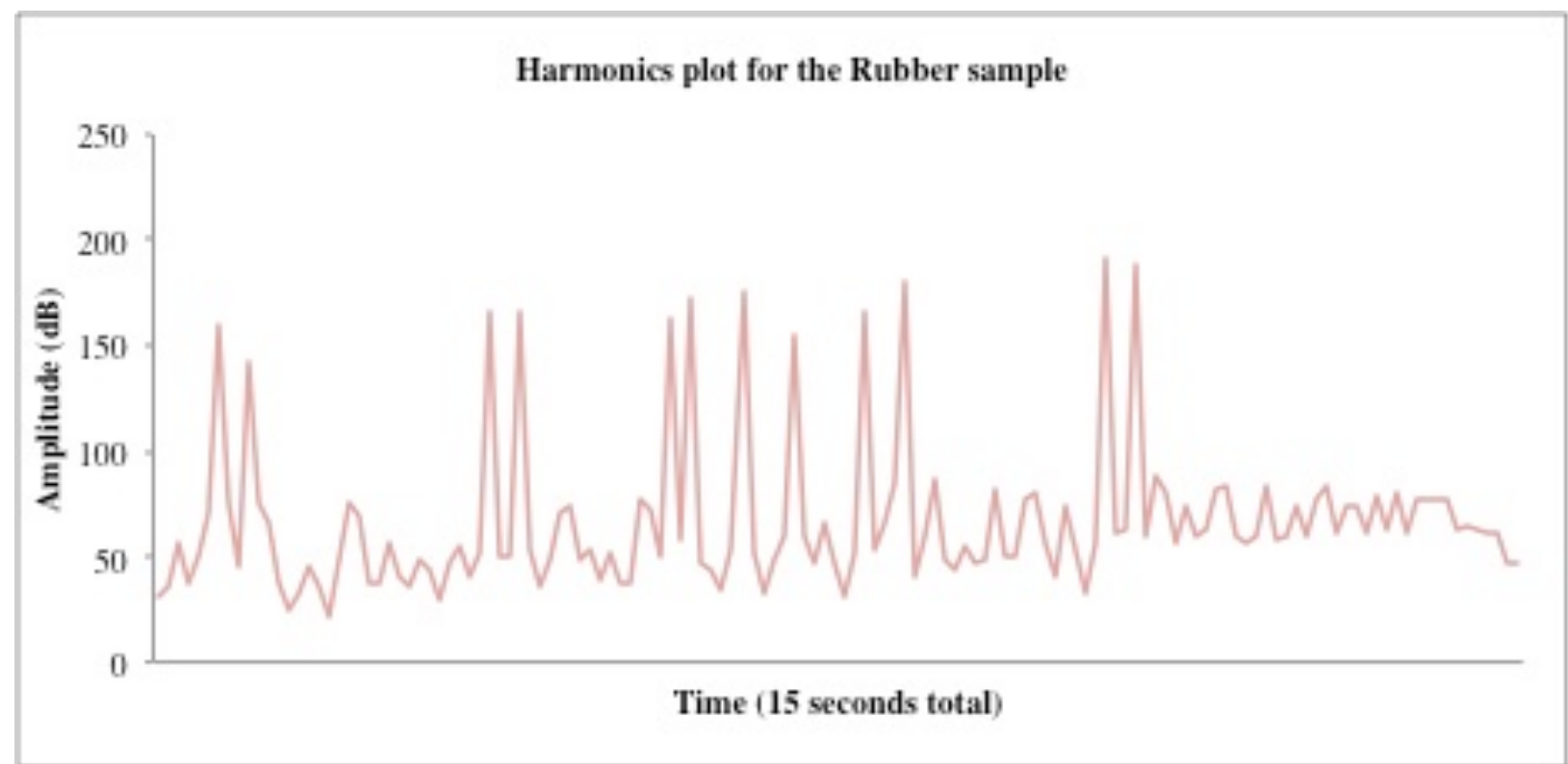

Figure 50: Harmonics plot for the rubber sample.

See Figure 51 for a combined plot of the two samples. As seen in the plots, the amplitudes of the harmonics are very different, indicating that the material with a higher attenuation coefficient has lower harmonics amplitudes.

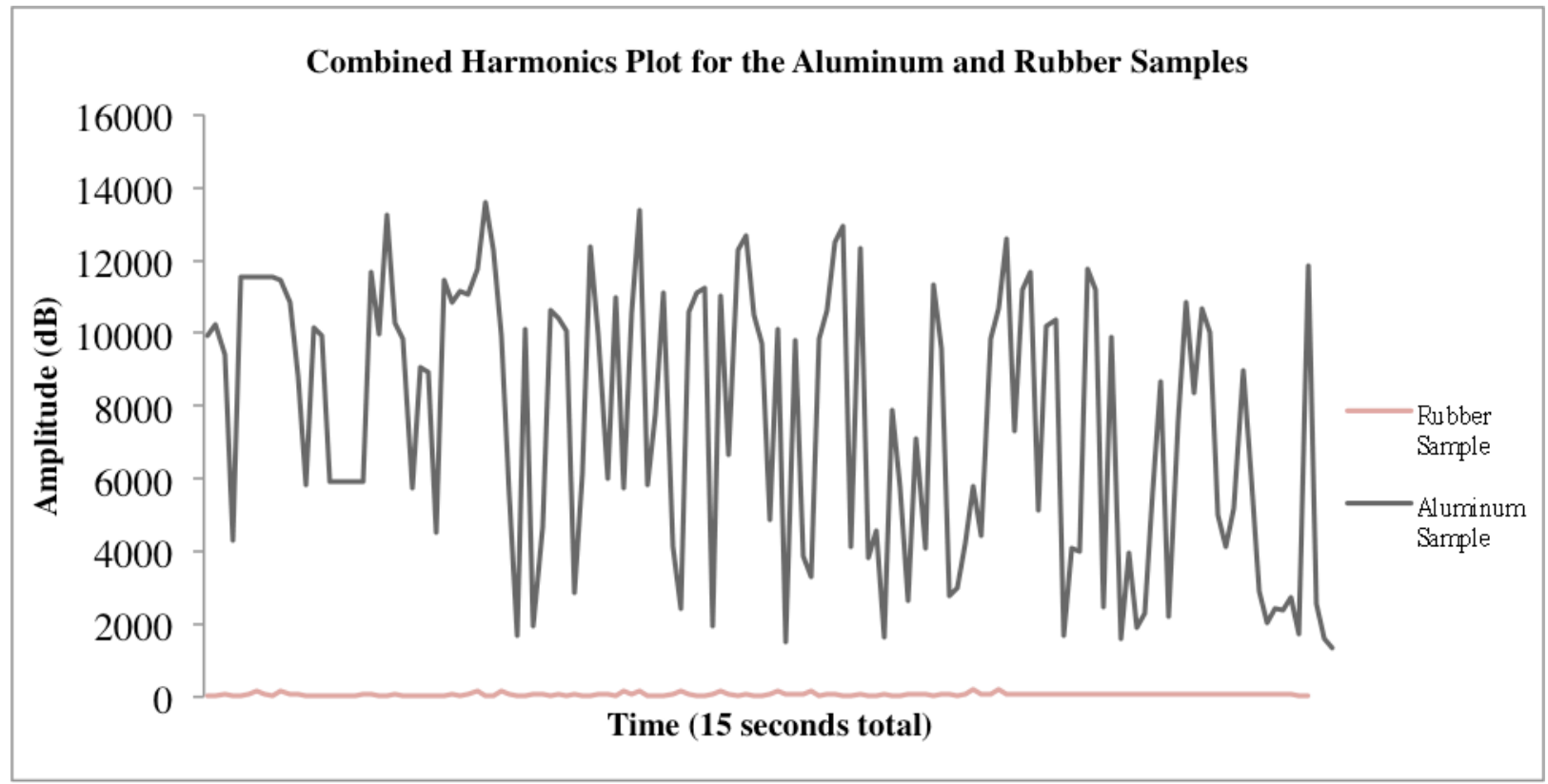

Figure 51: Combined harmonics plot for the aluminum and rubber samples. 
Interestingly, the attenuation coefficients of the materials and the average distortion values have similar percent differences. The percent difference between the attenuation coefficients is $190 \%$ and the percent difference between the average distortion values is $197 \%$. See Figure I1 in the Appendix I: Accessories to the Distortion Validation Tests for the calculation of the percent differences. The similarity in percent differences may indicate a minimum threshold sensing value in which material attenuation differences within a certain range cannot be detected using the processing in this validation code. However, this possibility requires future investigation with additional materials to compare a wide variety of attenuation coefficients. Regardless, the main outcome of this test - a lower amplitude from a higher attenuating material - supports the theory that a plot of harmonics will reflect differences in the attenuation coefficients of the material through which the signal is propagating.

\subsection{Sponge Water Content Validation Test}

The ability to detect water content in a material with a constant thickness was investigated using a sponge wetted with incremental amounts of water. See Figure 52 for an image of the setup for this test. First, the vulnerable electrical components of the prototype were protected from moisture and secured to the breadboard via insulating electrical tape. Since these piezos do not have a Plasti Dip coating, each piezo element was secured to a rubber eraser to make them easier to manipulate, reduce the conductive effect of touching the elements while tests are being run, prevent the solder points from contacting water, and minimize the effect of manually applied pressure on the driving elements of the piezos. A new sponge was removed from its packaging, weighed, and placed in a Ziploc bag. The harmonics of the dry sponge were measured at three locations. Then, the Ziploc bag was opened and one tablespoon of lukewarm water was carefully spread over the top of the sponge. The weighing and signal acquisition procedures were repeated at the same three locations for up to six tablespoons of water. See Appendix J: Accessories to the Sponge Water Content Validation Test for the raw and averaged data from this test. Additionally, see Figure 53 for a plot of the averaged acquired data from the Dry to $2 \mathrm{~T}$ levels. 


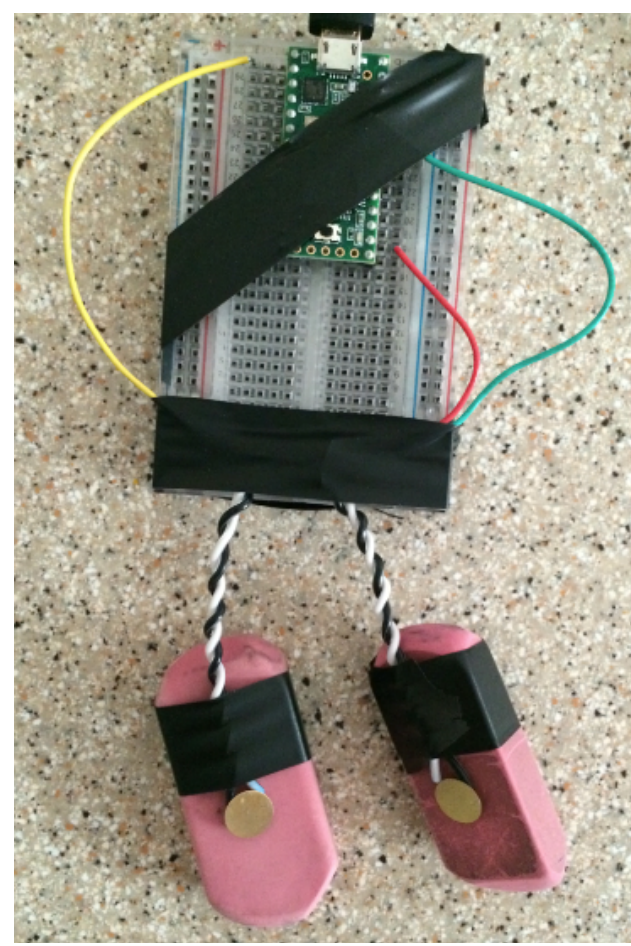

(A)

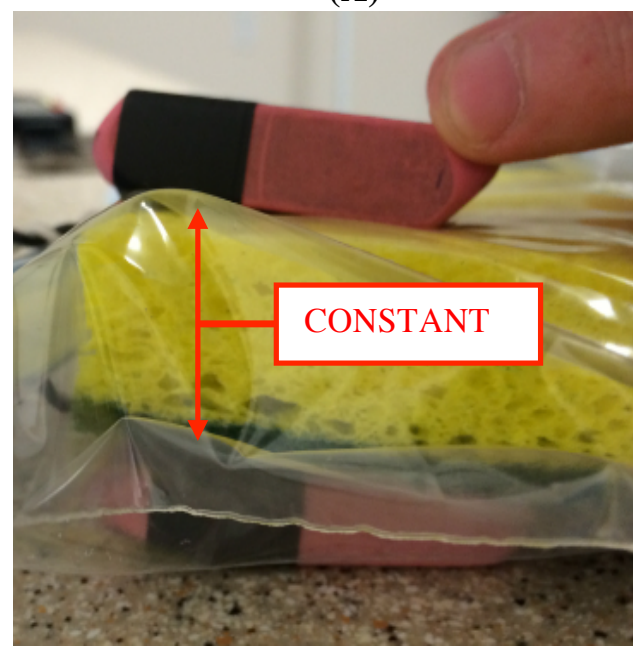

(C)

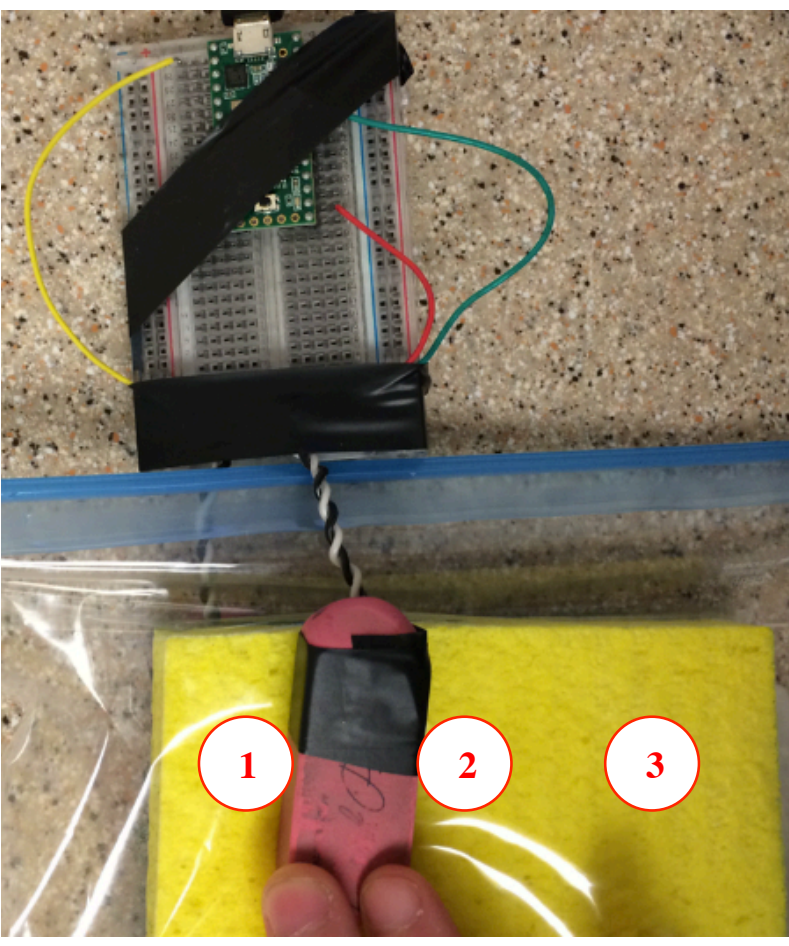

(B)

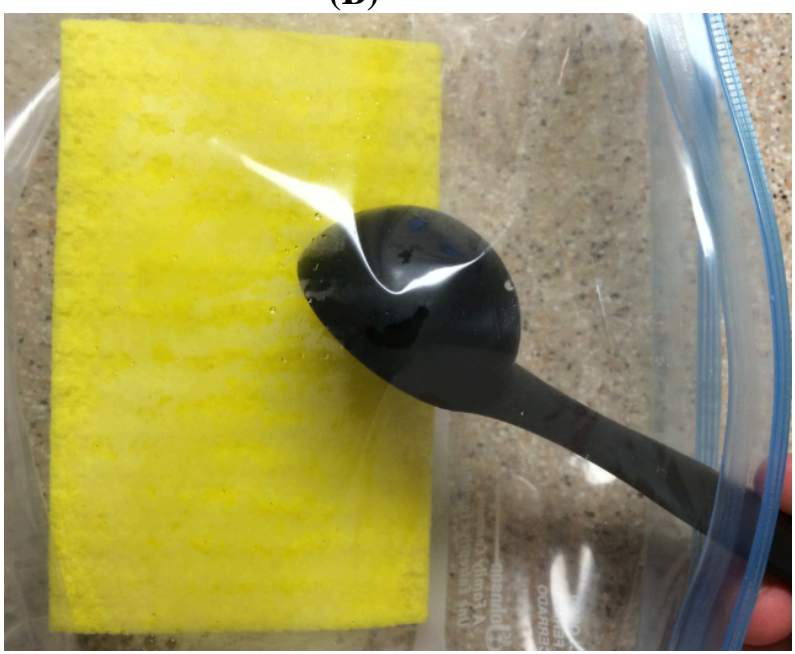

(D)

Figure 52: Prototype setup for the sponge water validation test. (A) Protected breadboard connections and connection of the piezo elements to the rubber backing, (B) Placement of sensors and measurement points on the sponge, $(C)$ Side view of the experimental setup with a constant material thickness, and (D) Method of adding water to the sponge. 


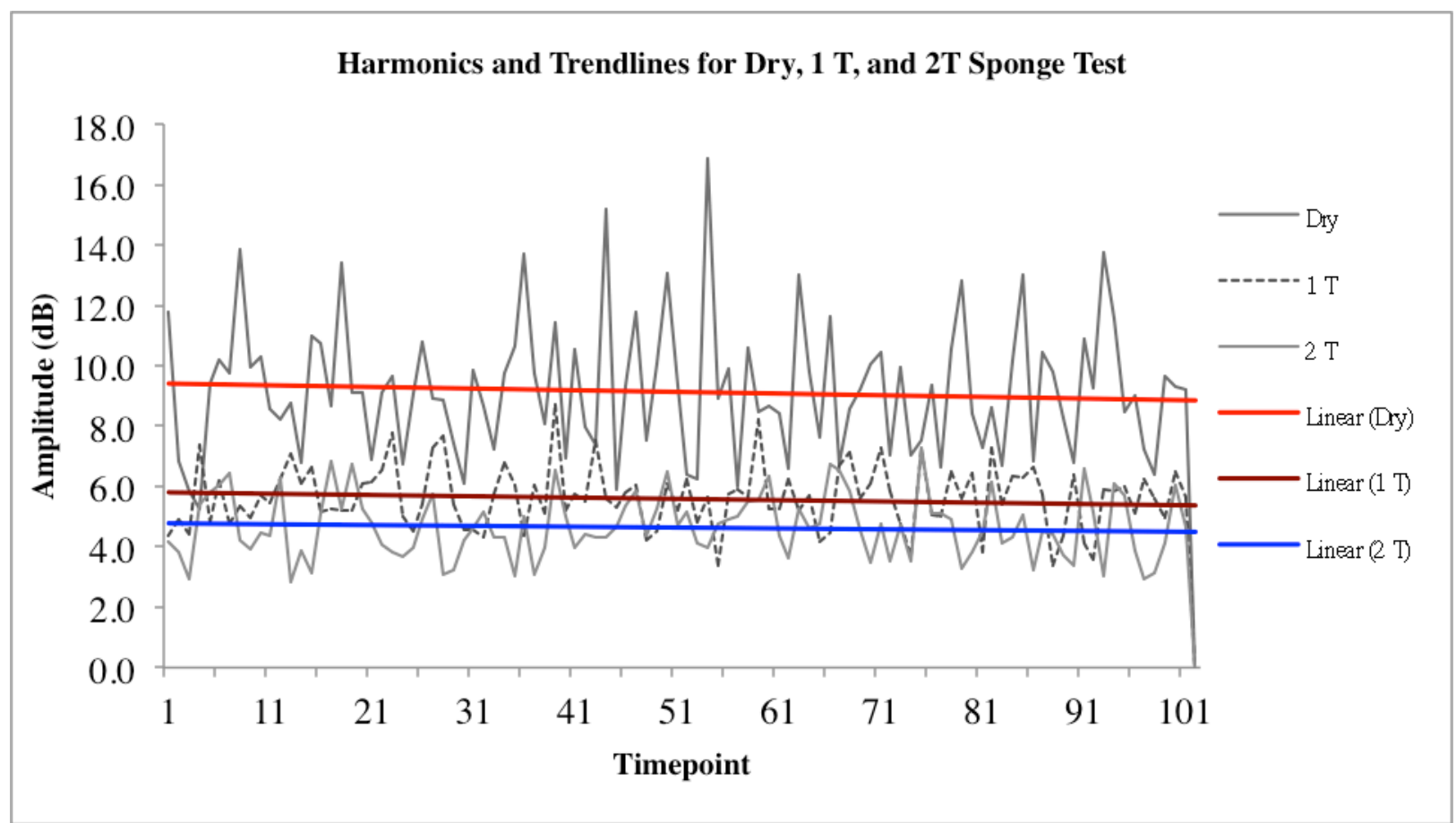

Figure 53: Harmonics and trendlines for the sponge test.

As seen in Figure 53 and consistent with the results from the distortion validation test, an increase in the water level of the sponge corresponds to a decrease in the harmonic amplitude. However, the reduction in harmonic amplitude is not consistent with an incremental increase in the amount of water within the sponge. In other words, increasing the water content by a second tablespoon did not cause the same drop in harmonic amplitude as adding the first tablespoon of water to the dry sponge. This observation was noted again when a third tablespoon of water was added. As seen in Figure 54, the average harmonic amplitude from the third tablespoon to the sixth tablespoon did not change by more than $0.5 \mathrm{~dB}$. This plateau of the average amplitude plot can be explained by three factors:

(1) The sponge, once saturated, does not change in attenuation.

(2) The geometry of the sponge, namely the coarse green layer, may cause the water to settle at the bottom of the sponge and affect the detection of increasing sponge water content.

(3) The inhomogeneity of the sponge macrostructure does not provide consistent attenuation behavior. 
A future, more precise, investigation on the behavior of the harmonics amplitude with samples of increasing water content can be performed by using homogenous blocks of agarose gels with various water contents. Regardless, the ability of the prototype to detect the initial increase in water content contributes to the validation of the method.

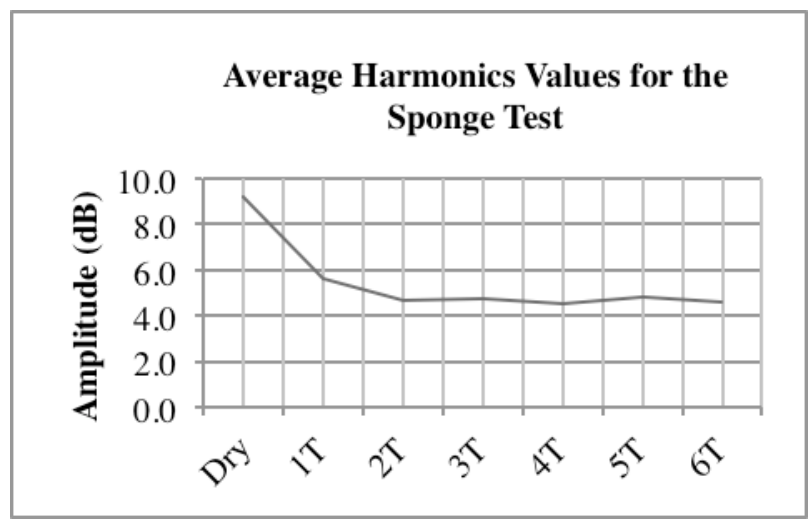

\section{Figure 54: Average harmonic amplitude values for the sponge test.}

\subsection{Meat Dehydration Test}

The distortion validation and sponge water content tests both showed an ability to detect a change in the acoustic properties of a material. However, the acoustic properties of tissues with various hydration states cannot be extrapolated from behavior in aluminum, rubber, and sponge materials. Further, it is unknown how the harmonic amplitude relates to the percentage dehydration of a tissue. For this reason, a final test was performed to assess if the prototype code can detect percent changes caused by the dehydration of muscle tissue. See Table XVI for the stepwise process, images, and a description of each action performed in the meat dehydration test. 
Table XVI: Stepwise process, images, and description of actions performed in the meat dehydration test.

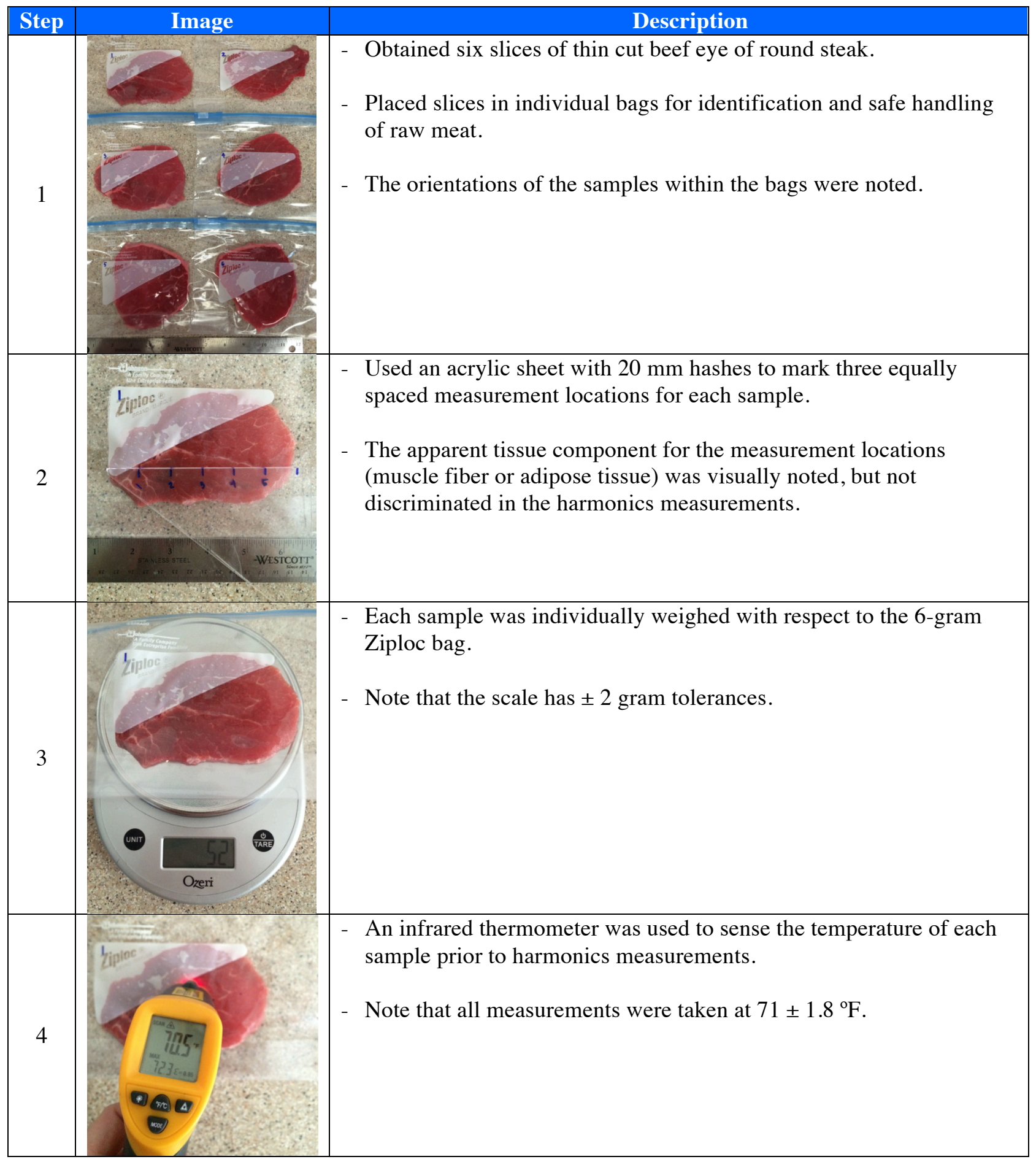




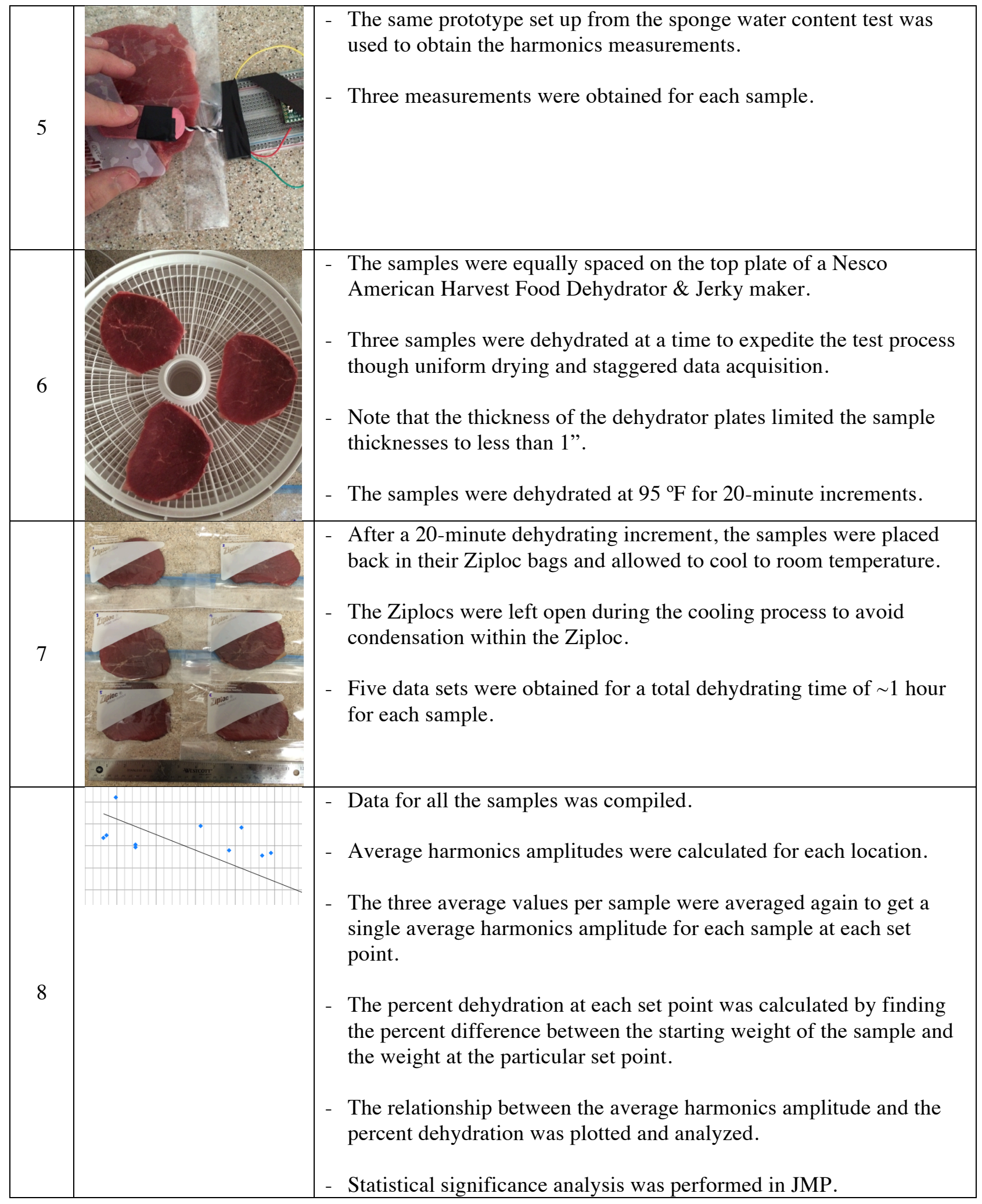


See Table XVII for a summary of the average harmonic amplitude for each sample and Table XVIII for a summary table used in the statistical analysis. Additionally, see Appendix K: Accessories to the Muscle Dehydration Test for the data table used to compile averages during testing and for a summary figure of the statistical analysis that was performed in JMP.

Table XVII: Summary table of the weight, \% dehydration, and average harmonics amplitude for each of the samples at four set points. Note that the first set point is the baseline value used to determine percent differences and is not included in trend analysis.

\begin{tabular}{|c|c|c|c|c|}
\hline Sample & Set & Weight (g) & $\%$ Dehydration & $\begin{array}{c}\text { Average } \\
\text { Harmonics } \\
\text { Amplitude (dB) }\end{array}$ \\
\hline \multirow{4}{*}{1} & 1 & 52 & $0 \%$ & 15.31 \\
\hline & 2 & 50 & $2 \%$ & 18.41 \\
\hline & 3 & 44 & $8 \%$ & 15.69 \\
\hline & 4 & 38 & $16 \%$ & 4.59 \\
\hline \multirow{4}{*}{2} & 1 & 56 & $0 \%$ & 19.81 \\
\hline & 2 & 52 & $4 \%$ & 13.74 \\
\hline & 3 & 46 & $10 \%$ & 13.36 \\
\hline & 4 & 42 & $14 \%$ & 4.57 \\
\hline \multirow{4}{*}{3} & 1 & 70 & $0 \%$ & 24.94 \\
\hline & 2 & 66 & $3 \%$ & 14.11 \\
\hline & 3 & 58 & $9 \%$ & 13.11 \\
\hline & 4 & 52 & $15 \%$ & 4.6 \\
\hline \multirow{4}{*}{4} & 1 & 70 & $0 \%$ & 18.16 \\
\hline & 2 & 66 & $3 \%$ & 13.87 \\
\hline & 3 & 60 & $8 \%$ & 13.57 \\
\hline & 4 & 50 & $17 \%$ & 4.62 \\
\hline \multirow{4}{*}{5} & 1 & 68 & $0 \%$ & 13.49 \\
\hline & 2 & 66 & $1 \%$ & 14.99 \\
\hline & 3 & 60 & $6 \%$ & 15.8 \\
\hline & 4 & 48 & $17 \%$ & 8.47 \\
\hline \multirow{4}{*}{6} & 1 & 76 & $0 \%$ & 14.58 \\
\hline & 2 & 74 & $1 \%$ & 14.72 \\
\hline & 3 & 70 & $4 \%$ & 26.89 \\
\hline & 4 & 58 & $13 \%$ & 8.78 \\
\hline
\end{tabular}


Table XVIII: Summary table of the average harmonic amplitudes at each test time point. The data points in bold were used for statistical analysis of a more hydrated state compared to a dehydrated state.

\begin{tabular}{|c|c|c|c|c|c|}
\hline Sample & Location & Set 1 Amplitude & \multicolumn{2}{|c|}{ Amplitude Set 3 Amplitude Set 4 Amplitude } \\
\hline 1 & 1 & 12.12 & $\mathbf{2 0 . 8}$ & 16.11 & $\mathbf{4 . 4 8}$ \\
\hline 1 & 2 & 14.35 & $\mathbf{1 8 . 7 7}$ & 16.41 & $\mathbf{4 . 4 8}$ \\
\hline 1 & 3 & 19.48 & $\mathbf{1 5 . 6 5}$ & 14.56 & $\mathbf{4 . 8 2}$ \\
\hline 2 & 1 & 19.06 & $\mathbf{1 3 . 8 5}$ & 13.75 & $\mathbf{4 . 3 5}$ \\
\hline 2 & 2 & 21.39 & $\mathbf{1 4 . 6 8}$ & 12.76 & $\mathbf{4 . 7 6}$ \\
\hline 2 & 3 & 18.99 & $\mathbf{1 2 . 7 1}$ & 13.56 & $\mathbf{4 . 6 1}$ \\
\hline 3 & 1 & 23.37 & $\mathbf{1 3}$ & 12.49 & $\mathbf{4 . 6}$ \\
\hline 3 & 2 & 28.76 & $\mathbf{1 4 . 1 1}$ & 13.07 & $\mathbf{4 . 9 9}$ \\
\hline 3 & 3 & 22.68 & $\mathbf{1 5 . 2 2}$ & 13.78 & $\mathbf{4 . 2}$ \\
\hline 4 & 1 & 25.81 & $\mathbf{1 3 . 9 2}$ & 14.73 & $\mathbf{4 . 5 3}$ \\
\hline 4 & 2 & 14.21 & $\mathbf{1 4 . 3 5}$ & 13.38 & $\mathbf{4 . 6 9}$ \\
\hline 4 & 3 & 14.46 & $\mathbf{1 3 . 3 4}$ & 12.58 & $\mathbf{4 . 6 4}$ \\
\hline 5 & 1 & 13.66 & $\mathbf{1 4 . 7 3}$ & 16.67 & $\mathbf{8 . 3 7}$ \\
\hline 5 & 2 & 14.19 & $\mathbf{1 4 . 9 9}$ & 15.24 & $\mathbf{8 . 2 8}$ \\
\hline 5 & 3 & 12.62 & $\mathbf{1 5 . 2 4}$ & 15.51 & $\mathbf{8 . 7 5}$ \\
\hline 6 & 1 & 17.83 & $\mathbf{1 4 . 6}$ & 16.54 & $\mathbf{9 . 0 6}$ \\
\hline 6 & 2 & 14.02 & $\mathbf{1 4 . 2 3}$ & 32.03 & $\mathbf{8 . 5}$ \\
\hline 6 & 3 & 11.89 & $\mathbf{1 5 . 3 4}$ & 32.1 & $\mathbf{8 . 7 8}$ \\
\hline
\end{tabular}

See Figure 55 for a plot showing the relationship between the average harmonics amplitude and percent dehydration at all sample locations for all set points. Note that this plot does not contain the initial $0 \%$ dehydration values because they were used to normalize the dehydration percentages for the other set points. Additionally, one outlier (>2 SD from mean, Set 6: 4\%, $26.89 \mathrm{~dB}$ ) value was excluded from the trend analysis. 


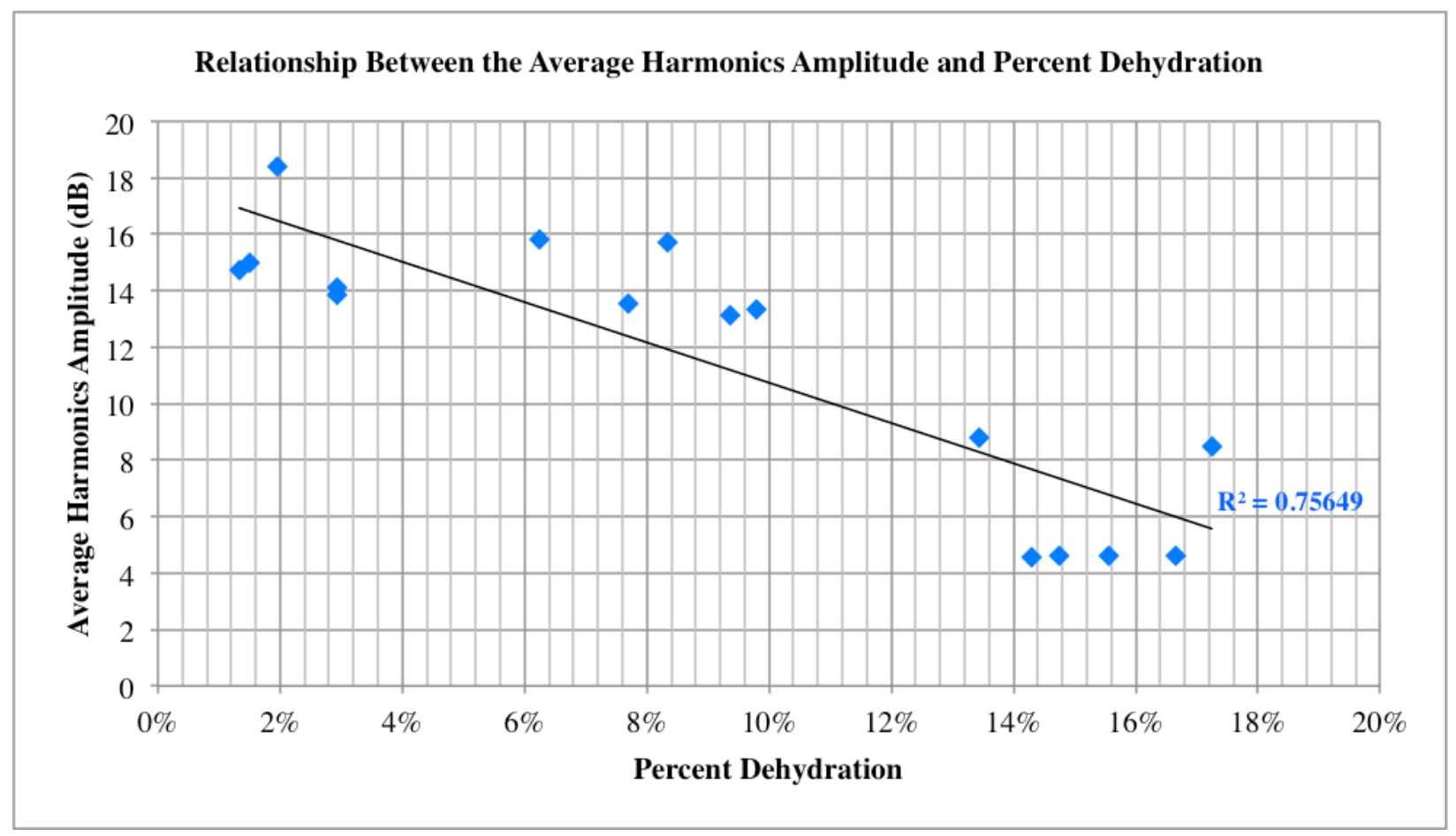

Figure 55: Relationship between the average harmonics amplitude and percent dehydration for all sample locations.

Statistical analysis in the form of a paired t-test between the average values from Set 2 and Set 4 ( $n=18)$ showed a statistically significant difference $(p<0.0001)$ between the harmonics amplitude at a more hydrated state compared to a dehydrated state. Overall, there is a linear trend between decreases in tissue water content and decreases in the average harmonics amplitude $\left(\mathrm{R}^{2}=0.756\right)$. The lack of a stronger $\mathrm{R}^{2}$ value can be explained by the experimental limitations and errors:

- The meat samples could not be more than 1" thick to fit in the Nesco dehydrator, a limitation that likely resulted in less tissue hydration at the start of the test. A higher starting hydration would allow for easier measurements of the small increments of hydration percentages. Additionally, a thicker sample is a more similar representation of a muscle that the device would monitor.

- The scale used to weigh the samples - and calculate subsequent dehydration percentages - could only measure \pm 2 grams. Considering that some weight changes were 2 or 4 grams, this is a significant experimental limitation and source of experimental error. 
- The Nesco dehydrator could not run continuously. To minimize the amount of time required for the test, all of the samples were measured after the same amount of time dehydrating. Thus, it was difficult to obtain a wider range of percent dehydration values.

Future use of thicker samples, a more precise scale, and a more advanced dehydrator can significantly reduce the experimental error in the test system and allow for further investigation of the signals at lower levels of dehydration (0\%-5\%). Overall, the trend between average harmonics amplitude and percent dehydration is a promising indication that the method used in the prototype can detect changes in the hydration status of muscle tissue. 


\section{CONCLUSION}

It was determined that the average harmonic amplitude of a received ultrasonic signal can be used to detect differences in muscle tissue hydration status. This outcome is particularly promising given that a $20 \mathrm{kHz}$ - the lowest limit of the ultrasonic range $-3.3 \mathrm{~V}$ square wave output through a readily available processor and inexpensive $18 \mathrm{kHz}$ piezo disc element was sufficient for detection. This setup has exciting future possibilities for implementation in a light wearable device with low power consumption.

\subsection{Limitations}

The limitations of the meat dehydration study were discussed as possible sources of experimental error. In addition to those limitations, it should be noted that the validation presented in this thesis is a first step toward the development of a continuous wearable hydration monitor. Future investigation into the optimum number of samples to average, how many measurements to acquire in a given time period, the time required for this method to detect a change in hydration status (how many samples to store in the memory for direct comparison), and the range of acceptable values to remain within a hydration status range will allow for real-time monitoring of hydration status. See the upcoming Future Functionality section for more discussion on how to test for and overcome these limitations.

\subsection{Future Functionality}

Refining the signal processing capabilities of the device will help increase the precision of the measurements. This refinement could mean adding additional filters during the signal acquisition process, adding signal amplification, or custom designing the piezo disc elements. Beyond adjustments to the code and transducers, the most immediate future step is to add wireless capabilities to the device. Prior to adding the Bluetooth module, it is important to develop a data storage system that uses the onboard memory by optimizing the number of samples taken, samples averaged, and the frequency of the signal acquisition process. Then, a method of selecting the appropriate data to leave, transfer, or overwrite must 
be designed. Finally, the frequency of data "push" to a device must be optimized to the power requirements of the BLE method.

Future integration of other metrics like heart rate, sweat rate, BMI, accelerometer data, skin temperature, and anthropometrics could improve the accuracy of the device. Theoretically, individual tests could be performed with concurrent data from one of the other metrics. Then, the effect - if any - of each metric on the processed signal can be isolated and used to adjust the signal prior to comparison with the established baseline. See Figure 56 for a basic diagram of this process.

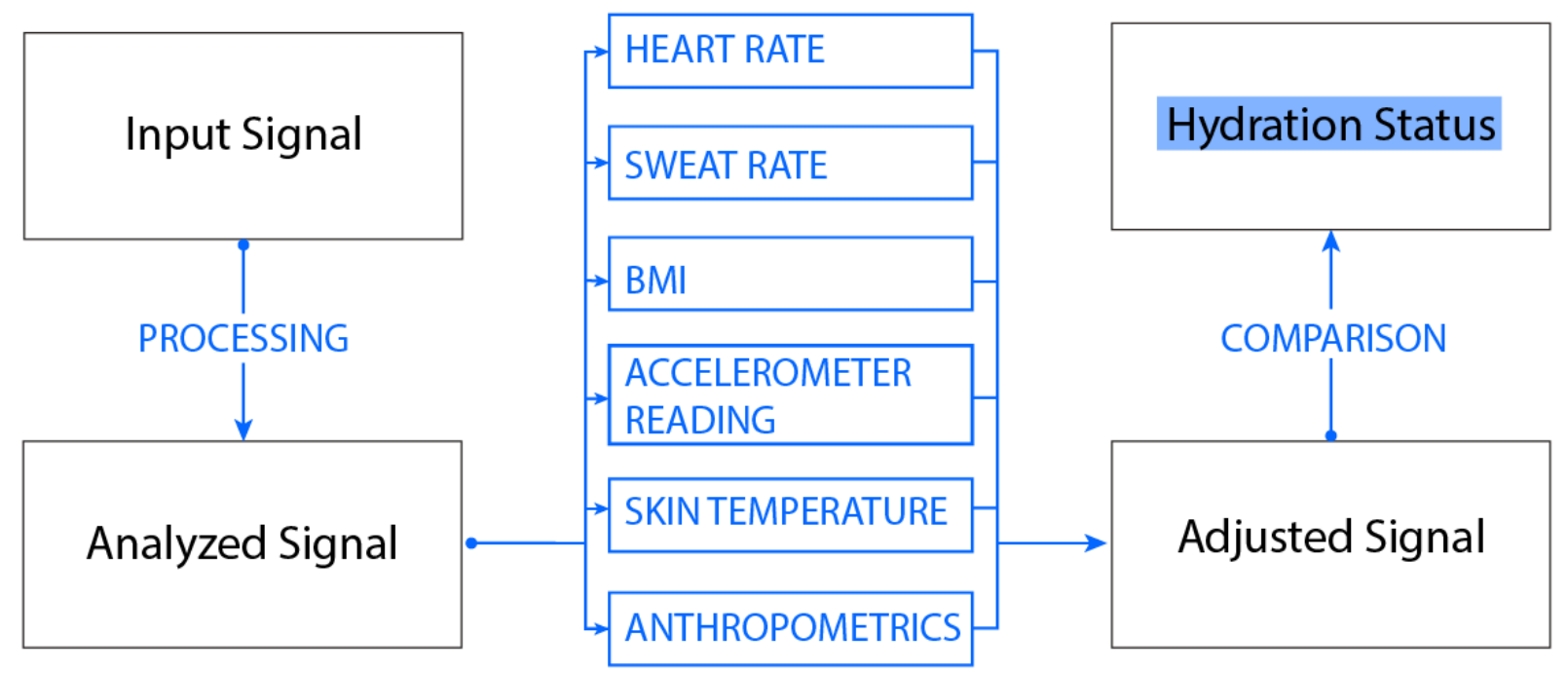

Figure 56: Flowchart for future adjustments with advanced metrics.

After determining the most important metrics to track in conjunction with the acquired signal, the appropriate inputs and/or sensors can be added to the device. For example, if anthropometrics or BMI has a significant effect on the signal, a user can add measurements during the calibration process. Likewise, if motion has a predictable effect on the acquired signal, an accelerometer can be added for signal adjustment. 


\subsection{Future Wrist Location}

Future investigation on the ability of the proposed method to detect changes in hydration status at a wrist location will allow for integration with other commonly available wearable devices. Changes in the harmonic amplitude of blood plasma or tendons could be detected by using a piezo transducer designed to probe at the specific depths of the desired tissue. See Figure 57 for a Solidworks model of a wrist concept device. Overall, this thesis showed promising indications for the future refinement of a wearable, continuous, and non-invasive ultrasonic method for monitoring body hydration level.
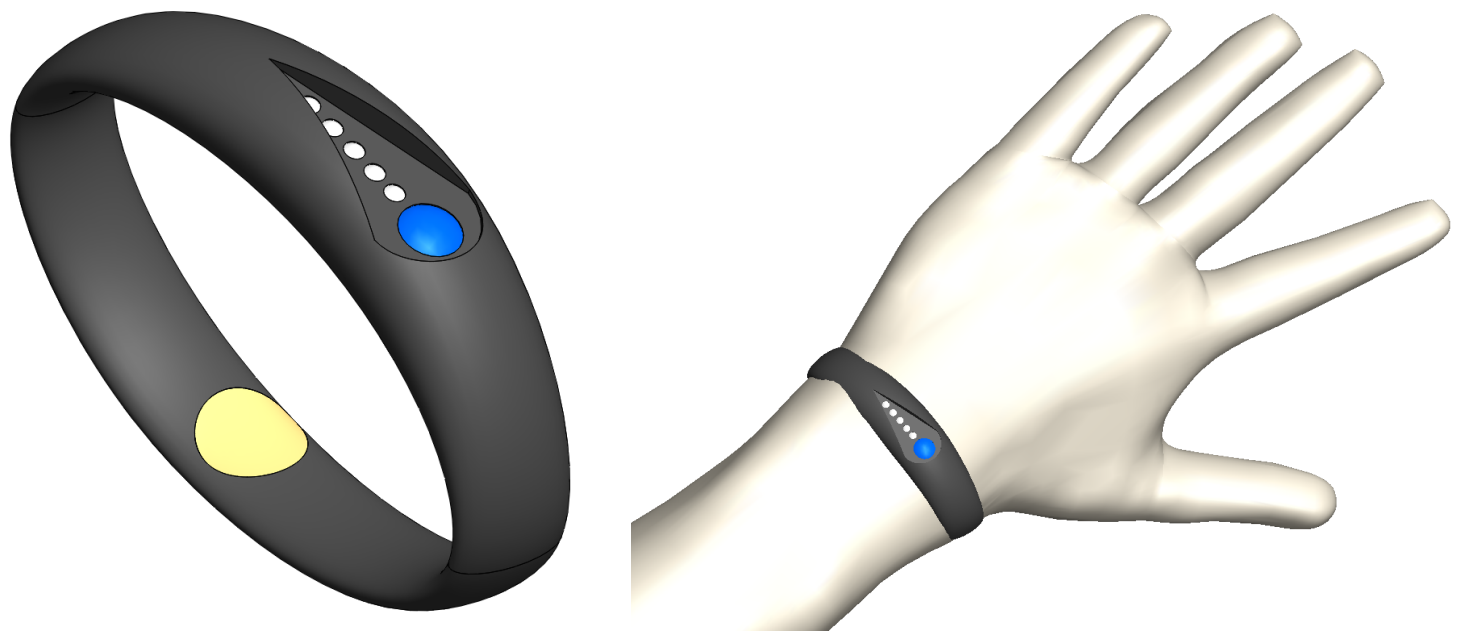

Figure 57: Images of a wrist concept model. 


\section{REFERENCES}

1. Kim S. Preventable Hospitalizations of Dehydration: Implications of inadequate primary health care in the United States. Ann Epidemiol. 2007;17(9):735-736.

doi:10.1016/j.annepidem.2007.07.043.

2. Gordon J a, An LC, Hayward R a, Williams BC. Initial emergency department diagnosis and return visits: risk versus perception. Ann Emerg Med. 1998;32(5):569-73. Available at: http://www.ncbi.nlm.nih.gov/pubmed/9795319.

3. Péronnet F, Mignault D, du Souich P, et al. Pharmacokinetic analysis of absorption, distribution and disappearance of ingested water labeled with $\mathrm{D}_{2} \mathrm{O}$ in humans. Eur J Appl Physiol. 2012;112(6):2213-22. doi:10.1007/s00421-011-2194-7.

4. Sarvazyan A, Tatarinov A, Sarvazyan N. Ultrasonic assessment of tissue hydration status. Ultrasonics. 2005;43(8):661-71. doi:10.1016/j.ultras.2005.03.005.

5. Alexy U, Cheng G, Libuda L, Hilbig A, Kersting M. 24 h-Sodium excretion and hydration status in children and adolescents. Clin Nutr. 2012;31(1):78-84. doi:10.1016/j.clnu.2011.08.014.

6. Vivanti A, Harvey K, Ash S. Developing a quick and practical screen to improve the identification of poor hydration in geriatric and rehabilitative care. Arch Gerontol Geriatr. 2010;50(2):156-64. doi:10.1016/j.archger.2009.03.003.

7. Gunter RL, Delinger WD, Porter TL, Stewart R, Reed J. Hydration level monitoring using embedded piezoresistive microcantilever sensors. Med Eng Phys. 2005;27(3):215-20. doi:10.1016/j.medengphy.2004.10.005.

8. Di Somma S, Navarin S, Giordano S, et al. The emerging role of biomarkers and bio-impedance in evaluating hydration status in patients with acute heart failure. Clin Chem Lab Med. 2012;50(12):2093-105. doi:10.1515/cclm-2012-0289.

9. Topchyan A, Tatarinov A, Sarvazyan N, Sarvazyan A. Ultrasound velocity in human muscle in vivo: perspective for edema studies. Ultrasonics. 2006;44(3):259-64. doi:10.1016/j.ultras.2006.02.003.

10. Utter AC, McAnulty SR, Sarvazyan A, Query MC, Landram MJ. Evaluation of ultrasound velocity to assess the hydration status of wrestlers. J Strength Cond Res. 2010;24(6):1451-1457.

11. Cheng H, Zhang Y, Huang X, Rogers J a., Huang Y. Analysis of a concentric coplanar capacitor for epidermal hydration sensing. Sensors Actuators A Phys. 2013;203:149-153. doi:10.1016/j.sna.2013.08.037.

12. Kestenbaum B. Nutrition and Hydration Status in Predialysis and Dialysis Patients by Multifrequency Bioimpedance Spectroscopy. Am J Kidney Dis. 2012;59(4):B91. doi:10.1053/j.ajkd.2012.02.311. 
13. Stewart R, Reed J, Zhong J, Morton K, Porter TL. Human hydration level monitoring using embedded piezoresistive microcantilever sensors. Med Eng Phys. 2007;29(10):1084-8. doi:10.1016/j.medengphy.2006.11.003.

14. Norman K, Stobäus N, Pirlich M, Bosy-Westphal A. Bioelectrical phase angle and impedance vector analysis--clinical relevance and applicability of impedance parameters. Clin Nutr. 2012;31(6):854-61. doi:10.1016/j.clnu.2012.05.008.

15. Hooper L, Bunn D, Jimoh FO, Fairweather-Tait SJ. Water-loss dehydration and aging. Mech Ageing Dev. 2013. doi:10.1016/j.mad.2013.11.009.

16. Zhu F, Liu L, Kotanko P, Levin NW. Estimation of Body Hydration in Dialysis Patients Using a Calf Bioimpedance Method. In: 2010 International Conference on Biomedical Engineering and Computer Science. Wuhan, China; 2010:2-5. Available at: http://ieeexplore.ieee.org/xpls/abs_all.jsp?arnumber=5462490. Accessed March 9, 2014.

17. Davies S, AC F, TG C. The use of cardiac ultrasonography by emergency physicians to assess hydration status in healthy volunteers. Ann Emerg Med. 2004;44(4):3-4.

18. Vivanti A, Harvey K, Ash S, Battistutta D. Clinical assessment of dehydration in older people admitted to hospital: what are the strongest indicators? Arch Gerontol Geriatr. 2008;47(3):340-55. doi:10.1016/j.archger.2007.08.016.

19. Snyder A. Pedometer use increases daily steps and functional status in older adults. J Am Med Dir Assoc. 2011;12(8):590-594.

20. Thomas L. Promoting physical activity in the workplace: using pedometers to increase daily activity levels. Heal Promot J Aust. 2006;17(2):97-102.

21. Kavouras S a, Arnaoutis G, Makrillos M, et al. Educational intervention on water intake improves hydration status and enhances exercise performance in athletic youth. Scand J Med Sci Sports. 2012;22(5):684-9. doi:10.1111/j.1600-0838.2011.01296.x.

22. Cheuvront SN, Kenefick RW, Charkoudian N, Sawka MN. Perspective Physiologic basis for understanding quantitative dehydration. Am J Clin Nutr. 2013;97:455-62. doi:10.3945/ajen.112.044172.Am.

23. Marieb EN, Hoehn K. Anatomy and Physiology. 4th ed. San Francisco, CA: Benjamin Cummings; 2011.

24. Koeppen BM, Stanton BA, eds. Berne and Levy Physiology. 6th ed. Philadelphia, PA: Mosby Elsevier; 2010.

25. Ely BR, Cheuvront SN, Kenefick RW, et al. Assessment of extracellular dehydration using saliva osmolality. Eur J Appl Physiol. 2014;114(1):85-92. doi:10.1007/s00421-013-2747-z.

26. Mingrone G, Bertuzzi A, Greco AV, et al. Unrealiable use of standard muscle hydration value in obesity. Am J Physiol Endocrinal Metab. 2001;(280):365-371. 
27. Pryor RR, Casa DJ, Holschen JC, O'Connor FG, Vandermark LW. Exertional Heat Stroke: Strategies for Prevention and Treatment From the Sports Field to the Emergency Department. Clin Pediatr Emerg Med.2013;14(4):267-278. doi:10.1016/j.cpem.2013.10.005.

28. Casa DJ, Armstrong LE, Hillman SK, et al. National athletic trainers' association position statement: fluid replacement for athletes. J Athl Train. 2000;35(2):212-24. Available at: http://www.pubmedcentral.nih.gov/articlerender.fcgi?artid=1323420\&tool=pmcentrez\&rendertype $=$ abstract.

29. Maughan RJ, Shirreffs SM. Development of hydration strategies to optimize performance for athletes in high-intensity sports and in sports with repeated intense efforts. Scand J Med Sci Sports. 2010;20 Suppl 2:59-69. doi:10.1111/j.1600-0838.2010.01191.x.

30. The Food and Nutrition Board. Dietary Reference Intakes : Electrolytes and Water.; 2004. Available at: http://fnic.nal.usda.gov/dietary-guidance/dietary-reference-intakes/dri-tables.

31. Casa DJ. Proper Hydration for Distance Running- Identifying Individual Fluid Needs. USA Track F Advis. 2002:1-12.

32. Prentice C, Stannard SR, Barnes MJ. The effects of binge drinking behaviour on recovery and performance after a rugby match. J Sci Med Sport. 2013:4-8. doi:10.1016/j.jsams.2013.04.011.

33. Chia M, Mukherjee S. Hydration status of heat-acclimatized youth team players during competition. Sci Sports. 2012;27(5):e51-e54. doi:10.1016/j.scispo.2011.10.009.

34. Kutlu M, Guler G. Assessment of hydration status by urinary analysis of elite junior taekwon-do athletes in preparing for competition. J Sports Sci. 2006;24(8):869-73. doi:10.1080/02640410500249357.

35. Yard EE, Gilchrist J, Haileyesus T, et al. Heat illness among high school athletes--United States, 2005-2009. J Safety Res. 2010;41(6):471-4. doi:10.1016/j.jsr.2010.09.001.

36. Kerr ZY, Casa DJ, Marshall SW, Comstock RD. Epidemiology of exertional heat illness among U.S. high school athletes. Am J Prev Med.2013;44(1):8-14. doi:10.1016/j.amepre.2012.09.058.

37. Aughey RJ, Goodman C a, McKenna MJ. Greater chance of high core temperatures with modified pacing strategy during team sport in the heat. J Sci Med Sport. 2014;17(1):113-8. doi:10.1016/j.jsams.2013.02.013.

38. Kingsley M, Penas-Ruiz C, Terry C, Russell M. Effects of carbohydrate-hydration strategies on glucose metabolism, sprint performance and hydration during a soccer match simulation in recreational players. J Sci Med Sport. 2013:2-6. doi:10.1016/j.jsams.2013.04.010.

39. Weber AF, Mihalik JP, Register-Mihalik JK, Mays S, Prentice WE, Guskiewicz KM. Dehydration and performance on clinical concussion measures in collegiate wrestlers. $J$ Athl Train. 2013;48(2):153-60. doi:10.4085/1062-6050-48.1.07.

40. Horswill C a., Janas LM. Hydration and Health. Am J Lifestyle Med. 2011;5(4):304-315. doi:10.1177/1559827610392707. 
41. Carter R, Cheuvront SN, Wray DW, Kolka M a., Stephenson L a., Sawka MN. The influence of hydration status on heart rate variability after exercise heat stress. J Therm Biol. 2005;30(7):495502. doi:10.1016/j.jtherbio.2005.05.006.

42. Sanchez LD, Corwell B, Berkoff D. Medical problems of marathon runners. Am J Emerg Med. 2006;24(5):608-15. doi:10.1016/j.ajem.2006.01.023.

43. Rösler a, Lehmann F, Krause T, Wirth R, von Renteln-Kruse W. Nutritional and hydration status in elderly subjects: clinical rating versus bioimpedance analysis. Arch Gerontol Geriatr. 2010;50(3):e81-5. doi:10.1016/j.archger.2009.06.007.

44. Suhr J a, Hall J, Patterson SM, Niinistö RT. The relation of hydration status to cognitive performance in healthy older adults. Int J Psychophysiol. 2004;53(2):121-5. doi:10.1016/j.ijpsycho.2004.03.003.

45. Godfrey H, Cloete J, Dymond E, Long A. An exploration of the hydration care of older people: a qualitative study. Int J Nurs Stud. 2012;49(10):1200-11. doi:10.1016/j.ijnurstu.2012.04.009.

46. Warren JL, Bacon WE, Haris T, Mcbean AM, Foley DJ, Phillips C. The burden and outcomes associated with dehydration among US elderly, 1991. Am J Public Health. 1991;84(8):1265-1269.

47. Park J, Je Y, Lee H, Moon W. Design of an ultrasonic sensor for measuring distance and detecting obstacles. Ultrasonics. 2010;50(3):340-6. doi:10.1016/j.ultras.2009.10.013.

48. Fadda R, Rapinett G, Grathwohl D, et al. Effects of drinking supplementary water at school on cognitive performance in children. Appetite. 2012;59(3):730-7. doi:10.1016/j.appet.2012.07.005.

49. Shanholtzer B a, Patterson SM. Use of bioelectrical impedance in hydration status assessment: reliability of a new tool in psychophysiology research. Int J Psychophysiol. 2003;49(3):217-226. doi:10.1016/S0167-8760(03)00143-0.

50. Lukaski HC, Hall CB, Siders W a. Assessment of change in hydration in women during pregnancy and postpartum with bioelectrical impedance vectors. Nutrition. 2007;23(7-8):543-50. doi:10.1016/j.nut.2007.05.001.

51. Cian C, Barraud P a, Melin B, Raphel C. Effects of fluid ingestion on cognitive function after heat stress or exercise-induced dehydration. Int J Psychophysiol. 2001;42(3):243-51. Available at: http://www.ncbi.nlm.nih.gov/pubmed/11812391.

52. Barr D, Gregson W, Reilly T. The thermal ergonomics of firefighting reviewed. Appl Ergon. 2010;41(1):161-72. doi:10.1016/j.apergo.2009.07.001.

53. Raines J, Snow R, Petersen A, Harvey J, Nichols D, Aisbett B. Pre-shift fluid intake: effect on physiology, work and drinking during emergency wildfire fighting. Appl Ergon. 2012;43(3):53240. doi:10.1016/j.apergo.2011.08.007.

54. Zorbas YG, Kakurin VJ, Kuznetsov N a, Yarullin VL. Fluid and salt supplementation effect on body hydration and electrolyte homeostasis during bed rest and ambulation. Acta Astronaut. 2002;50(12):765-74. Available at: http://www.ncbi.nlm.nih.gov/pubmed/12053941. 
55. Begum MN, Johnson CS. A review of the literature on dehydration in the institutionalized elderly. E Spen Eur E J Clin Nutr Metab. 2010;5(1):e47-e53. doi:10.1016/j.eclnm.2009.10.007.

56. Armstrong LE. Performing in Extreme Environments. Champaign, IL: Human Kinetics; 2000.

57. Reid SR, Bonadio W a. Outpatient rapid intravenous rehydration to correct dehydration and resolve vomiting in children with acute gastroenteritis. Ann Emerg Med. 1996;28(3):318-23. Available at: http://www.ncbi.nlm.nih.gov/pubmed/8780476.

58. Walsh NP, Montague JC, Callow N, Rowlands A V. Saliva flow rate, total protein concentration and osmolality as potential markers of whole body hydration status during progressive acute dehydration in humans. Arch Oral Biol. 2004;49(2):149-154. doi:10.1016/j.archoralbio.2003.08.001.

59. Yamada H, Louie K, Glimcher PW. Controlled water intake: a method for objectively evaluating thirst and hydration state in monkeys by the measurement of blood osmolality. J Neurosci Methods. 2010;191(1):83-9. doi:10.1016/j.jneumeth.2010.06.011.

60. Takaki T, Ishida N, Oe a., et al. Evaluation of hydration status based on urine specific gravity and urine osmolality in male collegiate players following soccer training. J Sci Med Sport. 2013;16:e78. doi:10.1016/j.jsams.2013.10.187.

61. Schmidt MC, Moore RS, Bryslan NL. The Effect of Education on Hydration Status of Female Collegiate Gymnasts at Southern Utah University. J Acad Nutr Diet. 2013;113(9):A86. doi:10.1016/j.jand.2013.06.303.

62. Simpson $\mathbf{J}$ a, Lobo DN, Anderson $\mathrm{J}$ a, et al. Body water compartment measurements: a comparison of bioelectrical impedance analysis with tritium and sodium bromide dilution techniques. Clin Nutr. 2001;20(4):339-43. doi:10.1054/clnu.2001.0398.

63. Liu L, Zhu F, G Raimann J, et al. Determination of fluid status in haemodialysis patients with whole body and calf bioimpedance techniques. Nephrology (Carlton). 2012;17(2):131-40. doi:10.1111/j.1440-1797.2011.01526.x.

64. Tsai Y-C, Tsai J-C, Chen S-C, et al. Association of Fluid Overload With Kidney Disease Progression in Advanced CKD: A Prospective Cohort Study. Am J Kidney Dis. 2014;63(1):68-75. doi:10.1053/j.ajkd.2013.06.011.

65. Asselin MC, Kriemler S, Chettle DR, Webber CE, Bar-Or O, Mcneill FE. Hydration status assessed by multi-frequency bioimpedance analysis. Appl Radiat Isot . 1998;49(5-6):495-7. Available at: http://www.ncbi.nlm.nih.gov/pubmed/21959720.

66. Brancaccio P, Limongelli FM, Paolillo I, D’Aponte A, Donnarumma V, Rastrelli L. Supplementation of Acqua Lete ${ }^{\circledR}$ (Bicarbonate Calcic Mineral Water) improves hydration status in athletes after short term anaerobic exercise. J Int Soc Sports Nutr. 2012;9(1):35. doi:10.1186/1550-2783-9-35. 
67. Ritz P, Vol S, Berrut G, Tack I, Arnaud MJ, Tichet J. Influence of gender and body composition on hydration and body water spaces. Clin Nutr. 2008;27(5):740-6.

doi:10.1016/j.clnu.2008.07.010.

68. Cox-Reijven PL, Soeters PB. Validation of bio-impedance spectroscopy: effects of degree of obesity and ways of calculating volumes from measured resistance values. Int J Obes Relat Metab Disord. 2000;24(3):271-80. Available at: http://www.ncbi.nlm.nih.gov/pubmed/10757619.

69. Bodystat Limited. Bodystat 1500 Series. 2014. Available at:

http://www.bodystat.com/1500/Product1/list.aspx.

70. ImpediMed. ImpediMed XiTRON Hydra 4200. 2008. Available at:

http://www.impedimed.com/products/xitron-hydra-4200/.

71. Fresenius Medical Care. Fresenius Medical Care BCM Body Composition Monitor. Available at: http://www.bcm-fresenius.com/9.htm. Accessed May 26, 2014.

72. Omron Healthcare Co Ltd. Model BF306 Instruction Manual. Device Instr Man. 2011:1-8.

73. MC10 INC. MC10 INC. 2013:10. Available at: http://www.mc10inc.com/consumerproducts/sports/hydration-sensor/.

74. Clothtech. Breaking free. Futur Mater by WTIN. 2012;(October):18-19. Available at: http://www.mc10inc.com/wp-content/uploads/2012/12/Future-Materials-October-2012-MC10Article.pdf.

75. Springer S. Sports wearables are the wave of the future. The Boston Globe. http://www.bostonglobe.com/sports/2014/05/24/sports-wearables-are-wavefuture/4gwNDNBYxPCEkD4h9yYf8K/story.html. Published May 25, 2014.

76. Dickson A, Carbeck J, Kacyvenski I, Schlatka B. Electronics for detection of a condition of tissue. 2013. Available at: https://www.google.com/patents/WO2013033724A1?cl=en.

77. Sarvazyan A. Ultrasonic water content monitor and methods for monitoring tissue hydration. 2006:1-8.

78. Sarvazyan A. Infant hydration monitor. 2007:1-8.

79. ClinicalTrials.gov (NCT01482208). Clinical Evaluation of Ultrasonic Hydration Monitor for Infants ( IHM-01 ). ClinicalTrials.gov. 2014. Available at:

http://clinicaltrials.gov/show/NCT01482208.

80. Artann Laboratories. Artann Laboratories Recent News: NIH Funding. 2013. Available at: http://www.artannlabs.com/news.html. Accessed May 30, 2014.

81. United States Food and Drug Administration. Medical Devices: Is this product a medical device? 2014. Available at: http://www.fda.gov/medicaldevices/deviceregulationandguidance/overview/classifyyourdevice/uc m051512.htm. Accessed May 30, 2014. 
82. United States Food and Drug Administration. Product Classification - Medical Device Data System. 2014. Available at:

http://www .accessdata.fda.gov/scripts/cdrh/cfdocs/cfpcd/classification.cfm?ID=2502. Accessed May 30, 2014.

83. United States Food and Drug Administration. Mobile Medical Applications. 2014. Available at: http://www.fda.gov/medicaldevices/productsandmedicalprocedures/connectedhealth/mobilemedic alapplications/default.htm. Accessed May 30, 2014.

84. Krouse A. iPads, iPhones, Androids, and Smartphones: FDA Regulation of Mobile Phone Applications as Medical Devices. Indiana Health Law Rev. 2012;9(2):731-764.

85. Noninvasive Medical Technologies. Premarket Notification - ZOE Fluid Status Monitor. 2012. Available at:

http://www.fda.gov/medicaldevices/deviceregulationandguidance/howtomarketyourdevice/premar ketsubmissions/premarketapprovalpma/ucm046719.htm. Accessed May 30, 2014.

86. Samsung Electronics Co. Samsung 510 (k) Summary Submission - Healthcare Data Management Mobile Application. 2013;510. Available at:

http://www.accessdata.fda.gov/cdrh_docs/pdf13/k132148.pdf. Accessed May 30, 2014.

87. United States Food and Drug Administration. CFR - Code of Federal Regulations Title 21. 2014. Available at: http://www.accessdata.fda.gov/scripts/cdrh/cfdocs/cfcfr/cfrsearch.cfm. Accessed May 30, 2014.

88. ASTM. ASTM Electronics Standards. 2014. Available at: http://www.astm.org/Standards/electronics-standards.html. Accessed May 30, 2014.

89. ISO. ISO Standards Catalogue for Electronics. 2014. Available at: http://www.iso.org/iso/iso_catalogue/catalogue_ics/catalogue_ics_browse.htm?ICS1=31. Accessed May 30, 2014.

90. NCRP. National Council Radiation Protection Report \#113: Exposure criteria for medical diagnostic ultrasound: I. Criteria based on thermal mechanisms. Bethesda, MD; 1992.

91. Federal Communications Commission. FCC - Rules \& Regulations for Title 47. 2014. Available at: http://www.fcc.gov/encyclopedia/rules-regulations-title-47. Accessed May 30, 2014.

92. Szabo T. Diagnostic Ultrasound Imaging: Inside Out. 2nd ed. San Francisco, CA: Elsevier; 2014. Available at: http://books.google.com/books?hl=en\&lr=\&id=-

Fd1Pkeh2T0C\&oi=fnd\&pg=PP2\&dq=Diagnostic+Ultrasound+Imaging:+Inside+Out\&ots=VNdY yX4FRS\&sig=ltsOFIBClWQ45iGTVH8nI246nkU. Accessed February 25, 2014.

93. Chan V, Perlas A. Basics of Ultrasound Imaging. In: Narouze SN, ed. Atlas of Ultrasound-Guided Procedures in Interventional Pain Management. New York, NY: Springer New York; 2011:1320. doi:10.1007/978-1-4419-1681-5.

94. Safari A, Akdoğan EK, eds. Piezoelectric and Acoustic Materials for Transducer Applications. New York, NY: Springer US; 2008. doi:10.1007/978-0-387-76540-2. 
95. Piezo Film Sensors Technical Manual. Norristown, PA; 1999.

96. Sarabia EG, Llata JR, Robla S, Torre-Ferrero C, Oria JP. Accurate estimation of airborne ultrasonic time-of-flight for overlapping echoes. Sensors (Basel). 2013;13(11):15465-88. doi: $10.3390 / \mathrm{s} 131115465$.

97. Hedrick WR, Hykes, David L, Starchman DE. Ultrasound Physics and Instrumentation. 4th ed. St. Louis, MO: Elsevier Mosby; 2005:445.

98. Ensminger D, Bond L. Ultrasonics: Fundamentals, Technologies, and Applications. 3rd ed. New York, NY: CRC Press; 2012. Available at:

http://books.google.com/books?hl=en\&lr=\&id=xH4rAPh2uIwC\&oi=fnd\&pg=PP1\&dq=Ultrasoni cs:+Fundamentals,+Technologies,+and+Applications\&ots=SCs18Ado2P\&sig=_KpWU1ZZ_eIoSs hyEPE9RPiw0CA. Accessed February 25, 2014.

99. Sanches JM, Faine AF, Suri JS, eds. Ultrasound Imaging: Advances and Applications. New York, NY: Springer US; 2012.

100. Malizos K, Protopappas V, Fotiadis D. Guided ultrasound wave propagation in intact and healing long bones. Ultrasound Med Biol. 2006;32(5):693-708.

101. Burckhardt C. Speckle in ultrasound B-mode scans. IEEE Trans Son Ultrason SU. 1978;25(1):16.

102. Olympus NDT. Panametrics-NDT Ultrasonic Transducers Technical Notes. Olympus NDT Tech Guid. 2006:39-49. Available at: https://www .olympus-ims.com/data/File/panametrics/UTtechnotes.en.pdf. Accessed April 20, 2014.

103. Chegg. Definition of Phase Shift. Chegg Electr Eng Concepts. 2014. Available at: http://www .chegg.com/homework-help/definitions/phase-shift-4. Accessed May 30, 2014.

104. National Security and Veterans Affairs. US Census Table 509 . Military Personnel on Active Duty by Location : 1980 to 2010.; 2012. Available at:

http://www.census.gov/compendia/statab/2012/tables/12s0508.pdf.

105. US Census Bureau. US Census Table 1247 . Participation in NCAA Sports by Sex : 2009 to 2010.; 2012:2012.

106. NFHS. High School Sports Participation Increases for 24th Consecutive Year.; 2014:2-3.

107. NCAA Research Committee. Estimated Probability of Competing in Athletics Beyond the High School Interscholastic Level Beyond the High School Interscholastic Level.; 2013:8-10.

108. Schappert SM, Bhuiya F. Availability of pediatric services and equipment in emergency departments: United States, 2006.; 2012:1-21. Available at: http://www.ncbi.nlm.nih.gov/pubmed/22690535.

109. Administration on Aging. Aging Statistics. Dep Heal Hum Serv. 2014. Available at: http://www.aoa.gov/Aging_Statistics/. Accessed May 30, 2014. 
110. USFA. National Fire Department Census Quick Facts. Natl Fire Dep Census. 2014. Available at: http://apps.usfa.fema.gov/census/summary.cfm. Accessed May 30, 2014.

111. IHS Electronics and Media. Wearable Technology - Market Assessment. Englewood, CO; 2013.

112. Amazon. Cell Phones \& Accessories: Armbands. 2014. Available at: http://www.amazon.com/s/ref=nb_sb_noss?url=node=7073962011\&fieldkeywords $=\& \mathrm{rh}=\mathrm{n}: 2335752011, \mathrm{n}: 2407755011, \mathrm{n}: 2407760011, \mathrm{n}: 7073962011$. Accessed May 25, 2014.

113. Best Buy. Find the Best: Research Smartphones. Find Best Res Smartphones Online. 2014. Available at: http://smartphones.findthebest.com/. Accessed May 30, 2014.

114. Lee J-B, Kim T-W, Min Y-K, Yang H-M. Long distance runners present upregulated sweating responses than sedentary counterparts. PLoS One. 2014;9(4):e93976. doi:10.1371/journal.pone.0093976.

115. Gray H. Gray's Anatomy of the Human Body. 20th ed. (Lewis WH, ed.). New York, NY: Bartleby.com; 2000. Available at: http://www.bartleby.com/107/indexillus.html.

116. Newark Electronics. Multicomp MCFT-9T-18A1-115 piezo element. Newark Elem 14 Prod Cat. 2014. Available at: http://www.newark.com/multicomp/mcft-9t-18a1-115/piezoelement/dp/25R0595. Accessed May 30, 2014.

117. McMaster-Carr. McMaster-Carr: Rubber Coating. McMaster-Carr Online Cat. 2014;5911(562). Available at: http://www.mcmaster.com/\#9560t7/=s940a2. Accessed May 30, 2014.

118. PJRC. Teensy USB Development Board. PJRC Online Store. 2014. Available at: https://www.pjrc.com/store/teensy31.html. Accessed May 30, 2014.

119. SparkFun Electronics. SparkFun LED Tactile Button - Blue. SparkFun Prod Cat. 2014;(16). Available at: https://www.sparkfun.com/products/10443. Accessed May 30, 2014.

120. SparkFun Electronics. SparkFun LED - Assorted (20 pack). SparkFun Prod Cat. 2014;(5). Available at: https://www.sparkfun.com/products/12062. Accessed May 30, 2014.

121. SparkFun Electronics. SparkFun Vibration Motor. SparkFun Prod Cat. 2014;(26). Available at: https://www.sparkfun.com/products/8449. Accessed May 30, 2014.

122. SparkFun Electronics. SparkFun: Polymer Lithium Ion Battery - 400mAh. SparkFun Prod Cat. 2014. Available at: https://www.sparkfun.com/products/10718. Accessed May 30, 2014.

123. Digi-Key Corporation. Digi-Key: Bluetooth 4.0 BLE113-A-V1 BlueGiga Technologies Inc. DigiKey Corp Online Cat. 2014. Available at: http://www.digikey.com/product-detail/en/BLE113-AV1/1446-1028-1-ND/4245526. Accessed May 30, 2014.

124. McMaster-Carr. McMaster-Carr: Easy to Machine ABS Sheets. McMaster-Carr Online Cat. 2014;5911(562). Available at: http://www.mcmaster.com/\#8586k451/=s94dz2. Accessed May 30, 2014. 
125. McMaster-Carr. McMaster-Carr: Elastic Hook \& Loop Cinching Strap. McMaster-Carr Online Cat. 2014;5911(562). Available at: http://www.mcmaster.com/\#3029t148/=s94eyl. Accessed May $30,2014$.

126. United States Department of Labor. OSHA Construction eTool : Electrical Incidents - How Electrical Current Affects the Human Body. Occup Saf Heal Adm Electr Incidents. 2014. Available at:

https://www.osha.gov/SLTC/etools/construction/electrical_incidents/eleccurrent.html. Accessed May 30, 2014.

127. National Physical Laboratory. The speed and attenuation of sound. Tables Phys Chem Constants. 2014;268(281). Available at: http://www.kayelaby.npl.co.uk/general_physics/2_4/2_4_1.html. Accessed June 4, 2014. 


\section{APPENDICES}

\section{Appendix A: Survey Responses}

Athletes and coaches were surveyed via email for currently owned devices, knowledge of dehydration, desired design considerations, and interest in a hydration monitor. Athletes were asked the following questions:

1. Are you aware of the importance of proper hydration? What do you know about proper hydration?

2. How do you assess how much water you need to drink throughout the day and while training?

3. Would you use a wearable, continuous, and non-invasive hydration monitor while exercising?

4. Would you use the hydration monitor during the day (while not exercising)?

5. If you would use the hydration monitor, what are the biggest design requirements you have for such a device?

6. What sports / fitness activities are you regularly involved in?

7. What fitness monitoring devices do you currently use (heart rate monitors, apps, GPS watches, etc.)?

8. Any comments regarding the functionality of the device (what would you want it to do?), hydration testing, or general comments would be greatly appreciated!

Coaches were asked the following questions:

1. What sport / fitness activity do you coach?

2. Do you use health status monitoring of any sort (weight, BMI, heart rate, fitness tests, etc.) for your team?

3. Would you want your athletes to wear health status monitors during exercise, training, or competition?

4. Do you think proper hydration is an important part of a training regimen?

5. Would you want your athletes to use a wearable, continuous, and non-invasive hydration monitor during exercise, training, or competition?

Out of respect of maintaining anonymity for the survey responders, individual survey answers are not included in this thesis. See Table A1 for a summary of the responses.

Table XIX: Summary table of survey responses.

\begin{tabular}{|l|l|l|}
\hline \multirow{4}{*}{ Athletes } & \# Responses & 10 \\
\cline { 2 - 3 } & Sports / Activities & $\begin{array}{l}\text { Swimming, Triathlons (x3), CrossFit (x2), Ultimate Frisbee (x2), } \\
\text { Volleyball, Football }\end{array}$ \\
\cline { 2 - 3 } & Levels Represented & NCAA D1, Adult Fitness, Professional Leagues \\
\hline \multirow{3}{*}{ Coaches } & \# Responses & 9 \\
\cline { 2 - 3 } & Sports / Activities & $\begin{array}{l}\text { Track, Cross Country, Men's Soccer, Women's Soccer (x2), } \\
\text { Wrestling, Beachbody, Ultimate Frisbee, CrossFit }\end{array}$ \\
\cline { 2 - 3 } & Levels Represented & High School, NCAA D1, Adult Fitness, Professional Leagues \\
\hline
\end{tabular}




\section{Appendix B: Kickstarter Review Table}

Table XX: Goal amounts and total amounts raised for hydration-related products on Kickstarter.

\begin{tabular}{|l|l|l|l|}
\hline Product* & \multicolumn{1}{|c|}{ Tech } & Goal (\$)* & Raised (\$)* \\
\hline Dash & Tracking & 260,000 & $3,390,551$ \\
\hline EMOTIV & EEG & 100,000 & $1,643,117$ \\
\hline Omate & Watch & 100,000 & $1,032,352$ \\
\hline AGENT & Watch & 100,000 & $1,012,742$ \\
\hline Bia & Tracking & 400,000 & 408,160 \\
\hline ALPHA & HR & 100,000 & 321,314 \\
\hline Melon & EEG & 100,000 & 290,941 \\
\hline Nava & Water Bottle & 50,000 & 261,677 \\
\hline LUMO & Back Posture & 100,000 & 200,504 \\
\hline Flyfit & Tracking & 90,000 & 123,817 \\
\hline PROMiXX & Water Bottle & 30,000 & 58,898 \\
\hline ILUMI & Water Bottle & 10,000 & 35,608 \\
\hline
\end{tabular}

* Information gathered via searching on kickstarter.com. 
Appendix C: Manufacturer Supplied Component Datasheets, Diagrams, and Drawings

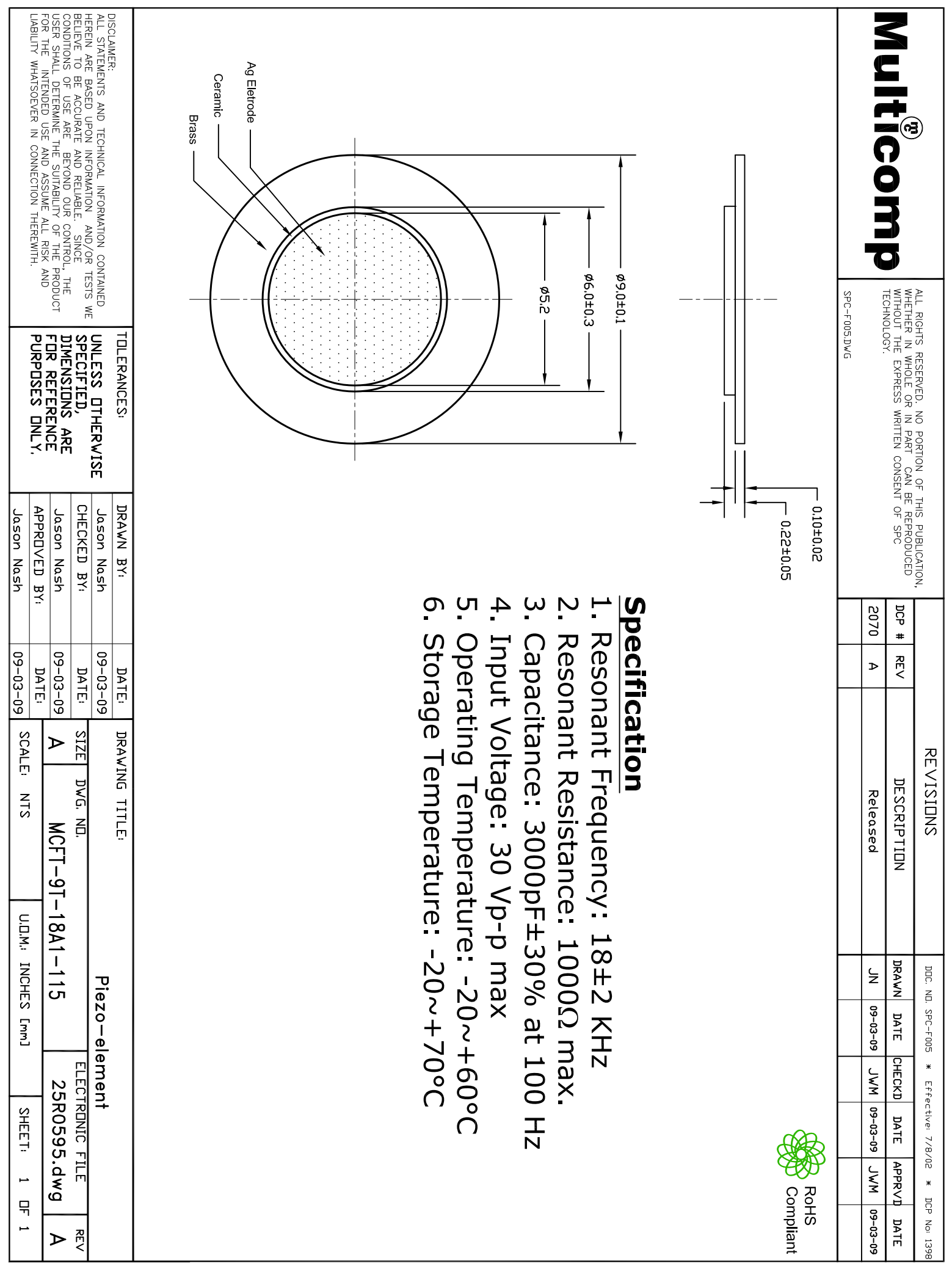

Figure 58: $18 \mathrm{kHz}$ piezoceramic disc element drawing ${ }^{116}$. 


\section{Teensy 3.1}

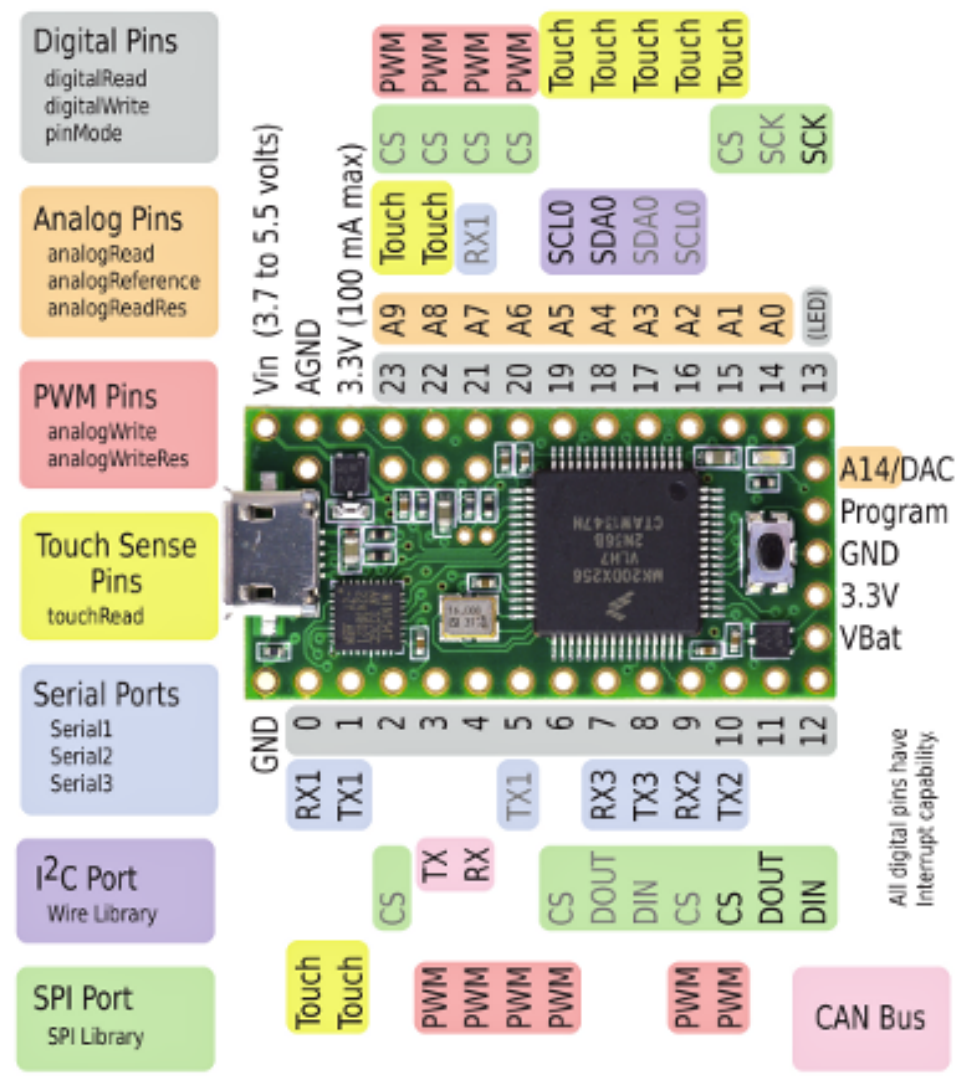

Teensy 3.1

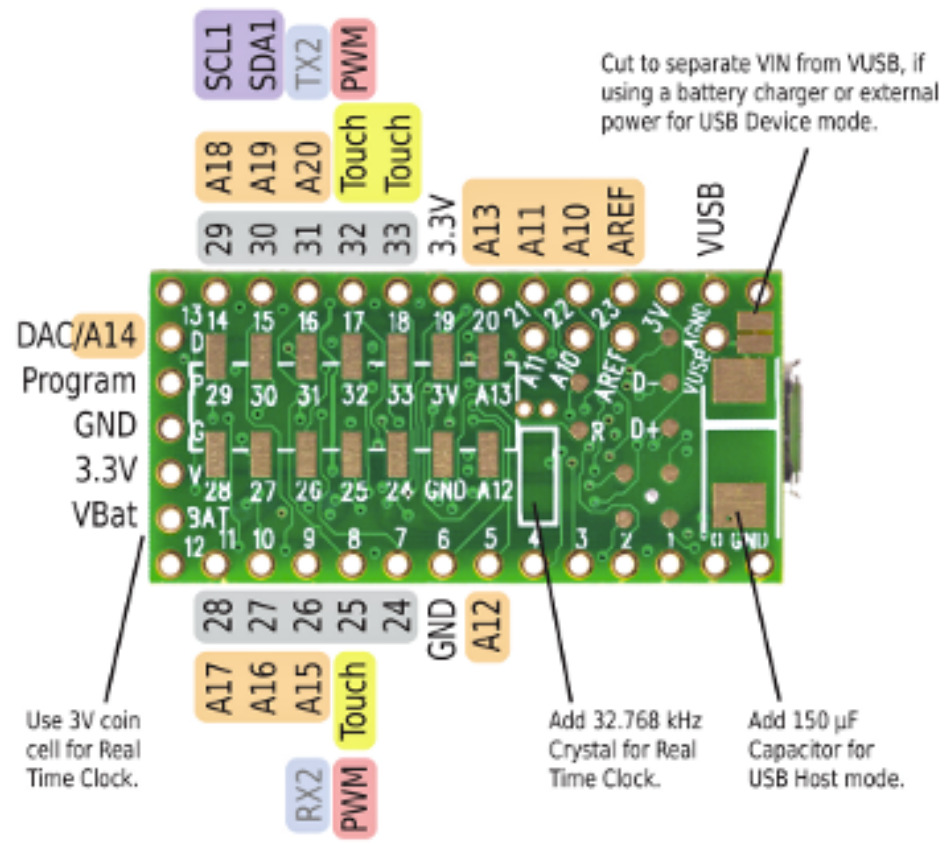

Figure 59: Teensy 3.1 pinouts diagram ${ }^{118}$. 


\section{OmTen electronics}

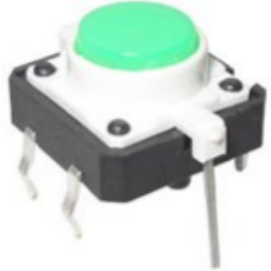

\section{TSD1265}
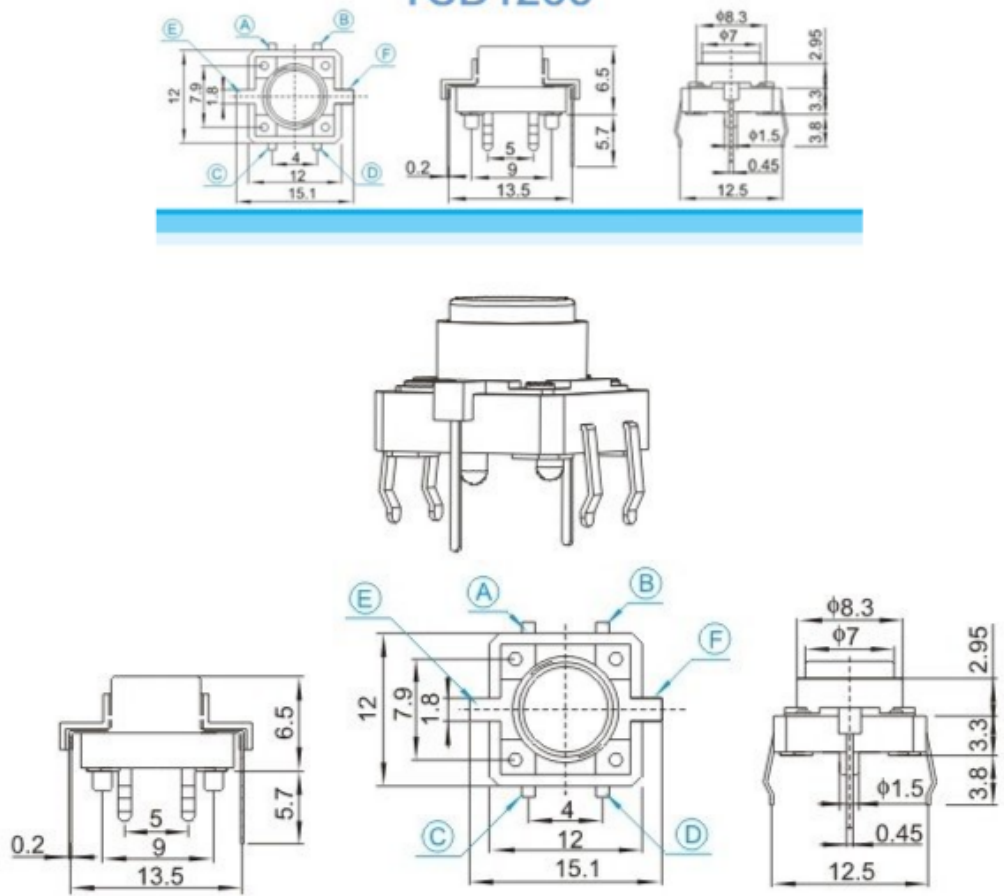

Figure 60: Blue tactile LED button drawing ${ }^{119}$.

LED MIXED PACK

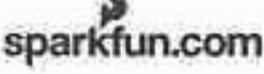

\begin{tabular}{|r|c|c|c|}
\hline COLOR & BFIGHFNESS & WAVELEVGIH & VDFOP \\
\hline BASIC RED & $150-200 \mathrm{mcd}$ & $620-625 \mathrm{~nm}$ & $2.0-2.4 \mathrm{~V}$ \\
BASIC YELLOW & $150-200 \mathrm{mcd}$ & $587-591 \mathrm{~nm}$ & $2.0-2.4 \mathrm{~V}$ \\
BASIC BLUE & $300-400 \mathrm{mcd}$ & $465-467.5 \mathrm{~nm}$ & $3.0-3.4 \mathrm{~V}$ \\
& & & $2.0-2.4 \mathrm{~V}$ \\
\hline
\end{tabular}

Figure 61: Multicolor LEDs infosheet ${ }^{120}$. 
PRECISION MICRODRIVES

\begin{tabular}{|l|r|}
\hline Specification & Value \\
\hline Voltage [V] & 3 \\
Frame Diameter [mm] & 10 \\
Body Length [mm] & 3.4 \\
Weight [g] & 1.2 \\
Voltage Range [V] & $2.5 \sim 3.8$ \\
Rated Speed [rpm] & 12000 \\
Rated Current [mA] & 75 \\
Start Voltage [V] & 2.3 \\
Start Current [mA] & 85 \\
Terminal Resistance [Ohm] & 75 \\
Vibration Amplitude [G] & 0.8 \\
\hline
\end{tabular}

www.precisionmicrodrives.com

Tel: +44 (0) 1932252482

Fax: +44 (0) 1932325353

Email: sales@precisionmicrodrives.com
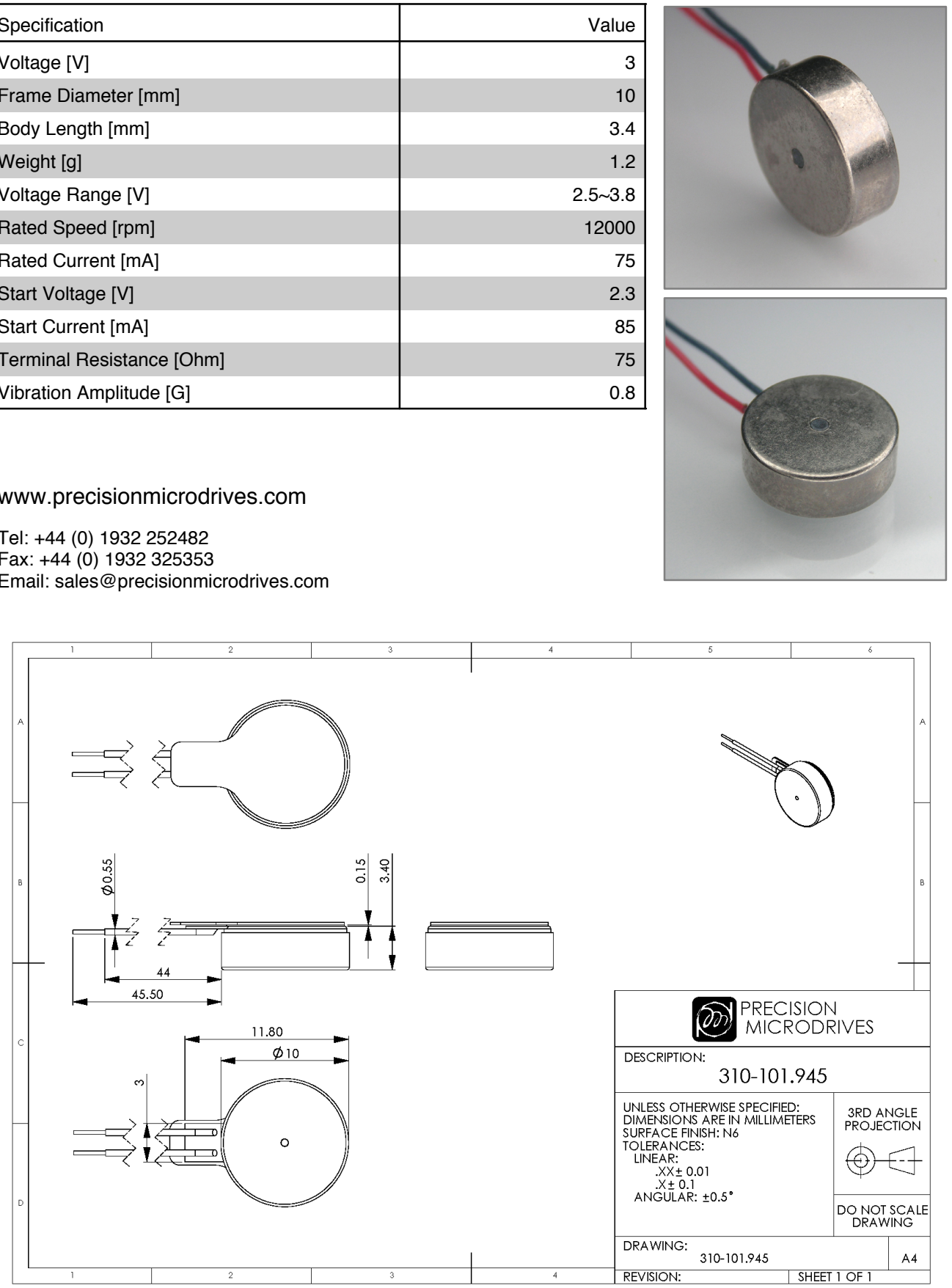

Copyright $\odot 2008$ Precision Microdrives Limited. Registered in England and Wales No. 5114621. Registered Office: Unit 23, Cannon Wharf, 35 Evelyn Street, London, SE8 5RT, UK. VAT Registered: GB 900123884

Figure 62: Vibration motor datasheet and drawing ${ }^{121}$. 


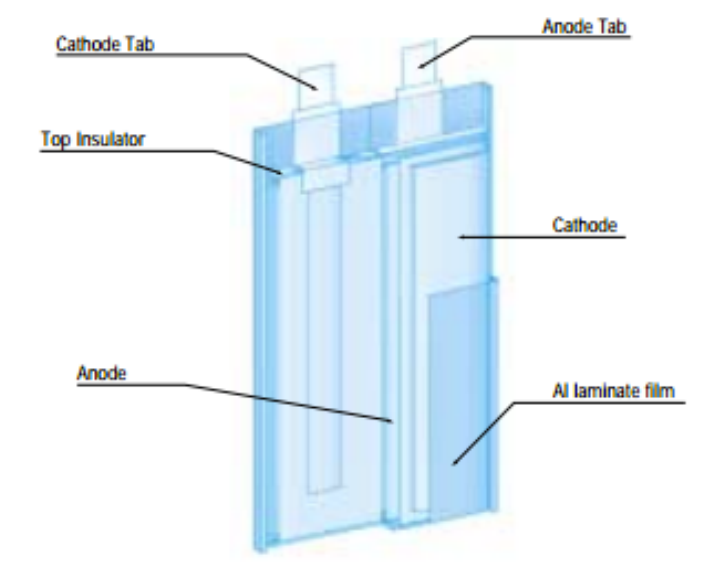

Figure 63: Polymer lithium ion battery internal components diagram ${ }^{122}$.
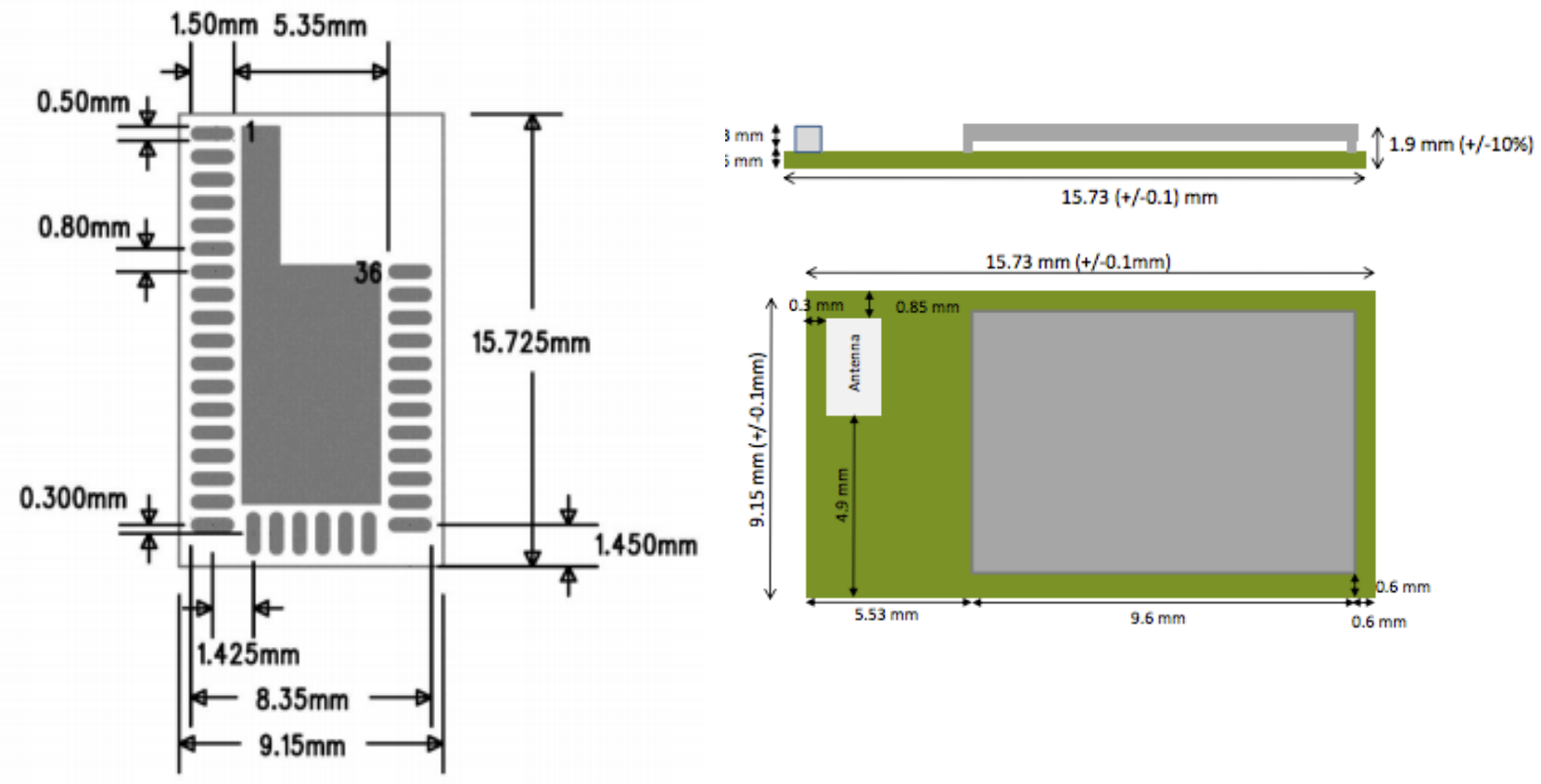

Figure 24: Bluetooth LE module drawing ${ }^{123}$. 
Ferformix

*Estimate

N/A-Not Applicable

N/R-Not Restricted

N/E-Not Established

MATERIAL SAFETY DATA SHEET

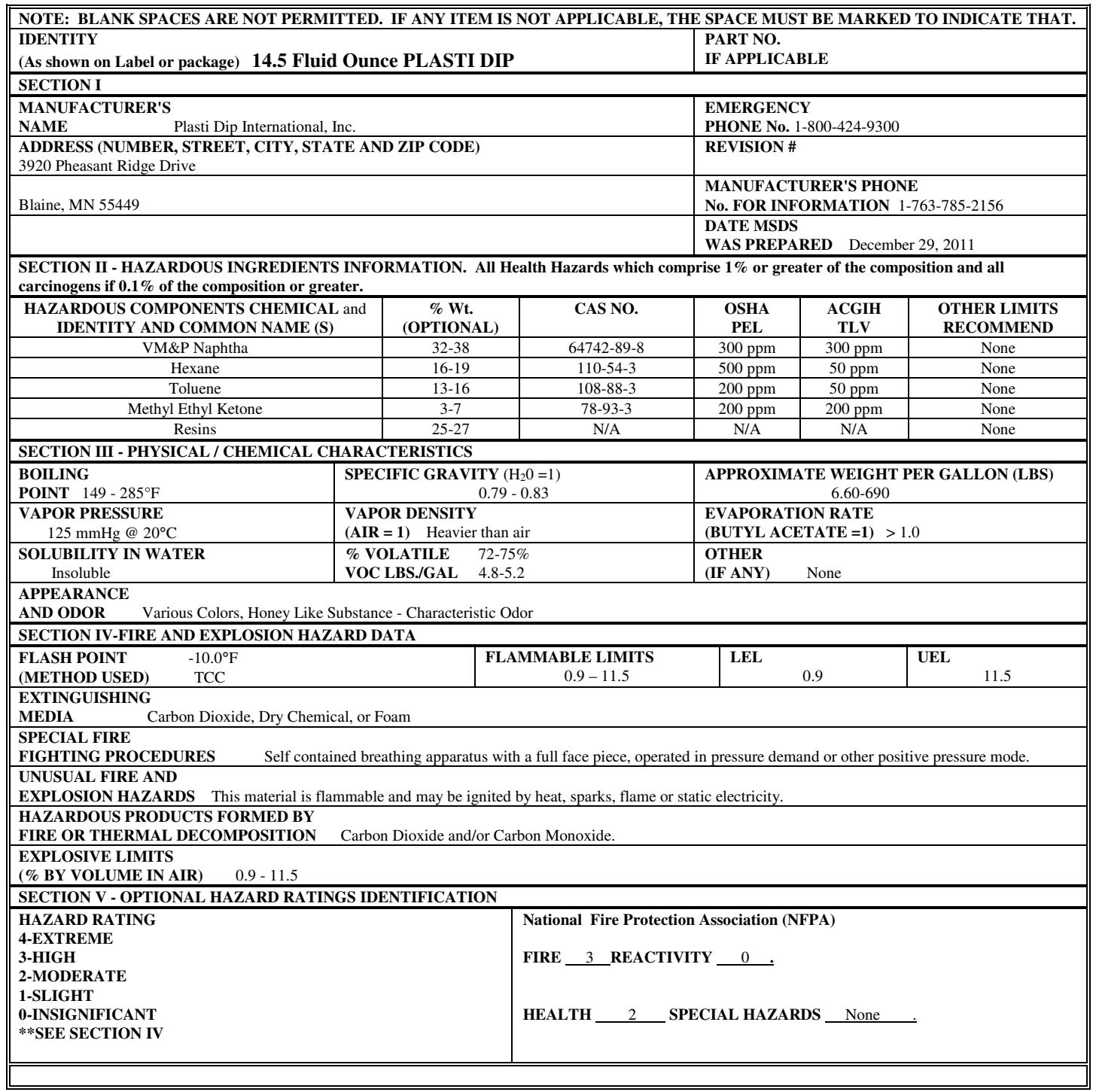

This is the "front" when printed in duplex. Page 1 of 2 pages if not duplex. 


\section{(Appendix D: Plasti Dip MSDS continued)}

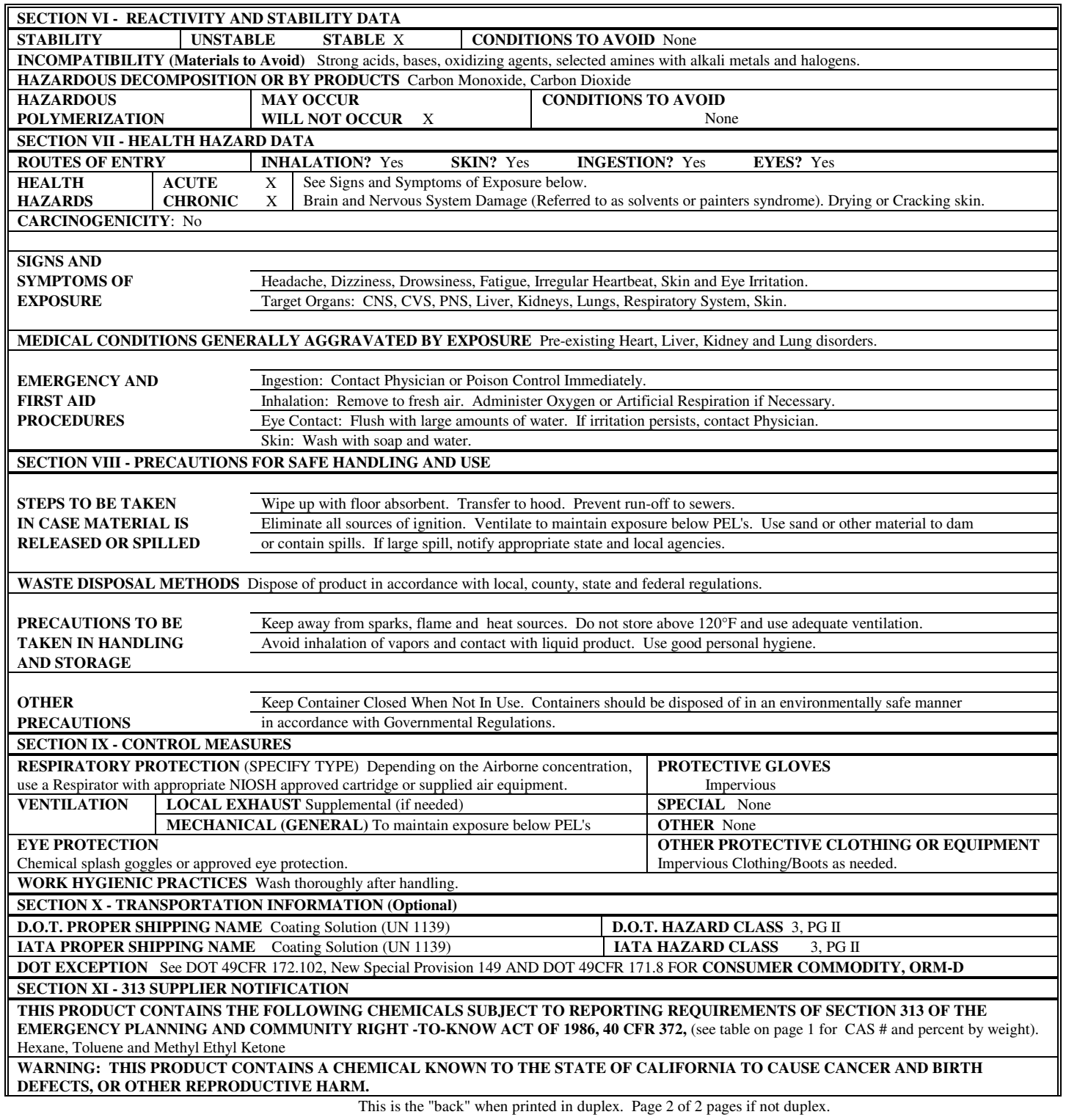

Prepared By: Mark Kenow

THE INFORMATION PROVIDED HEREIN IS BASED ON DATA CONSIDERED ACCURATE. NO WARRANTY IS EXPRESSED OR IMPLIED REGARDING THE ACCURACY OF THE DATA OR THE RESULTS OBTAINED FROM ITS USE. SINCE THE INFORMATION CONTAINED HEREIN MAY BE APPLIED
VENDOR ASSUMES NO RESPONSIBLITY FOR THE RESULTS OF ITS USE 


\section{Appendix E: Arduino Code - Teensy Acquisition}

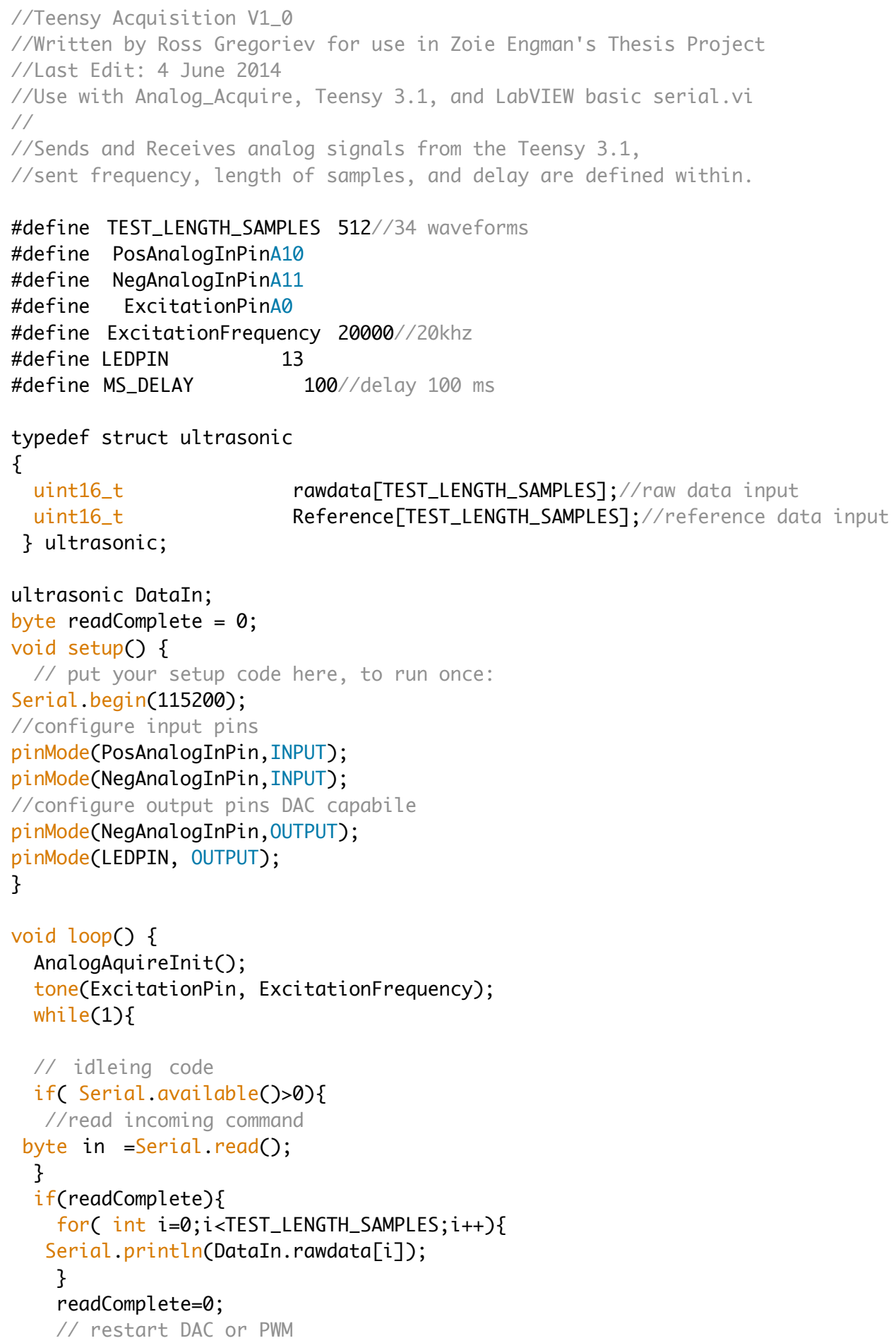




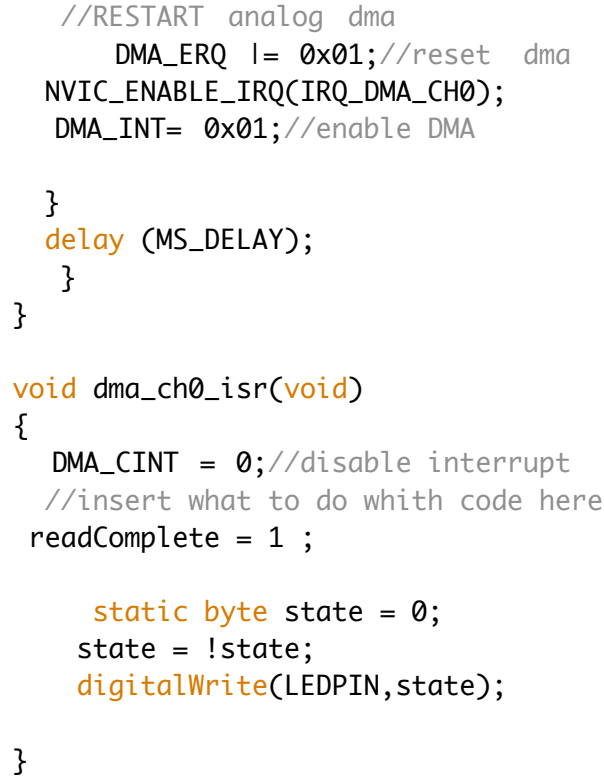




\section{Appendix F: Arduino Code - Analog Acquire}

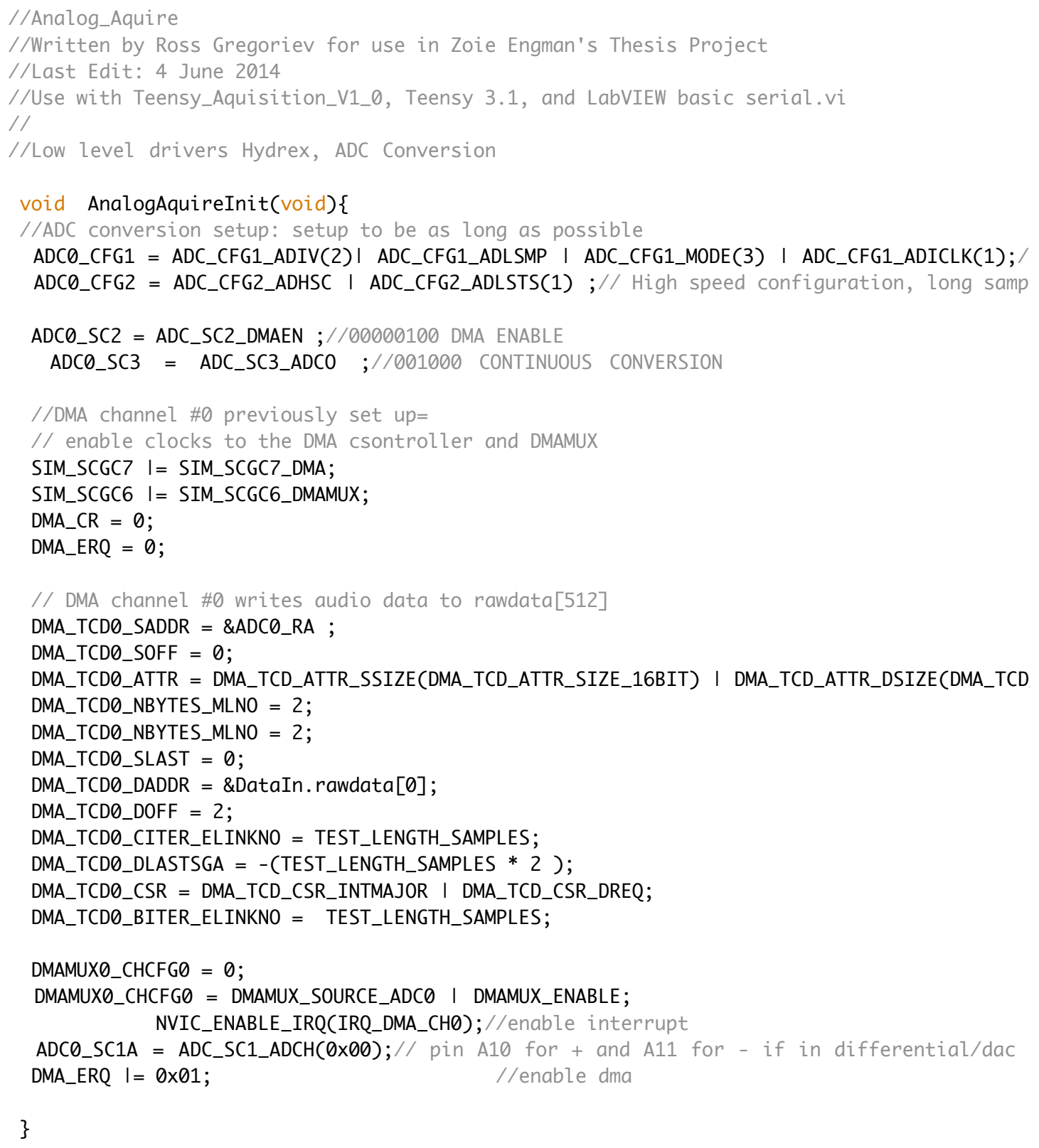


Appendix G: LabVIEW Block Diagram Panel

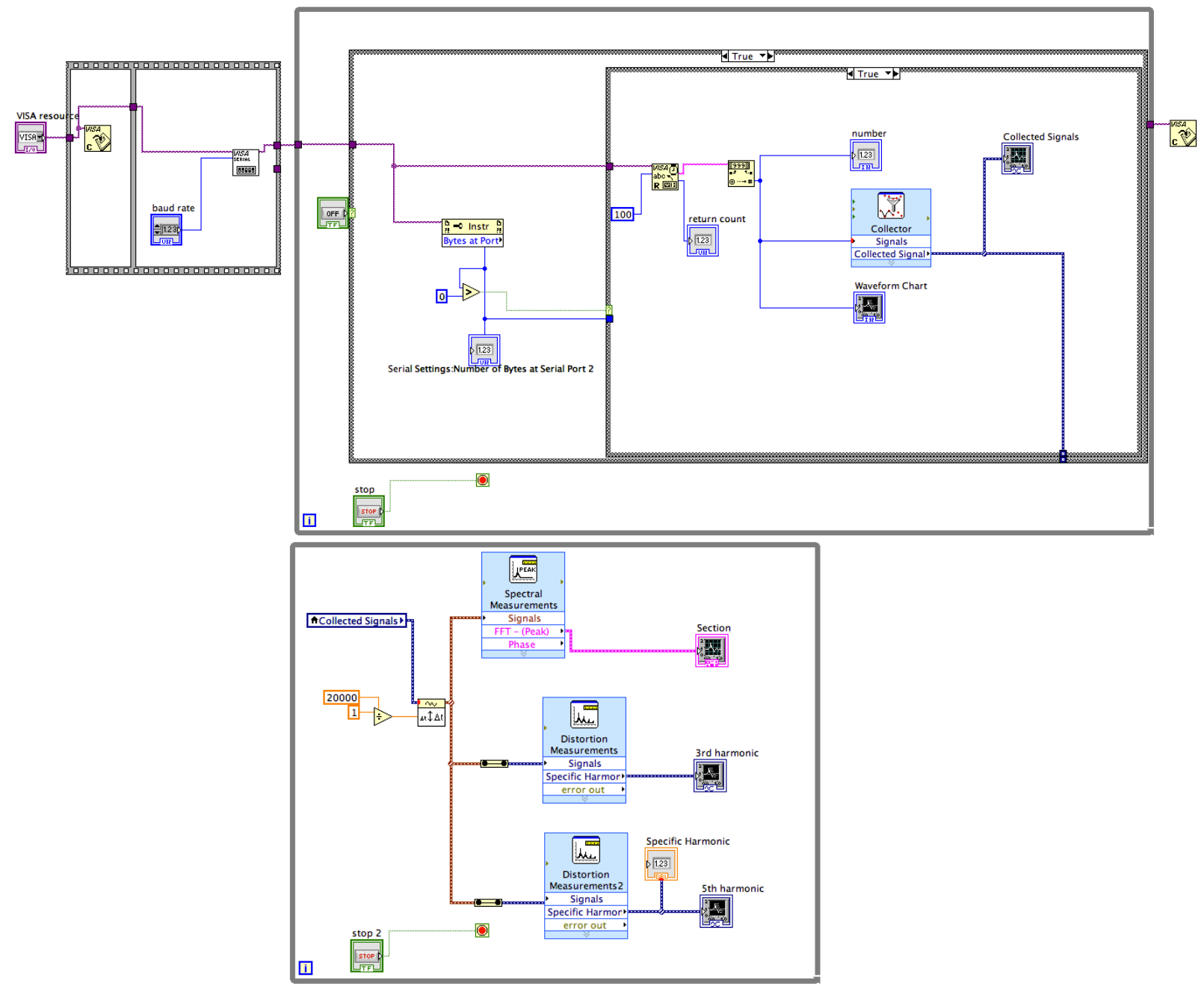




\section{Appendix H: LabVIEW Front Panel}

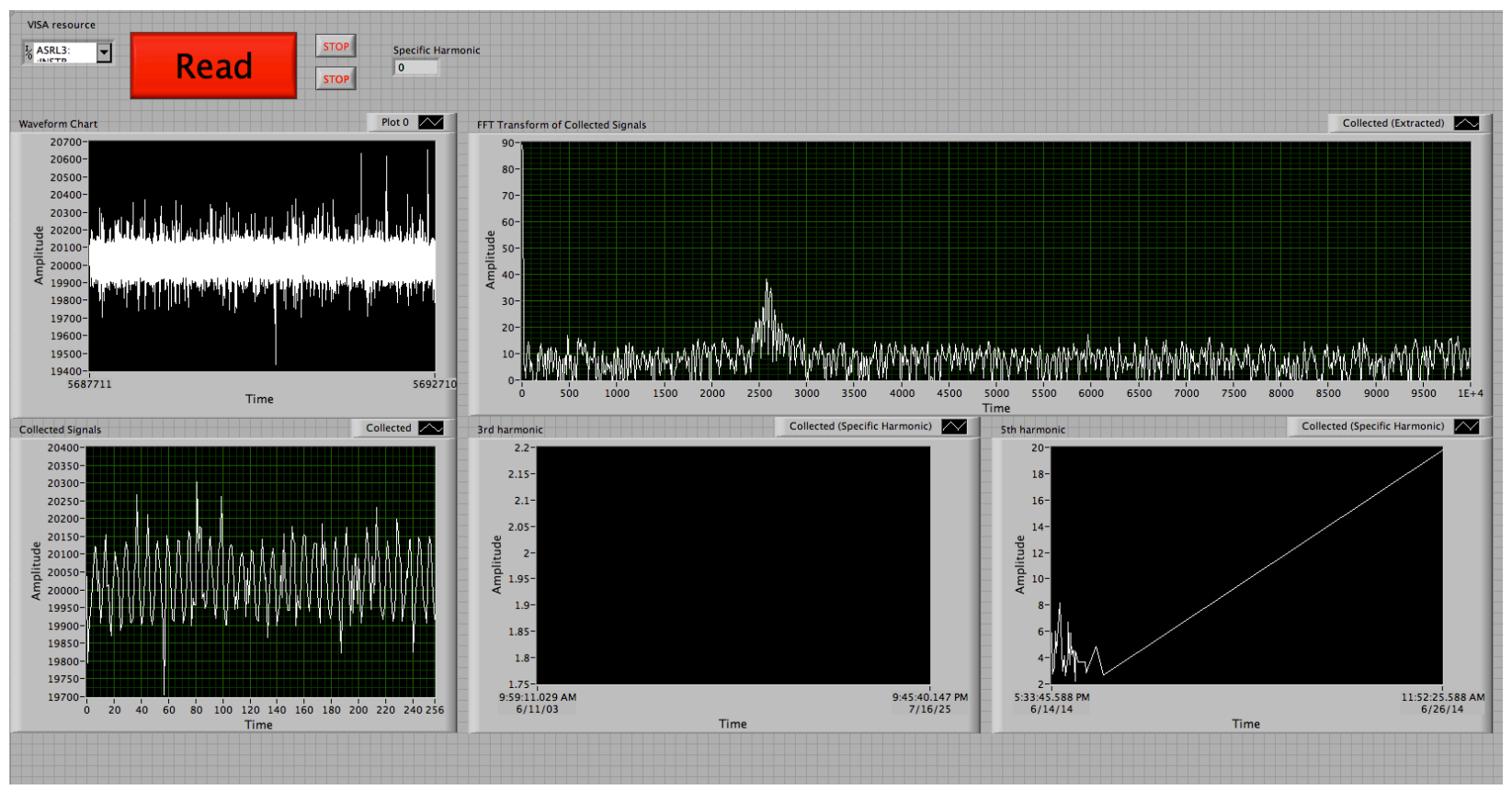

Appendix I: Accessories to the Distortion Validation Tests

$\%$ Difference $=\frac{|\Delta V|}{\frac{V_{1}+V_{2}}{2}}$

$\%$ Diff $_{\text {Attenuation Coeff }}=\frac{|15.0-0.4|}{\frac{15.0+0.4}{2}} * 100$

$\%$ Diff $_{\text {Attenuation Coeff }}=190 \%$

$\%$ Diff $_{\text {Average Distortion }}=\frac{|7614.5-66.6|}{\frac{7614.5+66.6}{2}}$

$\%$ Diff $_{\text {Average Distortion }}=197 \%$

Figure 65: Calculation of the percent difference between the attenuation coefficients and the average distortion value for each signal.

Table XXI: Raw data for the distortion validation tests. 


\begin{tabular}{|c|c|c|c|c|c|c|c|}
\hline $\begin{array}{c}\text { Time - } \\
\text { Collected } \\
\text { (Specific } \\
\text { Harmonic) }\end{array}$ & $\begin{array}{l}\text { Amplitude - } \\
\text { Collected } \\
\text { (Specific } \\
\text { Harmonic) }\end{array}$ & $\begin{array}{l}\text { Time - } \\
\text { Collected } \\
\text { (Specific } \\
\text { Harmonic) }\end{array}$ & $\begin{array}{l}\text { Amplitude - } \\
\text { Collected } \\
\text { (Specific } \\
\text { Harmonic) }\end{array}$ & $\begin{array}{l}\text { Time - } \\
\text { Collected } \\
\text { (Specific } \\
\text { Harmonic) }\end{array}$ & $\begin{array}{l}\text { Amplitude - } \\
\text { Collected } \\
\text { (Specific } \\
\text { Harmonic) }\end{array}$ & $\begin{array}{l}\text { Time - } \\
\text { Collected } \\
\text { (Specific } \\
\text { Harmonic) }\end{array}$ & $\begin{array}{l}\text { Amplitude - } \\
\text { Collected } \\
\text { (Specific } \\
\text { Harmonic) }\end{array}$ \\
\hline 04:04.3 & 9925.3 & 17:02.9 & 30.5519 & 44:20.3 & 9696.39 & 03:53.9 & 30.4286 \\
\hline $15: 17.3$ & 10231.2 & 28:14.9 & 36.0797 & $52: 52.3$ & 4891.4 & 13:34.9 & 51.9579 \\
\hline $29: 40.3$ & 9420.38 & 42:38.9 & 56.1258 & 01:24.3 & 10110.8 & 23:49.9 & 165.259 \\
\hline $38: 12.3$ & 4307.61 & 15:32.9 & 37.49 & $10: 28.3$ & 1508.69 & $35: 47.9$ & 52.5902 \\
\hline $47: 10.3$ & 11550.1 & 43:22.9 & 49.4677 & $20: 20.3$ & 9800.84 & 47:39.9 & 65.5677 \\
\hline $47: 12.3$ & 11544.5 & 54:45.9 & 71.0579 & $30: 14.3$ & 3853.49 & 57:30.9 & 5.3168 \\
\hline $47: 15.3$ & 11535.8 & 06:38.9 & 158.818 & $39: 26.3$ & 3301.58 & 09:15.9 & 80.899 \\
\hline $47: 17.3$ & 11530 & 16:30.9 & 75.8923 & 49:43.3 & 9834.38 & 24:40.9 & 0.1229 \\
\hline $47: 20.3$ & 11521 & 25:02.9 & 45.4644 & $59: 37.3$ & 10636.3 & 34:48.9 & 59.0795 \\
\hline $47: 44.3$ & 11444.2 & $36: 25.9$ & 142.791 & $: 40.3$ & 12522.8 & 02:12.9 & 6381 \\
\hline 04:49.3 & 45.4 & 48:22.9 & 459 & 2.3 & 28.7 & 21:34.9 & 2205 \\
\hline 20:09.3 & 8818.4 & 59:10.9 & 6857 & $26: 44.3$ & 113.77 & 30:19.9 & 4.3693 \\
\hline $29: 24.3$ & 5831.91 & 08:05.9 & 37.3787 & $35: 16.3$ & 12317.4 & 50:08.9 & 4.2834 \\
\hline $37: 56.3$ & 10130.3 & 19:45.9 & 24.4488 & $43: 48.3$ & 3822.91 & 59:36.9 & 6.4071 \\
\hline $54: 27.3$ & 9926.67 & $31: 41.9$ & 32.1407 & $52: 20.3$ & 4547.94 & 21:18.9 & 9.1174 \\
\hline $04: 23.3$ & 5896.12 & 41:50.9 & 44.7335 & $00: 52.3$ & 1639.07 & $38: 22.9$ & 81.7093 \\
\hline $04: 27.3$ & 5904.01 & 50:22.9 & 35.1677 & 09:24.3 & 7891.06 & 49:25.9 & 50.6844 \\
\hline 04:29.3 & 5908.11 & 59:25.9 & 21.4034 & $17: 56.3$ & 5753.22 & 00:56.9 & 50.2658 \\
\hline $04: 32.3$ & 5914.48 & 11:30.9 & 47.9876 & $26: 28.3$ & 2642.85 & 12:30.9 & 77.0507 \\
\hline 04:35.3 & 5921.1 & 22:57.9 & 74.9449 & $35: 45.3$ & 7075 & 21:02.9 & 80.0747 \\
\hline $14: 16.3$ & 11673.7 & 33:02.9 & 68.8839 & $45: 23.3$ & 4067.36 & $32: 42.9$ & 56.1552 \\
\hline 24:02.3 & 9968.92 & 41:34.9 & 37.9355 & 01:35.3 & 11330.6 & 42:16.9 & 39.7675 \\
\hline $34: 12.3$ & 13246.2 & 52:29.9 & 37.6429 & $46: 41.3$ & 9583.85 & 54:03.9 & 73.7149 \\
\hline 43:59.3 & 10258.1 & 04:32.9 & 55.7061 & $57: 13.3$ & 2793.65 & 03:42.9 & 52.9612 \\
\hline 54:03.3 & 9859.74 & 15:42.9 & 40.1672 & $08: 52.3$ & 2993.74 & 12:14.9 & 33.1425 \\
\hline 01:45.3 & 32.3 & 24:20.9 & 5.4834 & 04.3 & 225.83 & 23:48.9 & .9535 \\
\hline 11:48.3 & 43.08 & 36:07.9 & .1433 & 15.3 & 785.48 & $35: 36.9$ & 90.792 \\
\hline $20: 20.3$ & 8919.31 & 47:21.9 & 3.0887 & $40: 43.3$ & 4423.17 & 46:22.9 & 61.69 \\
\hline $28: 52.3$ & 4509.86 & 58:22.9 & 29.5843 & $50: 51.3$ & 9844.2 & 55:36.9 & 62.0071 \\
\hline 38:09.3 & 11434 & 07:41.9 & 46.7181 & 00:04.3 & 10654.6 & 05:22.9 & 187.565 \\
\hline 47:49.3 & 10846.4 & 19:30.9 & 55.1581 & $08: 36.3$ & 12603.9 & 16:57.9 & 60.0463 \\
\hline 58:02.3 & 11133.8 & $30: 48.9$ & 41.3086 & $17: 08.3$ & 7307.17 & 26:59.9 & 88.0307 \\
\hline $07: 46.3$ & 11044.7 & $38: 41.9$ & 52.1983 & $25: 40.3$ & 11205.1 & $37: 34.9$ & 80.9194 \\
\hline $17: 51.3$ & 11767.4 & 49:34.9 & 165.658 & $34: 12.3$ & 11671 & 46:49.9 & 56.8683 \\
\hline $27: 27.3$ & 13609.6 & 59:08.9 & 50.5038 & $42: 44.3$ & 5149.96 & 14:25.9 & 74.5647 \\
\hline $37: 08.3$ & 12280.3 & $10: 39.9$ & 50.0009 & $51: 16.3$ & 10191 & 43:36.9 & 59.5349 \\
\hline $45: 40.3$ & 9940.48 & 21:58.9 & 165.526 & $00: 26.3$ & 10377.8 & 02:54.9 & 62.318 \\
\hline
\end{tabular}




\begin{tabular}{|c|c|c|c|c|c|c|c|}
\hline $54: 12.3$ & 5510.96 & $31: 18.9$ & 52.4977 & $10: 28.3$ & 1702.56 & 19:30.9 & 81.7337 \\
\hline 02:44.3 & 1674.22 & 42:19.9 & 36.421 & $20: 18.3$ & 4077.1 & 28:30.9 & 84.0702 \\
\hline 11:30.3 & 10087 & 54:22.9 & 49.2553 & $30: 26.3$ & 3983.87 & 56:52.9 & 59.5471 \\
\hline $21: 21.3$ & 1948.23 & 06:03.9 & 71.2102 & 40:20.3 & 11745.4 & 06:56.9 & 56.5311 \\
\hline $31: 21.3$ & 4638.7 & 14:54.9 & 74.3751 & $50: 12.3$ & 11184.6 & $18: 27.9$ & 59.9559 \\
\hline $41: 27.3$ & 10628 & $23: 42.9$ & 49.1703 & $58: 18.3$ & 2488.56 & $28: 14.9$ & 84.1507 \\
\hline $51: 22.3$ & 10412.8 & $35: 49.9$ & 53.7899 & 08:04.3 & 9866.56 & $38: 31.9$ & 58.762 \\
\hline 01:30.3 & 10039.1 & 47:21.9 & 38.4638 & $16: 36.3$ & 1593.98 & 50:04.9 & 59.8272 \\
\hline 11:00.3 & 2860.79 & $57: 34.9$ & 51.0893 & $25: 08.3$ & 3942.02 & 02:16.9 & 73.4153 \\
\hline $19: 32.3$ & 6121.42 & 07:15.9 & 37.187 & $33: 40.3$ & 1919.2 & $10: 54.9$ & 59.7051 \\
\hline 28:04.3 & 12383.2 & 19:08.9 & 37.0785 & 42:12.3 & 2310.88 & 19:52.9 & 76.3875 \\
\hline $36: 36.3$ & 9948.67 & $30: 26.9$ & 77.3406 & $50: 44.3$ & 5671.38 & $31: 36.9$ & 83.924 \\
\hline 45:08.3 & 6001.38 & $40: 14.9$ & 73.0502 & 59:58.3 & 8643.1 & 41:42.9 & 61.4621 \\
\hline $53: 40.3$ & 10992.8 & 48:58.9 & 50.2766 & 09:54.3 & 2203.28 & 53:02.9 & 74.3402 \\
\hline 03:09.3 & 5757.79 & 00:20.9 & 162.06 & 20:09.3 & 7555.48 & 02:06.9 & 73.137 \\
\hline 13:14.3 & 10551.6 & 12:18.9 & 58.6759 & 29:09.3 & 10859.2 & 13:07.9 & 61.3309 \\
\hline $22: 18.3$ & 13378.9 & 22:54.9 & 172.932 & $39: 55.3$ & 8342.44 & 23:02.9 & 78.4906 \\
\hline $30: 42.3$ & 5832.14 & $32: 10.9$ & 47.4466 & $50: 23.3$ & 10674.7 & $36: 14.9$ & 62.1188 \\
\hline 40:40.3 & 7800.24 & 44:01.9 & 43.6095 & 59:00.3 & 10003.2 & 44:56.9 & 80.2566 \\
\hline 50:48.3 & 11089.3 & $55: 48.9$ & 34.4108 & $07: 32.3$ & 4993.67 & 58:58.9 & 61.7117 \\
\hline 00:12.3 & 4124.73 & 05:34.9 & 52.9697 & 16:04.3 & 4143.51 & $10: 59.9$ & 76.8942 \\
\hline 10:04.3 & 2406.68 & 14:06.9 & 175.434 & $24: 36.3$ & 5187.71 & 11:03.9 & 77.0456 \\
\hline 19:00.3 & 10604.6 & $25: 22.9$ & 52.413 & $33: 08.3$ & 8990.24 & 11:06.9 & 77.159 \\
\hline $27: 32.3$ & 11091.1 & $36: 47.9$ & 33.3129 & 41:44.3 & 6033.12 & 11:08.9 & 77.2346 \\
\hline $36: 52.3$ & 11244.2 & 48:14.9 & 48.92 & $51: 35.3$ & 2897.29 & 28:33.9 & 62.9398 \\
\hline 46:43.3 & 1962.37 & $56: 57.9$ & 59.1494 & $01: 16.3$ & 2051.66 & 42:04.9 & 63.9211 \\
\hline $56: 20.3$ & 11002.9 & 09:04.9 & 154.057 & 11:01.3 & 2418.7 & 03:39.9 & 63.1263 \\
\hline 06:45.3 & 6675.02 & $20: 35.9$ & 60.3492 & $19: 36.3$ & 2375.94 & 15:29.9 & 60.4023 \\
\hline 15:38.3 & 12283.1 & $30: 54.9$ & 47.5578 & $30: 58.3$ & 2724.04 & 26:54.9 & 60.4237 \\
\hline $25: 52.3$ & 12697.7 & 40:23.9 & 66.0939 & 40:51.3 & 1750.59 & $35: 42.9$ & 47.6432 \\
\hline $35: 46.3$ & 10504.6 & 52:17.9 & 47.3516 & 49:56.3 & 11843.9 & $35: 43.9$ & 47.680 \\
\hline
\end{tabular}

Table XXII: Summary table for the distortion validation test.

\begin{tabular}{|l|r|r|}
\hline \multicolumn{1}{|c|}{ Metric } & \multicolumn{1}{c|}{ Aluminum } & \multicolumn{1}{c|}{ Rubber } \\
\hline Average & 7614.5 & 66.6 \\
\hline Max & 13609.6 & 190.8 \\
\hline Min & 1344.2 & 21.4 \\
\hline Stdev & 3670.4 & 35.3 \\
\hline
\end{tabular}




\section{Appendix J: Accessories to the Sponge Water Content Validation Test}

Table XXIII: Sample weights for the sponge water content test.

\begin{tabular}{|l|r|}
\hline Sample & Weight (g) \\
\hline Dry & 24 \\
\hline $1 \mathrm{~T}$ & 36 \\
\hline $2 \mathrm{~T}$ & 50 \\
\hline $3 \mathrm{~T}$ & 60 \\
\hline $4 \mathrm{~T}$ & 74 \\
\hline $5 \mathrm{~T}$ & 104 \\
\hline $6 \mathrm{~T}$ & 124 \\
\hline
\end{tabular}

Table XXIV: Raw data for dry, 1T, and 2T of the sponge water content test. Dry $=$ sponge prior to water added, Samples given in the form of \#TL where \# = number of tablespoons added and $L=$ location of the measurement.

\begin{tabular}{|c|c|c|c|c|c|c|c|c|}
\hline Dry 1 & Dry 2 & Dry 3 & $1 \mathrm{~T} 1$ & $1 \mathrm{~T} 2$ & $1 \mathrm{~T} 3$ & $2 \mathrm{~T} 1$ & $2 \mathrm{~T} 2$ & $2 \mathrm{T3}$ \\
\hline 11.6116 & 15.2787 & 8.51108 & 3.47935 & 4.14777 & 5.49769 & 5.34698 & 3.44292 & 3.66312 \\
\hline 2.82473 & 11.7086 & 5.96021 & 5.01598 & 7.95644 & 1.83152 & 4.00356 & 4.94778 & 2.4842 \\
\hline 5.84431 & 4.72547 & 6.96679 & 5.47366 & 4.67466 & 3.08421 & 1.44331 & 3.40356 & 3.90317 \\
\hline 6.79996 & 5.42303 & 3.55741 & 9.58503 & 8.29311 & 4.32393 & 5.78056 & 4.41149 & 5.9978 \\
\hline 15.2515 & 8.13265 & 4.82126 & 2.56101 & 7.14567 & 4.71867 & 5.31109 & 3.25692 & 8.89031 \\
\hline 18.4167 & 7.32567 & 4.85874 & 6.33385 & 5.34898 & 6.87699 & 5.19399 & 8.26373 & 4.70799 \\
\hline 7.51577 & .569 & 4.09844 & 4.55317 & 5.25846 & 4.50123 & 5.10209 & 8.26653 & 5.9803 \\
\hline 13.4042 & 24.0276 & 4.09541 & 5.72173 & 6.70004 & 3.64283 & 3.46998 & 6.77382 & 2.45366 \\
\hline 6.2212 & 16.8997 & 621 & 6.87559 & 4.92018 & 3.07791 & 3353 & 3.8319 & 2.54455 \\
\hline 12.9593 & 5.87366 & 12.1136 & 3.8389 & 7.56584 & 5.66874 & 2071 & 6.66652 & 4.82393 \\
\hline 7.82393 & 8.97018 & 8.88995 & 5.39262 & 5.69511 & 5.3466 & 3.55395 & 5.30268 & 4.18226 \\
\hline 10.6721 & 6.41658 & 7.58359 & 8.26414 & 8.34357 & 2.09147 & 4.26688 & 4.19891 & 10.3517 \\
\hline 11.4121 & 9.53099 & 5.34801 & 8.15764 & 11.6232 & 1.54188 & 2.83677 & 2.08519 & 3.57834 \\
\hline 6.55674 & 5.01274 & 8.77464 & 7.75658 & 7.03634 & 3.45514 & 4.90733 & 3.8576 & 2.92593 \\
\hline 12.475 & 10.4198 & 10.1193 & 7.36221 & 8.49315 & 4.00271 & 3.57733 & 3.24601 & 2.50184 \\
\hline 7.85241 & 16.5869 & 7.82059 & 5.48135 & 6.57541 & 3.42497 & 5.40216 & 5.67145 & 4.28083 \\
\hline 9.09899 & 11.147 & 5.76761 & 9.3191 & 3.26202 & 3.14877 & 5.1566 & 6.29928 & 9.06294 \\
\hline 21.8304 & 12.8855 & 5.57123 & 6.60381 & 4.19958 & 4.74761 & 2.84601 & 5.42015 & 7.52296 \\
\hline 7.98378 & 10.0881 & 9.23785 & 5.61363 & 7.69813 & 2.33926 & 6.46737 & 8.57731 & 5.10656 \\
\hline 11.8997 & 11.0259 & 4.47447 & 3.50542 & 7.34566 & 7.45266 & 5.50344 & 4.20289 & 6.00657 \\
\hline 7.77658 & 7.40888 & 5.55014 & 6.30758 & 6.66969 & 5.51027 & 7.93523 & 3.37048 & 3.14973 \\
\hline 7.85689 & 11.451 & 7.96671 & 7.79743 & 8.63159 & 3.21238 & 4.27466 & 3.28719 & 4.62501 \\
\hline 12.5108 & 11.0932 & 5.29356 & 7.61016 & 7.18033 & 8.48044 & 3.97432 & 5.82308 & 1.67493 \\
\hline
\end{tabular}




\begin{tabular}{|c|c|c|c|c|c|c|c|c|}
\hline 10.2787 & 5.61694 & 4.28294 & 4.02278 & 7.67584 & 3.38584 & 3.52383 & 4.19633 & 3.3395 \\
\hline 11.7291 & 9.64156 & 5.78346 & 3.62019 & 7.59601 & 2.29961 & 4.32201 & 2.61726 & 4.98201 \\
\hline 11.8623 & 14.0852 & 6.35887 & 6.38528 & 7.30646 & 2.51547 & 3.17098 & 3.11246 & 8.44549 \\
\hline 6.42159 & 11.2316 & 9.0821 & 8.01563 & 6.80716 & 6.95543 & 3.41231 & 4.9063 & 8.92028 \\
\hline 13.0407 & 8.58482 & 4.89853 & 12.5036 & 7.14829 & 3.38638 & 3.68613 & 2.30886 & 3.18257 \\
\hline 6.07101 & 9.49728 & 6.76815 & 6.56077 & 6.24846 & 3.42747 & 4.81406 & 1.26826 & 3.67623 \\
\hline 5.43439 & 8.98164 & 3.94468 & 3.97662 & 3.61754 & 6.09936 & 6.49893 & 3.15768 & 2.96837 \\
\hline 11.577 & 11.0238 & 7.01433 & 4.48735 & 2.22775 & 6.91223 & 6.3872 & 3.50929 & 3.94291 \\
\hline 6.81476 & 14.6306 & 4.54565 & 5.24587 & 3.80817 & 3.84331 & 5.84026 & 4.61753 & 5.05751 \\
\hline 10.3563 & 5.63997 & 5.77377 & 4.33519 & 10.0577 & 2.78847 & 4.81898 & 5.88616 & 2.27529 \\
\hline 14.5173 & 6.06865 & 8.63827 & 7.39359 & 8.13539 & 4.83549 & 5.01316 & 3.57035 & 4.44457 \\
\hline 13.5423 & 12.5025 & 5.82366 & 7.64006 & 4.66075 & 5.79089 & 3.24535 & 2.62341 & 3.29743 \\
\hline 16.2078 & 17.8472 & 7.04987 & 6.68307 & 2.98355 & 3.38881 & 3.46815 & 5.1243 & 6.36591 \\
\hline 8.67746 & 18.1529 & 2.37411 & 7.13008 & 4.41678 & 6.65536 & 2.76664 & 2.03934 & 4.44401 \\
\hline 11.0526 & 8.87438 & 4.28081 & 3.91928 & 5.9594 & 5.41401 & 4.94103 & 1.72585 & 5.24632 \\
\hline 15.2864 & 14.9293 & 4.1321 & 10.0754 & 6.64817 & 9.37958 & 6.109 & 7.86891 & 5.63044 \\
\hline 8.63545 & 7.60665 & 4.62427 & 3.75231 & 8.04521 & 3.75776 & 5.79314 & 6.16111 & 3.14691 \\
\hline 12.3401 & 9.38365 & 9.97428 & 8.11416 & 6.20973 & 2.92523 & 3.56905 & 5.32882 & 2.9517 \\
\hline 8.88986 & 8.83753 & 6.14893 & 5.52844 & 6.69691 & 4.21573 & 4.314 & 2.99672 & 5.87182 \\
\hline 6.77443 & 12.7189 & 2.70791 & 7.43078 & 7.99637 & 7.14267 & 2.46234 & 5.73408 & 4.74774 \\
\hline 13.458 & 26.6159 & 5.4847 & 5.16981 & 8.16283 & 3.41887 & 4.32809 & 3.45851 & 5.09697 \\
\hline 8.68899 & 194 & 649 & 1344 & 15 & 746 & 3.95105 & 4.78974 & 5.2423 \\
\hline 10.2089 & 346 & 796 & 473 & 49 & 3.94366 & 022 & 2878 & 0438 \\
\hline 7.87041 & .757 & 606 & 364 & 878 & 4.46126 & 79 & 441 & 895 \\
\hline 6.80534 & 826 & 593 & 094 & 528 & 56 & 777 & 392 & 9028 \\
\hline 17.1 & 10.3847 & 2.69106 & 5.12385 & 5.26924 & 3.17724 & 5.97652 & 5.73323 & 4.02464 \\
\hline 11.0103 & 22.3816 & 5.78928 & 3.96515 & 9.16278 & 5.13226 & 7.19496 & 5.90591 & 6.44525 \\
\hline 12.4864 & 10.3088 & 5.20603 & 7.80097 & 315 & 4.62716 & 787 & 4.90996 & 2.26318 \\
\hline 6.63703 & 5.70359 & 132 & 7.71846 & 216 & 996 & 3.74394 & 7.06779 & 4.68997 \\
\hline 3.40763 & 11.1063 & 4.20304 & 5.66861 & 4.86991 & 289 & 2.45002 & 7.51684 & 2.39621 \\
\hline 21.9458 & 23.0592 & 5.57394 & 4.18134 & 7.07335 & 5.69773 & 3.05573 & 4.74133 & 4.08176 \\
\hline 13.1846 & 9.93643 & 3.66751 & 3.85225 & 4.44221 & 1.86293 & 4.15362 & 4.93655 & 5.23224 \\
\hline 12.6372 & 8.42846 & 8.62712 & 4.60767 & 8.62033 & 3.99443 & 3.00408 & 7.19562 & 4.47634 \\
\hline 9.59513 & 4.88728 & 3.45899 & 5.69686 & 5.00489 & 6.92738 & 3.78709 & 4.82678 & 6.35084 \\
\hline 14.5817 & 9.27483 & 7.88431 & 7.17188 & 3.27592 & 6.49973 & 3.4054 & 8.33746 & 4.74956 \\
\hline 8.30255 & 8.459 & 8.59954 & 9.43961 & 7.71215 & 7.45952 & 4.65668 & 5.57952 & 6.40237 \\
\hline 9.4805 & 9.74255 & 6.74445 & 6.61585 & 6.33758 & 2.8869 & 6.52527 & 8.12137 & 4.40631 \\
\hline 11.0481 & 5.06057 & 9.14658 & 7.18484 & 4.68263 & 3.88828 & 3.34675 & 5.01968 & 4.79939 \\
\hline 11.8812 & 5.09676 & 2.83292 & 5.88376 & 7.46104 & 5.45723 & 3.00835 & 2.80136 & 5.01985 \\
\hline 15.1504 & 17.9058 & 5.96289 & 8.40766 & 2.10275 & 5.15105 & 7.93268 & 4.41837 & 3.42466 \\
\hline 16.3533 & 6.16636 & 6.92102 & 5.23671 & 6.87915 & 4.96893 & 4.67915 & 5.85817 & 3.37965 \\
\hline
\end{tabular}




\begin{tabular}{|c|c|c|c|c|c|c|c|c|}
\hline 7.14201 & 13.4744 & 2.28919 & 6.94575 & 2.9882 & 2.55293 & 3.79109 & 6.15916 & 4.40941 \\
\hline 9.8792 & 18.5869 & 6.35807 & 5.3597 & 3.45118 & 4.64836 & 9.81358 & 5.99512 & 4.47741 \\
\hline 5.6235 & 10.8627 & 3.74017 & 9.71725 & 5.56931 & 4.7678 & 6.45386 & 2.53009 & 10.6172 \\
\hline 7.16606 & 9.86616 & 8.71031 & 8.61444 & 5.85354 & 6.94223 & 3.28832 & 6.12457 & 8.19458 \\
\hline 3.66388 & 16.5077 & 7.40806 & 4.94301 & 7.25844 & 4.58131 & 4.00909 & 3.40245 & 6.2284 \\
\hline 10.4222 & 9.02094 & 10.7311 & 4.583 & 6.72276 & 7.0253 & 2.99343 & 5.03759 & 2.34613 \\
\hline 12.3559 & 8.48655 & 10.4447 & 9.27592 & 5.93164 & 6.61473 & 5.29423 & 3.64605 & 5.38355 \\
\hline 9.02198 & 8.368 & 3.78727 & 8.44338 & 2.52061 & 6.61774 & 2.42072 & 3.66527 & 4.46422 \\
\hline 10.9666 & 10.125 & 8.77952 & 5.89909 & 4.02636 & 4.33313 & 4.70975 & 6.21299 & 3.17242 \\
\hline 7.61786 & 8.04704 & 5.44639 & 2.84586 & 6.43971 & 1.90208 & 2.88114 & 4.41387 & 3.26497 \\
\hline 7.56769 & 10.2489 & 4.76294 & 9.93861 & 9.52404 & 2.28136 & 8.62762 & 6.94141 & 6.28814 \\
\hline 14.9735 & 7.68326 & 5.4352 & 4.0227 & 6.15986 & 5.00472 & 7.03809 & 2.92612 & 5.34295 \\
\hline 8.03708 & 7.66061 & 4.17262 & 6.50853 & 4.50175 & 4.00836 & 2.97837 & 6.08199 & 6.28722 \\
\hline 12.6897 & 7.43487 & 11.4607 & 6.71345 & 6.61894 & 6.20206 & 4.00907 & 5.84931 & 4.80848 \\
\hline 14.6444 & 15.7795 & 8.00544 & 6.12633 & 5.25083 & 5.38891 & 4.18912 & 1.97692 & 3.75019 \\
\hline 9.7816 & 8.61164 & 6.80444 & 8.36323 & 7.0903 & 3.83371 & 4.11951 & 4.04388 & 3.34832 \\
\hline 11.4917 & 8.01468 & 2.35721 & 5.39507 & 3.54755 & 2.46602 & 3.32111 & 7.36416 & 2.826 \\
\hline 7.98338 & 8.45273 & 9.35013 & 5.11026 & 8.97498 & 7.75358 & 4.76038 & 6.20435 & 7.43618 \\
\hline 8.34854 & 6.08537 & 5.62912 & 7.37184 & 4.28947 & 4.49289 & 5.19256 & 3.00721 & 4.23544 \\
\hline 14.2692 & 10.3886 & 5.751 & 6.97195 & 4.91457 & 7.15174 & 4.14411 & 3.62217 & 5.11997 \\
\hline 14.6433 & 17.3608 & 6.97558 & 8.96852 & 3.63016 & 6.33985 & 3.18428 & 6.26739 & 5.7505 \\
\hline 9.28155 & 7.76652 & 3.44148 & 7.0961 & 5.95032 & 6.94509 & 2.37484 & 3.30661 & 3.96106 \\
\hline 17.966 & 9.50899 & 3.92823 & 10.3875 & 4.77295 & 654 & 1113 & 591 & 2661 \\
\hline 892 & 14 & 829 & 4.76726 & 3.70067 & 924 & 468 & 683 & 7878 \\
\hline 10.066 & 10.4936 & 4.18005 & 3.57986 & .613 & 2.96945 & 2.56558 & 3.60621 & 5.05046 \\
\hline 7.81417 & 8.88737 & 3.67514 & 3.81717 & 9.25317 & 6.16626 & 2.99878 & 4.155 & 2.98277 \\
\hline 15.0811 & 9.57705 & 8.00406 & 5.89553 & 3.45803 & 3.046 & 5.84985 & 2.98954 & 10.9857 \\
\hline 13.1612 & 9.51374 & 5.16361 & 4.979 & 2.8 & 2.91716 & 4.7486 & 6.73248 & 4.01268 \\
\hline 15.4475 & 23.6505 & 2.11667 & 5.79446 & 4.66838 & 7.24247 & 3.97157 & 2.46682 & 2.7126 \\
\hline 8.06709 & 21.3551 & 5.35918 & 5.79051 & 7.13732 & 4.68424 & 5.34928 & 5.92331 & 7.01554 \\
\hline 9.05266 & 11.7776 & 4.62538 & 5.78765 & 8.04684 & 4.17481 & 4.8781 & 4.81644 & 7.48 \\
\hline 12.0274 & 10.3333 & 4.73983 & 5.78401 & 5.58097 & 4.02548 & 5.92232 & 1.97278 & 3.7697 \\
\hline 10.1309 & 5.32038 & 6.21682 & 5.78227 & 8.97931 & 3.99847 & 2.60335 & 1.95332 & 4.21522 \\
\hline 8.05848 & 5.43211 & 5.76167 & 5.77974 & 5.8503 & 5.20417 & 2.32847 & 2.83355 & 4.2423 \\
\hline 8.58838 & 13.5759 & 6.7237 & 5.88056 & 6.39775 & 2.6133 & 2.78814 & 4.49181 & 5.12823 \\
\hline 10.8746 & 11.2384 & 5.83399 & 6.11215 & 8.89847 & 4.49179 & 4.2646 & 7.71151 & 6.19512 \\
\hline
\end{tabular}


Table XXV: Raw data for 3T, 4T, 5T, and 6T of the sponge water content test. Dry = sponge prior to water added, Samples given in the form of \#TL where \# = number of tablespoons added and $L=$ location of the measurement.

\begin{tabular}{|c|c|c|c|c|c|c|c|c|c|c|c|}
\hline & & & & & & & & & & & \\
\hline & & & & & & & & & & & \\
\hline & & & & & & & & & & & \\
\hline & & & & & & & & & & & \\
\hline & & & & & & & & & & & \\
\hline & & & & & & & & & & & \\
\hline & & & & & & & & & & & 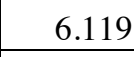 \\
\hline & & & & & & & & - & & & \\
\hline & & & & & & & & & & & \\
\hline & & & & & & & & & & & \\
\hline & & & & & & & & & & & 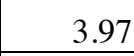 \\
\hline & & & & & & & & & & & 21 \\
\hline & & & & & & & & & & & 06 \\
\hline 14 & & & & & & & & & & 286 & 08 \\
\hline 392 & 45 & 78 & 71 & 33 & 202 & 91 & & 396 & & 624 & 22 \\
\hline & & 19 & & & & 33 & & 364 & & 542 & \\
\hline & & 39 & & & & & & 17 & & & \\
\hline & & 8 & & & & & & & & & \\
\hline & & & & & & & & & & & \\
\hline & & & & & & & & & & & \\
\hline & & & & & & & & & & & \\
\hline & & & & & & & & & & & \\
\hline & & & & & & & & & & & \\
\hline & & & & & & & & & & & \\
\hline & & & & & & & & & & & \\
\hline & & & & & & & & 361 & & & \\
\hline & & & & & & & & 555 & & 486 & \\
\hline & & & & & & & & & & & \\
\hline & & & & & & & & & & & \\
\hline & & & & & & & & & & & \\
\hline & & & & & & & & & & & \\
\hline & & & & & & & & & & & \\
\hline & & & & & & & & 096 & & 04 & 57 \\
\hline & & & & & & & & 61 & & & \\
\hline & & & & & & & & - & & - & 22 \\
\hline & & 0.1105 & & & & & & & & $x_{1}$ & \\
\hline
\end{tabular}




\begin{tabular}{|c|c|c|c|c|c|c|c|c|c|c|c|}
\hline & & & 9178 & & & & & & & 52 & \\
\hline & & & & & & & & & & & \\
\hline & & & & & & & & & & & \\
\hline & & & & & & & & & & & \\
\hline & & & & & & & & & & & \\
\hline & & & & & & & & & 583 & 558 & \\
\hline 3.3943 & & & & 2.96942 & & & & & & 475 & \\
\hline & 35 & & & & & & & & & & 8477. \\
\hline & & & & & & & & & & & \\
\hline & & & & & & & & & & & \\
\hline & & & & & & & & & & & \\
\hline & & & & & & & & & & & \\
\hline & & & & & & & & & 17 & & 367 \\
\hline & & & & & & & & & & & 93 \\
\hline & & & & & & & & & & & 304 \\
\hline & 67 & & & & & & & & .31 & 640 & \\
\hline & & & & & & & & & & & 779 \\
\hline & & & & 497 & & & & & & & \\
\hline & & & & & & & & & & & \\
\hline & & & & & & & & & & & \\
\hline & & & & & & & & & & & \\
\hline & & & & & & & & & & & \\
\hline & & & & & & & & & & & \\
\hline & & & & & & & & & & & \\
\hline & & & & & & & & & & & \\
\hline & & & & & & & & & & & \\
\hline & & & & & & & & & 41 & & 46 \\
\hline & & & & & & & & & & & 597 \\
\hline & 66826 & 50962 & & 01 & & & & & & & 763 \\
\hline & & & & & & & & & & & \\
\hline & & & & & & & & & & & \\
\hline & & & & & & & & & & & \\
\hline & & & & & & & & & & & \\
\hline & & & & & & & & & & & \\
\hline & & & & & & & & & & & \\
\hline & & & & & & & & & & & 02 \\
\hline & & & & & & & & & & & \\
\hline & & & & & & & & & & & \\
\hline & & & & & & & & & & & \\
\hline
\end{tabular}




\begin{tabular}{|c|c|c|c|c|c|c|c|c|c|c|c|}
\hline & 31 & 97 & 48 & 4.4 & 699 & & 8 & 94304 & 4.24446 & 6.51842 & 618 \\
\hline 47 & 311 & 18 & +32 & 93 & 661 & 48 & 88 & 82 & .03677 & 26741 & 441 \\
\hline 64 & 6694 & 82 & 5.02042 & 64 & 969 & 816 & 71 & 549 & 0473 & 33 & \\
\hline 57 & 2.76658 & 946 & 639 & 251 & 183 & 628 & 244 & 57 & 19 & 249 & \\
\hline 372 & 31 & 59 & 735 & 384 & 101 & 168 & 994 & 003 & 53 & 082 & \\
\hline 2.9677 & 59 & 007 & 055 & 359 & 5.73414 & 264 & 393 & 477 & 14 & 213 & \\
\hline 3.40396 & 6.54 & 618 & 939 & 207 & 3.68608 & 007 & 706 & 446 & & 49 & \\
\hline 73 & 54 & 795 & 465 & 929 & 5.13876 & 367 & 74 & 767 & & 324 & \\
\hline 6.41456 & 3.60003 & 104 & 785 & 073 & 843 & 303 & & 415 & & 4.31 & \\
\hline 08 & 2 & 14 & 068 & 9.02602 & .78616 & 5 & 62 & 725 & 69 & & \\
\hline 420726 & 4.3 & 8 & 236 & 267 & 194 & 4. & 86 & 55 & 74 & 466 & \\
\hline 4 & 5 & 4 & 0 & 5 & 17 & 4 & 7 & 6 & & & \\
\hline 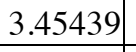 & 16 & 1 & 79 & & 7 & 4 & 02 & 8 & 7 & 99 & \\
\hline & & & 668 & & & & & & & 24 & \\
\hline & & 4 & & & 6 & & & 21 & & 31 & \\
\hline & & & & & & & & & & & \\
\hline & & & & & & & & & & & \\
\hline & & & 28 & & & & & & & & \\
\hline 137 & & & & & & & & & & & \\
\hline & & 85 & 45 & 36 & 432 & 63 & 77 & & 27 & 02 & 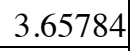 \\
\hline 4.4642 & 2.64732 & 99 & 2.77957 & & 7.00586 & 2. & 02 & 83 & & & 12 \\
\hline 5.4879 & 7171 & 1 & 5. & 442 & 12 & 442 & 88 & 303 & 93 & 54 & 3.90856 \\
\hline 1. & 4 & 9 & 2 & 79 & 55 & 6 & 2 & 04 & 02 & 9 & 4.52876 \\
\hline 3. & 4 & 18 & 6 & 58 & 28 & & 73 & 24 & 5 & 02 & 4.8128 \\
\hline 4.31329 & 2.51 & 68 & 59 & 28 & 00 & 74 & 00 & 27 & 45 & 15 & . \\
\hline 3.0691 & 2.51231 & 55 & 6 & 8 & 5 & 4 & 4 & 4.50413 & 6.78987 & 02 & 2.88556 \\
\hline
\end{tabular}


Table XXVI: Averaged waveforms used in the generation of the sponge water content test plot.

\begin{tabular}{|c|c|c|c|c|c|}
\hline Average Dry & Average 1T & Average 2T & $\begin{array}{l}\text { Average Dry } \\
\text { (cont.) }\end{array}$ & $\begin{array}{l}\text { Average 1T } \\
\text { (cont.) }\end{array}$ & $\begin{array}{l}\text { Average } 2 \mathrm{~T} \\
\text { (cont.) }\end{array}$ \\
\hline 6.377 & 4.164 & 5.486 & 7.187 & 3.297 & 3.608 \\
\hline 4.616 & 4.081 & 4.176 & 4.094 & 5.504 & 5.229 \\
\hline 3.522 & 3.903 & 5.331 & 2.984 & 4.470 & 3.107 \\
\hline 4.967 & 3.354 & 4.365 & 2.041 & 4.423 & 4.605 \\
\hline 3.597 & 4.324 & 3.662 & 5.259 & 3.580 & 5.954 \\
\hline 3.795 & 5.082 & 5.020 & 6.435 & 4.720 & 5.833 \\
\hline 3.396 & 4.967 & 4.115 & 5.582 & 4.862 & 4.911 \\
\hline 3.320 & 4.453 & 4.093 & 4.620 & 4.486 & 4.969 \\
\hline 3.822 & 4.161 & 4.883 & 6.403 & 4.666 & 5.693 \\
\hline 4.665 & 4.193 & 4.787 & 5.038 & 5.546 & 4.109 \\
\hline 6.530 & 4.725 & 4.983 & 3.700 & 5.479 & 5.663 \\
\hline 3.997 & 5.005 & 4.579 & 4.844 & 5.662 & 3.754 \\
\hline 7.036 & 4.651 & 3.921 & 3.196 & 4.545 & 5.458 \\
\hline 6.750 & 5.164 & 5.643 & 2.554 & 5.466 & 5.212 \\
\hline 4.833 & 5.327 & 5.110 & 4.103 & 4.986 & 4.677 \\
\hline 3.413 & 3.988 & 4.804 & 3.882 & 4.934 & 4.874 \\
\hline 4.976 & 4.944 & 4.374 & 6.207 & 3.487 & 3.576 \\
\hline 4.246 & 3.677 & 4.629 & 8.055 & 3.550 & 4.805 \\
\hline 3.236 & 7.100 & 4.191 & 3.736 & 3.115 & 4.355 \\
\hline 5.281 & 4.476 & 4.107 & 4.089 & 4.206 & 3.889 \\
\hline 3.116 & 5.923 & 6.258 & 3.577 & 5.271 & 4.002 \\
\hline 4.930 & 5.151 & 4.198 & 3.790 & 4.168 & 3.321 \\
\hline 4.224 & 5.609 & 3.823 & 2.911 & 6.559 & 5.648 \\
\hline 2.494 & 4.648 & 5.407 & 5.762 & 6.225 & 5.879 \\
\hline 5.524 & 4.099 & 3.433 & 4.768 & 3.317 & 3.682 \\
\hline 5.583 & 7.318 & 4.109 & 4.854 & 4.747 & 4.528 \\
\hline 5.490 & 3.987 & 4.261 & 3.604 & 5.031 & 5.371 \\
\hline 6.940 & 6.414 & 6.289 & 4.094 & 4.802 & 5.724 \\
\hline 6.862 & 4.966 & 6.087 & 5.951 & 4.823 & 4.159 \\
\hline 5.268 & 4.427 & 3.250 & 5.337 & 2.966 & 4.955 \\
\hline 4.538 & 7.276 & 4.526 & 2.966 & 3.749 & 2.888 \\
\hline 4.720 & 5.027 & 4.031 & 4.955 & 4.439 & 3.207 \\
\hline 2.993 & 4.942 & 4.897 & 3.507 & 5.794 & 3.120 \\
\hline 4.555 & 4.044 & 6.722 & 5.907 & 5.997 & 6.301 \\
\hline 5.772 & 3.652 & 6.535 & 5.558 & 4.033 & 3.898 \\
\hline 5.372 & 4.828 & 4.543 & 4.952 & 4.689 & 4.595 \\
\hline 2.956 & 6.548 & 4.334 & 4.592 & 4.427 & 4.727 \\
\hline
\end{tabular}




\begin{tabular}{|c|c|c|c|c|c|}
\hline 3.657 & 4.557 & 5.743 & 4.712 & 4.123 & 5.505 \\
\hline 2.116 & 3.520 & 4.702 & 4.051 & 5.438 & 5.485 \\
\hline 4.872 & 4.075 & 5.811 & 4.818 & 3.369 & 5.621 \\
\hline 6.228 & 4.088 & 6.224 & 3.311 & 4.130 & 5.435 \\
\hline 5.653 & 3.222 & 5.264 & 3.483 & 3.631 & 4.194 \\
\hline 5.417 & 5.692 & 4.190 & 4.248 & 4.053 & 4.201 \\
\hline 4.602 & 4.223 & 3.984 & 3.515 & 4.373 & 4.933 \\
\hline 5.082 & 5.797 & 6.959 & 6.105 & 5.705 & 4.406 \\
\hline 6.114 & 6.882 & 6.335 & 4.906 & 4.991 & 4.265 \\
\hline 5.470 & 5.449 & 3.475 & 4.690 & 5.452 & 3.373 \\
\hline 7.523 & 4.442 & 3.004 & 3.315 & 3.066 & 3.498 \\
\hline 5.340 & 4.055 & 4.960 & 5.473 & 6.102 & 5.751 \\
\hline 4.033 & 3.647 & 4.892 & 4.823 & 4.778 & 4.831 \\
\hline 6.140 & 3.453 & 5.871 & & & \\
\hline & & & & & \\
\hline
\end{tabular}




\section{Appendix K: Accessories to the Muscle Dehydration Test}

Table XXVII: Summary table of the temperatures, weights, and averaged locational data from the muscle dehydration test.

\begin{tabular}{|c|c|c|c|c|c|c|c|}
\hline & & \multicolumn{6}{|c|}{ Sample } \\
\hline & & 1 & 2 & 3 & 4 & 5 & 6 \\
\hline \multirow{6}{*}{ Set 1} & Temp & 70.5 & 70 & 71.2 & 70 & 70.3 & 70.3 \\
\hline & Weight & 52 & 56 & 70 & 70 & 68 & 76 \\
\hline & Location 1 & 12.120 & 19.061 & 23.369 & 25.813 & 13.661 & 17.833 \\
\hline & Location 2 & 14.349 & 21.389 & 28.759 & 14.213 & 14.194 & 14.023 \\
\hline & Location 3 & 19.485 & 18.992 & 22.684 & 14.465 & 12.621 & 11.894 \\
\hline & \begin{tabular}{|l|} 
Sample \\
Average \\
\end{tabular} & 15.318 & 19.814 & 24.937 & 18.163 & 13.492 & 14.583 \\
\hline \multirow{6}{*}{ Set 2} & Temp & 71.8 & 71.8 & 71.8 & 70.9 & 70.9 & 70.7 \\
\hline & Weight & 50 & 52 & 66 & 66 & 66 & 74 \\
\hline & Location 1 & 20.797 & 13.847 & 12.998 & 13.918 & 14.730 & 14.604 \\
\hline & Location 2 & 18.769 & 14.677 & 14.111 & 14.347 & 14.987 & 14.225 \\
\hline & \begin{tabular}{|l|} 
Location 3 \\
\end{tabular} & 15.651 & 12.708 & 15.223 & 13.341 & 15.241 & 15.335 \\
\hline & \begin{tabular}{|l|} 
Sample \\
Average
\end{tabular} & 18.406 & 13.744 & 14.111 & 13.869 & 14.986 & 14.722 \\
\hline \multirow{6}{*}{ Set 3} & Temp & 71.7 & 71.9 & 71.4 & 71.3 & 71.2 & 71.2 \\
\hline & Weight & 44 & 46 & 58 & 60 & 60 & 70 \\
\hline & Location 1 & 16.11 & 13.75 & 12.49 & 14.73 & 16.67 & 16.54 \\
\hline & Location 2 & 16.41 & 12.76 & 13.07 & 13.38 & 15.24 & 32.03 \\
\hline & Location 3 & 14.56 & 13.56 & 13.78 & 12.58 & 15.51 & 32.10 \\
\hline & \begin{tabular}{|l} 
Sample \\
Average
\end{tabular} & 15.6934 & 13.3564 & 13.1129 & 13.5664 & 15.8037 & 26.8894 \\
\hline \multirow{6}{*}{ Set 4} & Temp & 71.4 & 71.6 & 71.2 & 70.5 & 70.7 & 69.2 \\
\hline & Weight & 38 & 42 & 52 & 50 & 48 & 58 \\
\hline & Location 1 & 4.48 & 4.35 & 4.60 & 4.53 & 8.37 & 9.06 \\
\hline & Location 2 & 4.48 & 4.76 & 4.99 & 4.69 & 8.28 & 8.50 \\
\hline & \begin{tabular}{|l|} 
Location 3 \\
\end{tabular} & 4.82 & 4.61 & 4.20 & 4.64 & 8.75 & 8.78 \\
\hline & $\begin{array}{l}\text { Sample } \\
\text { Average }\end{array}$ & 4.59 & 4.57 & 4.60 & 4.62 & 8.47 & 8.78 \\
\hline
\end{tabular}




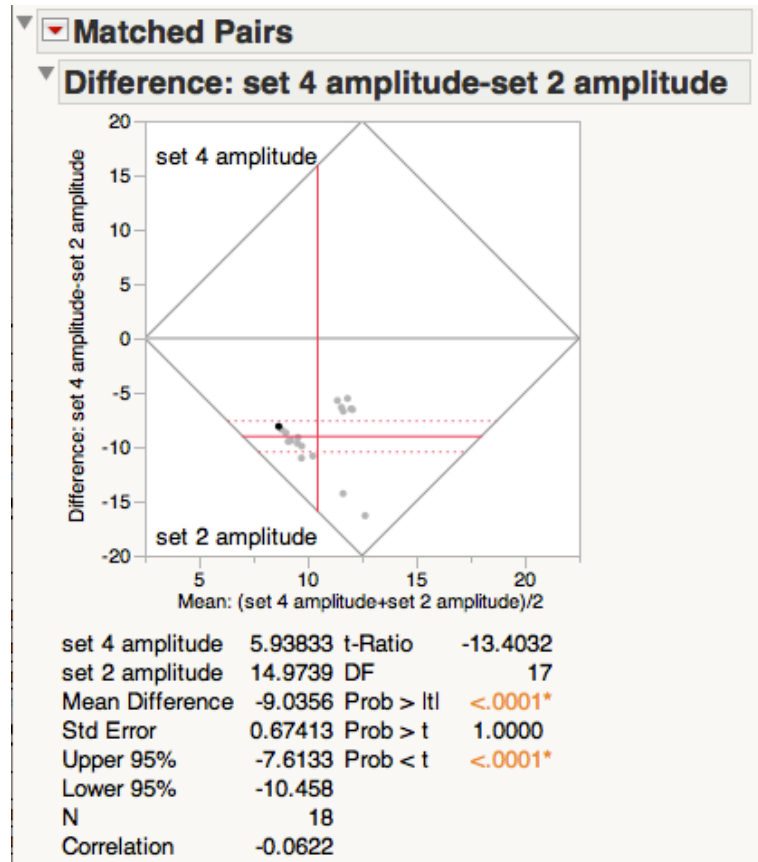

Figure 66: Paired t-test analysis for Set 2 and Set 4. 